Portland State University

PDXScholar

\title{
Effects of participant roles on input interactions and comprehensible output
}

Larry Douglas Morgan

Portland State University

Follow this and additional works at: https://pdxscholar.library.pdx.edu/open_access_etds

Part of the Applied Linguistics Commons, and the Bilingual, Multilingual, and Multicultural Education Commons

Let us know how access to this document benefits you.

\section{Recommended Citation}

Morgan, Larry Douglas, "Effects of participant roles on input interactions and comprehensible output" (1992). Dissertations and Theses. Paper 4431.

https://doi.org/10.15760/etd.6315

This Thesis is brought to you for free and open access. It has been accepted for inclusion in Dissertations and Theses by an authorized administrator of PDXScholar. Please contact us if we can make this document more accessible: pdxscholar@pdx.edu. 
AN ABSTRACT OF THE THESIS OF Larry Douglas Morgan for the Masters of Art in TESOL presented June 24, 1992.

Title: Effects of Participant Roles on Input Interactions and Comprehensible Output.

APPROVED BY THE MEMBERS OF THE THESIS COMMITTEE:

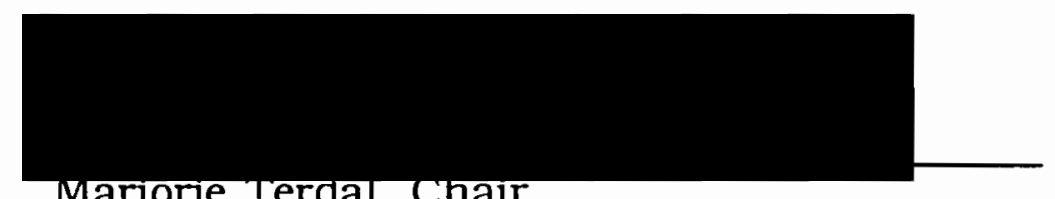
lvarjorie reraal, chair

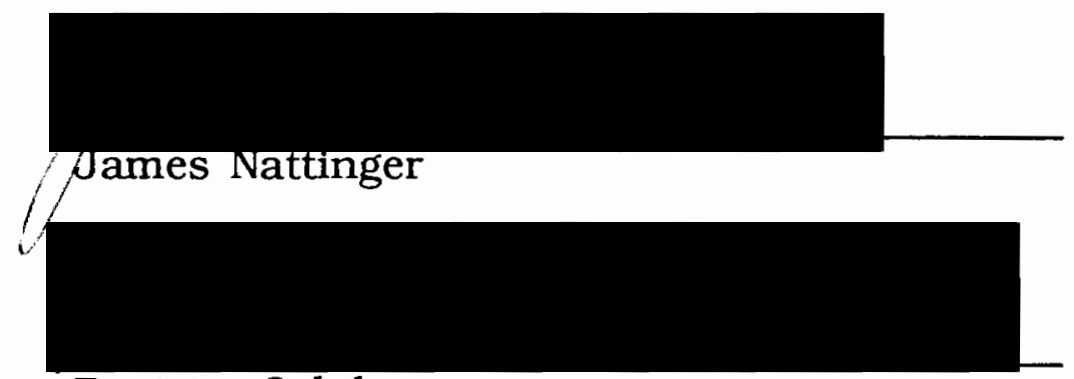

Beatrice Oshika

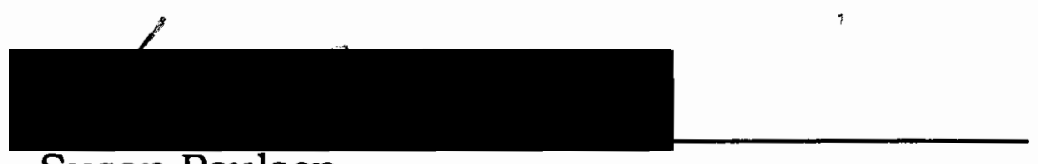

Susan Poulsen

The purpose of this thesis is to investigate what effect, if any, the social roles between second language learners and their conversational partners have on the types and frequencies of the following discourse categories: (a) input interactional modifications 
(b) corrections of language learners' linguistic errors by others and (c) language learners' production of comprehensible output. This study also seeks to corroborate previous research findings with regards to negotiation of meaning interactions (Pica, 1988; Pica, Holliday, Lewis \& Morgenthaler, 1989) and other-corrections of language learners' linguistic errors (Chun, Day, Chenoweth \& Luppescu, 1982).

In order to test the effect that participant roles have on both input interactions and comprehensible output production, discourse samples are obtained from the conversational dyads of four language learner subjects engaged in information exchange tasks. The four dyad types included in the experimental design are language learner with (a) language learner classmate, (b) language teacher, (c) native speaker friend and (d) native speaker peer-stranger.

Significant differences are found among the dyad types with regards to several aspects of conversational behavior. Contrary to Pica's (1988) findings, teachers modify or "correct" their language leaner partners' utterances significantly more often than they use repetition confirmation checks. The language learner with teacher dyads are also not as adept at negotiation of meaning interactions as language learner with peer-stranger dyads. Though peer-strangers have fewer negotiation of meaning interactions, they have a higher rate of successful completions. Peer-strangers also supply a lower frequency of correction of their language learner partners' syntactic errors than do either the teachers or the native speaker friends. 
The native speaker friend and language learner classmate dyads appear to have interactions that are especially beneficial to the second language acquisition process. Language learners in information exchange task interactions with native speaker friends produce more syntactically modified comprehensible output than they do in other relationship types. Syntactic modifications, according to Swain (1985), can assist the inductive realization of grammatical form within the language learners' interlanguage structure. These results suggest that friendship has a positive effect on the second language acquisition process.

The language learner subjects are found to have self-corrected significantly more syntactic errors in the dyads with their classmates than they do when interacting with teachers and native speaker friends. If syntactical modifications of output are realized as changes in the language learners' interlanguage, self-corrections of syntactic errors may function in the same manner. Thus, language learners' high frequency of syntactic self-corrections in the language learner dyads may contribute to their interlanguage in much the same way that comprehensible output responses are presumed to do.

Two additional findings provide mixed results. First, the type of signal given to language learners to indicate that a communication breakdown has occurred may influence the amount of comprehensible output that is produced. This conclusion supports that of Pica et al. (1989). However, the results are contradictory. It may be that 
language learners produce comprehensible output regardless of the intrinsic nature of the signal type given to them by their dyad partner.

Secondly, error corrections by native speaker dyad partners are found to have a positive correlation with language learners' comprehensible output production. It may be, however, that it is the nature of information exchange tasks to encourage both the production of comprehensible output and the amount of error correction supplied by native speakers.

Each of the dyad types have positive aspects that seem to promote the language learner subjects' understanding and use of the English language. Exposure to a wide variety of native speakers may enhance second language learners' opportunity to acquire the target language. 
EFFECTS OF PARTICIPANT ROLES ON INPUT INTERACTIONS AND COMPREHENSIBLE OUTPUT

\section{by}

LARRY DOUGLAS MORGAN

A thesis submitted in partial fulfillment of the requirements for the degree of

MASTER OF ARTS

in

TESOL

Portland State University

1992 
TO THE OFFICE OF GRADUATE STUDIES:

The members of the Committee approve the thesis of Larry Douglas Morgan presented June 24, 1992.

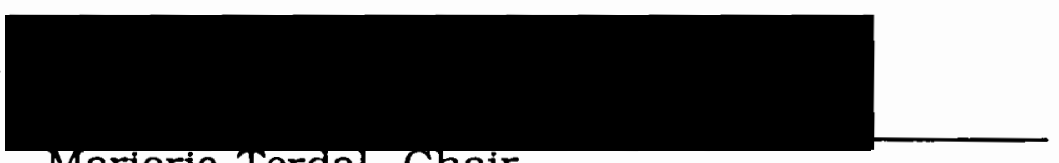
Marjorie Terdal, Chair
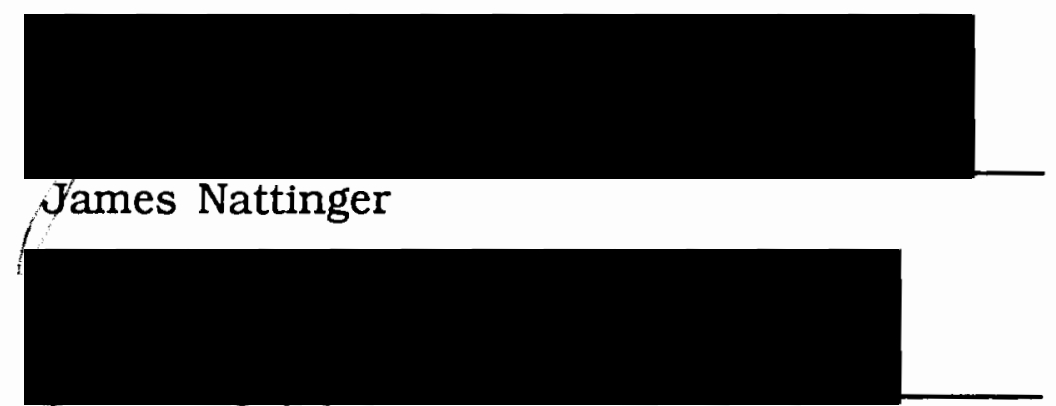

Beatrice Oshika

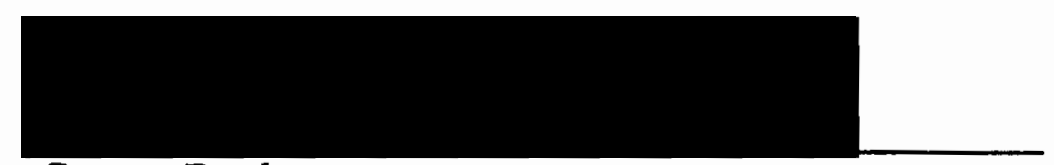

Susan Poulsen

APPROVED:

yames Nattinger, Chair, Department of Applied Linguistics

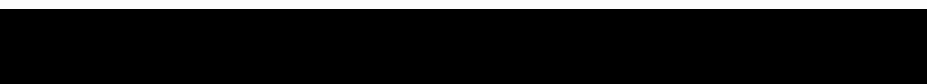

C. William Savery, vice Provost forgeraduate Studies and Research 


\section{ACKNOWLEDGEMENTS}

I am especially grateful for the support and inspiration given to me by Dr. Marjorie Terdal. She is a fantastic educator. I am indebted to Dr. John Laughlin and Rene Ordanez for their valuable assistance in the development of the statistical analysis used in this study. Finally, I couldn't have written this thesis without the encouragement, patience and love I received from Nancy and Chelsea. 
TABLE OF CONTENT

PAGE

ACKNOWLEDGEMENTS $\ldots \ldots \ldots \ldots \ldots \ldots \ldots \ldots \ldots$ iii

LIST OF TABLES $\ldots \ldots \ldots \ldots \ldots \ldots \ldots \ldots \ldots \ldots \ldots \ldots$ vii

\section{CHAPTER}

I RESEARCH PROBLEM AND HYPOTHESES

Introduction $\ldots \ldots \ldots \ldots \ldots \ldots \ldots \ldots$

Hypotheses ..................... 3

Hypothesis One

Hypothesis Two

Hypothesis Three

Hypothesis Four

Hypothesis Five

Hypothesis Six

Hypothesis Seven

Hypothesis Eight

Hypothesis Nine

III REVIEW OF THE LITERATURE $\ldots \ldots \ldots \ldots \ldots \ldots 7$

Introduction $\ldots \ldots \ldots \ldots \ldots \ldots \ldots \ldots$

Comprehensible Input $\ldots \ldots \ldots \ldots \ldots \ldots$

First Language Acquisition

Language Learner Directed Speech Input Hypothesis

Interactional Modifications $\ldots \ldots \ldots \ldots \ldots 12$

Metalinguistic Input 
Negotiation of Meaning $\ldots \ldots \ldots \ldots \ldots 14$

Interactional Structure

Differences in Language Learners

Differences in Native Speakers

Negotiation of Meaning Taxonomy

Comprehensible Output . . . . . . . . . . 19

Previous Research

Output Hypothesis

Output in Negotiations of Meaning

Output Taxonomy

Participant Roles ................. 27

In the Classroom

Outside the Classroom

Conclusion $\ldots \ldots \ldots \ldots \ldots \ldots \ldots \ldots \ldots \ldots \ldots \ldots \ldots \ldots \ldots$

III RESEARCH PROCEDURES $\ldots \ldots \ldots \ldots \ldots \ldots \ldots \ldots$

Dyad Structure .................... 31

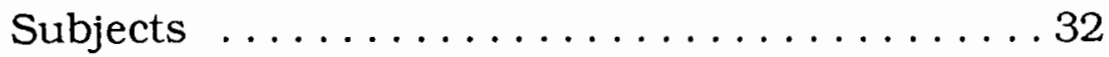

Language Learners

Teachers

Friends

Peer-Strangers

Information Exchange Tasks $\ldots \ldots \ldots \ldots 38$

Introductory Lesson Task: The Garden

LL/LL Dyad Task: People Cards

LL/TE Dyad Task: Grab Bag

LL/FR Dyad Task: Drawing Pictures

LL/ST Dyad Task: Code Flags and Pennants

Subjects' Assessment of Task Difficulty

Procedures ..................... . . 44

Pilot Study

Data Collection Procedures

Transcription Procedures 
Data Analysis $\ldots \ldots \ldots \ldots \ldots \ldots \ldots \ldots$

Negotiation of Meaning Interactions

Signals

Responses

Embedded Negotiation

Completion Moves

Error Coding

Error Categories

Language Learner Self-Corrections

Correction of Errors by Others

Conclusion $\ldots \ldots \ldots \ldots \ldots \ldots \ldots \ldots \ldots$

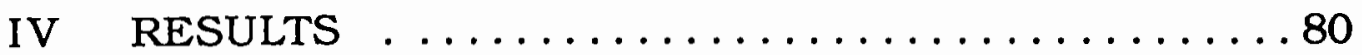

Introduction $\ldots \ldots \ldots \ldots \ldots \ldots \ldots$

Statistical Tests Used

Data Organization

Hypotheses Findings . . . . . . . . . . . . 84

Negotiation of Meaning Hypotheses

Hypothesis One

Hypothesis Two

Hypothesis Three

Hypothesis Four

Hypothesis Five

Error Correction Hypotheses

Error Type and Frequency

Hypothesis Six

Hypothesis Seven

Hypothesis Eight

Hypothesis Nine

V SUMMARY, DISCUSSION AND CONCLUSION $\ldots \ldots .158$

Summary $\ldots \ldots \ldots \ldots \ldots \ldots \ldots \ldots \ldots$

Research Problem

Methods

Results

Hypothesis One

Hypothesis Two

Hypothesis Three

Hypothesis Four 
Hypothesis Five

Hypothesis Six

Hypothesis Seven

Hypothesis Eight

Hypothesis Nine

Discussion $\ldots \ldots \ldots \ldots \ldots \ldots \ldots \ldots \ldots \ldots$

Teacher Dyads

Friend Dyads

Peer-Stranger Dyads

Language Learner Dyads

Signal Frequency

Conclusion ................... 192

Methodological Limitations

Implications

Future Research

REFERENCES . . . . . . . . . . . . . . . . 205 APPENDICES

A SAMPLE gUUESTIONNAIRES ........... 209

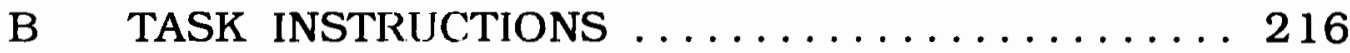

C TASK POSTERS $\ldots \ldots \ldots \ldots \ldots \ldots \ldots \ldots \ldots \ldots \ldots$

D TRANSCRIPTION GUIDE $\ldots \ldots \ldots \ldots \ldots \ldots \ldots \ldots$

E SAMPLE TRANSCRIPT .............. 229 


\section{LIST OF TABLES}

TABLE

PAGE

Language Iearners' English Language Background and TOEFL Scores $\ldots \ldots \ldots \ldots \ldots \ldots$

III Teacher Information $\ldots \ldots \ldots \ldots \ldots \ldots \ldots$

IV Friend Information $\ldots \ldots \ldots \ldots \ldots \ldots \ldots \ldots$

V Peer-Stranger Information $\ldots \ldots \ldots \ldots \ldots$

VI Native Speaker Assessment of Task Difficulty . . . 44

VII Dyad Order $\quad \ldots \ldots \ldots \ldots \ldots \ldots \ldots \ldots \ldots \ldots$

VIII Transcript Sample $\ldots \ldots \ldots \ldots \ldots \ldots \ldots \ldots \ldots$

IX Dyad Length in Time and C-Units $\ldots \ldots \ldots \ldots \ldots 4$

X Triggers Per C-Units, Language Learner Subjects . . 86

XI Mean Triggers Per LLHI C-Units, All Dyads . . . . . 87

XII Triggers Per LLHI C-Units, All Dyads $\ldots \ldots \ldots \ldots 8$

XIII Triggers Per LLHI C-Units, Peer-Strangers . . . . 88

XIV Combined Completion Categories Per LLHI C-Units, All Data $\ldots \ldots \ldots \ldots \ldots \ldots \ldots \ldots \ldots \ldots$

XV Completion Categories Per LLHI C-Units, All Data . 91 XVI Completion Categories Per Total Triggers, All Data 92 XVII Successful Completions Per Total Triggers, $4 \mathrm{~A}, 4 \mathrm{~B}, 4 \mathrm{AB}, 4 \mathrm{C}$, All Dyads $\ldots \ldots \ldots \ldots \ldots$ 
XVIII Successful Completions Per Total Triggers,

4A, 4B, 4AB, 4C, Peer-Strangers ......... 94

XIX Speaker Continuation Resolve Moves (4C) Per Total

Triggers, Peer-Strangers ............. 95

XX Unsuccessful Outcomes Per Total Triggers,

Native Speaker Dyads ..............96

XXI Unsuccessful Outcomes Per LLHI C-Units,

Native Speaker Dyads .............. 97

XXII Repetition Signals Per Total Signals, Teachers

and language Learners . ............. 99

XXIII Repetition Signals Per Total Confirmation Checks,

All Dyads ......................99

XXIV Signal Types Per Total Signal Count, All Data ... 100

XXV Confirmation Checks Per Total Signal Count,

Language Learners Only $\ldots \ldots \ldots \ldots \ldots 101$

XXVI Modification Signals Per Total Signal Count,

Language Learner and Native Speaker

Dyads ...................... 102

XXVII Confirmation Checks Per Total Signal Count,

Teachers Only ................. 102

XXVIII Elaboration-Continuation Confirmation Checks Per

Total Signal Count, Friends ........... 103

XXIX Signal Categories Per Total Signal Count,

Peer-Strangers Only .............. 104 
XXX Clarification Requests Per Total Signals,

Friends .................. 105

XXXI Signal Calegories Per Total Signal Count,

Teachers Only ................ 106

XXXII Signal Categories Per Total Signal Count,

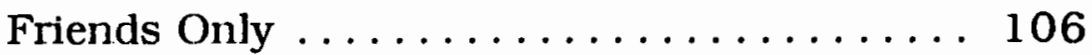

XXXIII Signals Become Comprehensible Output Response

Per Total Comprehensible Output Count,

All Data $\ldots \ldots \ldots \ldots \ldots \ldots \ldots \ldots \ldots$

XXXIV Signals Become Comprehensible Output Response

Per Total Comprehensible Output Count,

Confirmation Signals Combined, All Data . . . 109

XXXV Signals Become Comprehensible Output Response

Per Total Signal Type Count, All Data ...... 110

XXXVI Signals Become Comprehensible Output Response

Per Total Comprehensible Output Count,

Friends Only ................ 112

XXXVII Signals Become Comprehensible Output Response

Per Total Signal Type Count, Friends Only . . 113 XXXVIII Comprehensible Output Per LLHI C-Units,

All Dyads $\ldots \ldots \ldots \ldots \ldots \ldots \ldots \ldots \ldots \ldots \ldots$

XXXIX Comprehensible Output Per Total Triggers,

All Dyads $\ldots \ldots \ldots \ldots \ldots \ldots \ldots \ldots \ldots \ldots \ldots$ 
XI Comprehensible Output Per LLHI C-Units, Peer-Strangers .............. 118

XII Comprehensible Output Subcategories Per Total Comprehensible Output Count, All Data .... 120

XLII Comprehensible Output Subcategories Per Total Comprehensible Output Count. Friends Only . 121

XLIII Response Type Per Total Triggers, All Data . . . . 122 XLIV Affirmation Responses (3F) Per Total Triggers,

Teachers .................. 124

XLV Repetition of Signal (3C) Per Total Triggers, All Dyads . . . . . . . . . . . . . 125

XLVI Inability to Respond (3G) Per Total Triggers,

Language Learner and Native Speaker Dyads . 126 XLVII Inability to Respond (3G) Per Total Triggers,

Peer-Strangers . ............. 127

XLVIII Repetition of Trigger (3E) Per Total Triggers,

All Dyads $\ldots \ldots \ldots \ldots \ldots \ldots \ldots \ldots \ldots \ldots$

XIIX Error Type Per Language Learner C-Units,

All Data ................... 130

L Error Type Per Total Error Count, All Data .... 132

LI Error Type Per Total Language Learner C-Units,

Language Learners Only $\ldots \ldots \ldots \ldots \ldots$

LII Errors Per Language Learner C-Units, All Dyads . 134 
LIII Errors Per Language Learner C-Units,

Language Learner Subjects . . . . . . . . 135

LIV Error Corrections Per Total C-Units, All Dyads . . 137

LV Error Correction Per Total C-Units, Language

Learner and Native Speaker Dyads ....... 138

LVI Self-Corrections of Error Type Per Total Error

Type Count, All Data ........... 140

LVII Self-Correction of Error Type Per Total

Language Learner C-Units, All Data . . . . . . 141

LVIII Self-Correction of Error Type Per Total

Language Learner C-Units, Language

Learners Only . . . . . . . . . . . . 143

LIX Self-Correction of Syntactic Errors Per Total

Language Learner C-Units, Language Learner

and Native Speaker Dyads $\ldots \ldots \ldots \ldots \ldots 143$

LX Self-Correction of Omission Errors Per Total

Language Learner C-Units, Peer-Strangers . . 145

LXI Other-Correction of All Error Types Per Total

C-Units, All Data . . . . . . . . . . . . 146

LXII Other-Correction of Phonological Errors Per

Total C. Units, Language Learner and Native

Speaker Dyads ............... 147

LXIII Friend Correction of Errors Per Total C-Units . . 151 
LXIV Other-Correction of Syntactic Errors Per Total C-Units, All Dyads .................... 152

LXV Correlation of Comprehensible Output Per C-Unit and Other-Corrections of Language Learners' Errors Per C-Unit, Language Learner Dyads Only ...................... 155

LXVI Correlation of Comprehensible Output Per C-Unit And Other-Corrections of Language Learners' Errors Per C-Unit, Native Speaker Dyads Only . . . . . . . . . . . . . . . 156 LXVII Correlation of Native Speaker Dyads ........ 156 


\section{CHAPTER I}

\section{RESEARCH PROBLEM AND HYPOTHESES}

\section{INTRODUCTION}

Discourse analysis is a research tool used in the study of first and second language acquisition. The findings from discourse analysis studies have helped broaden the range of investigation into second language acquisition. Early research focused on the behavior of native speakers in conversational interactions with language learners. Native speakers were found to contribute to the second language acquisition process by altering or modifying (a) the type of speech directed at language learners, (b) the input to make it more comprehensible to the language learner, and (c) the metalinguistic input through modifications of the interactional structure of the conversation. In more recent research, the output produced by second language learners has been examined in order to understand how it fits into a model for second language acquisition. The interconnective nature of input, interactional modifications and output frequencies is being now recognized by many discourse analysis researchers. What has been lacking from the model that is being constructed is an analysis of the possible effects that social roles may have on these three communication categories. The purpose of this research is to examine 
how different participant social roles between second language learners and their conversational partners may influence the types and frequencies of input, interactional modifications and output that occur.

Research investigating the effects of participant roles on the conversational interactions between second language learners and native speakers has been limited and indirect. Initial research has indicated that English language learners' production of comprehensible output occurs most often in response to clarification requests on the part of the English language native speaker (Pica, Holliday, Lewis, \& Morgenthaler, 1989). Research has also suggested that English language teachers may produce fewer clarification requests than do other English native speakers (Pica, 1988; Pica et al. 1989). However, these previous studies were not designed to directly test the effect that the native speakers' and language learners' social roles with respect to each other may have had on the input modifications produced. Likewise, it is unknown whether the language learners' subsequent responses vary as a result of the type of relationship they have with the native speaker.

Both the input modifications and the language learners' responses occur during negotiations of meaning interactions. The effect of participant roles on the frequency and nature of meaning negotiations has not been examined before. Furthermore, native speakers' corrections of language learners' linguistic errors are thought to vary according to the type of discourse in which the 
participants are engaged (Chun, Day, Chenoweth, \& Luppescu, 1982). However, previous studies were not designed to examine the specific effect, if any, that participation roles have on the types and frequencies of error correction supplied. Finally, the correlation between comprehensible output production and frequency of error correction has not been previously included in a research design.

\section{HYPOTHESES}

The research presented here was designed to determine whether conversation participants' roles in paired interaction produce different outcomes in the following discourse categories: (a) the types and frequencies of native speakers' interactional modifications, (b) the frequency of negotiation of meaning interactions, (c) native speakers' correction of language learners' linguistic errors and (d) language learners' production of comprehensible output. The predictions and independent and dependent variables are stated in the hypotheses that follow.

\section{Hypothesis One}

Signals of total or partial lack of understanding of language learner (LL) utterance per communication unit (c-unit) will occur most often in dyads with other language learners (LL/LL dyads). Native speaker (NS) friends and native speaker peer-strangers will each produce more signals of total or partial lack of understanding of $L L$ 
utterance per c-units than will native speaker language teachers. The independent variable is the relationship of the LL to the other dyad participant. The dependent variable is the signal of total or partial lack of understanding of LL utterance.

\section{Hypothesis Two}

LL/teacher dyads (LL/TE) will display more completed negotiation of meaning interactions per c-unit than will the other dyads. The independent variable is the relationship of the LL to the other dyad participant. The dependent variable is the completed negotiation of meaning interaction.

\section{Hypothesis Three}

English language teachers' input modifications will contain more repetitions of language learners' speech per c-unit than those of native speaker friends and peer-strangers. The independent variable is the relationship of the $L L$ to the NS dyad partner. The dependent variable is the repetition of $\mathrm{LL}$ utterance.

\section{Hypothesis Four}

Language learners will be more likely to produce comprehensible output in response to clarification requests than in response to confirmation checks (from Pica et al., 1989). The independent variables are the clarification requests and confirmation 
checks produced by the other dyad participant. The dependent variable is the LL production of comprehensible output.

Hypothesis Five

Language learners will produce the most comprehensible output per c-units in LL/NS peer-stranger dyads. The remaining dyads will exhibit language learner production of comprehensible output per cunit in the following order (from most to least): (a) LL/LL, (b) LL/NS friend and (c) LL/teacher. The independent variable is the relationship of the LL to the other dyad participant. The dependent variable is the LL's production of comprehensible output.

\section{Hypothesis Six}

Native speakers' correction of LLs' linguistic errors per c-unit will occur more frequently in LL/teacher dyads, less frequently in LL/NS friend dyads and least frequently in LL/NS peer-stranger dyads. The independent variable is the relationship of the LL to the NS dyad participant. The dependent variable is the NS's correction of the LL's linguistic errors.

\section{Hypothesis Seven}

NSs' correction of language learners' linguistic errors of a factual or discourse nature per total LL linguistic error count will occur more frequently than correction of grammatical errors per total LL linguistic error count. The independent variable is the NSs' correction of the 
LLs' linguistic errors. The dependent variables are the NSs' correction of the LLs' linguistic errors of a factual or discourse nature and the NSs' correction of LLs' linguistic errors in grammar.

\section{Hypothesis Eight}

The LL/NS friend dyads will correct the highest percentage of factual or discourse errors per total LL linguistic error count followed by LL/teacher dyads, LL/NS peer-stranger dyads and LL/LL dyads respectively. The independent variable is the relationship of the LL to other dyad participants. The dependent variable is the correction of LL linguistic errors of a factual or discourse nature.

\section{Hypothesis Nine}

There will be a negative correlation between the error correction of language learners' linguistic errors per c-unit supplied to the language learners and the amount of language learners' comprehensible output per c-unit produced. The independent variable is the correction of LL linguistic errors. The dependent variable is the LL production of comprehensible output.

All independent and dependent variables will be described in full in Chapter III of this manuscript. The definition of all the preceding terms, including comprehensible output, input interactions and negotiations of meaning, will be presented in Chapter II. 


\section{CHAPTER II}

\section{REVIEW OF THE LITERATURE}

\section{INTRODUCTION}

Input, language that is addressed to second language learners by other users of the target language, is widely accepted as a crucial aspect in second language acquisition. Second language learners' exposure to target language input provides the learners with data about the features of the target language. Studies of the role of input in the language learning process of children's first language show some similarities to the role that input may play for second language learners. Input is simplified, made "comprehensible" for both first and second language learners. Krashen's Input Hypothesis (1983) will be examined in this regard.

Discourse analysis research into the role of target language input has primarily focused on the function that input has in helping target language users develop effective strategies and tactics to strengthen the communication interaction. Research has revealed that comprehensible input seems to be negotiated during the interaction between language learners and target language users. This interaction frequently involves a negotiation process that focuses on the meaning of the communicative event as language users attempt to forestall or 
overcome communication breakdowns. Recent research will also be presented that suggests that comprehensible output on the part of language learners, in addition to the input from target language users, is important for the acquisition of language. In addition, the nature of the language tasks required in the communication event may influence the input and output modifications that are exhibited. This review will conclude by presenting research findings that examine how the participant roles in communication events affect interactional modifications.

\section{COMPREHENSIBLE INPUT}

\section{First Language Acquisition}

Children seem to learn their first language in much the same way all over the world. Linguists have speculated that this may be due to an innate human propensity for language learning. The speed with which children learn their first language gives this speculation much appeal. However, linguists, due to the difficult nature of measuring qualities of the human brain, have only been able to theorize about the innate nature of language acquisition. It has been demonstrated, however, that children deprived of language input do not develop language ability (Moskowitz, 1978). Language input is the only source of information children have about the particular language used in their linguistic environment. However, input alone apparently is not a sufficient condition for language acquisition. Research has 
indicated that the language input must be combined with real communication before the child can acquire a language (Moskowitz, 1978).

The language children are given as input seems to be modified in order to foster communication success. Snows (1972) research findings indicated that mothers' speech to children is simplified, more redundant and less ambiguous than the speech used in normal adult discourse. The modifications that mothers make in their speech to young children depend, in part, on the reactions of the child. The more the communication event exhibits signs of failure, the more the mothers modify their speech. Mothers' utterances are generally reduced, repetitive, consistent and contain linguistic information that is relevant to the communication event. Research that has examined the type of speech that native speakers provide non-native speakers, language learner directed speech, has indicated some similarities to the child directed speech features that Snow discovered (Tarone, 1980)

\section{Language Learner Directed Speech}

Language learner (LL) directed speech, also known as "foreigner talk" (Ferguson, 1975) , has been characterized as a slowed, articulate rate of speech, with long pauses, reduced syntactic forms, much repetition, a reliance on gestures and contextual information and a simple vocabulary containing few idioms, recognizable slang and a high 
frequency of repeated common lexical items (Hatch, Shapira \& Gough, 1978). Tarone (1980) has suggested that the function of LL directed speech may be to provide the language learner with comprehensible input in order to sustain the communication event. She notes that native speakers are willing to abandon their intended communication goal if the language learner has misunderstood or not understood the intended meaning.

However, LL directed speech is also used to negotiate and clarify "the learner's intended meaning, or to provide alternate means of communicating the native speaker's intended meaning" (Tarone, 1980, p. 424). LL directed speech may involve both production and communication strategies on the part of the native speaker. Gass and Varonis (1985a) found, in this regard, that native speakers make changes in the style and range of their LL directed speech as a direct function of the language learner's ability to understand and be understood. Further, the more aware native speakers are of their need to produce LL directed speech, the more apt they are to control the discourse though the use of this modified type of input (Hirvonen, 1985).

\section{Input Hypothesis}

Krashen (1983) has proposed the Input Hypothesis to explain the relationship that child and LL directed speech have to the language acquisition process. language learners, according to 
Krashen's theory, do not "learn" to speak or use the target language. Instead, the target language emerges independently as language learners have built up linguistic competence by understanding target language input. The input provides data that is used by the learners to construct new syntactic structures. These structures would otherwise be unavailable to the learners because they would not be part of the learners' language competence base (Ellis, 1985). This input, however, must be "comprehensible" to the language learners before it can be internalized.

Krashen (1983) claims that comprehensible input must contain language structures that are "a bit beyond" the language learners' current competence $(i+1)$. Krashen also maintains that language learners acquire language competence by "going for meaning, by focusing on what is said rather than how it is said" (p. 38). The quest for successful communication on the part of native speakers interacting with non-native speakers involves an effort by the native speaker to provide this type of $i+1$ comprehensible input. The modified input characteristic of LL directed speech may function to provide comprehensible input so that communication and understanding can take place. 


\section{INTERACTIONAL MODIFICATIONS}

\section{Metalinguistic Input}

Comprehensible input, however, appears to involve a more complex process than the mere addition of the individual contributions to the communication event by the learner and the native speaker. Instead, their joint efforts combine to produce input that functions so that the learner can be understood as well as understand (Ellis, 1985). The need to foster successful communication will result in modifications to the interactional structure of the conversation as well as the input modifications in the LL directed speech (Long, 1983a). These interactional modifications have been characterized as metalinguistic input (Schachter, 1986). Metalinguistic input functions to alert language learners that their utterance was in some way not understood by the native speaker.

Long's (1983a) research revealed incidents where interactional modifications, metalinguistic input, occurred while input modifications, though anticipated, were absent. In fact, modifications to the input occurred with less frequency than did modifications to interaction (Long, 1981). Long's review of the literature on modified input and modified interaction in native speaker/non-native speaker (NS/NNS) conversation suggests that the supposed role of input in second language acquisition can be "explained more parsimoniously by modifications in interaction" (p. 275). 
Long's analysis of native speaker/non-native speaker discourse indicated that native speakers modified communication interactions in order to avoid discourse confusion or misunderstanding. In the event that conversational trouble did occur, native speakers displayed modified interactional behavior designed to repair the discourse misunderstanding. In order to make input discourse analysis more systematic, Long (1983a) devised a taxonomy of these native speaker interactional modifications.

Modifications designed to forestall or prevent communication difficulties are called conversational strategies. Features of this type of interactional modifications include willingness to relinquish topiccontrol, the selection of salient topics and the treating of topics in a cursory fashion. Native speakers also work to make new topics clear to the language learner by the use of closures and fillers as signals that a new topic is being introduced. Additionally, native speakers tend to move the topic to the beginning of their utterance in order to focus the learners' attention on the new information. Stressing key words, using a slowed cadence and including well placed pauses also serve to enhance topic saliency. Comprehension checks are examples of a strategy that native speakers use when a communication breakdown is anticipated. Comprehension checks are a direct appeal for verification of the hearers' understanding. According to Long, this strategy is used frequently in NS/NNS discourse. 
Interactional modification tactics, as opposed to strategies, are used by the native speaker to repair the discourse when a strategy or input modification has failed to head off a communication breakdown. Tactical modifications include accepting unintentional language learner topic-switches, requests for clarification, repetition of the learner's utterance in order to gain confirmation of comprehension and a general tolerance of learner ambiguity.

\section{NEGOTIATION OF MEANING}

\section{Interactional Structure}

Modifications made by native speakers in their conversation interactions, while necessary, may not be sufficient to provide the language learner with comprehensible input. Long (1983b) developed a theoretical model that predicted that communication engaging the language learner in a two-way communicative task with another target language user would provide more comprehensible input than would one-way tasks. Long's model was suggested by the findings of a study that he conducted in which one-way tasks (vicarious narratives, giving instructions and expressing opinions) were compared with two-way tasks (conversation and information-gap activities). Long found that the need to signal and elicit vital information resulted in the negotiation for meaning by "modifications in the interactional structure of conversation as participants seek to make incoming speech comprehensible" (p. 352). Negotiation for meaning exchanges 
are the conversational interactions that occur when a total or partial lack of understanding occurs between the conversation participants. The resulting interactional modification that takes place completes the negotiation exchange (Gass \& Varonis, 1985b).

Pica et al. (1985) came to similar conclusions as those of Long. Their results implied that while two-way communication interaction had a positive effect overall on comprehension, two-way interaction combined with interactional modifications brought about the most comprehension on the part of the language learner. Moreover, interactional modifications that produced the greatest redundancy of input (i.e., repetitions of input) had the largest observable effect.

These results would tend to confirm longitudinal study results that have suggested that frequently occurring forms in the input available to language learners become the basis for the learners' interlanguage rule formation (Wagner-Gough \& Hatch, 1975). Interlanguage describes the language rule system that learners construct for use on the continuum between their native language and perfect fluency in the target language (Schumann, 1982).

\section{Differences In Language Learners}

A study by Scarcella and Higa (1981) revealed that younger second language learners received more simplified and understandable $(i+1)$ LL directed speech than did older learners. Yet, results of these studies indicated that the older learners were more 
advanced than the younger learners in the early stages of second language acquisition. Older learners were observed to "negotiate" input that was beyond their linguistic competence. Older learners worked and invested more effort in the communication process in order to understand and be understood by the native speaker. Scarcella and Higa concluded that the simplified input received by the younger learner was not as "optimal" as the input received by the older learner through the work of negotiation. The active involvement in the conversation by the older learners may have had the effect of "charging" the input, making it more meaningful. This, in turn, may facilitate acquisition (Stevick, 1980).

Seliger (1983) pointed out that language input that is a result of learner initiated interactions may provide the learner with material that is more readily internalized. Seliger found that learners whom he identified as "High Input Generators" produced significantly more qualitative and quantitative language than did less interactive learners. The studies of Scarcella and Higa and Seliger seem to imply that there may exist a causal relationship between meaning negotiation and comprehensible input.

\section{Differences in Native Speakers}

Ehrlich, Avery, and Yorio (1989) attempted to find out if this assumption about the relationship of negotiation and interaction to comprehensible input and second language acquisition obtains in a 
straightforward, predictable fashion. The study examined the discourse structure of NS/NNS dyads engaged in a problem solving task. The native speakers were categorized as fitting one of two profiles: skeletonizers and embroiderers. Skeletonizers were more willing to abandon negotiations of meaning when the meanings were embedded within more salient and general features of the topic. Embroiderers, on the other hand, were much less willing to abandon the negotiation of embedded topics even when persisting in negotiation threatened or impeded NNS understanding of the more immediate and general discourse.

Sources of NNS lack of understanding are more readily located at a shallow topic level while topics that are more deeply embedded are difficult to negotiate successfully. Analysis of the embroiderer NS/NNS conversations revealed many more discourse meaning negotiations yet far fewer incidents of NNS understanding. This study points out that the mere presence of negotiation of meaning interactions does not necessarily provide comprehensible input. Instead, skeletonizing strategy appears to result in more comprehensible input despite the fact that this strategy is characterized by negotiation abandonments of embedded topic meaning. 
Negotiation of Meaning Taxonomy

Varonis and Gass (1985), based on previous research as well as research of their own, proposed a model for negotiation of meaning. They depart from the usual description to NS/NNS discourse to focus on the "non-understanding" interactions that take place between nonnative speakers. The model consists of a trigger, an indicator that acknowledges the trigger, a response to the indicator that shows awareness that a non-understanding has occurred as well as an attempt to clarify and a reaction to the response. The last component is optional while the first three are mandatory in a successful meaning negotiation.

The trigger is any utterance by the speaker that is not fully understood by the hearer. Speakers are not aware that they have triggered a non-understanding until the hearer reacts. Unless the hearer chooses to ignore the non-understood utterance, an indication signal is given to alert the speaker that the utterance was some way unacceptable or was not able to be interpreted clearly. Comprehension checks, clarification checks, repetitions and other interactional modifications function as indicators.

The response by the speaker to the indicator is the third component of the model. Responses include a repetition of the previous utterance, an expansion, paraphrasing, a reduction of the input or perhaps simply an acknowledgement that the indicator has been given. If the last response is given and if the hearer chooses 
to indicate again that a non-understanding has taken place, then the negotiation continues, becoming embedded in a potential series of clarifications.

The optional reaction to the speaker's response essentially keeps the focus on the negotiation before moving back to the point in the conversation where the non-understanding had disrupted the flow. This last component, when utilized, may have the effect of confirming that the response to the indicator had successfully negotiated the meaning of the utterance in question. The third component of this model, response to the indicator, suggests that language learners' input in the discourse plays an important role in the resolution of communication difficulties. In the next section, this output on the part of the learners is examined more closely.

\section{COMPREHENSIBLE OUTPUT}

\section{Previous Research}

The role that negotiation of meaning plays in the production of comprehensible input appears to correlate with the skill of the native speaker at modifying both the input and the interactional function to supply meaning at a discourse level that is available to the language learner. Scarcella and Higa (1981), as well as Seliger (1983), have presented evidence that the interaction activity of the language learner also contributes to the type and amount of comprehensible input that is supplied. Corder (1967) made a distinction between 
what the learner has available as input and what the learner actually realizes as "intake".

Gaies (1980), in an expansion on Corder's theory, proposed that learner feedback controls the pace and nature of native speaker (specifically teacher-generated) input. Gaies' research was based on the assumption that intake control on the part of the language learner can be quantified through discourse analysis. According to Gales, the ways in which learners convey comprehension, request information, and negotiate discourse topics provide evidence that language input data are cognitively processed.

\section{Qutput Hypothesis}

Swain (1985) points out that "comprehensible output" may play as important a role in language acquisition as comprehensible input does. She argues that the emphasis on comprehensible input and accompanying focus on the conversational interaction modifications in which meaning is negotiated do not take into adequate account the process learners initiate in the communication interaction. When language learners have the opportunity to modify their output, to make it comprehensible, they are expanding and exploiting their interlanguage in creative ways. Swain suggests that language acquisition is assisted by this creative process.

Swain came to this conclusion through her examination of test results from Grade Six French immersion students in Canada. The 
results showed that the students' performance on subject matter tests correlated positively with results obtained by students in the regular English programs. These results suggested to Swain that the immersion students were receiving input that was understandable and focused on meaning. In other words, the students were exposed to sufficient comprehensible input in the immersion classrooms.

However, the immersion students' grammatical competence did not test out at the same level as that of comparably aged native French speakers. Thus, in spite of having received sufficient comprehensible input (seven years), the French immersion students were not able to competently use the target language in communicative situations with a grammatical performance that was equivalent to that of native speakers.

Immersion students, Swain noted, rarely used the target language outside of the classroom environment. Further, they rarely had the opportunity to engage in two-way, negotiated meaning exchanges. Swain argued that negotiating input is essential to language acquisition, not because the learner is focusing on meaning, as Krashen has suggested, but, rather, because by being understood, by getting meaning across, the learner is able to focus on form. Swain suggests that one important function of learner output is learners are able to provide themselves with an opportunity for getting their message across by extending or "stretching" the linguistic resources they have acquired. Learners are "pushed" to produce a message that 
is conveyed "precisely, coherently and appropriately" (p. 249). This modified, more target-like linguistic production by the language learner has been labeled "comprehensible output" by Swain.

Being pushed to produce comprehensible output is likened by Swain to a concept that parallels Krashen's $i+1$. The more demands that have been placed on language learners to make themselves understood, the more the learners are forced to produce comprehensible output. Comprehensible output extends the linguistic competence of the learner by providing opportunities to use the target language in a meaningful manner within the contextualized framework of the communication event. Learners are able to use comprehensible output to test out hypotheses about the target language, both semantically and, more importantly, syntactically. Thus, learners' output can assist inductive realization of grammatical form.

\section{Output In Negotiations Of Meaning}

Pica (1988) sought to test whether learners' output was modified during negotiation of meaning interactions. Specifically, Pica was investigating whether language learners would modify their output towards more target-like forms when asked to clarify or confirm their output by native speakers. Pica suggested that learners would adjust their interlanguage to make it more comprehensible when native speakers signaled a communication problem. The results of the study indicated that this did happen some of the time. More often, 
however, the native speaker produced the modification before the language learner's attempt to provide the new modified input had been successfully completed. On the other hand, when the learners did succeed in producing their own modification of their output, their modifications generally included target-like forms.

Pica discovered that comprehensible output frequently occurred in response to native speakers' interactional modifications of repetition and explicit requests. Repetition signals were especially helpful. Pica speculated that by repeating the language learners' own words, the native speakers were signaling that the utterances were partially understood, and that the learner needed "only to go slightly beyond this level of production in order to achieve comprehensibility" (p. 66). The results gave some credibility to Swain's notion about the parallel nature of comprehensible input and comprehensible output containing structures that are $i+1$.

Pica, Holliday, Lewis, and Morgenthaler (1989) restructured the previous study in an attempt to elicit fewer native speaker modifications of the learners' output and to encourage more output adjustments on the part of the learners themselves. The previous study's language learners were of low proficiency. This may have had the effect of both limiting the learners' modification capability as well as influencing the native speakers' desire to provide the modifications for the learners. Further, the previous study's native speakers were language teachers who were adept at providing the learners with 
target language models and in the habit of doing so. Finally, the use of interviews and conversations produced conditions that may have allowed the native speakers to select and control the communication topics.

The new study looked at learners of intermediate proficiency, in communication events with native speakers who were not teachers using interactive tasks that were designed to give the learners and native speakers different degrees of control. The tasks included an "information-gap" task, a "jigsaw" task and a discussion session. Information-gap tasks had already been shown to have a positive influence on the generation of classroom interactional modifications (Doughty \& Pica, 1986). Information-gap tasks are defined as activities "which require an information exchange for their completion" (p. 309).

The results of the study revealed that language learners did produce comprehensible output during the course of a negotiated interaction with a native speaker. The language learners modified their output most often when the native speaker signaled lack of understanding through the use of clarification requests. In contrast, language learners rarely modified their output when provided with a model utterance for confirmation by the native speaker. Unlike the previous study, repetition of the learners' utterance was used far less by the native speakers than clarification requests when seeking learner modification of output. This suggested to the researchers that 
language teachers use different tactics to encourage learners' production of modified output than do native speakers who lack experience in language teaching and whose communication goals are not, necessarily, to promote language production on the part of the learner.

Pica et al. (1989) also noted that the use of clarification signals and the subsequent learner output modifications were not significantly affected by the structure of the different communication tasks involved. However, there appeared to be a statistical tendency suggesting that information-gap tasks provide a context that promotes more native speaker signaling of a need for clarification. Accordingly, the language learners were afforded more opportunity in the information-gap tasks to modify their output.

\section{Output Taxonomy}

Using Varonis and Gass' (1985) model of negotiated interaction as a guide, Pica (1988) and Pica et al. (1989) developed a taxonomy for coding learners' comprehensible output. Following the language learner's trigger, the hearer indicates, or "signals", a lack of understanding. The hearer performs this signal by making an explicit statement or request for clarification, or through a confirmation request. The confirmation request can take several different forms. These forms include a repetition of the language learner's utterance, a modification of the utterance or a completion or elaboration of the 
utterance. While the hearer's incomprehension signal may be aimed at the semantic content of the utterance, the signal can also indicate a need to understand grammatical and phonological features that have restricted understanding. A single signal may include information that indicates a lack of understanding of two or more of these features.

The language learner's response can take one of many different forms. The learner can respond by switching the topic or by supplying new information that is not directly responsive to the hearer's signal. The learner can also respond by repeating all or part of the trigger. The hearer's confirmation check may also elicit a simple acknowledgement or, perhaps, an indication of difficulty or inability to respond on the part of the language learner. All of these response categories reveal strategies on the part of the language learner to continue the conversation, to find a way to repair the trouble, but they do not represent an effort on the part of the language learner to provide the hearer with additional comprehensible input.

However, Pica et al. (1989) did find data that indicated that learners do modify the trigger by providing comprehensible output. Learner self-modification of the trigger includes phonological, semantic, morphological and syntactic modification. Phonological modification includes careful repetition of the trigger with a special emphasis put on pronunciation. Semantic modification involves the use of synonyms, paraphrases and examples. Learners produce morphological modifications through addition, substitution or 
deletion of inflectional morphemes and/or functors. Finally, syntactic modification is accomplished through embedding and elaboration in clauses.

The hearer then responds to the learner's response to the incomprehension signal. This move on the part of the hearer completes the negotiation transaction. The hearer can provide this response by giving an explicit signal of comprehension, continuing the conversation from the point of disruption, or, in the event of failure of the negotiation, move to a new topic. Should the negotiation fail, and should the hearer desire to signal again that the trigger has not been understood, the original signal or a modification of that signal can be repeated. All hearer's signals and language learner's responses to those signals can be repeated for successive turns in the conversations. The duration of a completed negotiation is dependent only on the hearer's and speaker's desire and ability to succeed.

\section{PARTICIPANT ROLES}

\section{In the Classroom}

Researchers have also begun to examine how participant roles in communication events influence conversational interactional modifications. Pica and Doughty (1985a, 1985b; Doughty and Pica, 1986) compared teacher-fronted classroom interactions with the interactions that occurred in language learners' group work. Their 
findings indicated that neither the teacher-fronted nor the group format influenced the negotiation of input as much as did the task that was employed to stimulate the input. Decision-making tasks did not force the participants to negotiate for meaning in either participation pattern. However, in light of their findings that group work provided the students with many more opportunities to interact, information exchange tasks were found to result in an increase in interactional modifications. In addition, pair work discourse proved to be more conducive to negotiated modification than did the group work when the task at hand involved a required information exchange. Varonis and Gass (1985) found evidence to support these findings. NNS/NNS pairs were observed to spend more time in negotiation interactions and those negotiations produced more comprehensible input than did similar whole classroom activities.

\section{Outside the Classroom}

Very little research has been done to study the effect of the participants' roles with respect to each other on conversational interactions. Long (1981) speculated that the grammatical structure of the input provided to language learners by native speakers was influenced by several factors. Spontaneous conversation between language learners of limited proficiency and native speakers who perceive themselves to be of higher social status may result in more ungrammatical language learner directed speech. 
Varonis and Gass (1985) argue that language learners do not lose face by negotiating meaning with other language learners. On the other hand, the inequality of target language status in NS/NNS discourse discourages negotiation because negotiation has the effect of highlighting the differences between them. However, as these two researchers pointed out in another study (Gass \& Varonis, 1985b), conversation participants who have a lot in common, who share a mutual belief system, may also have less of a need to negotiate meaning. Further, the participant who needs the information imparted will exhibit more modification indicators than will the participant who holds the information. This last finding indicates that the roles the native speaker and language learner hold with respect to the discourse information to be shared may influence the negotiation modification data in a manner similar to the influence shown by information-gap tasks on interactional modification frequency.

Chun, Day, Chenoweth, and Luppescu (1982) found that, in social settings, native speakers correct the errors made by their language learner friends but do so only infrequently. When error correction is supplied, native speakers focus on errors of a factual nature. Grammatical and syntactical errors are rarely corrected. Chun et al. admit that they did not measure the degree of friendship that existed between the dyads who were observed. It is possible that closer friendships would allow the native speaker to feel more comfortable about correcting their friends' language errors. 
Conversely, familiarity with the language learners' interlanguage may cause the native speakers to be so accustomed to the errors that they no longer hear them. This study also did not focus on what the language learners did, if anything, with the error corrections when they were supplied.

\section{CONCLUSION}

This review of the literature has revealed that research has examined the role of input in language acquisition by examining the discourse interactional modifications that occur in the negotiation of meaning. Language learners' apparently need to derive both comprehensible input and produce comprehensible output during the language acquisition process. Tasks that encourage and require the exchange of information appear to provide the best environment for interactional modifications to occur. While there has been some research that has examined the effect that group and dyad participant patterns have on the quantity of negotiation interactions, the differences or influences that participant roles may have on discourse interactions and modifications have not been studied in much depth. 
CHAPTER III

\section{RESEARCH PROCEDURES}

\section{DYAD STRUCTURE}

Discourse samples were obtained from the conversational dyads of four language learner subjects engaged in information exchange tasks. The dyads varied according to the role of the language learner with respect to the other dyad participant. There were four dyad types included in the research design: (a) language learner and language learner classmate (LL/LL), (b) language learner and language teacher (LL/TE), (c) language learner and native speaker friend (LL/FR), and (d) language learner and native speaker peer-stranger (LL/ST). Fourteen dyads were included in the study: three LL/LL, four LL/TE, four LL/FR and three LL/ST. One of the LL/LL dyads was comprised of two of the research subjects working together. The remaining two LL/LL dyads each contained one of the language learner research subjects with one of their classmates. One of the language learner subjects did not participate in a LL/ST dyad. The language learner subjects were assured that their course grade would not be adversely affected by their participation in the dyad experiments. All of the subjects received coded identities in order to insure anonymity. 


\section{SUBJECTS}

There were seventeen subjects included in the study: (a) six English language learners, (b) four English language teachers, (c) four native speaker "friends" and (d) three native speaker peer-strangers.

\section{Language Learners}

The language learner subjects for this study were all enrolled at the American Language Academy (ALA) located on the campus of Southern Oregon State College. Subjects were drawn from the Level III Listening and Speaking class. The ALA program consists of five levels and these Level III students were considered by the ALA staff and administration to be "intermediary" students. The entire class 19 students) was required to participate in the introduction lesson, the LL/LL dyad experiment and the LL/ST experiment as part of their scheduled curriculum.

The four language learner subjects tracked through the different dyad types were self-selected. This self-selection process was the result of asking for volunteers in the class who would be willing to participate in additional dyad experiments outside of regularly scheduled class time. In addition, the language learners were required to be able to identify American "friends" who would also be willing to participate in the experiment. Six language learners met the first criteria but only four could meet the second. 
Table I lists demographic information about the six language learner subjects included in the data. The first four subjects listed (LL 113, LL 125, LL 137 and LL 149) are the subjects tracked through the various dyad types. The remaining two subjects participated in an LL/LL dyad experiment with one of the four tracked subjects. Two of the tracked subjects, LL 113 and LL 125, worked together in the LL/LL dyad experiment. All of the LL/LL dyads were comprised of participants from different countries and with different native languages.

TABLE I

\section{LANGUAGE LEARNER INFORMATION}

\begin{tabular}{lccllc}
\hline Subject & Gender & Age & Ll & Dyad Partner & Months in U.S. \\
\hline LL 113 & M & 24 & Korean & LL 149 & 2 \\
LL 125 & F & 26 & Portuguese & LL 1225 & 4 \\
LL 137 & M & 21 & Turkish & LL 1237 & 3 \\
LL 149 & F & 18 & Spanish & LL 113 & 3 \\
LL 1225 & F & 19 & Japanese & LL 125 & 1 \\
LL 1237 & M & 22 & Japanese & LL 137 & 4 \\
\hline
\end{tabular}

The subjects were close in age and had similar English language educational backgrounds (see Table II). LL 113 listed 10 years previous study of English, but admitted orally that this included a fairly limited exposure within the Korean educational system. The subjects were all fairly new to the United States and had become acquainted with each other at ALA within two months of the time of the experiment. 
In answer to a questionnaire (Appendix A), the subjects reported that they "occasionally" or "rarely" met each other outside of class. All of the subjects said that they were not very familiar with the culture of their LL dyad partner. Both of the participants in one of the dyads (LL 137 with LL 1237) reported that it was "not very easy" to understand their partner's spoken English. The remaining four learners all reported that their partner's spoken English was "easy" to understand.

\section{TABLE II}

LANGUAGE LEARNERS' ENGLISH LANGUAGE BACKGROUND AND TOEFL SCORES

\begin{tabular}{lccc}
\hline Subject & Years of English Study & TOEFL & Listening Section \\
\hline LL 113 & 10 & 533 & 51 \\
LL 125 & 1 & 467 & 49 \\
LL 137 & 1 & 477 & 49 \\
LL 149 & 5 & 470 & 49 \\
\hline
\end{tabular}

The subjects had tested into Level III using the ALA standardized test. They were considered by their teacher, and by the ALA administration, to be of equal proficiency. The Test of English as a Foreign Language (TOEFL) was administered to all of the language learners at the completion of the teaching term as part of ALA standard procedures. This testing occurred approximately three weeks after the completion of the dyad experiments. The test scores of the four self-selected language learners show that three of the learners' totals were within ten points. The fourth, LL 113, tested much higher. However, his score on the listening section was 
only slightly higher than the other three learners (51 verses 49 points). Moreover, the range of total TOEFL score, 67 points, falls with the range used by other studies (70 points, Pica et al., 1989, 110 points, Rulon \& McCreary, 1986).

\section{Teachers}

Four English language teacher subjects were selected from the ALA staff of five. The four teachers were selected because they were able to meet with the language learners in the LL/TE dyad experiment at the same scheduled time of day. One teacher was not able to participate at the scheduled LL/TE time and was thus excluded from the subject pool. The remaining teachers were matched to language learners by gender and mutual availability. As Table III shows, all of the teachers met the research design criteria of a minimum of one year English language teaching experience. In addition, all of the teachers spoke at least one second language (L2) and had lived abroad for an extended period of time.

TABLE III

TEACHER INFORMATION

\begin{tabular}{lcccccc}
\hline Subject & Gender & Age & L2s & LL Partner & Yrs. Abroad & Yrs. Teaching \\
\hline TE 231 & M & 35 & 2 & LL 113 & 3 & 5 \\
TE 252 & F & 33 & 1 & LL 125 & 3 & 6 \\
TE 273 & M & 41 & 2 & LL 137 & 8 & 18 \\
TE 294 & F & 39 & 2 & LL 149 & 7 & 12 \\
\hline
\end{tabular}


Three of the teachers have MA degrees in TESOL (or equivalent). The one teacher without the advanced degree, TE 273, was certified in English as a Second Language teaching and had been an English language teacher for over eighteen years.

\section{Friends}

The four friend subjects were selected by their language learner dyad partners. Two were peer-friends (FR 341 and FR 303) and two were "host-mothers" (FR 372 and FR 334). One of the host-mothers described her relationship with the language learner as "very close". She had known the language learner for over a year and had visited the language learner's family in Mexico. The remaining native speaker friends had a relationship with their language learner friends of a much shorter duration. These friends described their friendship as being "close". Two of the language learners, LL 113 and LL 149 . described their relationship with the friend in the same terms that their friend had. The other two described their friendship as "casual". The casual label was presented as being less strong than "close" (see Appendix A).

Only one of the friends spoke a second language. Though all of them had travelled to a foreign country, none of the four had ever lived abroad. Demographic information about the native speaker friends is listed in Table IV. 
TABLE IV

FRIEND INFORMATION

\begin{tabular}{|c|c|c|c|c|c|c|}
\hline$\overline{\text { Subject }}$ & Gender & Age & LL Partner & Length of & Friends & hip Rating \\
\hline & & & & Friendship & Friend & LL \\
\hline FR 341 & $\overline{\mathbf{M}}$ & 24 & LL 113 & 2 months & close (2) & close (2) \\
\hline FR 372 & $\mathbf{F}$ & 38 & LL 125 & 1 month & close (2) & casual (3) \\
\hline FR 303 & $\mathbf{M}$ & 19 & LL 137 & 2 months & close (2) & casual (3) \\
\hline FR 334 & $\mathbf{F}$ & 59 & LL 149 & 1 year & v. close (1) & v. close (1) \\
\hline
\end{tabular}

\section{Peer-Strangers}

The native speaker peer-strangers were self-selected from a Business Research class at Southern Oregon State College. The students self-selected in response to a request for volunteers given to them by the researcher during their regularly scheduled class time. All of the peer-strangers spoke at least one second language (L2). In addition, all the peer-strangers had travelled to a foreign country though none of them had lived abroad. The strangers were matched in the LL/ST dyad experiment with a language learner of similar age and gender. The peer-strangers had never met the language learner subjects prior to the experiment. Table V shows peer-stranger demographic information. 
TABLE V

PEER-STRANGER INFORMATION

\begin{tabular}{lccccc}
\hline Subject & Gender & Age & LL Partner & L2s & $\begin{array}{c}\text { Daily Contact } \\
\text { with LL students }\end{array}$ \\
\hline ST 421 & M & 21 & LL 113 & 2 & occasionally (3) \\
ST 432 & F & 21 & LL 125 & 1 & occasionally (3) \\
ST 454 & F & 21 & LL 149 & 1 & most days (2) \\
\hline
\end{tabular}

\section{INFORMATION EXCHANGE TASKS}

Four dyad information exchange tasks as well as one task used as an introductory lesson were created for use in this study. The dyad tasks were designed to ensure that both dyad participants possessed information needed by the other dyad member in order to complete the task. Tasks of equal difficulty and duration length (thirty minutes) were part of the design criteria. Each of the dyad tasks was used with only one type of relationship dyad. In all dyad tasks, participants were encouraged to give detailed descriptions. The participants were also encouraged to ask questions if they were unclear about their partner's descriptions. Samples of the task instruction sheets are in Appendix B.

The settings where the tasks were carried out varied according to the dyad relationship. The introductory lesson, the LL/LL dyad tasks, the LL/TE dyad task and the LL/ST dyad task all took place in ALA classrooms. ALA classes are taught on the campus of Southern Oregon State College in regular college classrooms. Each of the LL/FR 
dyad tasks took place in a different location. Two experiments took place in the friend's home. Of the remaining two, one was conducted in an ALA classroom and the other in a college dorm study lounge. No interruptions occurred in any of the dyad experiments with the exception of the two in the friends' homes. However, these interruptions (by family members) were brief and did not appear to interfere with or impede the participants' performance of the task.

\section{Introductory Lesson Task: The Garden}

The purpose of the introductory lesson, a whole-class information exchange activity, was to familiarize the language learners with the information exchange concept. This familiarity was important to ensure that the interactional modification data collected in the subsequent dyad experiments would be due only to the needs on the part of the participants to exchange information and not due to the need on the part of the language learners to clarify the procedures of the information exchange task itself.

The "garden" task was adapted from an activity used by Doughty and Pica (1986). Each student received a file folder containing a partially completed garden plot and twenty-two loose garden pieces that needed to be "planted". Each folder had a strip of sky, a large land area and a central pond as reference points. In addition, every folder had three items "planted" in a fixed location. These permanent locations corresponded to a finished master plot held by the teacher. 
Each student's information about fixed positions was different. Together, all the students possessed the necessary information to complete the garden construction. In other words, all the gardens superimposed on each other would reveal the locations of all twentyfive garden pieces as constructed on the master plot.

The students were required to share information while keeping their own gardens out of sight of their classmates. The file folders, were constructed with propping devices that would shield each student's information area. The unplanted pieces had to be described verbally and could not be shown to the other students. The pieces included flowers, trees, bushes, benches, streams, ducks, sea gulls, rocks and clouds of varying shapes and colors.

\section{LL/LL Dyad Task: People Cards}

Both participants received file folders with propping devices containing a poster and set of picture cards. Each poster was divided into sixteen boxes and each box contained a picture of a figure adapted from The Great Waldo Search (Handford, 1989). Each deck of picture cards contained twenty-five cards. Sixteen of the cards had pictures that matched the poster held by the other person. The remaining nine cards had pictures very similar, yet slightly different, to the poster-pictures. Varying hand or leg positions, attire, hair styles or accessories made the pictures distinguishable from one another.

The participants' task was to construct a facsimile of their 
partners' poster using the picture cards provided. Each participant took turns describing one of their poster pictures so that their partner could choose and arrange his or her cards in the correct order. Appendix $\mathrm{C}$ has a sample of the poster used in the task.

\section{LL/TE Dyad Task: Grab Bag}

This activity was similar to the task used by Hawkins (1985). The participants received a file folder with propping devices containing blank paper and a pencil. Each participant was also provided with a paper bag containing various small items. The items in each of the bags were different. The items in the teacher's bag included a pair of pliers, a tape dispenser, a travel alarm clock and a small coin purse. The language learner's bag contained an electrical plug adapter, an ornate hair clip, a decorative comb and a drafting compass.

The object of the task was to describe an object from the bag to the partner so that the partner could accurately draw the item on his or her paper. The participant could describe the item in any way preferred including naming the item. The participants took turns describing and drawing.

\section{LL/FR Dyad Task: Drawing Pictures}

This task was adapted from an activity used by Ehrlich et al. (1989). Both participants received file folders with propping devices containing a poster, a drawing paper and a pencil. Each poster was 
divided into sixteen squares. Some of the squares were blank while others contained simple drawings. Each participants' poster contained different pictures in different squares than those on their partner's poster. The friend's poster had pictures of a tulip, a direction arrow, a fish, the letter A, a snail in the top section of a diagonally divided square and a square divided into quarters. The language learner's poster contained pictures of a large ship, a cup with the letter $\mathrm{V}$ on it, the letter $\mathrm{L}$, a lamp, a sunflower and a hose bib in the bottom section of a diagonally divided square. The drawing page was identical to the poster and was provided so that the posters could be reused.

The object of the task was to describe each picture and its location to the partner so that the partner could accurately draw the item on his or her drawing paper. The participant could describe the item in any way preferred including naming the item. The participants took turns describing and drawing. Appendix $\mathrm{C}$ has a sample of a poster used in the task.

\section{LL/ST Dyad Task: Code Flag and Pennants}

Both participants received file folders with propping devices containing a poster, a drawing paper and four colored marking pens (yellow, blue, red and black). Each poster was divided into thirty-five squares. Some of the squares were blank while others contained colored pictures of international code flags and pennants. Each 
participants' poster contained different pictures in different squares from those on their partners' poster. The drawing page was identical to the poster and was provided so that the posters could be reused.

The object of the task was to describe each code flag or pennant, its color pattern and its location to the partner so that the partner could accurately draw and color it on his or her drawing paper. Highly accurate reproductions were encouraged. The participants took turns describing and drawing. Appendix $\mathrm{C}$ has a sample of a poster used in the task.

\section{Subjects' Assessment of Task Difficulty}

One of the task design criteria was to create tasks of equal difficulty. Table VI shows the native speakers' assessment of the difficulty of the task they were assigned.

\section{TABLE VI}

NATIVE SPEAKER ASSESSMENT

OF TASK DIFFICULTY

\section{DIFFICULTY SCALE}

\begin{tabular}{lccccc}
\cline { 2 - 6 } Subjects & $\begin{array}{c}\text { Easy } \\
(1)\end{array}$ & $(2)$ & $(3)$ & $(4)$ & $\begin{array}{c}\text { Difficult } \\
(5)\end{array}$ \\
\hline Teachers & 0 & 0 & 3 & 1 & 0 \\
Friends & 0 & 2 & 2 & 0 & 0 \\
Peer-Strangers & 0 & 3 & 0 & 0 & 0 \\
\hline
\end{tabular}

The peer-strangers assessed their task as slightly less difficult to do than did the friends. The teachers rated their task as more 
difficult. This assessment was not a comparison across tasks, but, rather, an assessment of the specific task undertaken.

The language learners, however, were asked to assess task difficulty across the tasks. The task with their classmate was considered the easiest by three of the four language learner subjects. The remaining subject found the task with the teacher to be the easiest. The most difficult task selection varied across the subjects: two chose the friend task, one the language learner task, and one the peer-stranger task. Relevant research results related to task difficulty will be discussed in Chapter IV.

\section{PROCEDURES}

\section{Pilot Study}

Two non-native speakers were asked to participate in the pilot study. The pilot subjects were both visiting professors at Southern Oregon State College from the People's Republic of China. Their English language proficiency was quite high, near fluency. The pilot session took place in the home of the researcher. Each of the dyad tasks was performed for ten minutes. The session was audio-recorded with the tape recorder in full view of the participants. The researcher observed the subjects performing the task.

After performing all four dyad tasks for ten minutes, the subjects gave verbal feedback to the researcher regarding the task instructions, the task materials and the relative difficulty of the task. The subjects 
found the tasks engaging and interesting. It was their opinion that the tasks were of equal difficulty. In fact, the pilot subjects suggested that the tasks be made more difficult. In view of the fact that the pilot subjects possessed high English language ability, their suggestion was not followed. Moreover, task instructions were altered, as a result of the pilot study, to allow task participants to refer to task items by name. This would allow the participants to focus on details and avoid circumlocution that was strictly the result of avoiding an item's linguistic identity.

\section{Data Collection Procedures}

The Level III Listening and Speaking teacher at ALA was asked to give the introductory lesson ("The Garden") to her class in order to introduce the information exchange concept to the students. The teacher agreed to schedule the introductory lesson, the LL/LL dyad task and the LL/ST dyad task during regularly scheduled class time. The introductory lesson was given on a Monday beginning the fourth week of a ten-week term. Nine students, as well as the researcher, were in attendance at class that day. An audio tape recorder was operating in full view of all the students. The teacher introduced the researcher, who asked the students if they would be willing to participate in a research project designed to test the effects that information exchange tasks have on language learning. 
The lesson began with the teacher reminding the students of other information exchange lessons that she had used in class a few weeks earlier. The teacher, who was looking at the master garden plot, began by describing the location of one of the trees. The student to the teacher's left followed by describing where one of her flowers was located. From this point in the lesson, until class time had run out, the students assumed total control of the activity. Further, except for a couple of humorous comments, the teacher did not take part again in the exchange of information.

The students quickly discovered that many of the garden pieces were similar in appearance. They worked together to clarify location, color, shapes and sizes. The students seemed motivated to complete the task. Aggressive students "pushed" more reticent students to share their information in order for the class to finish the task within the allotted time (50 minutes). One student had rearranged her "fixed" locations, causing some confusion. The students appeared to forget they were using a second language as they "argued" about the "right" location for some of the garden pieces.

At the end of the class time, all the students were given a questionnaire (see Appendix A). The questionnaires were designed to obtain demographic information regarding subject age, gender, time in the U.S., previous amount of formal English instruction, L1 and native country. Other information included on the survey form were questions about the student's attitude toward the lesson and self- 
assessment regarding English proficiency. Subject self-selection, as described previously, occurred at this time.

The LL/LL dyad experiments took place the following day during the regularly scheduled class meeting. Nine students were present. The dyad groupings and dyad classroom locations were assigned by the researcher. The dyads were grouped by same gender and different native language. One student performed the task with the classroom teacher. Every dyad was assigned a separate classroom and at no time during the information exchange were any people other than the dyad members present in the room. Each classroom had an audio-tape recorder operating in full view of the dyad participants. All the LL/LL dyads were recorded but the data used in this study were drawn only from the four subjects tracked through the different dyad configurations.

Beginning with LL 113 and LL 149 dyad, the task instructions were read verbally by the researcher to each dyad containing a research subject. The classroom teacher read the instructions to the dyads whose members had not self-selected themselves as part of the additional dyad experiments. The subjects were able to read an instruction sheet (see Appendix B) to themselves as the researcher read it to them out loud. The subjects were then given an opportunity to ask for clarification regarding the task instructions. Each dyad was given thirty minutes to complete the task. The time limit for each dyad began upon completion of the task instruction presentation and 
clarification. At the end of thirty minutes, questionnaires were administered. Information sought included subject assessment of the task, the comprehensibility of their LL partner and their familiarity of their partner's culture.

The LL/ST dyads were set up similar to the LL/LL dyad experiments. These experiments took place on Friday of the same week during regularly scheduled class time. Nine language learners and nine peer-strangers were present. The researcher read the instructions and answered questions for the dyads containing the tracked language learner subjects. The ALA Listening and Speaking teacher set up the other dyad groups. All of the dyads were recorded but the data used in this study were drawn only from the four subjects tracked through the different dyad configurations.

The remaining experiments followed the same general procedures. The language learner subject and partner met with the researcher at an agreed upon time and place. The native speaker subjects were told that they would be part of a research project designed to test the effects that information exchange tasks have on language learning. An audio-tape recorder was set up in full view of the dyad participants. Task instructions were read out loud while the participants read their own instruction sheets to themselves. The subjects were given the opportunity to ask questions about the task procedures. The researcher then left the room and did not return until thirty minutes had elapsed. At that time questionnaires were 
administered to both dyad participants. The LL/FR dyads experiments differed only to the extent that two of the experiments were conducted in the home of the "friend".

The dyad experiments followed the schedule shown in Table VII. The introductory lesson was given on a Monday, followed by the LL/LL dyad experiment on Tuesday and the LL/ST experiment on Friday on the same week. A total of ten days passed between the introductory lesson and the completion of the last dyad experiment. Though most subjects had completed all four of their dyad experiments by Saturday of the same week, subjects LL 137 and FR 303 had their session on Wednesday of the next week. Each of the language learner subjects performed only one dyad experiment per day with the exception of the LL 125 with TE 294 experiment. This dyad took place shortly after the conclusion of the class introductory lesson on Monday.

TABLE VII

DYAD ORDER

ORDER

\begin{tabular}{lllll} 
Subject & First & Second & Third & Fourth \\
\hline LL 113 & LL/LL & LL/TE & LL/ST & LL/FR \\
LL 125 & LL/LL & LL/FR & LL/TE & LL/ST \\
LL 137 & LL/LL & LL/TE & LL/FR & LL** \\
LL 149 & LL/TE & LL/LL & LL/FR & LL/ST
\end{tabular}


The subjects were assigned different dyad type experiment order in an attempt to minimize the effect that experimental order would have on the data collected. However, three of the four learners did the LL/LL dyad task first. It is not known whether the task order influenced the data that were collected. As the schedule reveals one of the subjects did not complete all four tasks. This was due to the fact that LL 137 did not attend class the day the LL/ST experiments were conducted.

\section{Transcription Procedures}

Twenty minutes of each dyad experiment were transcribed for data collection purposes. Each transcription begins with the language learner subject's first turn to share the information that he or she held. A complete transcription guide was developed for this research (see Appendix D). Following Brock (1986), Rulon and McCreary (1986) and Pica et al. (1989), the subjects' linguistic production was coded in the transcripts by communication units (c-units).

C-units were originally developed by Loban (1963) for a study using elementary school children's language. According to Loban's definition, a c-unit is an independent clause including any of its dependent clausal modifiers. Second language researchers have modified the c-unit definition with regards to language structure (Brock, 1986, Rulon \& McCreary (1986). Following the second language research guide, it is not necessary for the grammatical 
structure of the independent clause to be "correct" in order to be a c-unit. Instead, an independent clause is considered a c-unit if it can stand on its own with regards to its referential, pragmatic or semantic meaning within the discourse structure.

Every independent clause is a c-unit and no c-unit can contain more than one independent clause. Thus, by definition, every utterance, no matter the length, contains at least one c-unit. Some examples of c-units using data collected in the LL 125 with FR 372 experiment are shown in Table VIII. The entire transcription of this dyad experiment is included in Appendix E. A description of transcription notations can be found in Appendix D.

\section{TABLE VIII}

\section{TRANSCRIPT SAMPLE}

\begin{tabular}{|c|c|c|}
\hline C-unit & Subject & Transcription Text \\
\hline 1 & LL 125 & $\begin{array}{l}\text { Ah, / I will describe the, (.1) the box, (.1) ah, } \\
\text { (.) next / these one, / that you already } \\
\text { describe / me. }\end{array}$ \\
\hline 2 & FR 372 & O. $\underline{\mathrm{K}}$ \\
\hline $\begin{array}{l}3 \\
4\end{array}$ & LL 125 & $\begin{array}{l}\text { On the first line / is the (.) four, / forty. } \\
\text { (.1) The last one / in the first line. }\end{array}$ \\
\hline 5 & FR 372 & O.K \\
\hline 6 & LL 125 & $\begin{array}{l}\text { And, ahm, / [et's], (.2) ahm, / you, / you have } \\
\text { in your [keet-], / in your kitchen. }\end{array}$ \\
\hline 7 & FR 372 & Um-huh. \\
\hline 8 & LL 125 & Uh, you use / to drink [cof-], / in the morning. \\
\hline 9 & FR 372 & A cup? \\
\hline 10 & LL 125 & Yes, / a cup. \\
\hline
\end{tabular}


LL 125's first "turn" has only one c-unit (c-unit \#1) while the second turn contains two. The clausal modifier "that you already describe me" is not an independent clause (capable of standing on its own) and, thus, not a separate c-unit. The two clauses LL 125's second turn are classified as two separate c-units (\#3 and \#4) because both are capable of communicating meaning independent of the other.

FR 372's first three utterances are each considered c-units because every utterance, no matter the length, must contain at least one c-unit. These utterances are used in an elliptical fashion and could be replaced by an independent clause. It follows, then, that elliptical clauses like "A cup?" (c-unit \#9) are considered to be independent clauses and are assigned a c-unit value. However, the utterance "yes, a cup" (c-unit \#10) is considered only one c-unit because the "yes" merely introduces the independent clause and could not be replaced by a different independent clause.

The transcriptions varied in length and c-unit totals (see Table IX). The LL 149 and FR 334 were the only dyad to finish their task before the twenty minute transcription goal could be met. Though LL 113 and LL 149 performed the LL/LL dyad experiment together, two different transcription figures were gathered. Each transcript in this study began with the tracked language learner's first time to share information that he or she held. Thus, the LL 113 with LL 149 transcript begins at a different point in the task performance than does the LL 149 with LL 113 transcript. 
Data transcribing was concluded as close to a twenty minute length as possible. However, negotiation of meanings interactions were transcribed to completion. It is for this reason that the LL 125 with ST 432 transcript is of a longer length.

Some utterances were clearly intended to show understanding or signal the speaker to continue. In Table VIII, FR 372's c-units \#2 and \#5 are typical of "affirmation" signals. Affirmation signals (AFF) are produced by the hearer to indicate to the speaker that the previous utterance has been understood and that the speaker should continue. "Continuation" signals (CONT), such as c-unit \#7, do not necessarily show understanding but neither are they signals of a partial or lack of understanding. Instead, continuation signals seem to be used by the hearer to encourage the speaker to continue. Hearers seem to use continuation moves in an effort to head off potential communication trouble. Table IX shows the total affirmation and continuation c-unit count for each dyad. The possible effects of affirmation and continuation c-unit totals on statistical analysis are discussed in Chapter IV.

The tape recordings were generally of good sound quality with one exception. The participants in the LL 137 with LL 1237 dyad experiment changed their positions in the classroom during the task performance, moving away from the tape recorder. This caused the tape sound quality to diminish. The move seemed to be motivated by a desire to sit at desks that the participants found more comfortable. 
The data from this experiment were obtained through the use of better tape processing equipment than was used in transcribing the other tapes.

TABLE IX

DYAD LENGTH IN TIME AND C-UNITS

\begin{tabular}{|c|c|c|c|c|}
\hline$\overline{\text { Subject }}$ & Minutes & C-units & $\begin{array}{c}\text { AFF/CONT } \\
\text { C-units }\end{array}$ & $\begin{array}{l}\text { C-units less } \\
\text { AFF/CONT }\end{array}$ \\
\hline \multicolumn{5}{|l|}{$\overline{\text { LL } 113}$} \\
\hline with LL 149 & $20: 04$ & 716 & 123 & 599 \\
\hline TE 231 & $20: 28$ & 525 & 70 & 455 \\
\hline FR 341 & $20: 17$ & 501 & 89 & 412 \\
\hline ST 421 & 20:06 & 412 & 76 & 336 \\
\hline \multicolumn{5}{|l|}{ LL 125} \\
\hline with LL 1225 & $20: 22$ & 444 & 84 & 360 \\
\hline TE 252 & $20: 02$ & 504 & 70 & 434 \\
\hline FR 372 & $20: 13$ & 438 & 60 & 378 \\
\hline ST 432 & $21: 10$ & 490 & 105 & 387 \\
\hline \multicolumn{5}{|l|}{ LL 137} \\
\hline with LL 1237 & $20: 24$ & 452 & 65 & 387 \\
\hline TE 273 & $20: 07$ & 591 & 53 & 548 \\
\hline FR 303 & $20: 16$ & 464 & 53 & 411 \\
\hline \multicolumn{5}{|l|}{ LL 149} \\
\hline with LL 113 & $20: 22$ & & 120 & 585 \\
\hline TE 294 & $20: 18$ & 656 & 142 & 514 \\
\hline FR 334 & $16: 45$ & 506 & 56 & 450 \\
\hline ST 454 & $19: 58$ & 536 & 108 & 428 \\
\hline MEAN & $20: 03$ & 530 & 85 & 445 \\
\hline \multicolumn{5}{|l|}{$\mathrm{AFF}=$ Affirmation } \\
\hline
\end{tabular}

The fourteen dyad experiments were transcribed by the researcher. Five minute portions were independently transcribed by students in a Second Language Acquisition class at Portland State University who followed the transcription methods described in the Appendix D. There was a high degree of consistency between the 
transcripts produced by the students and those produced by the researcher.

\section{DATA ANALYSIS}

\section{Negotiation of Meaning Interactions}

Negotiation of meaning interactions were coded according to the Varonis and Gass (1985) model as modified by Pica et al. (1989). In addition, several new categories were added to each section of the model. In the discussion that follows, examples are given from the research data for each component of the negotiation of meaning model used in the data coding. Most examples are from the LL 125 and FR 372 dyad and were chosen for their brevity whenever possible. The data presented follow the form shown in Table VII and are identified by c-unit number and subject code. Intra-rater reliability of random transcripts for negotiation of meaning interaction identification was 95\%.

\section{$\underline{\text { Signals }}$}

Negotiation of meaning interactions begin with a speaker utterance, a trigger, followed by a hearer utterance indicating total or partial lack of understanding. This indicator is the signal component of the negotiation of meaning model. Semantic, syntactic, phonological or pragmatic incomprehension on the part of the hearer may trigger the signal indicator. Signals can take five different forms. 
The first four categories presented here were operationalized in accordance with Pica et al. (1989). The last category, indirect indicators, was added to the model for use in this study. All model categories are coded by number and letter. Signals receive the number 2 code. Intra-rater reliability of signal coding was $91 \%$.

Clarification request (2A). Clarification requests are direct and/or explicit statements or requests for clarification of the speaker's trigger utterance.

$\begin{array}{llll}\text { Trigger } & 412 & \text { LL } 125 & \begin{array}{l}\text { Is in the half, / is in the half / of } \\ \text { [day], (.) the circle. }\end{array} \\ 2 A & 413 & \text { FR } 372 & \begin{array}{l}\text { (.) O.K., so three o'clock / is a big } \\ \text { one.? }\end{array}\end{array}$

Confirmation check (2B, 2C, 2D). There are three different types of confirmation checks. Signal $2 B$ is a request for confirmation performed by repeating the trigger.

$\begin{array}{llll}\text { Trigger } & 11 & \text { LL } 125 & \begin{array}{l}\text { But, / ah, (.3) ah, (.1) is not round, } \\ \text { [r-], ah, round. } \\ \text { Not round. }\end{array} \\ 2 B & 12 & \text { FR 372 } & \begin{array}{l}\text { N } \\ \text { 2B }\end{array}\end{array}$

Signal $2 \mathrm{C}$ requests confirmation by modifying the trigger.

$\begin{array}{llll}\text { Trigger } & 203 & \text { LL } 125 & \text { (.1) [Dees] line / is / not very (.) } \\ \text { [theen]. } & \text { (.1) It's not thin? }\end{array}$

An elaboration or completion of the trigger is the third type of confirmation check, signal 2D.

$\begin{array}{llll}\text { Trigger } & 300 & \text { LL } 125 & \text { (.) You can / draw a [bi-], um-- } \\ 2 D & 301 & \text { FR } 372 & \text { (.1) A big center? }\end{array}$

Indirect indicator (2E). This signal category was devised by the researcher to account for signals that did not fit into the Pica et al. 
model. These signals were used by both native speakers and language learners when they were unable or, perhaps, unwilling to use a clarification request or a confirmation check to indicate that a trigger had occurred. In many cases indirect indicators were given as a signal that the hearer needed more information. Most indirect signals were short utterances; "oh", "hmmm", "wow", etc.

$\begin{array}{llll}\text { Trigger } & 348 \text { LL } 125 & \text { (.) No, in the circle. } \\ 2 E & 349 \text { FR } 372 & \text { Oh. } \\ \text { Trigger } & \text { 284a LL 125 } & \text { / It's very... } \\ 2 E & 285 \text { a FR 372 } & \text { Is it... } \\ & \text { 284b LL 125 } & \text { ‥popular one. } \\ & \text { 285b FR 372 } & \text {...eh, it, (.1) um-- }\end{array}$

\section{Responses}

The language learner's response to the signal can take one of nine different forms. Some of the responses may be strategies on the part of the language learner to repair the trouble. Some may ignore the signal altogether. Still others represent attempts by the language learners to modify their output in order to provide more comprehensible input to the hearer. The nine response categories include two that were added to the model for use in this study. The response categories receive the number 3 code. Intra-rater reliability of response category coding wa $90 \%$.

Topic switch (3A). A topic switch is a strategy on the part of the language learner used to repair the damage to the conversation without directly addressing the trouble contained in the trigger. 
Information exchange tasks did not lend themselves to the use of this strategy. Very few topic switches occurred in the data that were gathered. The topic switches that were identified occurred when the subject changed the focus of the topic description.

$\begin{array}{llll}\text { 2A } & \text { 33a } & \text { TE 231 } & \text { Heh-eh, / what... } \\ & 34 & \text { LL 113 } & \text { And-- } \\ & \text { 33b } & \text { TE 231 } & \text { \%does the ribbon look like? } \\ & 35 & & \text { / I don't know. } \\ \text { 3A } & 36 & \text { LL 113 } & \begin{array}{l}\text { (.) And the, (.1) it has, / uh, / a } \\ \text { certain device / behind the ribbon. }\end{array}\end{array}$

Indirect response (3B). In this response the language learner supplies information that is relevant to the topic but not directly responsive to the signal of incomprehension received. Unlike the topic switch (3A), indirect responses hold the focus on information that is related to the trigger. However, the trigger, itself, is not repaired.

\begin{tabular}{|c|c|c|c|}
\hline $\begin{array}{l}\text { Trigger } \\
2 B \\
3 B\end{array}$ & $\begin{array}{l}393 \\
394 \\
395\end{array}$ & $\begin{array}{l}\text { LL } 125 \\
\text { Te } 252 \\
\text { LL } 125\end{array}$ & $\begin{array}{l}\text { O.K. twelve / tines. } \\
\text { Twelve / tines? } \\
\text { Not very, / very thin.. }\end{array}$ \\
\hline Trigger & $293 k$ & LL 125 & $\begin{array}{l}\text {..[re-], uh, [de], / the middle is / } \\
\text { bigger than the / petals, / petals? }\end{array}$ \\
\hline & $\begin{array}{l}295 \\
296 \\
297\end{array}$ & FR 372 & $\begin{array}{l}\text { The petals? } \\
\text { O.K }\end{array}$ \\
\hline
\end{tabular}

Repeat signal (3C). In this strategy, the language learner repeats the hearer's signal. In response to clarification requests and confirmation checks, the language learner is able to indicate to the hearer that the modification of the language learner's trigger is 
correct. Indirect signals, $2 \mathrm{E}$, were not repeated in the data collected for this study.

\begin{tabular}{|c|c|c|c|}
\hline $\begin{array}{l}\text { Trigger } \\
2 \mathrm{C} \\
3 C\end{array}$ & $\begin{array}{l}25 \\
26 \\
27 \\
28\end{array}$ & $\begin{array}{l}\text { LL } 125 \\
\text { FR } 372 \\
\text { LL } 125\end{array}$ & $\begin{array}{l}\text { (.) Goes a little [whide-t]-- } \\
\text { Wider? } \\
\text { At the top? } \\
\text { Wider, / on the top, / yeah. }\end{array}$ \\
\hline $2 A$ & $36 \mathrm{~b}$ & FR 372 & $\begin{array}{l}\text {...that's where the bottom of the } \\
\text { Icupsl (.) begins? }\end{array}$ \\
\hline $3 C$ & 38 & LL 125 & Begins. \\
\hline
\end{tabular}

Comprehensible output (3D). This language learner response is a self-modification of the trigger. The response contains modified output that approaches or equals the target language form. The data in this study found comprehensible output in negotiations of meaning in both semantic and syntactic sub-categories. A semantic 3D is a modification using synonyms, paraphrasing or examples. Intra-rater reliability of comprehensible output responses was $94 \%$. Intra-rater reliability of the two sub-categories was also $94 \%$.

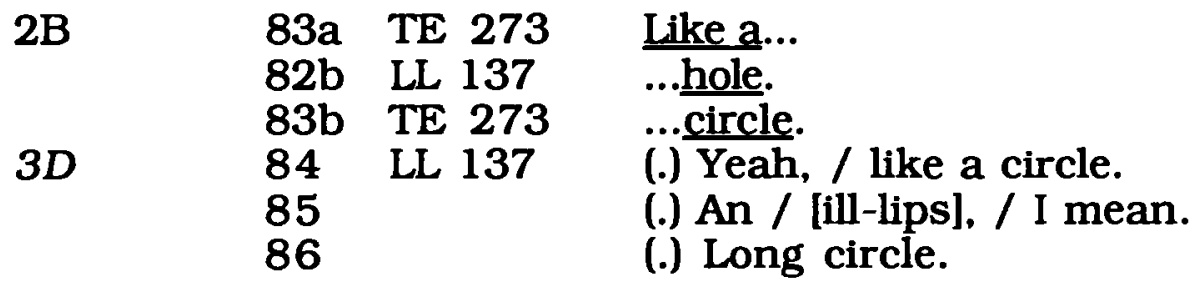

$\begin{array}{llll}\text { Trigger } & 35 & \text { LL 125 } & \text { This looks square. } \\ \text { 2B } & 36 & \text { Te 252 } & \text { Everything is square. } \\ & 37 & & \text { O.K., wait a minute, let's see. } \\ 3 D & 38 & \text { LL 125 } & \text { Like a cube. }\end{array}$


A syntactic 3D is an output modified morphologically or through the use of embedding and elaboration in clause(s).

\begin{tabular}{|c|c|c|c|}
\hline Trigger & 5 & LL 125 & $\begin{array}{l}\text { And / it has, (.2) really it has (.1) } \\
\text { one [prin-ciple] / side. }\end{array}$ \\
\hline $2 \mathbf{E}$ & 6 & Te 2 & Umm. \\
\hline 3B & 7 & & But, (.1) it, it has / four sides. \\
\hline $2 \mathrm{E}$ & 8 & Te: & Ummn. \\
\hline $3 D$ & 0 & & $\begin{array}{l}\text { But one is principle because, / } \\
\text { (.) it goes on. / on the wall. }\end{array}$ \\
\hline \multirow{4}{*}{$\begin{array}{l}\text { Trigger } \\
2 D \\
3 D\end{array}$} & 300 & & \multirow{4}{*}{$\begin{array}{l}\text { (.) You can / draw a [bi-], um-- } \\
\text { (.1) A big center? } \\
\text { A big center / in the middle of, / } \\
\text { eh, exactly in the middle of the... } \\
\text { In,... }\end{array}$} \\
\hline & $\begin{array}{l}301 \\
302 a\end{array}$ & $\begin{array}{l}\text { FR } 372 \\
\text { LL } 125\end{array}$ & \\
\hline & & & \\
\hline & & & \\
\hline
\end{tabular}

Pica et al. (1989) listed a phonological 3D category as well, but this category was absent in the data gathered for this study. Phonological self-modification did occur, however, not within negotiations of meaning interactions. Phonological self-modification is discussed within the error taxonomy described in this chapter.

Repeats trigger (3E). With this strategy, the language learner attempts to reintroduce the trigger to the hearer for comprehension. In many cases, the repetition of the trigger also indicates to the hearer that the language learner does not possess the linguistic resources needed to modify the output.

$\begin{array}{llll}\text { Trigger } & 105 & \text { LL } 125 & \begin{array}{l}\text { (.2) On the, on the / right, right } \\ \text { side of these [rec-tambles] / are } \\ \text { / another (.) row. }\end{array} \\ \text { 2E } & 106 & \text { TE 252 } & \begin{array}{l}\text { Hmm. } \\ \text { (.) Row? }\end{array}\end{array}$


Trigger 80 LL 125 And down.

$\begin{array}{llll}2 \mathrm{E} & 81 & \text { TE } 252 & \text { Oh. } \\ 3 E & 82 & \text { LL } 125 & \text { Down. }\end{array}$

Affirmation response (3F). This is another strategy employed by the language learner to show awareness that a signal has been given. In many cases, this response is used by the language learner to confirm the hearer's modification of the language learner's output.

\begin{tabular}{|c|c|c|c|}
\hline Trigger & 45 & LL 125 & Eh, / under? \\
\hline $2 \mathrm{D}^{\circ}$ & 46 & FR 372 & $\begin{array}{l}\text { (.) Going, uh, (.) up / from the } \\
\text { bottom / of the cup? }\end{array}$ \\
\hline $3 F$ & 47 & LL 125 & Yeah. \\
\hline $2 A$ & 413 & FR 372 & $\begin{array}{l}\text { (.) O.K., so three o'clock / is a big } \\
\text { one.? }\end{array}$ \\
\hline $3 F$ & 414 & LL 125 & Yes. \\
\hline
\end{tabular}

Inability to respond (3G). With this response the language learner indicates that he or she is having difficulty or experiencing an inability to respond to the signal. This type of response usually triggers a new signal from the hearer.

\begin{tabular}{|c|c|c|c|}
\hline $\begin{array}{l}2 A \\
3 G\end{array}$ & $\begin{array}{l}317 \\
318\end{array}$ & $\begin{array}{l}\text { FR } 372 \\
\text { LL } 125\end{array}$ & $\begin{array}{l}\text { (.) How wide is that petal? } \\
\text { (.) Umm, (.) the size, / the, the } \\
\text { size of the the-- }\end{array}$ \\
\hline $2 \mathrm{D}$ & 319 & FR 372 & (.) Pencil? \\
\hline $\begin{array}{l}2 A \\
3 G\end{array}$ & $\begin{array}{l}477 \\
478 \\
479\end{array}$ & $\begin{array}{l}\text { TE } 252 \\
\text { LL } 125\end{array}$ & $\begin{array}{l}\text { (.) I don't understand. } \\
\text { / What do you mean by narrow? } \\
\text { (.) I don't know, it's narrow, so-- }\end{array}$ \\
\hline $\begin{array}{l}2 \mathrm{~A} \\
3 G \\
2 \mathrm{D}\end{array}$ & $\begin{array}{l}107 \\
108 \\
109\end{array}$ & $\begin{array}{l}\text { TE } 273 \\
\text { LL } 137 \\
\text { TE } 273\end{array}$ & $\begin{array}{l}\text { (.1) What kind / of flowers? } \\
\text { (.) Flowers / are, (.2) ummm-- } \\
\text { (.) Like a rose. }\end{array}$ \\
\hline
\end{tabular}

Continuation of trigger $(3 \mathrm{H})$. This response category was devised by the researcher to account for responses on the part of the 
language learner that continued the trigger move by ignoring the signal. This strategy had mixed results. Sometimes the added information was enough to create understanding in the hearer. At other times, however, the hearer simply repeated the signal, essentially demanding that the language learner acknowledge that a trigger had occurred.

\begin{tabular}{|c|c|c|c|}
\hline $\begin{array}{l}\text { Trigger } \\
2 \mathrm{D} \\
3 H\end{array}$ & $\begin{array}{l}132 a \\
133 \\
132 b \\
134\end{array}$ & $\begin{array}{l}\text { LL } 125 \\
\text { TE } 252 \\
\text { LL } 125 \\
\text { TE } 252\end{array}$ & $\begin{array}{l}\text { One... } \\
\text { One box. } \\
\text { (..big side. } \\
\text { (.) O.K. }\end{array}$ \\
\hline $\begin{array}{l}\text { Trigger } \\
2 \mathrm{E} \\
3 \mathrm{H} \\
2 \mathrm{E} \\
3 \mathrm{D}\end{array}$ & $\begin{array}{l}284 a \\
285 a \\
284 b \\
285 b \\
286\end{array}$ & $\begin{array}{l}\text { LL } 125 \\
\text { FR } 372 \\
\text { LL } 125 \\
\text { FR } 372 \\
\text { LL } 125\end{array}$ & $\begin{array}{l}\text { / It's very... } \\
\text { Is it... } \\
\text {...popular one. } \\
\text {...eh, it, (.1) um-- } \\
\text { (.) Is / like, (.1) there } \\
\text { the, / in the middle, }\end{array}$ \\
\hline $\begin{array}{l}\text { Trigger } \\
2 \mathrm{D} \\
3 \mathrm{H} \\
2 \mathrm{~B} \\
3 \mathrm{C}\end{array}$ & $\begin{array}{l}232 a \\
233 \\
232 b \\
234 \\
235\end{array}$ & $\begin{array}{ll}\text { LL } & 137 \\
\text { TE } & 273 \\
\text { LL } & 137 \\
\text { TE } & 273 \\
\text { LL } & 137\end{array}$ & $\begin{array}{l}\text { (.) All... } \\
\text { On the edge. } \\
\text {...around. } \\
\text { (.) All around. } \\
\text { On the edge, / yeah. }\end{array}$ \\
\hline
\end{tabular}

Comprehension checks (3I). Occasionally, the language learner will respond to the signal using a comprehension check. This type of response is a direct check of the hearer's understanding (Long, 1983a). Though the use of comprehension checks within a negotiation of meaning is rare, they do occur and it was necessary to add the category to the negotiation model.

$\begin{array}{llll}\text { Trigger } & 89 & \text { LL } 125 & \begin{array}{l}\text { One (.1) up. } \\ \text { And one down. } \\ \text { (.) But-- }\end{array} \\ & 90 & & \begin{array}{l}\text { (.) Hmmm. } \\ \text { 2E }\end{array} \\ 3 I & 92 & \text { TE } 252 & \text { Can you make them? }\end{array}$




\begin{tabular}{|c|c|c|c|}
\hline $\begin{array}{l}2 A \\
3 I\end{array}$ & $\begin{array}{l}111 \\
112\end{array}$ & $\begin{array}{l}\text { TE } 273 \\
\text { LL } 137\end{array}$ & $\begin{array}{l}\text { (.) Many / petals. } \\
\text { (.) I mean, (.) you know (.) the, (.) } \\
\text { um, / cotton? }\end{array}$ \\
\hline $\begin{array}{l}\text { Trigger } \\
2 \mathrm{E} \\
3 I\end{array}$ & $\begin{array}{l}440 \\
441 \\
442\end{array}$ & $\begin{array}{l}\text { LL } 125 \\
\text { TE } 252 \\
\text { LL } 125\end{array}$ & $\begin{array}{l}\text { / And this part / is more narrow. } \\
\text { (.1) Hmm. } \\
\text { (.2) Did / you / put? }\end{array}$ \\
\hline
\end{tabular}

Comprehension checks (CC) were found to occur more often as the trigger that begins a negotiation of meaning.

$\begin{array}{llll}\text { CC-Trigger } & \text { LL } 137 & \text { (.) You know for / [t-], (.) for tie? } \\ & 254 & \text { TE } 273 & \text { (.) Um-huh. } \\ \text { 2D } & 255 & & \text { (.) In the middle / section. } \\ \text { 3C } & 256 & \text { LL } 137 & \text { (.) In the middle / section. }\end{array}$

Comprehension checks were also used by the language learner to obtain affirmation (AFF) of understanding from the hearer. In this case, the comprehension check was not given in response to a signal and no subsequent negotiation of meaning interaction ensued.

$\begin{array}{llll}\text { CC } & 269 & \text { LL } 137 & \begin{array}{l}\text { (.) You know sometimes / } \\ \text { Japanese womens / use it (.) for } \\ \text { (.) hair. }\end{array} \\ \text { AFF } & 270 \text { TE } 273 & \text { (.) Um-huh. }\end{array}$

\section{Embedded Negotiation}

Some negotiations contained more than one signal and response type. In these embedded negotiations, language learners' responses essentially become new triggers.

\begin{tabular}{|c|c|c|c|}
\hline Trigger & 203 & LL 125 & $\begin{array}{l}\text { (.1) [Dees] line / is / not very (.) } \\
\text { [theen]. }\end{array}$ \\
\hline $2 \mathrm{C}$ & 204 & FR 372 & (.1) It's not thin? \\
\hline $3 C$ & 205 & LL 125 & Thin. \\
\hline $2 A$ & $\begin{array}{l}206 \\
207\end{array}$ & FR 372 & $\begin{array}{l}\text { So it's thick? } \\
\text { Kind of thick. }\end{array}$ \\
\hline $3 C$ & 208 & LL 125 & Kind of. \\
\hline $2 \mathrm{E}$ & 209 & FR 372 & Just-- \\
\hline
\end{tabular}




\begin{tabular}{|c|c|c|c|}
\hline $\begin{array}{l}3 G \\
2 \mathrm{D}\end{array}$ & $\begin{array}{l}210 \\
211\end{array}$ & $\begin{array}{l}\text { LL } 125 \\
\text { FR } 372\end{array}$ & $\begin{array}{l}\text { Not-- } \\
\text { Not very thick? }\end{array}$ \\
\hline Trigger & 106 & LL 137 & $\begin{array}{l}\text { (.) The [motive] / on this (.) [eh-], } \\
\text { (.) the [motive] / on / the, (.) on } \\
\text { this hair clip / is, (.) eha, / } \\
\text { flowers. }\end{array}$ \\
\hline $2 A$ & 107 & TE 273 & (.1) What kind / of flowers? \\
\hline $3 G$ & 108 & LL 137 & (.) Flowers / are, (.2) ummm-- \\
\hline $2 \mathrm{D}$ & 109 & TE 273 & (.) Like a rose. \\
\hline $3 G$ & 110 & LL 137 & (.1) Not rose. \\
\hline $2 A$ & 111 & TE 273 & (.) Many / petals. \\
\hline $3 I$ & 112 & LL 137 & $\begin{array}{l}\text { (.) I mean, (.) you know (.) the, (.) } \\
\text { um, / cotton? }\end{array}$ \\
\hline $2 B$ & 113 & TE 273 & (.1) Cotton? \\
\hline $3 E$ & 114 & LL 137 & (.) Cotton. \\
\hline $2 A$ & 115 & TE 273 & $\begin{array}{l}\text { (.) Ah, so, (.) it's kind of a / bushy } \\
\text { / kind of flower. }\end{array}$ \\
\hline $3 F$ & 116 & LL 137 & (.) Yeah. \\
\hline
\end{tabular}

\section{Completion Moves}

Varonis and Gass (1985) recognized that the hearer would often react to the speaker's response before the conversation moved beyond the negotiation of meaning interaction. However, in their original model, this component was an optional one. The model as revised by Pica (1988) and Pica et al. (1989) changed this optional completion move into a structured part of the interaction. According to the new model, the negotiation of meaning could not be completed until the hearer had either provided an explicit signal of comprehension (4A) or signaled comprehension by making a topic continuation move (4B). The data collected for this study revealed that these two categories are insufficient to account for all negotiation of meaning completions. Three additional categories (4AB, 4C, 4D) were identified and are 
operationalized below. Completion move categories receive the number 4 code. Intra-rater reliability for completion move coding was $90 \%$.

Comprehension signal (4A). The hearer signals to the language learner that the response is acknowledged and understood.

$\begin{array}{llll}\text { 2D } & 51 & \text { FR } 372 & \text { Oh, a / question mark? } \\ 3 \mathrm{C} & 52 & \text { LL 125 } & \text { A question mark. } \\ 4 A & 53 & \text { FR } 372 & \text { O.K. } \\ & & & \\ \text { 2A } & 83 a & \text { TE } 252 & \text { (.) Horizontal, or... } \\ 3 C & 84 & \text { LL 125 } & \text { Horizontal. } \\ & 83 b & \text { TE 252 } & \text {...vertical? } \\ 4 A & 85 & & \text { Oh, horizontal. O.K. }\end{array}$

Continuation move (4B) With this move the hearer implicitly shows understanding by continuing the conversation from the point of the trigger interruption. The hearer may continue the conversation on the same topic or switch to a new topic. The nature of the information exchange tasks used in this study may have limited the range of topic switching that occurred.

\begin{tabular}{|c|c|c|c|}
\hline $\begin{array}{l}2 A \\
3 F \\
4 B\end{array}$ & $\begin{array}{l}21 \\
22 \\
23\end{array}$ & $\begin{array}{l}\text { ST } 454 \\
\text { LL } 149 \\
\text { ST } 454\end{array}$ & $\begin{array}{l}\text { (.) Oh, (.) are they / thin (.) lines? } \\
\text { (.2) Hee, / is kind of, (.) yeah. } \\
\text { (.) Let's see if I can do this. }\end{array}$ \\
\hline $\begin{array}{l}2 C \\
3 C \\
4 B\end{array}$ & $\begin{array}{l}292 \\
293 \\
294\end{array}$ & $\begin{array}{l}\text { TE } 252 \\
\text { LL } 125 \\
\text { TE } 252\end{array}$ & $\begin{array}{l}\text { Hope. } \\
\text { Hope, yes. } \\
\text { (.2) Ahhh, (.1) maybe it's / better } \\
\text { to just draw a rectangle. }\end{array}$ \\
\hline
\end{tabular}


Combined signal ( $4 A B)$. Sometimes the hearer gave a confirmation of understanding followed immediately by a continuation move.

\begin{tabular}{|c|c|c|c|}
\hline $\begin{array}{l}2 \mathrm{D} \\
3 \mathrm{C} \\
4 A \\
4 B\end{array}$ & $\begin{array}{l}409 \\
410 \\
411\end{array}$ & $\begin{array}{l}\text { FR } 372 \\
\text { LL } 125 \\
\text { FR } 372\end{array}$ & $\begin{array}{l}\text { (.2) Oh, like / three o'clock? } \\
\text { Three o'clock. } \\
\text { (.) Oh, O.K. } \\
\text { I must be / too high. }\end{array}$ \\
\hline $\begin{array}{l}2 \mathrm{~B} \\
3 \mathrm{~F} \\
4 A \\
4 B\end{array}$ & $\begin{array}{l}38 \\
39 \\
40 \\
41\end{array}$ & $\begin{array}{l}\text { TE } 252 \\
\text { LL } 125 \\
\text { TE } 252\end{array}$ & $\begin{array}{l}\text { Like a cubel } \\
\text { Yes. } \\
\underline{\mathrm{O} . \mathrm{K}} \\
\text { And, and, like / three cubes? }\end{array}$ \\
\hline
\end{tabular}

Speaker continuation-resolve move $(4 \mathrm{C})$. The hearer did not always initiate the completion of a negotiation of meaning interaction. The data revealed that speakers sometimes responded to the signal and then, before the hearers' next turn could occur, continued the conversation. In this type of speaker initiated continuation move, the negotiation of meaning would be successfully completed.

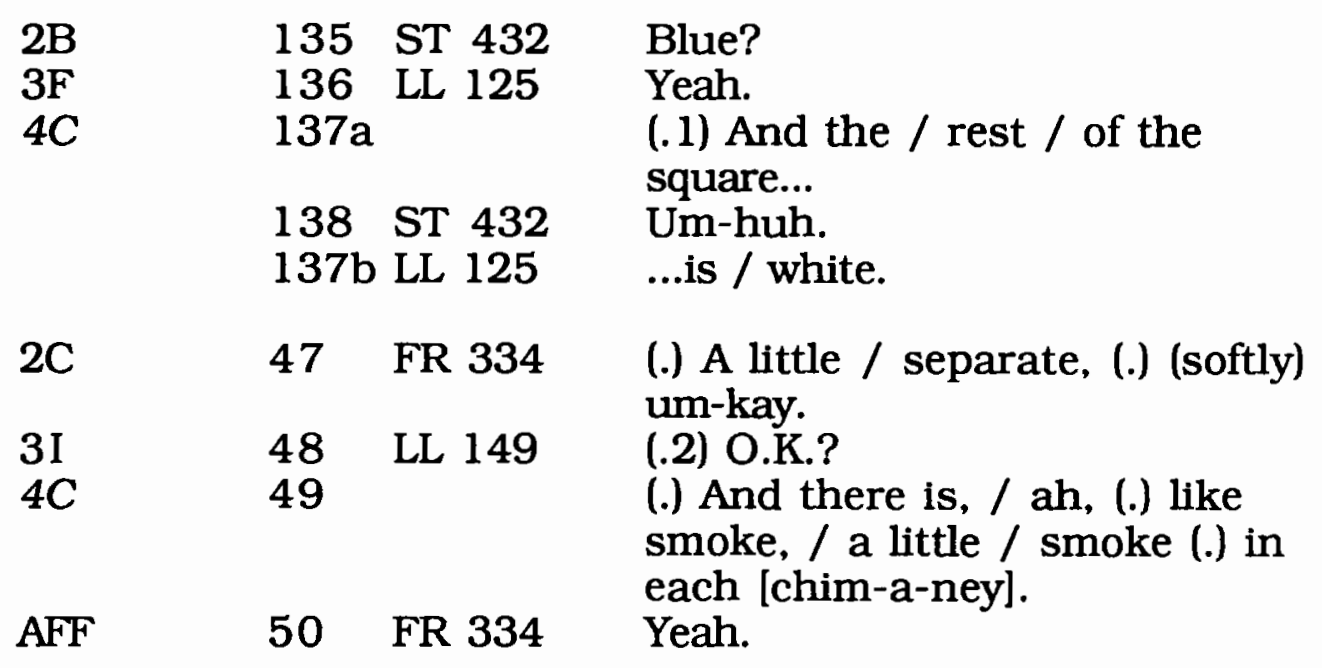

Speaker continuation-new trigger (4D). The speaker initiates a continuation move but, unlike a continuation-resolve move, this 
completion move results in a new negotiation of meaning interaction. It differs from an embedded negotiation because it is the new information offered by the speaker, not the response to the signal, that triggers the new negotiation of meaning interaction.

\begin{tabular}{|c|c|c|c|}
\hline $2 \mathrm{D}$ & 104 & TE 273 & (.) Oh, / it's a hair clip. \\
\hline $3 C$ & 105 & LL 137 & (.) Hair clip. \\
\hline $4 D$ & 106 & & $\begin{array}{l}\text { (.) The [motive] / on this (.) [eh], } \\
\text { (.) the [motive] / on / the, (.) on } \\
\text { this hair clip / is, (.) eha, / } \\
\text { flowers. }\end{array}$ \\
\hline $2 A$ & 107 & TE 273 & (.1) What kind / of flowers? \\
\hline $2 \mathrm{C}$ & 192 & FR 372 & $\begin{array}{l}\text { O.K.. / right on the edge of the } \\
\text { page? }\end{array}$ \\
\hline $3 F$ & 193 & LL 125 & Yes. \\
\hline $4 D$ & 194 & & Ah, leave / [deece-a] space, ah-- \\
\hline $2 \mathrm{C}$ & $195 a$ & FR 372 & Just a little space... \\
\hline $3 \mathrm{D}$ & $\begin{array}{l}196 a \\
195 b\end{array}$ & $\begin{array}{l}\text { LL } 125 \\
\text { FR } 372\end{array}$ & $\begin{array}{l}\overline{\text { Just }} \text { a } \ldots \\
\text {...over? }\end{array}$ \\
\hline & $196 \mathrm{~b}$ & LL 125 & $\begin{array}{l}\text {... [da], [de] space of [de], [de-de], (.) } \\
\text { the pencil. }\end{array}$ \\
\hline $4 \mathrm{~A}$ & 197 & FR 372 & O.K \\
\hline 12 & 198 & & (.) And a \\
\hline
\end{tabular}

\section{Error Coding}

The identification of language learners' linguistic errors follows the taxonomy developed by Chun et al. (1982). Language learner errors are defined as the use of a linguistic item in a way recognizable to native speakers of the language as deviant or in some way lacking fluency. All language learner errors were identified and coded by category. In addition, all language learner self-corrections of errors were coded by error category. Finally, the corrections of language learner errors by others were classified according to the error type. 
The error taxonomy, definition of language learner self-correction and correction by others is discussed in turn. Examples of each type of error, self-correction and correction by others are given from the research data. As with the negotiation of meaning interaction examples, examples were chosen for their brevity whenever possible. Interrater reliability scores from random transcripts for error type identification, other-correction and self-correction were $97 \%, 94 \%$ and $82 \%$ respectively.

\section{Error Categories}

The taxonomy contains six categories. The first five categories were operationalized by Chun et al. (1982). The sixth category, phonological errors, was added to the taxonomy for use in analyzing the data of this study. All errors are coded with letter abbreviations.

Discourse errors (DE). These are errors beyond the sentence level; errors related to turn-taking, pauses, topic switching, code switching, opening and closing moves or inappropriate response to the input. Very few discourse errors are included in the data collected in this study. It may be that the nature of the information exchange task caused the conversational dyads to interact within a highly prescribed and structured discourse form.

DE: Use of "el" from LL's L1.

427a LL 125 Then / [el] small one, / a big one, / a small

(LL 125 with FR 372) one / and / then / go to the... 
DE: Inappropriate response "Yes" to "either/or" question form. 219 LL $1237 \quad$ (.) With his / right hand (.) or left / hand. 220 LL $137 \quad$ Yes.

Factual error (FE).This category is comprised of utterance errors related to truth value. Like discourse errors very few of these errors were contained in the data.

FE: Identifying the letter " $L$ " when the proper identification was the letter "A".

268 LL 125 (.1) And, um, (.) now, / um, / one box / before the, / [theese] one, / the letter / "L".

269 FR 372 (.1). "L"?

270 LL 125 No, / the letter / "A"

FE: Use of "two" when the truth value was "three".

336 LL 113 So / the plug. / plugs has / two, (.) two, um,

(LL 113 with TE 231)

(.4) two, (.2) ah, three hands.

The factual errors in the second example ("two") were counted as three separate errors. Repeated errors in all categories were counted in the same manner.

Word choice errors (WC). Errors of this type included all incorrect additions or lexical choices on the part of the language learner of words from all word types; nouns, verbs, adjectives, adverbs, prepositions, etc.

WC: Use of "to" instead of "from".

$39 \mathrm{~b}$ LL 125 ...uh, / you / leave one finger, / uh, to the top...

(LL 125 with FR 372)

WC: Use "type" instead of "shape".

34 LL 137 (.3) I mean the / type / is like (.) butterfly.

(LL 137 with TE 273) 
WC: Use of "went" instead of "want".

11 LL 125 Eh, when lye-], when you [went] to / turn on

(LL 125 with TE 252)

(.) something and / you will need, ah, (.1) to put (.) it--

Syntactic errors (SE). Errors of syntax include incorrect tense agreement, morphology, word order and article agreement.

SE: Use of "these" instead of "this" and "describe" instead of "described".

1 LL 125 Ah, / I will describe the, (.1) the box, (.1) ah, (.) next / these one, / that you already

(LL 125 with FR 372) describe / me.

SE: Use of "small" instead of "smaller".

3 LL 125 And a little small than the (.) alarm clock.

(LL 125 with TE 252)

SE: Use of "put just" instead of "just put".

341 LL 137 (.) O.K., / you can put / just a / circle.

(LL 137 with TE 273)

Omission errors (OE). These errors include the omission of all word types that are otherwise required by the rules of English grammar. Nouns, verbs, articles and auxiliaries are among the types of words omitted. The examples show the omitted words in bracketed italics.

67 LL 125 (.) Uh, [it] is / kind of (.) [a] big / letter.

(LL 125 with FR 372)

78 LL 125 One is up.

79 TE 252 Two.

80 LL 125 And lone is] down.

(LL 125 with TE 252)

The second example, the omission of "one is", is a phrasal omission and was counted as one omission error. 
Phonological errors (PE). This category encompasses all language learner errors in pronunciation. Chun et al. (1982) excluded phonological errors from their taxonomy. Their stated reason for doing so was the difficulty they encountered distinguishing phonological errors from "systematic nonnative phonological patterns which prevail throughout the speech of nonnative speakers" (p. 539). Many pronunciation errors of this "systematic" nature occurred in the data of this report. For example, the Spanish Ll subject frequently pronounced "the" as "dee". This type of phonological error was included in the error count identified in this study. False starts were also counted as phonological errors. Phonological errors, at times, were triggers of a negotiation of meaning interaction.

PE: Use of "et's" instead of "it's". Use of "keet-" instead of "kitchen".

6 LL 125 And, ahm, / [et's], (.2) ahm, / you, / you have (LL 125 with FR 372) in your [keet-], / in your kitchen.

While the second error ("keet-") may be considered a false start, it may also be a mispronunciation, or inability to pronounce the word.

PE: Use of "rec-tambles" instead of "rectangles".

105 LL 125 (.2) On the, on the / right, right side of these

(LL 125 with TE 252) [rec-tambles] / are / another (.) row.

\section{Language Learner Self-Corrections}

Language learners' self-corrections of errors were identified in all error categories with the exception of discourse errors. Selfcorrections were counted as such if they occurred before the language 
learner had moved on to a new topic or topic focus. Also, language learners' self-correction of errors did not include errors corrected as part of a negotiation of meaning interaction. Self-corrections that occurred within the trigger-signal-response model were identified as per the coding system described earlier in this chapter.

Factual self-corrections. The language learner corrects an error in truth value.

FE: Correct "two" to "three".

331 LL 113 So / the plug, / plugs had / two, (.) two, um, (LL 113 with TE 231) (.4) two, (.2) ah, three hands.

The self-correction count is also three. Just as the factual error ("two") was counted as three errors, the self-correction is considered to correct all of the errors counted.

Word choice self-corrections. The language learner corrects an incorrect addition of a word or a word choice error by omitting the word and/or substituting the correct choice.

WC: Omit "a".

214 LL 113 Umm, (.2) is it just arrow / or something. (.)

(LL 113 with FR 341)

a [somethi-], / a some, / or something else?

In this utterance, the language learner first made an incorrect selfcorrection with the addition of "a" before finally correctly omitting it.

WC: Change "on" to "in".

16a LL 125 In the bottom, / on the bottom...

17 FR 372 Ah.

16b LL 125 ...of the (.) cup,... 
Syntactic self-corrections. The language learner correctly changes an incorrect usage of language with regards to tense agreement, article agreement, morphology or word order.

SE: Change "the" to "this".

268 LL 125 (.) , um, (.) now, / um, / one box / before the, / (LL 125 with FR 372) [theese] one, / the letter / "L".

The phonological error that occurs in the self-correction "theese" is counted as a PE though the change from "the" to "this" is counted as a syntactic error self-correction.

$\mathrm{SE}$ : Change "is" to "are".

349 LL 137 (.) And (.) on this (.) [s-circle], there is some,

(LL 137 with TE 231) (.1) ehh, (.2) [de-], / there are some, (.) I mean / pictures of.

SE: Change "he" to "his".

552 LL 149 (.) And he, / his hat.

(LL 149 with LL 113)

SE: Change "it's make" to "it makes".

40 LL 113 (.) Is, (.) it's, ah, (.) make, / it makes the (.)

(LL 113 with ST 421) square (.) [hatch].

SE: Change "he wearings" to "he's wearing".

414a LL 125 (.) He wearings a, / he's wearing a (.)

415 LL 1225 Skirt?

414b LL 125 ...long skirt. 
Omission self-corrections. The language learner adds the correct omitted word. The omission error is shown in bracketed italics.

OE: Add "an".

78b LL 137

79 FR 303

...(.) what's [an] arrow?

80 LL 137 I know an arrow / but , / in the [boook].

OE: Add subject "the little triangle" to the sentence.

506 LL $149 \quad$ (.) And [subject] is, (.) eh, (.1) the [leetle] /

(LL 149 with ST 454) triangle / is (.) yellow.

OE: Add "one".

168 LL 125 Under [dis] / yellow [one].

169 (.1) In the second / line.

170 ST $432 \quad$ (.1) The second line.

171 LL 125 Yes.

172 ST 432 Um-'kay.

173 LL 125 (.) Under [de] / yellow one.

This last example is considered an omission error self-correction even though several c-units occur before the correction takes place.

Phonological self-corrections. This category includes language learner self-correction of all phonological errors including false starts.

PE: Change the false start "sq-" to "square".

15 LL 125 [Sq-], not, (.1) more square.

(LL 125 with FR 372)

PE: Change "de" to "the".

222a LL 125 (.1) Is very, / [de] [letder] is (.) near [de], (.) the beginning of the, eh, near [de], [de] (.)

223 FR 372 O.K.

222b LL 125 ...of the (.) box.

This example illustrates how the self-correction can occur in

systematic errors as defined by Chun et al. (1982). The language 
learner also makes the same phonological error ("de") immediately after the self-correction followed by another self-correction.

PE: Change "ju-eh" to "you" and "leap" to "leave".

344 LL 125 (.) Because, uh, (.) [ju-eh], (.) [leap], (.) you /

(LL 125 with FR 372) should leave / just a / [let-dle] space.

\section{Correction of Errors by Others}

Language learners' errors were also corrected by their dyad partners. Other-corrections of errors were found in four of the error categories. There were no other-corrections of errors of a factual and discourse nature. Corrections were counted as such if they occurred before the language learner had moved on to a new topic or topic focus. Error corrections by others could be overt or covert. An overt error correction involved the dyad partner plainly pointing out that a language learner error had occurred as well as providing the correct form. Most error corrections, however, were covert. The dyad partner would repeat the utterance supplying the corrected form within the repetition. The dyad partner may not have been consciously correcting the language learner's linguistic error. Instead, the error may have triggered a signal from the partner to indicate to the language learner that a negotiation of meaning was warranted. 
Word choice corrections. The dyad partner supplies or models the correct word choice including the omission of incorrect words.

WC: Correct "file" to "row".
$\begin{array}{ll}\text { 341a LL 149 } & \text { In the / second... } \\ \text { 342a LL 113 } & \text { A second... } \\ \text { 341b LL 149 } & \text {...file. } \\ \text { 342b LL 113 } & \text {...row. }\end{array}$

WC: Correct "related" to "next".

375 LL 137 / You can just draw / this stuff.

376 TE 273 (.1) In the circle.

377 LL 137 Not.

378 (.) Eh, (.) related (.) [t-], to--

379 TE 273 Next to.

wC: Correct "in" with "at".

335 LL 125 But, / ah, [theese] line / I have start in [de], / in [de] point?

336a / And go through / the...

337a ST 432 Well, you don't...

336b LL 125 ....base?

337b ST $432 \quad$...start at the point.

Syntactic corrections. The dyad partner supplies or models the correct syntax form.

SE: Corrects "cuts" to "cut".
405 LL 125
Like, (.1) uh, (.1) looks like (.1) some, some,
406 ST 432 some, / someone / cuts / the flag.
(laughs)
407 ST 432 Cut the tip off it.
SE: Corrects "scale" to "scales".
269 FR 303
(.) Oh, (.) uh, (.) scales.
270 LL 137
(.) Scale.
271 TR 303
/ Or (.) does he have?
272 FR 303 (.) No, (.) no / scales. 
SE: Corrects "he" to "she".

158 LL 149 Does / she have kind of a / tree / in his, / in

159 LL 113 She.

160 LL 149 He's kind of--

161 LL 113 She.

SE: Corrects "no" to "not".

168 LL 149 (.2) But / no in the, / no in the hole.

169 TE 294 (.) Yeah.

170 LL 149 That, (.) that, that one is a hole.

171 a TE 294 Not...

172 LL 149 So is--

$171 b$ TE 294 ...in the hole.

Omission corrections. The dyad partner supplies or models the omitted word. Most language learner omission errors that were corrected by the dyad partner were errors caused by omitting English articles. In the examples listed, the omission error is in bracketed italics.

OE: Correct by adding "the".

158 LL 113 And (.1) fourth one and fifth one / is, (.) uh, / just, (.) just right side / of [the] longest stack.

159a FR 341 (.) Right side...

160 LL 113 (.) Un-huh.

159b FR $341 \quad$...of the longest stack.

OE: Correct by adding "a".

88 LL 125 (.) Is it still [a] square, / right?

89 ST 432 This is a square.

OE: Correct by adding "on the".

239 LL 113 And / the handle is (.1) lon the] right side.

240 FR 341 (.) The handle is / on the right side.

The omission correction of the phrase "on the" is counted as one omission error correction. 
Phonological corrections. The dyad partner supplies or models the correct pronunciation of the phonological error.

PE: Overt correction of pronunciation of "porcelain".

\begin{tabular}{|c|c|}
\hline 359a LL 137 & $\begin{array}{l}\text { (.) And / also, (laughs) (.1) something is } \\
\text { related / to the top of / this [person], (.) eh, } \\
\text { (.) Iporsonall (1) lpor-l }\end{array}$ \\
\hline $\begin{array}{lll}360 & \text { TE } & 273 \\
359 b & \text { LL } & 137 \\
361 & \text { TE } & 273 \\
362 & & \end{array}$ & $\begin{array}{l}\text { Porcelain. } \\
\text { (..) Nersonal]. } \\
\text { (.) Not person. } \\
\text { Porcelain. }\end{array}$ \\
\hline
\end{tabular}

PE: Corrects pronunciation of "thin".

203 LL 125 (.1) [Dees] line / is / not very (.) [theen].

204 FR 372 (.1) It's not thin?

PE: Corrects pronunciation of "rectangle".

95a LL 125 The [rec-], the [reek-tangles]...

96 TE 125 The rectangles.

Multiple corrections. Often the dyad partner corrects more than one error within a single c-unit. Each error corrected was coded as a different correction by others.

OE: Correct by adding "an".

Pe: Corrects pronunciation of "ellipse".

72 LL 137 . / And, (.) eh, (.) in the middle, (.) there is long (.) [cir-], / not circle, / but (.) like [an] [ell-lips].

73 (.) Is it / same in--

74 TE 273 An ellipse.

$\mathrm{OE}$ : Correct by adding "the".

$\mathrm{OE}$ : Correct by adding "a".

399 LL 113 [the] Tail / looks like / [a] triangle.

400a FR 341 (.) Yeah, / the...

401 LL 113 Hmh.

400b FR $341 \quad$...tail looks like a triangle.

$\mathrm{OE}$ : Correct by adding "the".

WC: Correct "size" to "width".

374 LL 125 And, and (.) half / in [the] size / too.

375 FR 372 Oh, in, in, in / the width, how- 
SE: Corrects "besides" to "beside".

PE: Corrects pronunciation of "little".

386 LL 125 Besides / the / [leetle] one.

387 FR 372 Beside the little one, / O.K.

\section{CONCLUSION}

The descriptions of the subjects, tasks, data collection procedures, transcription methods and coding taxonomies were designed to make replication of this study possible. The descriptions of the taxonomies will also be especially useful in interpretation of the statistical analysis presented in the next chapter.

There are several limiting factors inherent in the research design presented here. Of these, the most serious may be a possible difference in dyad task difficulty. The relative proficiency of the language learner subjects is another area for concern. The subjects' command of English may have been more diverse than their placement within the same level of the ALA program was hoped to control for. These limiting factors and others will be discussed in more detail as the findings are presented in Chapter IV and in the concluding observations made in Chapter V. 


\section{CHAPTER IV}

\section{RESULTS}

\section{INTRODUCTION}

\section{Statistical Tests Used}

Eight of the hypotheses outlined in Chapter I were statistically tested using a one way analysis of variance test (ANOVA). The ANOVA test was used to see if the independent variables had statistically different means. When the ANOVA test allowed the null-hypothesis to be rejected and when the number of replicates among the samples were equal, Tukey's test was used to determine which of the independent variable means were significantly different from each other.

The assumptions underlying the ANOVA test were held to be true. It was assumed that the groups tested were representative of the general population with normal distribution and that all the populations had the same variance. The samples, while representative, were not randomly selected. The subjects were generally self-selected or selected by other subjects. This was not considered to be a serious threat to the validity of the ANOVA results. Though the sample sizes were not equal, they were not markedly 
different. Thus, the equal variance assumption was not violated. The critical alpha value was set at $\mathbf{p}<.05$.

For hypothesis nine, a simple regression test was used for the statistical analysis. The independent variable and dependent variable were assumed to be independent from all other variables. They were further assumed to be normally distributed with a linear relationship existing between the two. The data were considered to be interval for this test. A table of intercorrelations is presented showing that no problems associated with multicollinearity exist. The critical alpha value was set at $\mathrm{p}<.05$.

\section{Data Organization}

The data were organtzed into two main groupings according to the hypotheses being tested. For the hypotheses related to negotiation of meaning interactions, some data were excluded from the analysis. Only data generated during interactions that occurred when the tracked language learner subject held the information to be shared were included in the result totals. Of course, there were also negotiations of meaning interactions that were triggered by the dyad partners during their information-sharing turn. However, those interactions do not directly address this study's hypotheses.

The language learner subjects also triggered negotiation of meaning interactions when their dyad partners were sharing information. These interactions were excluded from the statistical 
analysis as well. The research was designed to examine meaning interactions when the language learner was "in charge" of the information sharing. The triggers that occurred during the dyad partner's information-sharing did not fit the parameters of the research design. The total amount of these excluded language learner subject triggers (49) was a small percentage (6\%) of the total triggers identified (765). The data used in the analysis of the negotiation of meaning hypotheses are referred to throughout the findings as language learner held information (LLHI) c-units.

The hypotheses that examine language learner linguistic errors were statistically tested using the entire corpus of data that was identified. Errors, self-correction of errors and other-correction of errors were not limited to only LLHI. The possible cumulative effect of other-corrections on comprehensible output, as tested in Hypothesis Nine, made inclusion of all other-corrections essential. This, in turn, made identification of all errors and self-corrections mandatory.

The data were organized into c-units as described in Chapter III. All tests were run using both c-unit counts and c-unit counts adjusted for affirmation and continuation signals (see page 53). The $p$ value, as it related to the critical value $(\mathrm{p}<.05)$, never became more or less significant due to the adjusted c-unit counts. The following discussion of the results, then, will focus only on statistical analysis using the raw c-unit counts. 
The reason the adjusted c-unit count did not affect the statistical analysis may be a function of several different factors. Perhaps information exchange tasks provide enough structure to limit an excessive use of the affirmation/continuation signals. Open-ended tasks, such as discussion groups, may show a difference between the raw and adjusted c-unit count on the statistical tests. It may also be that these signals are constant across speakers' total c-unit production. In this case, task type would not change the relationship of the two c-unit counts. The adjusted count would always be a factor of total c-unit production as the data of this research seem to suggest.

Most hypotheses were tested using the taxonomy categories as measured by c-units. However, some data were analyzed using other measures. For example, clarification signals resulting in comprehensible output responses were measured as a factor of the total comprehensible output responses identified. The data control measures used for each test are mentioned within the discussions that follow.

The remainder of this chapter will be organized by hypotheses. Explanation of the reasoning underlying the predictions, presentation of all related findings and an interpretation of the possible reasons for the findings' occurrence will all be included in this chapter. Inclusion of interpretative remarks in the results chapter is suggested by Borg and Gall (1979). Their suggestion is followed in this report due to the large amount of findings that will be presented. The major results will 
be summarized in Chapter V. Chapter V will also contain additional discussion remarks.

\section{HYPOTHESES FINDINGS}

\section{Negotiation of Meaning Hypotheses}

The first five hypotheses make predictions related to negotiation of meaning interactions. The taxonomy presented in Chapter Three was used to code and organize the data for use in the statistical analysis that follows. Each of the first five hypotheses and related findings will be discussed in turn.

\section{Hypothesis One}

Hypothesis One predicted that signals of total or partial lack of understanding would occur most often in LL/LL dyads. The dyads with native speaker friends and peer-strangers were predicted to produce more signals of total or partial lack of understanding than would the dyads with teachers. The data used in this test included only LLHI c-units.

According to the negotiation of meaning model, signals will only be produced when a trigger has been given by the language learner subject. Assuming that the tasks were of equal difficulty, it was hypothesized that the language learners working together would have more difficulty understanding each other than would the other dyad groupings containing a native speaker. It was thought that the 
language learners would be at a disadvantage because of their lack of fluent proficiency in the English language. Teachers, on the other hand, would be the most experienced at understanding language learner speech. This experience was thought to be a positive influence that would limit the amount of meaning negotiations necessary to complete the task. Likewise, the relative inexperience of the friends and peer-strangers in interactions with language learners was predicted to result in the need for more negotiations of meaning than would be found with the language teachers.

With Hypothesis One, as with all subsequent hypotheses, ANOVA analysis of the data in question was tested against the language learner subjects as individuals to ascertain whether the behavior of a single subject may have skewed the results. Table $\mathrm{X}$ reveals that the language learner subjects produced an almost equivalent amount of triggers per c-unit.

Each of the first five hypotheses was tested in the same manner, and no evidence of abnormally distributed data was found in any of the results.

In Table $\mathrm{X}, \underline{\mathrm{CI}} \mathrm{S}$ refers to confidence intervals. Confidence intervals describe the range of the independent variable and are illustrated in the figure shown in the table. Subsequent tables will exclude the CI'S label in the interest of space. The diagram illustrating the confidence intervals will still be shown on all of the tables that follow. 
TABLE X

TRIGGERS PER C-UNITS,

LANGUAGE LEARNER

SUBJECTS

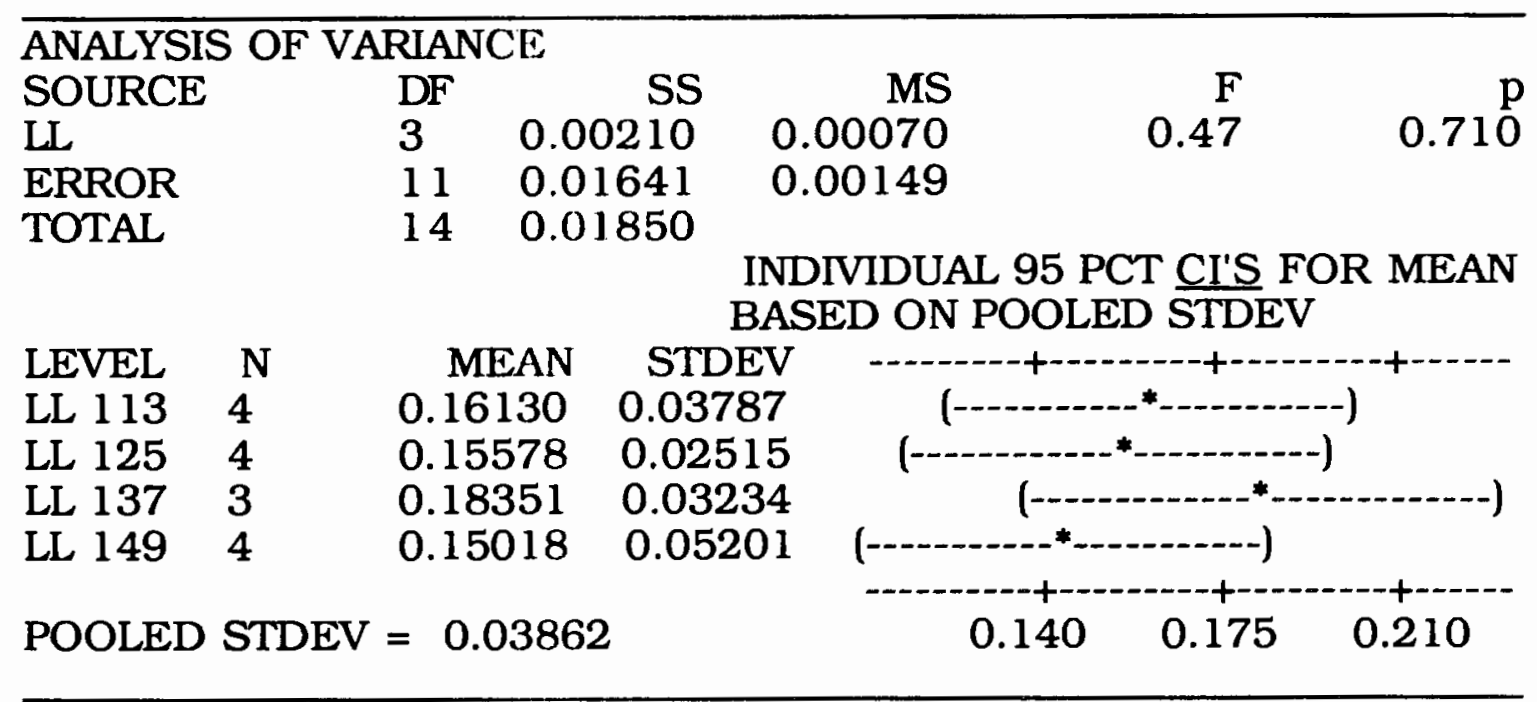

In Table XI, the means for the triggers per c-unit for each dyad type are given. The trigger mean counts (Trs.) and C-unit counts are inclusive of all language learner held information (LLHI). The number (n) of subjects in each dyad grouping remains the same in all the statistical analysis found in this research.

Hypothesis One does not seem to be supported by the data. The LL/LL, LL/FR and LL/TE dyads all produced nearly equivalent percentages of triggers per c-unit while the LL/ST dyad appears to have produced the least. An ANOVA test (Table XII) on the effect of dyad grouping on the amount of triggers per c-units produced does not show significant results $(\mathrm{p}=0.105)$. However, the means listed 
suggest that peer-stranger dyads produce fewer triggers than do the other native speaker dyads.

TABLE XI

MEAN TRIGGERS

PER LLHI C-UNITS,

ALL DYADS

\begin{tabular}{lrrrrrr}
\hline Subject & N & Trs. & S.D. & C-units & S.D. & $\%$ \\
\hline Teachers & 4 & 57.3 & 16.1 & 343.0 & 40.5 & $16.7 \%$ \\
Friends & 4 & 48.8 & 7.4 & 292.5 & 13.5 & $16.6 \%$ \\
Strangers & 3 & 29.0 & 9.6 & 262.0 & 69.9 & $11.1 \%$ \\
LLs & 4 & 51.0 & 19.0 & 310.3 & 84.2 & $16.2 \%$ \\
ALL & 15 & 47.7 & 16.2 & 304.6 & 58.9 & $15.5 \%$ \\
\hline
\end{tabular}

TABLE XII

TRIGGERS PER LLHI C-UNITS,

ALL DYADS

\begin{tabular}{|c|c|c|c|c|c|c|}
\hline \\
\hline \multicolumn{7}{|c|}{ SOURCE DF } \\
\hline \multicolumn{2}{|c|}{ DYAD } & 3 & 0.007027 & 0.002342 & 2.60 & 0.105 \\
\hline \multicolumn{2}{|l|}{ ERROR } & 11 & 0.009911 & 0.000901 & & \\
\hline \multicolumn{2}{|l|}{ TOTAL } & 14 & 0.016938 & & & \\
\hline YAD & $\mathbf{N}$ & $\mathrm{ME}$ & STDEV & & & $T_{T}-1$ \\
\hline Teachers & 4 & 0.16 & $7 \quad 0.04019$ & & $(-\cdots---$ & -.-.---) \\
\hline Friends & 4 & 0.16 & 0.02022 & & $(-\cdots--$ & ------) \\
\hline Strangers & 3 & $0.1]$ & 0.02513 & $(------\cdots)$ & -(-..---) & \\
\hline LLs & 4 & 0.16 & 0.02930 & & $\ldots+-*_{-}$ & -.--) \\
\hline \multicolumn{4}{|c|}{ POOLED STDEV $=0.03002$} & 0.10 & 0.140 & 0.175 \\
\hline
\end{tabular}

In Table XIII, ANOVA analysis of LL/ST dyads and the combined results from the LL/FR and LL/TE dyads does show significant results $(p=0.019)$. Apparently, peer-stranger dyads' interactions result in 
fewer negotiation of meaning interactions than do the other dyad groupings. It may be possible that peer-strangers are more tolerant of language learner incomprehensible input than are the other dyad participants. One reason for this tolerance may have been a desire on the part of the peer-stranger to foster a friendly, non-threatening atmosphere.

TABLE XIII

TRIGGERS PER LLHI C-UNITS, PEER-STRANGERS

\begin{tabular}{|c|c|c|c|c|c|c|}
\hline $\begin{array}{l}\text { SOURCE } \\
\text { ST/TEFR } \\
\text { ERROR } \\
\text { TOTAL }\end{array}$ & & $\begin{array}{l}\text { DF } \\
1 \\
9 \\
10\end{array}$ & $\begin{array}{l}\text { SS } \\
0.006668 \\
0.007337 \\
0.014006\end{array}$ & $\begin{array}{r}\text { MS } \\
0.006668 \\
0.000815\end{array}$ & $\begin{array}{r}F \\
8.18\end{array}$ & $\begin{array}{r}p \\
0.019\end{array}$ \\
\hline $\begin{array}{l}\text { DYAD } \\
\text { Te \& Fr } \\
\text { Strangers }\end{array}$ & $\begin{array}{l}N \\
8 \\
3\end{array}$ & $\begin{array}{l}\text { MEAN } \\
0.166 \\
0.111\end{array}$ & $\begin{array}{c}\text { STDEV } \\
0.02946 \\
0.02513\end{array}$ & (--- - & $(--)$ & ---+--- \\
\hline \multicolumn{4}{|c|}{ POOLED STDEV $=0.02855$} & 0.105 & 0.140 & 0.175 \\
\hline
\end{tabular}

The equivalency of task difficulty must also be questioned. The LL/ST task was rated slightly easier by the native speaker subjects than were the other tasks (see Table VI). The task involved a repetition of shapes and colors that was not as prevalent in the other tasks. Rather than being a product of the peer-relationship between the two subjects, the lower trigger ratio may have reflected the lack of a need to negotiate meaning due to relative task simplicity.

Nevertheless, the language learner subjects did not rate the LL/ST 
task as the easiest. In fact, one of the language learners rated this task as the most difficult.

\section{Hypothesis Two}

Hypothesis Two predicted that language learner with teacher dyads would display more completed negotiation of meaning interactions per c-unit than would the other dyad types. The data used to test this hypothesis included only the completed negotiations of meaning interactions identified within LLHI c-units.

According to the study by Ehrlich et al. (1989), native speakers' style with regards to descriptive detail affects the number of successful meaning negotiations that will occur. To help account for the difference between embedded negotiations and negotiations that are successfully concluded, Pica (1988) and Pica et al. (1989) added a mandatory completion component to the negotiation of meaning model. The hearer of the original trigger completes the negotiation according to this new obligatory component. Speaker continuationresolve moves $(4 \mathrm{C})$ and speaker continuation-new trigger moves (4D), as described in Chapter III, were added to the model used in this research to account for interactions that are concluded by the trigger speaker.

Negotiation of meaning interactions are encountered on a daily basis between language teachers and language learners. Teachers are probably familiar with the negotiation of meaning process. This 
familiarity with negotiation of meaning interactions was predicted to ensure more successful negotiation completions for the teachers than would be achieved by the other language learner dyad partners. Language learner with other language learner dyads were thought to be at the greatest disadvantage because of limited language skills.

The first analysis presented in this discussion is an ANOVA test of the combined categories of the Pica model with the two new categories devised for this research (Table XIV). Although Pica et al. listed two different components, they combined their completion category data for statistical purposes. The "combined" signal category (4AB) described in Chapter III is included in the combined categories shown in Table XIV. The p value (0.000) of this test is significant. Tukey's test shows that there are significant differences among all three categories. The combined categories of the Pica model occur far more often than either of the new speaker continuation move categories. Speaker continuation-resolve moves (4C) occur the least of all three categories.

An ANOVA analysis of mean counts of all the completion categories reveals that explicit comprehension signals (4A) occur more frequently than any of the other completion signals (Table XV). The difference between the other completion categories is not significant according to Tukey's test. 


\section{TABLE XIV}

COMBINED COMPLETION CATEGORIES

PER LLHI C-UNITS,

ALL DATA

\begin{tabular}{|c|c|c|c|c|c|c|}
\hline \multicolumn{5}{|c|}{ ANALYSIS OF VARIANCE } & \multicolumn{2}{|c|}{ TUKEYS TEST $\mathrm{D}=0.01$} \\
\hline SOURCE & & DF & SS & MS & $\mathrm{F}$ & \\
\hline FACTOR & & 2 & 0.037683 & 0.018842 & 147.39 & 0.000 \\
\hline ERROR & & 42 & 0.005369 & 0.000128 & & \\
\hline TOTAL & & 44 & 0.043052 & & & \\
\hline LEVEL & $\mathbf{N}$ & MEAI & STDEV & & -+ & --. \\
\hline $4 \mathrm{c} / \mathrm{cu}$ & 15 & 0.009 & 0.00635 & $\left(-*_{--}\right)$ & & \\
\hline $4 \mathrm{~d} / \mathrm{cu}$ & 15 & 0.021 & 0.01262 & $(--*--)$ & & \\
\hline $4 a b a b / c u$ & 15 & 0.0758 & 0.01356 & & & - ) \\
\hline$(4 a b a b=4$ & $4 b-$ & 4ab) & & $-\cdots$ & & \\
\hline POOLED & IDE & $=0$. & 131 & 0.02 & 0.050 & 75 \\
\hline
\end{tabular}

TABLE XV

COMPLETION CATEGORIES

PER LLHI C-UNITS,

ALL DATA

\begin{tabular}{|c|c|c|c|c|c|}
\hline \multicolumn{4}{|c|}{ ANALYSIS OF VARIANCE } & \multicolumn{2}{|l|}{ TUKEYS TEST } \\
\hline SOURCE & & $\mathrm{DF}$ & SOURCE & MS $F$ & \\
\hline \multirow{3}{*}{\multicolumn{2}{|c|}{$\begin{array}{l}\text { FACTOR } \\
\text { ERROR } \\
\text { TOTAL }\end{array}$}} & \multirow{3}{*}{$\begin{array}{l}4 \\
70 \\
74\end{array}$} & \multirow{3}{*}{$\begin{array}{l}0.010291 \\
0.007699 \\
0.017990\end{array}$} & 0.002573 & \multirow{3}{*}{0.000} \\
\hline & & & & 0.000110 & \\
\hline & & & & & \\
\hline LEVEL & $\mathbf{N}$ & \multirow{2}{*}{ MEAN } & STDEV & & 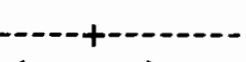 \\
\hline $4 \mathrm{a} / \mathrm{cu}$ & 15 & & 550.01309 & & $\left(---^{*}---\right)$ \\
\hline $4 b / c u$ & 15 & 0.01702 & 020.01188 & $\left(--*_{---}\right)$ & \\
\hline $4 a b / c u$ & 15 & 0.01565 & 350.00614 & $\left(--{ }^{*}---\right)$ & \\
\hline $4 \mathrm{c} / \mathrm{cu}$ & 15 & 0.00945 & 0.00635 & $\left(--{ }^{*}---\right)$ & \\
\hline $4 \mathrm{~d} / \mathrm{cu}$ & 15 & 0.02114 & $14 \quad 0.01262$ & $\left(--_{----)}\right.$ & \\
\hline \multicolumn{4}{|c|}{ POOLED STDEV $=0.01049$} & 0.015 & 0.045 \\
\hline
\end{tabular}

Analysis of the data using completion category per total triggers supports the results shown in Table XV (Table XVI). Meaning 
negotiations are most often successfully completed through the use of an explicit comprehension signal on the part of the hearer. Though speakers do make continuation moves, their moves appear to become new triggers (4D) more often than they result in a successful completion of the negotiation interaction (4C).

Analysis of the effect of dyad type on successful completions of meaning negotiations does not support Hypothesis Two. Using the categories of the Pica et al. model, the results are not significant with either completions per c-units $(\mathrm{p}=.686)$ nor with completions per total triggers $(p=.247)$. When speaker continuation-resolve moves are added to the data, the analysis of completions per c-units is still not significant $(\mathrm{p}=.31)$.

TABLE XVI

COMPLETION CATEGORIES

PER TOTAL TRIGGERS, ALL DATA

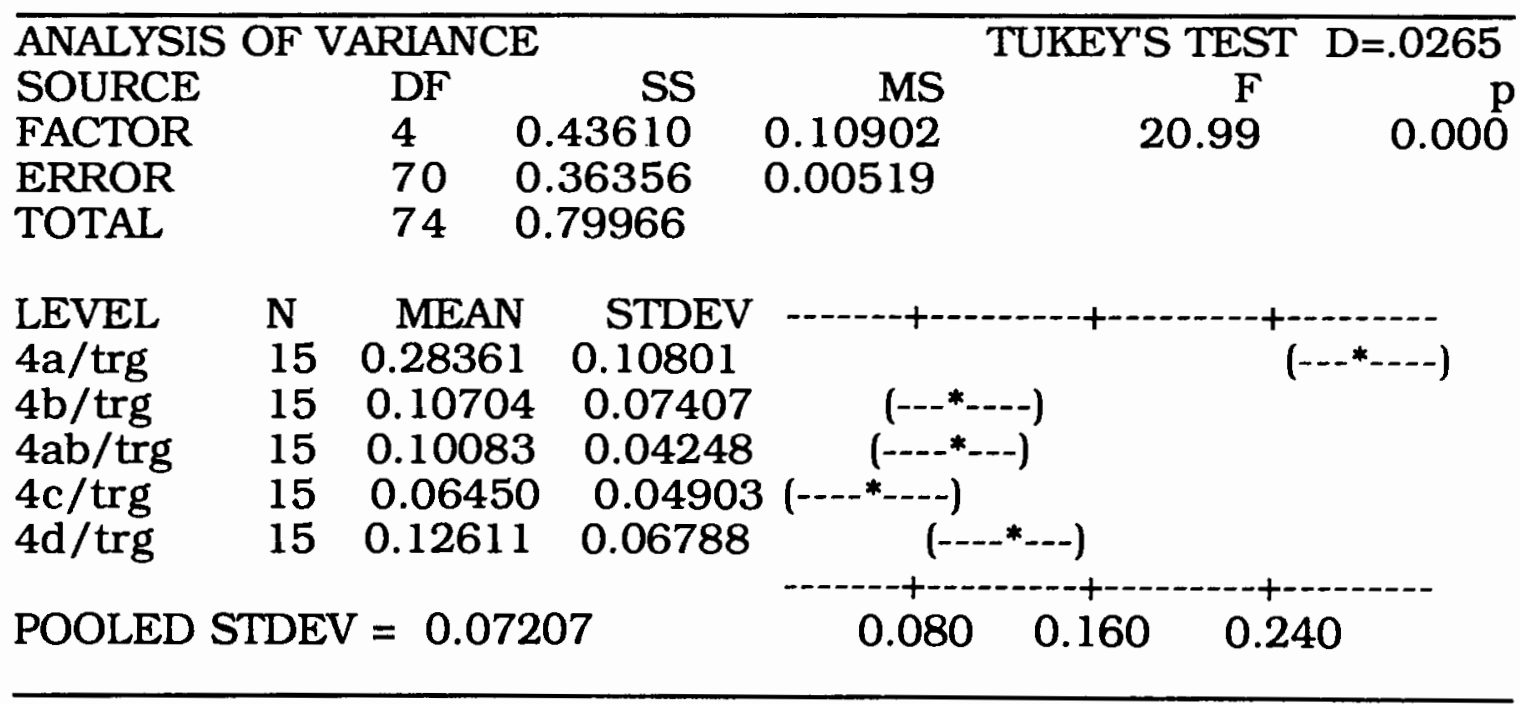


However, as the findings in Table XVII reveal, there is a significant difference when the speaker $(4 \mathrm{C}, 4 \mathrm{D})$ and hearer $(4 \mathrm{~A}, 4 \mathrm{~B}$, $4 \mathrm{AB})$ successful completion moves are combined and measured against the total triggers. The peer-strangers appear to have more successfully completed negotiations per trigger than do the other dyad types.

\section{TABLE XVII}

SUCCESSFUL COMPLETIONS

PER TOTAL TRIGGERS,

$4 \mathrm{~A}, 4 \mathrm{~B}, 4 \mathrm{AB}, 4 \mathrm{C}$,

ALL DYADS

\begin{tabular}{|c|c|c|c|c|c|}
\hline \multicolumn{6}{|c|}{ ANALYSIS OF VARIANCE } \\
\hline \multicolumn{6}{|c|}{$\begin{array}{l}\text { AINALYSIS OF VARIAIVCE } \\
\text { SOURCE }\end{array}$} \\
\hline DYAD & & 3 & 0.1289 & 0.0430 & 0.037 \\
\hline ERROR & & 11 & 0.1174 & 0.0107 & \\
\hline TOTAL & & 14 & 0.2464 & & \\
\hline LEVEL & $\mathbf{N}$ & MEAN & STDEV & + & \\
\hline Teachers & 4 & 0.4669 & 0.1458 & $(-\ldots-\ldots * \ldots)$ & \\
\hline Friends & 4 & 0.5160 & 0.0197 & $(-\cdots------)$ & \\
\hline Strangers & 3 & 0.7299 & 0.1313 & $(-\cdots$ & ---) \\
\hline LLs & 4 & 0.5546 & 0.0775 & $(--1-\infty *----)$ & \\
\hline POOLED S & & $=0.1$ & 33 & 0.60 & \\
\hline
\end{tabular}

When the LL/LL dyad data is excluded and the teacher and friend dyad data are combined, the analysis supports this preceding observation (Table XVIII). Peer-strangers apparently let the language learners resolve the negotiation far more often than do the other dyad types. Nevertheless, an analysis of variance does not show 
significant difference between the dyad types for test on speaker continuation-resolve moves $(4 \mathrm{C})$ per trigger $(\mathrm{p}=.340)$.

\section{TABLE XVIII}

\section{SUCCESSFUL COMPLETIONS}

PER TOTAL TRIGGERS, 4A, 4B, 4AB, 4C,

PEER-STRANGERS

\begin{tabular}{|c|c|c|c|c|c|c|}
\hline \\
\hline \multicolumn{7}{|c|}{ SOURCE } \\
\hline \multicolumn{2}{|l|}{ ST/TEFR } & 1 & 0.1241 & 0.1241 & 10.71 & 0.010 \\
\hline \multicolumn{2}{|l|}{ ERROR } & 9 & 0.1042 & 0.0116 & & \\
\hline \multicolumn{2}{|l|}{ TOTAL } & 10 & 0.2283 & & & \\
\hline LEVEL & $\mathbf{N}$ & MEAN & STDEV & --+ & $\cdots$ & +-- \\
\hline Strangers & 3 & 0.7299 & 0.1313 & & $-0^{*}$ & \\
\hline Te \& Fr & 8 & 0.4914 & 0.0998 & $\left(----*_{--\ldots--)}\right.$ & & \\
\hline \multicolumn{4}{|c|}{ POOLED STDEV $=0.1076$} & 0.45 & 0.75 & \\
\hline
\end{tabular}

However, when the peer-strangers' data are tested against the combined data of the teachers and friends, a significant difference is supported (Table XIX). The peer-strangers appear to allow the speaker to take control of the negotiation of meaning interaction.

These findings might help explain the results from Hypothesis One. Peer-strangers are involved in fewer negotiation of meaning interactions, yet their interactions are successfully completed more often than those of the other dyad types. Further, it is only with the addition of the speaker-continuation resolve move that the data show significant results. It would appear that the peer-strangers are more 
willing to let the language learners resolve the trigger problem on their own.

\section{TABLE XIX}

SPEAKER CONTINUATION RESOLVE

MOVES (4C) PER TOTAL TRIGGERS,

PEER-STRANGERS

\begin{tabular}{|c|c|c|c|c|c|c|}
\hline \multicolumn{7}{|c|}{ ANALYSIS OF VARIANCE } \\
\hline \multicolumn{7}{|c|}{ SOURCE DF } \\
\hline \multirow{2}{*}{\multicolumn{2}{|c|}{$\begin{array}{l}\text { ST/TEFR } \\
\text { ERROR }\end{array}$}} & 1 & 0.01267 & 0.01267 & 6.01 & 0.037 \\
\hline & & 9 & 0.01897 & 0.00211 & & \\
\hline \multicolumn{2}{|l|}{ TOTAL } & 10 & 0.03163 & & & \\
\hline LEVEL & $\mathbf{N}$ & ME $f$ & STDEV & & . & $\cdots+-\cdots$ \\
\hline Strangers & 3 & 0.1189 & 0.06479 & & -----* & (n)-- \\
\hline $\mathrm{Te} \& \stackrel{\mathrm{Fr}}{ }$ & 8 & 0.0427 & 0.03886 & $(-\cdots----\cdots$ & & \\
\hline \multicolumn{4}{|c|}{ POOLED STDEV $=0.04591$} & 0.050 & 0.100 & 0.150 \\
\hline
\end{tabular}

Two types of unsuccessful outcomes in a negotiation of meaning interaction can occur. The language learner response can become a new trigger, thus embedding the negotiation of meaning interaction. Analysis of embedded new triggers per total triggers does not show any difference among the dyads $(\mathrm{p}=.062)$.

The second type of unsuccessful negotiation interaction occurs when the speaker makes a continuation move that becomes a new trigger (4D). Analysis of these moves per total triggers likewise doesn't yield significant differences among the dyads $(p=.223)$. However, when the two types of unsuccessful negotiation of meaning outcomes are combined, significant differences are found to exist. 
The analysis of variance results in Table $X X$ (per total triggers) and Table XXI (per c-units) reveal that when the native speaker dyads are compared, the peer-strangers' interactions with language learners have fewer instances of new triggers and speaker continuation-new trigger moves (4D) resulting in new triggers. ANOVA tests on data comparing the peer-strangers with the combined teacher and friend dyad data support this finding. When measured against c-units, the p value was 0.012 . $P$ value was 0.010 when measured against total triggers. The negotiation of meaning interactions between language learners and peer-strangers appear to be more successful and have fewer instances of unsuccessful negotiations than do the other native speaker dyads.

TABLE XX

UNSUCCESSFUL OUTCOMES PER TOTAL TRIGGERS, NATIVE SPEAKER DYADS

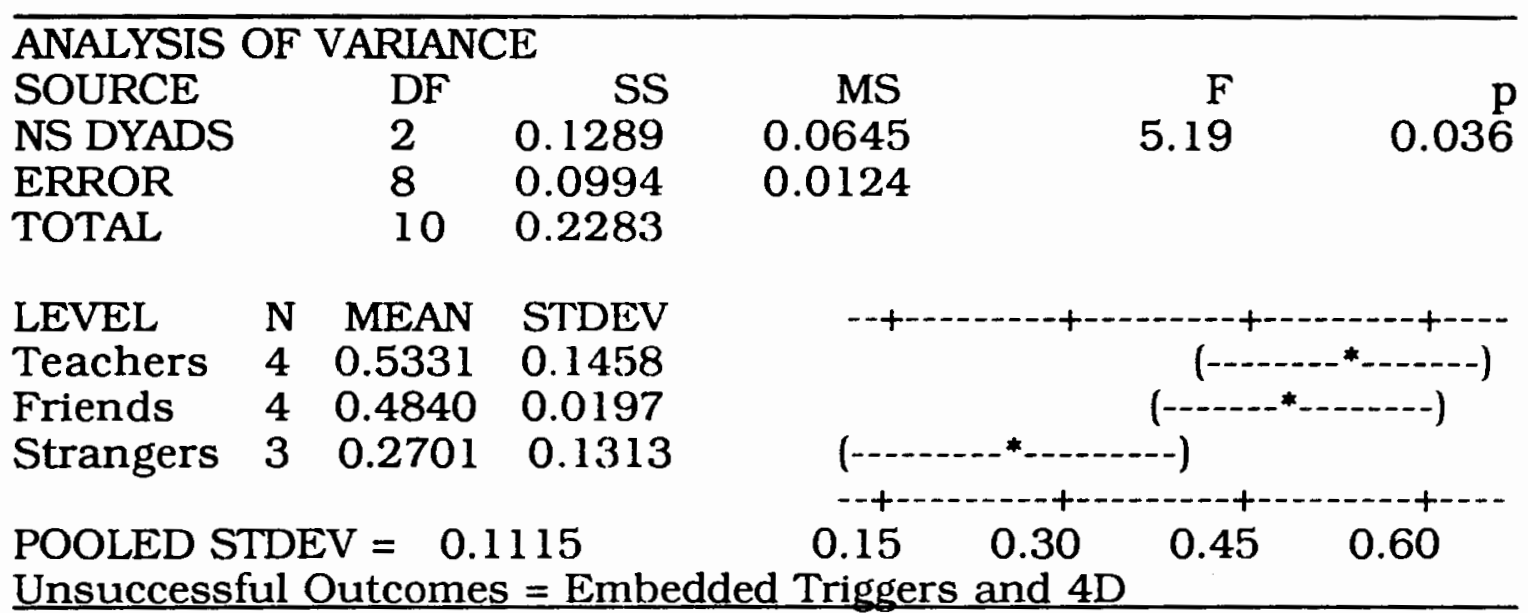


TABLE XXI

UNSUCCESSFUL OUTCOMES PER LLHI C-UNITS, NATIVE SPEAKER DYADS

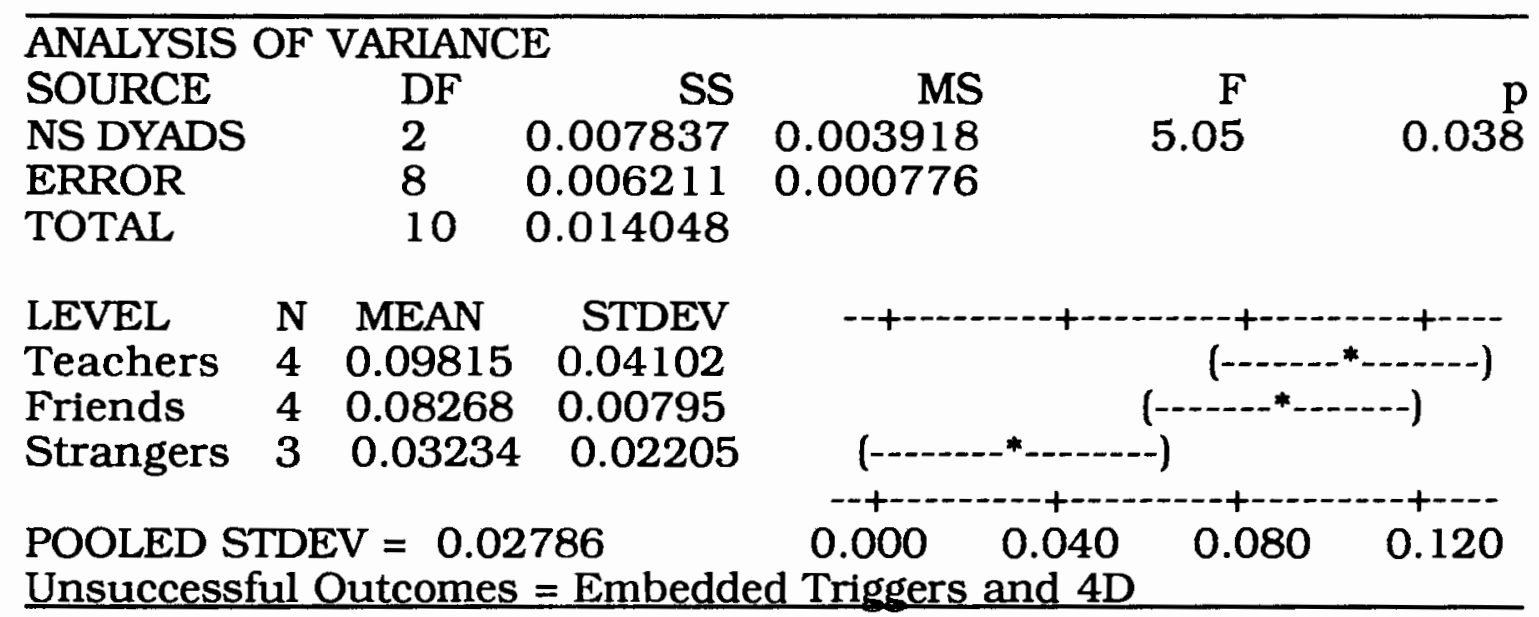

Although peer-strangers appear to interact differently with the language learners than do the other dyad partners, the equivalency of the tasks is still a potential moderating variable. The language learners did not rate the LL/ST task as being especially easy. The pilot study subjects also found the task challenging. However, it may be that the native speakers would have all found this particular task easy to do. Performing an easier task may have allowed the other native speakers (teachers and friends) to be more tolerant and patient when processing their language learner partners' incomprehensible output.

\section{Hypothesis Three}

Hypothesis three predicted that the dyads containing language teachers would use more repetition signals than dyads with the other native speakers. The data used to test this prediction were organized 
by LLHI c-units. Some of the tests measured signal categories per c-unit while others measured signal categories per total signals identified.

Pica (1988) found that language learners often were signaled that a trigger had occurred through the use of confirmation checks made by repeating the trigger utterance. A later study (Pica et al., 1989) found that non-teacher native speakers used trigger repetition far less than did the teacher subjects of the earlier study. However, the two studies were not consistent across the task type used in the experimental designs. It was hoped that by using equivalent information exchange tasks, that the effect of the role and experience of the dyad partner could be measured with regards to the type of signal given in response to the language learners' triggers.

When repetition signals (2B) per total signals identified are tested across all four dyad types, no significant difference is evident $(p=0.079)$. However, when the friend and peer-stranger dyad data are excluded from the analysis, a significant difference is found (Table XXII). Hypothesis Three is, thus, not supported by the evidence. Although there was no significant difference among the native speaker dyad groups in the use of repetition signals, teachers used the repetition signal less than the language learners' other language learner partners.

This finding is further supported when the repetition signal per total confirmation signal count data are analyzed (Table XXIII). Both 
the teachers and friends appear to have employed the repetition signal less often than did the language learners.

\section{TABLE XXII}

REPETITION SIGNALS PER TOTAL SIGNALS TEACHERS AND LANGUAGE LEARNERS

ANALYSIS OF VARIANCE

SOURCE

DYAD

ERROR

TOTAL
DF

1

6

7
SS

0.07787

0.03273

0.11060
MS

0.07787

0.00545

LEVEL N MEAN STDEV

$\begin{array}{llll}\text { Teachers } \quad 4 & 0.10965 & 0.02842\end{array}$

$\begin{array}{llll}\text { LLs } & 4 & 0.30697 & 0.10051\end{array}$

POOLED STDEV $=0.07386$

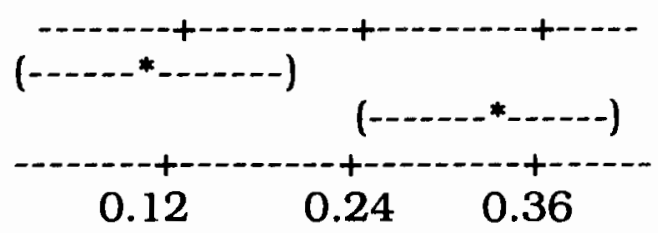

TABLE XXIII

REPETITION SIGNALS PER TOTAL

CONFIRMATION CHECKS, ALL DYADS

ANALYSIS OF VARIANCE

SOURCE

DYAD

ERROR

TOTAL

DF SS

$3 \quad 0.3491$

11

0.1996

14

0.5486

14.28

0.009

LEVEL N MEAN STDEV

$\begin{array}{llll}\text { Teachers } & 4 & 0.2365 & 0.0639\end{array}$

Friends

$\begin{array}{ll}4 & 0.3323\end{array}$

0.1514

Strangers

LLs

$\begin{array}{ll}3 & 0.4526\end{array}$

0.1217

$\begin{array}{ll}4 & 0.6331\end{array}$

0.1722

POOLED STDEV =

0.1347

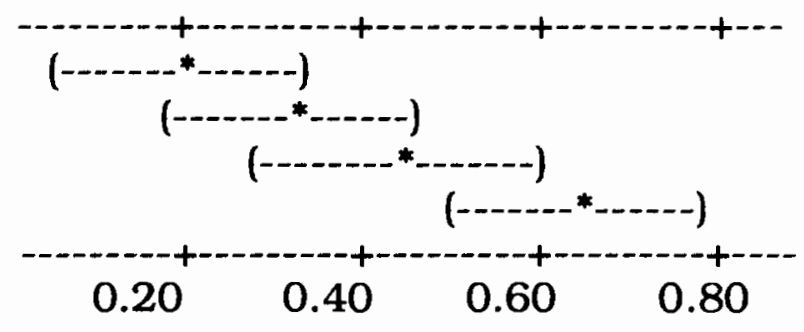


Repetition signals are just one of the five signal types that a hearer can use to indicate that a trigger has been given. The results in Table XXIV show that significant differences occurred between the signal categories when measured against total signal count. According to Tukey's test, clarification signals (2A) occurred more often than all the other signal categories. Repetition signals (2B) occurred significantly more often than did indirect indicators (2E). No significant difference is found between the three confirmation check signal categories $(2 \mathrm{~B}, 2 \mathrm{C}$ and $2 \mathrm{D})$.

TABLE XXIV

SIGNAL TYPES PER

TOTAL SIGNAL COUNT, ALL DATA

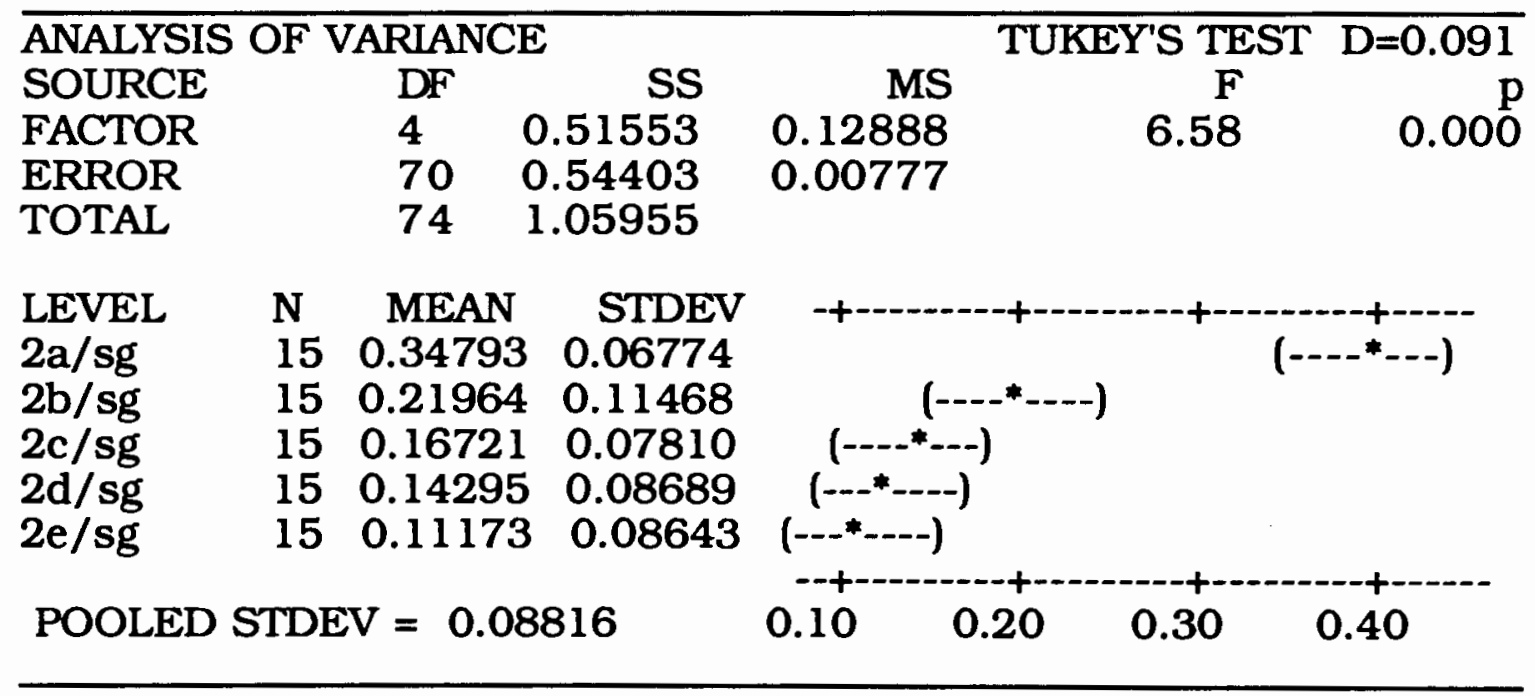

Repetition confirmation signals were found to occur more often in the language learner dyads. As indicated in Table XXV, language 
learners use repetition confirmation checks far more often than the other two confirmation check categories.

\section{TABLE XXV}

CONFIRMATION CHECKS

PER TOTAL SIGNAL COUNT,

LANGUAGE LEARNERS ONLY

\begin{tabular}{|c|c|c|c|c|c|c|c|}
\hline \multicolumn{5}{|c|}{$\overline{\text { ANALYSIS OF VARIANCE }}$} & \multicolumn{3}{|c|}{ TUKEY'S TEST $\mathrm{D}=0.164$} \\
\hline SOURCE & & $\mathrm{DF}$ & SS & & & & \\
\hline FACTOR & & 2 & 0.12963 & 0.06481 & & 9.46 & 0.006 \\
\hline ERROR & & 9 & 0.06165 & 0.00685 & & & \\
\hline TOTAL & & 11 & 0.19128 & & & & \\
\hline LEVEL & $\mathbf{N}$ & MEAI & STDEV & & & -+- & \\
\hline $2 \mathrm{~b} / \mathrm{sg}$ & 4 & $0.306 s$ & $\begin{array}{ll}7 & 0.10051\end{array}$ & & & & $--^{*}---$ \\
\hline $2 \mathrm{c} / \mathrm{sg}$ & 4 & 0.0845 & $5 \quad 0.06307$ & & *---) & & \\
\hline $2 d / s g$ & 4 & 0.0884 & 90.08044 & & *---) & & \\
\hline POOLED & TDI & $V=0 . c$ & 8277 & 0.00 & 0.12 & 0.24 & 0.36 \\
\hline
\end{tabular}

Modification confirmation signals (2C), on the other hand, were used far more often by the native speaker dyads than by the language learner dyads (Table XXVI). This seems logical since the native speakers would be considered to have more linguistic resources available to modify the trigger than would the language learners. Repetition confirmation signals appear to be the language learners' most available confirmation check strategy.

There is no significant difference in the mean frequencies of the native speaker dyads in the use of modifier confirmation checks ( $p=0.578$ ). However, the teachers as a group used modifying 
confirmation checks more often than repetition confirmation checks (Table XXVII).

\section{TABLE XXVI}

MODIFICATION SIGNALS PER TOTAL SIGNAL COUNT, LANGUAGE LEARNER AND NATIVE SPEAKER DYADS

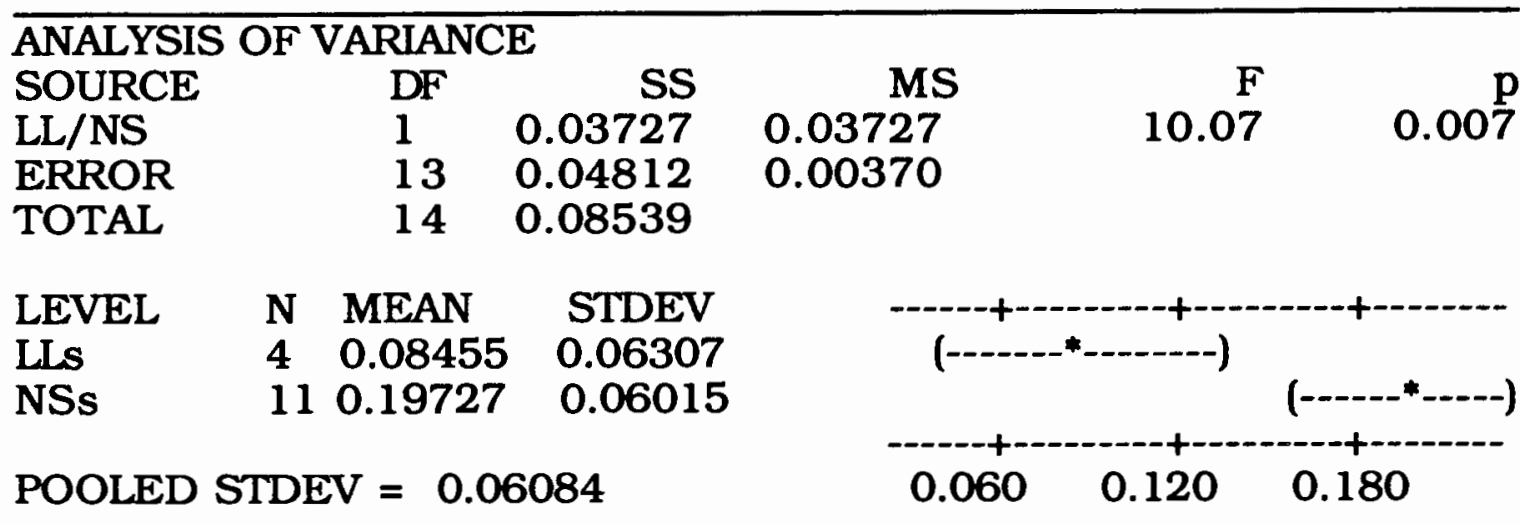

TABLE XXVII

CONFIRMATION CHECKS PER TOTAL SIGNAL COUNT, TEACHERS ONLY

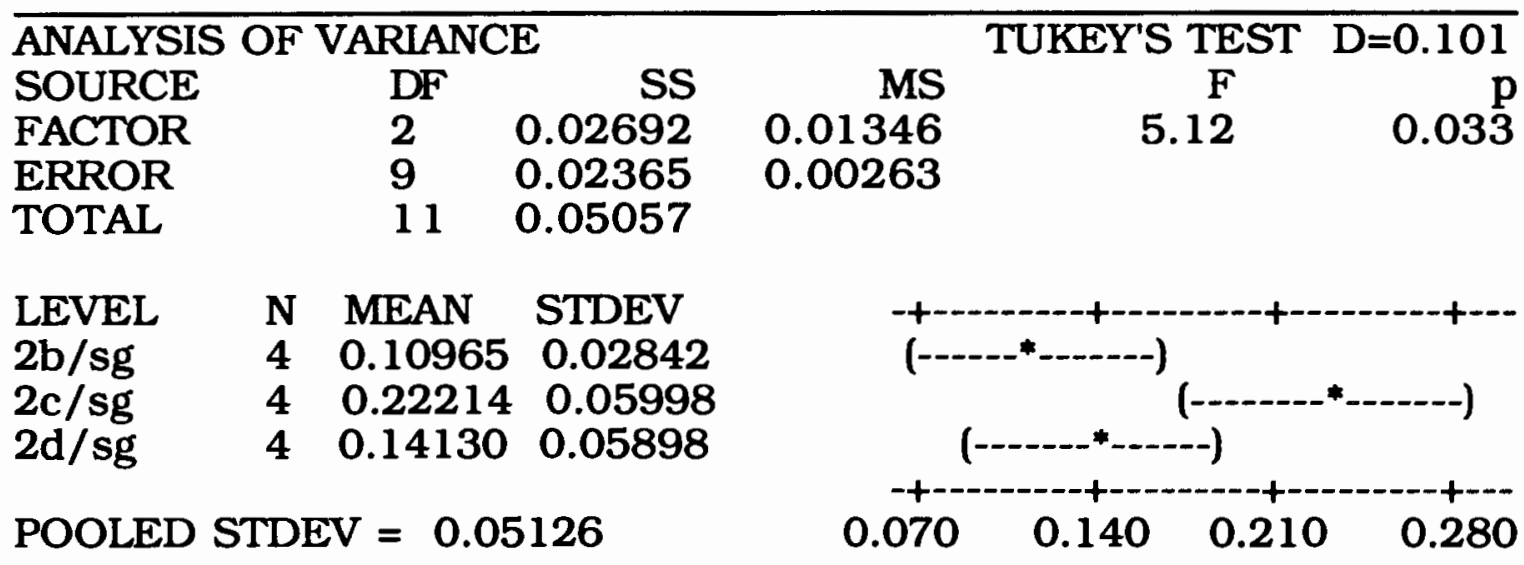


This would seem to be further evidence contradicting earlier research findings (Pica, 1988, Pica et al., 1989). Modifying the trigger would be most like a "correction". Teachers may be more inclined than other native speakers to intervene in this way.

Elaboration-continuation confirmation checks (2D) per total signal count are not significantly different among the four dyad types $(p=0.065)$. When the friend dyad data are tested against the combined teacher and peer-stranger data, however, the results show that the friends use this type of confirmation check more often than the other native speakers do (Table XXVIII). While the teachers use the modifying signal more, the friends may feel more comfortable "helping" their friends complete their thoughts through the use of the elaboration-continuation signal. Both of these confirmation signals are more intrusive than repetition signals.

\section{TABLE XXVIII}

\section{ELABORATION-CONTINUATION CONFIRMATION CHECKS} PER TOTAL SIGNAL COUNT,

\section{FRIENDS}

\begin{tabular}{|c|c|c|c|c|c|c|}
\hline \\
\hline \multirow{2}{*}{\multicolumn{7}{|c|}{$\begin{array}{lll}\text { SOURCE } & \text { DF } & \text { SS }\end{array}$}} \\
\hline \multirow{2}{*}{\multicolumn{2}{|c|}{$\begin{array}{l}\text { FR/TEST } \\
\text { ERROR }\end{array}$}} & 1 & 0.03015 & 0.03015 & & \\
\hline & & 9 & 0.03996 & 0.00444 & & \\
\hline \multicolumn{2}{|l|}{ TOTAL } & 10 & 0.07011 & & & \\
\hline \multirow{3}{*}{$\begin{array}{l}\text { LEVEL } \\
\text { Friends } \\
\text { Te \& St }\end{array}$} & $\mathbf{N}$ & MEAN & STDEV & -+- & --+- & $\cdots+----$ \\
\hline & 4 & 0.23201 & 0.05808 & 1 & ---- & -------) \\
\hline & & 0.12318 & 0.07052 & $(-\cdots+---1$ & & \\
\hline \multicolumn{4}{|c|}{ POOLED STDEV $=0.06663$} & 0.070 & 0.210 & 0.280 \\
\hline
\end{tabular}


It should be noted that the peer-strangers employ all confirmation signals without a significant difference in their use being statistically recognizable (Table XXIX).

\section{TABLE XXIX}

SIGNAL CATEGORIES PER TOTAL SIGNAL COUNT, PEER-STRANGERS ONLY

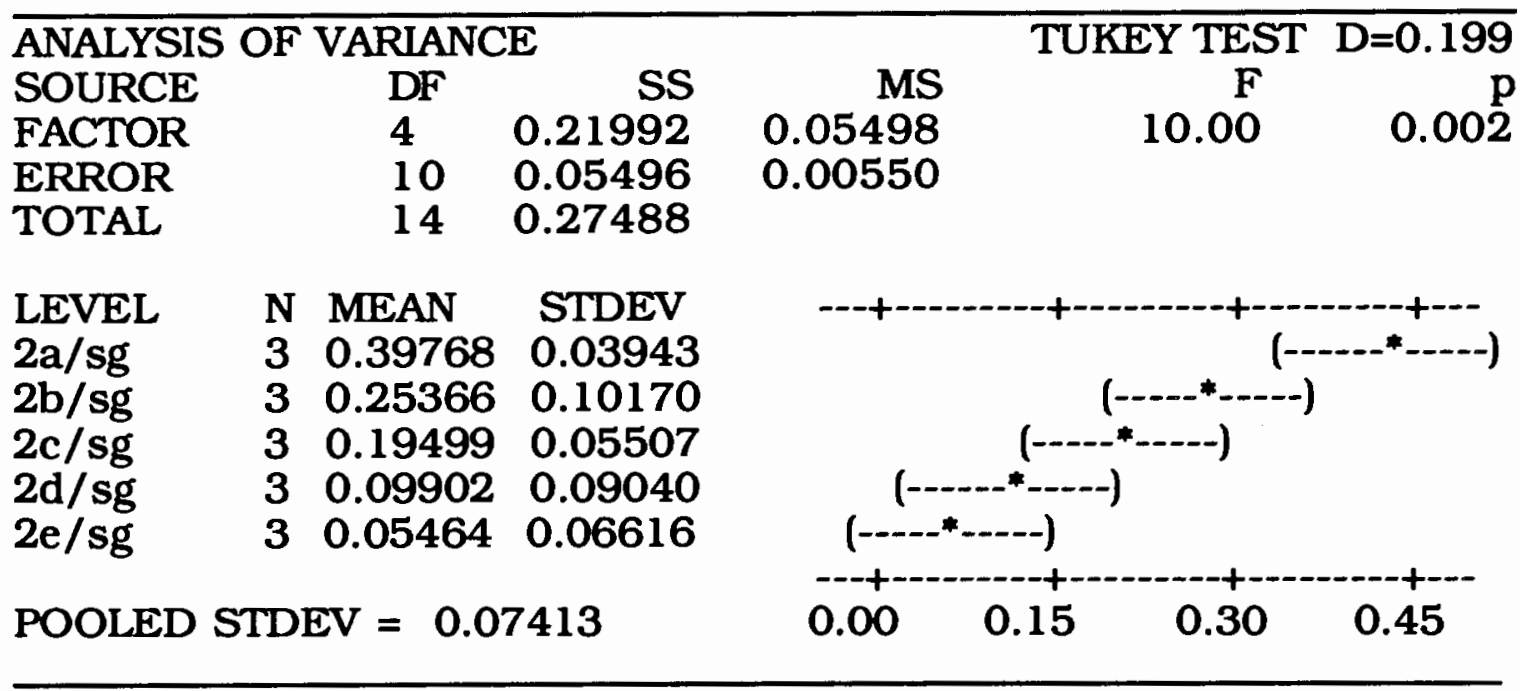

Indirect indicators (2E) are not found to occur significantly different across the four dyads ( $p=0.432$ ). All of the dyad types appeared to use this signal less often than the other signal categories. However, as revealed in Table XXIV, only clarification and repetition signals were found to occur significantly more often than indirect indicators.

The results shown in Table XXV indicate that clarification signals are used significantly more often than other signals. Across all four dyad types, however, an analysis of variance test shows no significant 
difference exists in the use of clarification signals $(p=0.108)$. Among the native speakers, different results were found. Friends used clarification less often than teachers and peer-strangers (Table $\mathrm{XXX}$ ).

\section{TABLE XXX}

\section{CLARIFICATION REQUESTS}

PER TOTAL SIGNALS

FRIENDS

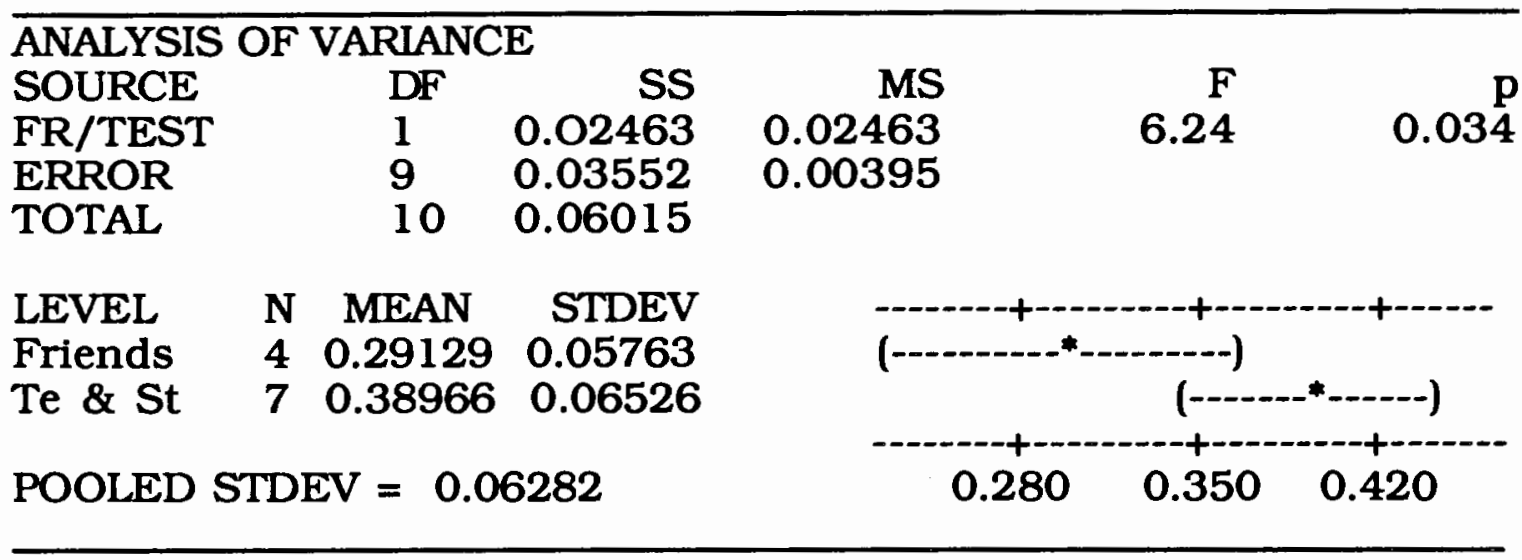

In fact, teachers (Table XXXI) and peer-strangers (Table XXIX) used clarification signals significantly more than all but one other signal type (2C for teachers and $2 \mathrm{~B}$ for peer-strangers). Friends (Table XXXII) differed by using clarification signals only significantly more often than they used indirect indicators (2E).

The fact that all four dyad types used clarification signals most often may indicate that information exchange tasks promote the use of this signal type. Pica et al. (1989) theorized that the use of clarification signals would promote more opportunities for the 
language learners to modify their output. In Hypothesis Four, the relationship of signal type to comprehensible output will be discussed.

\section{TABLE XXXI}

SIGNAL CATEGORIES PER TOTAL SIGNAL COUNT, TEACHERS ONLY

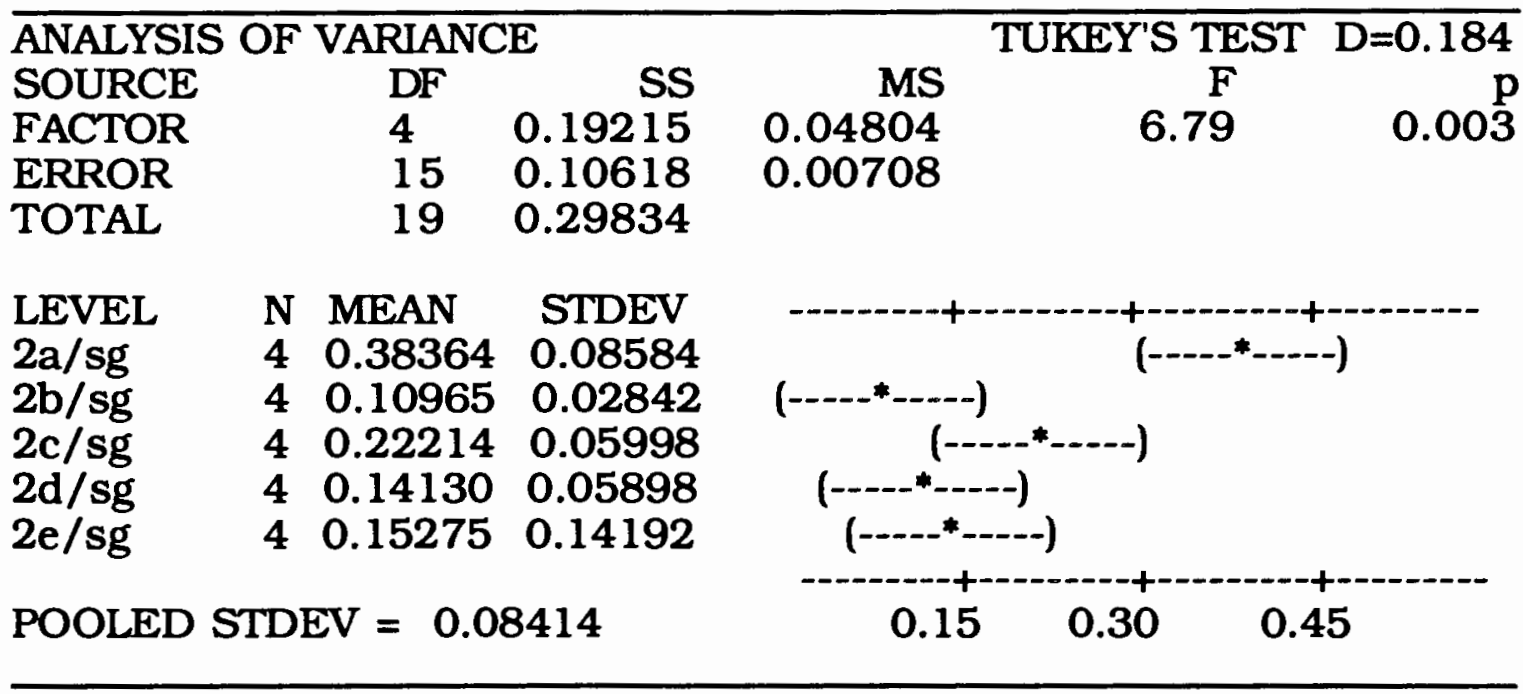

TABLE XXXII

SIGNAL CATEGORIES PER TOTAL SIGNAL COUNT, FRIENDS ONLY

ANALYSIS OF VARIANCE

SOURCE

FACTOR

ERROR

TOTAL
DF SS

$4 \quad 0.09339$

15

19

0.08940

0.18278

LEVEL N MEAN STDEV

$2 \mathrm{a} / \mathrm{sg} \quad \quad \quad 4 \quad 0.291290 .05763$

$2 \mathrm{~b} / \mathrm{sg}$

$2 \mathrm{c} / \mathrm{sg}$

$\begin{array}{ll}4 & 0.21677\end{array}$

0.12687

$4 \quad 0.17411$

0.06997

$2 \mathrm{~d} / \mathrm{sg}$

$\begin{array}{ll}4 & 0.23201\end{array}$

0.05808

$2 \mathrm{e} / \mathrm{sg}$

40.08582

0.04597

POOLED STDEV $=0.07720$

TUKEY'S TEST $\mathrm{D}=0.169$ MS

0.02335

0.00596

$\begin{array}{rr}\mathrm{F} & \mathrm{p} \\ 3.92 & 0.023\end{array}$

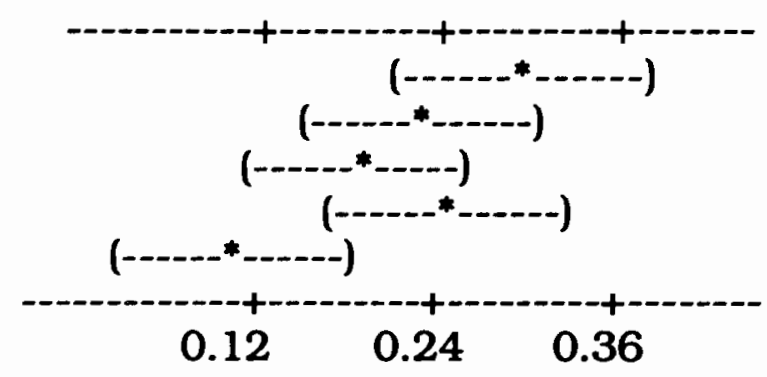




\section{Hypothesis Four}

In this hypothesis, it was predicted that language learners would be more likely to produce comprehensible output in response to clarification requests than in response to confirmation checks. The data used to test Hypothesis Four include only LLHI c-units. Some of the tests used measure comprehensible output response to signal type per total comprehensible output. Data were also organized by comprehensible output response to signal type totals per total signal type count.

Swain (1985) theorized that second language learners' acquisition of language is fostered when the language learners have an opportunity to modify their output during communication interactions. Pica et al. (1989) sought to find out whether comprehensible output increases or decreases in relation to the type of signal dyad partners give to language learners to indicate that meaning triggers have occurred. Pica (1988) had theorized that confirmation checks provide the language learners with clear linguistic models. The language learner would often only need to acknowledge these types of contributions to the conversation without any need to adjust their linguistic output. Clarification requests, on the other hand, increase the demand on the language learners to provide more information. Therefore, according to Pica (1988), clarification requests are expected to result in more comprehensible output responses than confirmation checks would. The Pica et al. (1989) results supported 
this hypothesis. Hypothesis Four was included in this research design in an attempt to verify these previous research findings.

Hypothesis Four is supported by the results. Clarification signals that resulted in modified, more target-like responses from the language learner occurred significantly more often than did any of the other signal types (Table XXXIII).

\section{TABLE XXXIII}

SIGNALS BECOME COMPREHENSIBLE OUTPUT RESPONSE PER TOTAL COMPREHENSIBLE OUTPUT COUNT,

$$
\text { ALL DATA }
$$

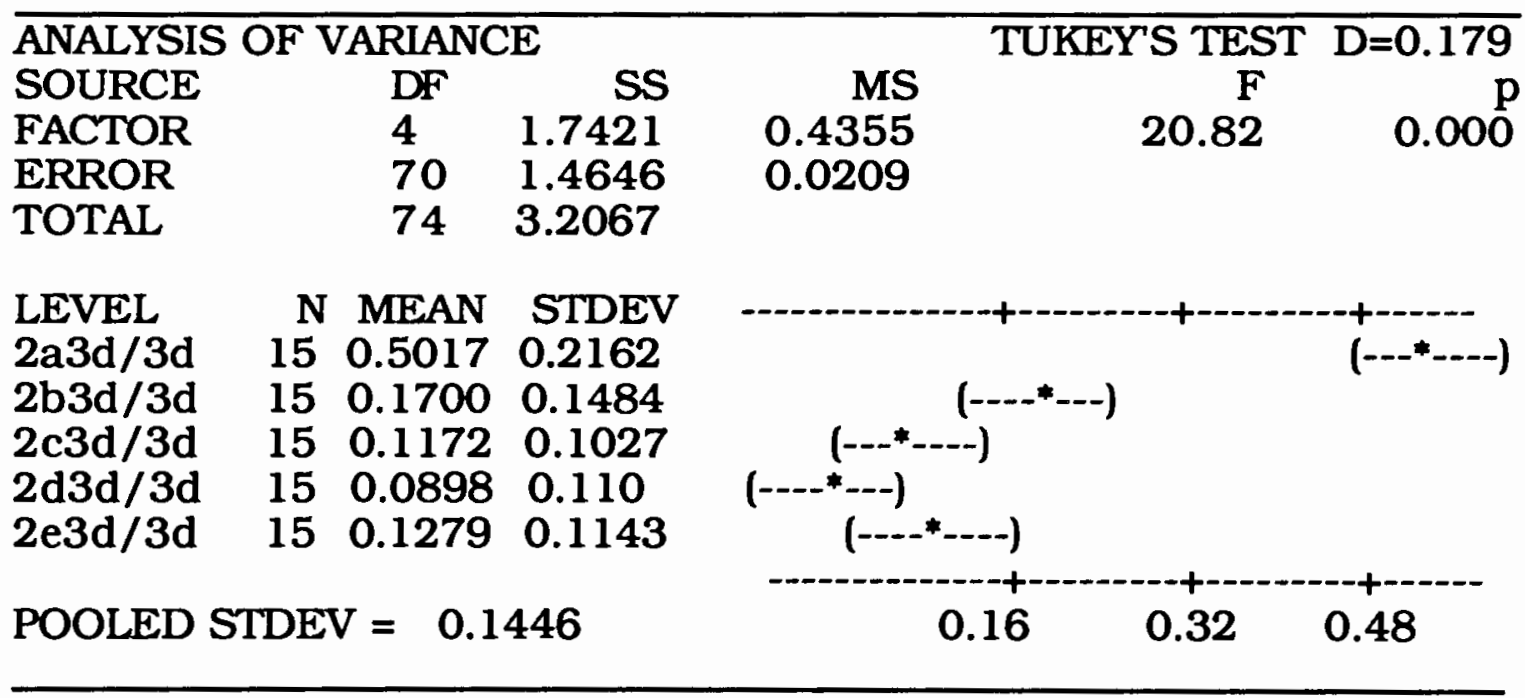

The remaining signal types have no significant differences among them. The data include indirect indicators (2E) which were shown during the analysis for Hypothesis Three to occur less often than clarification and repetition signals (Table XXIV). Yet, despite their relative lack of use, no significant difference is found in the 
comprehensible output resulting from indirect indicators and that from repetition signals.

When the three types of confirmation checks are grouped, different results are found (Table XXXIV). Confirmation checks and clarification requests do not differ significantly in the amount of comprehensible output observed. Both resulted, however, in significantly more comprehensible output than did the indirect indicator signal type.

\section{TABLE XXXIV}

SIGNALS BECOME COMPREHENSIBLE OUTPUT RESPONSE PER TOTAL COMPREHENSIBLE OUTPUT COUNT, CONFIRMATION SIGNALS COMBINED, ALL DATA

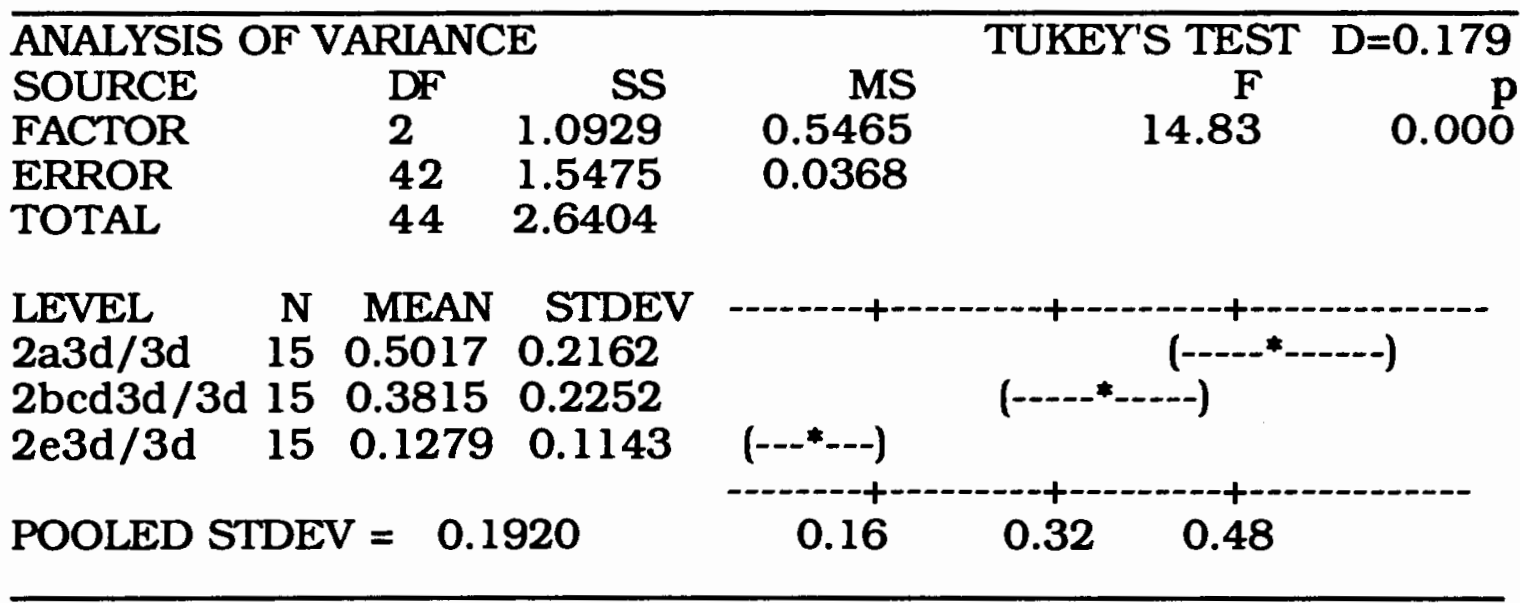

It may be that the relative lack of use of the indirect indicator signal influenced the results. If that is the case, then increasing the use of any particular signal type may result in more comprehensible output being observed. In other words, comprehensible output might 
occur independently of the type of signal type being given.

To test this assumption, the data were grouped according to signal type resulting in comprehensible output per the total signal type count. Significant differences are observed (Table XXXV). Tukey's test reveals that significant differences exist between the amount of comprehensible output observed in response to clarification requests per total clarification request signal count and those of modifying and elaboration-continuation confirmation checks.

\section{TABLE XXXV}

SIGNALS BECOME COMPREHENSIBLE OUTPUT RESPONSE PER TOTAL SIGNAL TYPE COUNT, ALL DATA

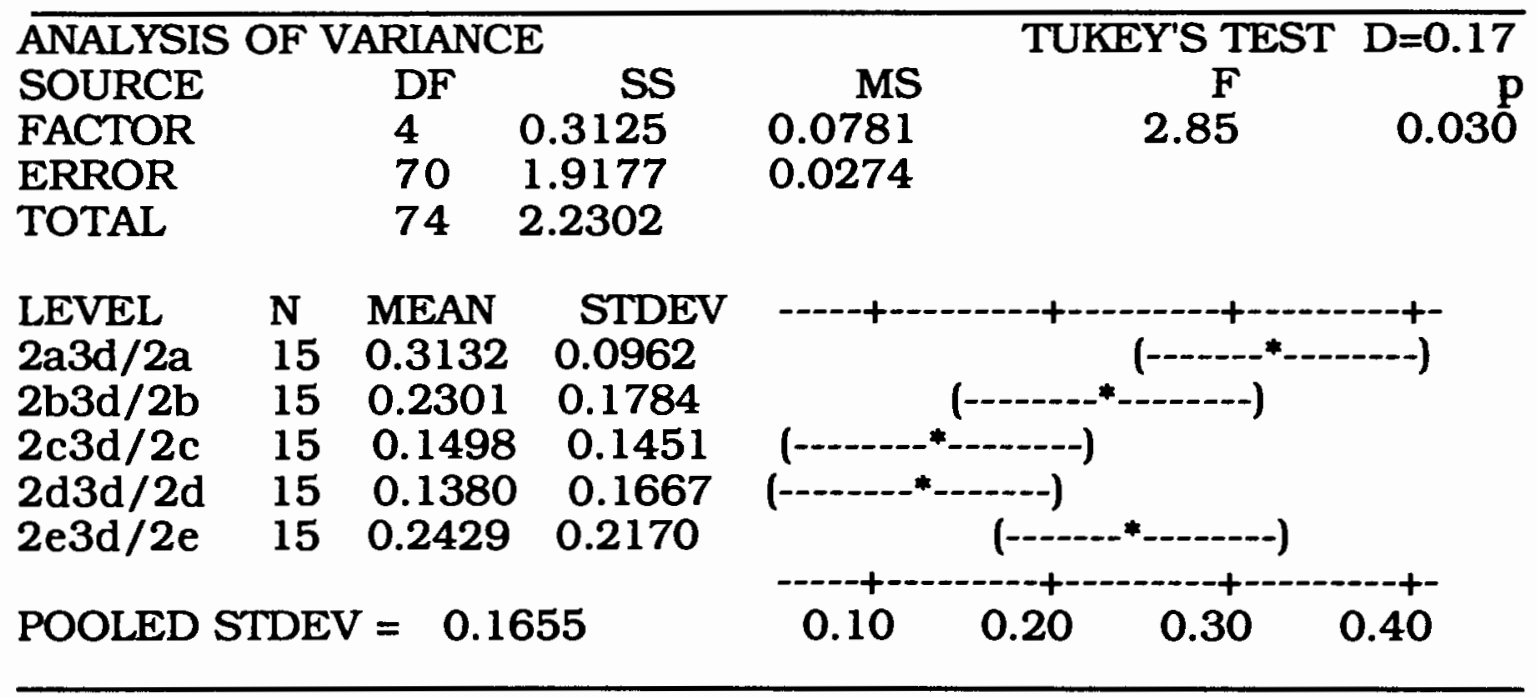

These results would seem to support the assumption that frequency of use of a signal type affects the amount of comprehensible output responses observed since clarification requests per total signal count were also produced significantly more often than either of these 
two types of confirmation checks (Table XXIV). However, clarification requests occurred significantly more often than all other signal categories (Table XXIV) and there is no significant difference in the amount of comprehensible output observed per signal type between clarification requests and the remaining signal types (repetition signals and indirect indicators). Further, repetition signals were found to occur significantly more often than indirect indicators (Table XXIV), yet in Table XXXV and Table XXXIII there is not any significant difference between the two. Frequency of use, then, may not be as influential as the type of signal used. These results would seem to confirm the findings of the Pica et al. study.

Results have shown that clarification signals appear to result in more comprehensible output responses than do other signal types. The data, grouped in the same configuration as shown in Table XXIII, were reorganized according to dyad type to check for differences related to participant roles. No significant differences were found between dyad counts of clarification requests becoming comprehensible output per total comprehensible output identified $(\mathrm{p}=0.691)$.

Data from each dyad type were then examined individually. Teachers $(p=0.001)$, peer-strangers $(p=0.015)$ and language learners $(p=0.003)$ all showed a significant difference between the use of clarification signals resulting in comprehensible output and all other signal types. These results support those results shown in Table 
XXXIII. As the findings in Table XXXVI show, however, data from the friends did not show significant difference $(p=0.110)$ between the signal types. Furthermore, friends had earlier been shown to use clarification signals less often than did other native speakers (Table $\mathrm{XXX}$ ). These results call into question again the findings relating frequency of use with comprehensible output observed.

\section{TABLE XXXVI}

SIGNALS BECOME COMPREHENSIBLE OUTPUT RESPONSE PER TOTAL COMPREHENSIBLE OUTPUT COUNT, FRIENDS ONLY

\begin{tabular}{|c|c|c|c|c|c|c|}
\hline & \multicolumn{2}{|c|}{ ANALYSIS OF VARIANCE } & \multicolumn{2}{|c|}{ TUKEY'S TEST $\mathrm{D}=\mathrm{n} . \mathrm{s}$. } \\
\hline \multirow{2}{*}{\multicolumn{2}{|c|}{$\begin{array}{l}\text { SOURCE } \\
\text { FACTOR }\end{array}$}} & DF & SS & MS & $\mathbf{F}$ & \\
\hline & & 4 & 0.2992 & 0.0748 & 2.27 & 0.110 \\
\hline \multicolumn{2}{|c|}{$\begin{array}{l}\text { FACTOR } \\
\text { ERROR }\end{array}$} & 15 & 0.4934 & 0.0329 & & \\
\hline \multicolumn{2}{|l|}{ TOTAL } & 19 & 0.7926 & & & \\
\hline \multirow{6}{*}{$\begin{array}{l}\text { LEVEL } \\
2 \mathrm{a} 3 \mathrm{~d} / 3 \mathrm{~d} \\
2 \mathrm{~b} \mathrm{~d} / 3 \mathrm{~d} \\
2 \mathrm{c} 3 \mathrm{~d} / 3 \mathrm{~d} \\
2 \mathrm{~d} 3 \mathrm{~d} / 3 \mathrm{~d} \\
2 \mathrm{e} 3 \mathrm{~d} / 3 \mathrm{~d}\end{array}$} & $\mathbf{N}$ & MEAN & STDEV & & $\cdots-\cdot-+$ & -+-- \\
\hline & 4 & 0.4348 & 0.2860 & & $(---$ & ) \\
\hline & 4 & 0.2119 & 0.2143 & & -.----) & \\
\hline & 4 & 0.0844 & 0.0689 & $(-\cdots-\cdots$ & $------)$ & \\
\hline & 4 & 0.1653 & 0.1631 & $(--$ & ---*-_-_-----) & \\
\hline & 4 & 0.1286 & 0.0733 & $(--\cdots)$ & 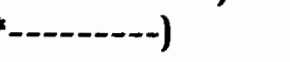 & \\
\hline \multicolumn{4}{|c|}{ POOLED STDEV $=0.1814$} & 0.00 & 0.40 & 0.60 \\
\hline
\end{tabular}

The friends, on the other hand, also used clarification signals more often than indirect indicators (Table XXXII) yet the results in Table XXXVI do not support the observance of any significant difference between these two signal types and the resulting comprehensible output responses. The evidence relating frequency of 
signal type use to comprehensible output responses observed appears to be contradictory.

In Table XXXV, significant differences were shown to exist between the amount of comprehensible output observed in response to clarification requests and that of modifying and elaborationcontinuation confirmation checks. When the data were reorganized according to dyad type, no significant differences were observed in any of the dyad types; (a) teachers, $p=0.302$, (b) friends, $p=0.140$, (c) peer-strangers, $p=0.840$, and (d) language learners, $p=0.541$. An example of one of these analyses is shown in Table XXXVII.

\section{TABLE XXXVII}

SIGNALS BECOME COMPREHENSIBLE OUTPUT RESPONSE PER TOTAL SIGNAL TYPE COUNT, FRIENDS ONLY

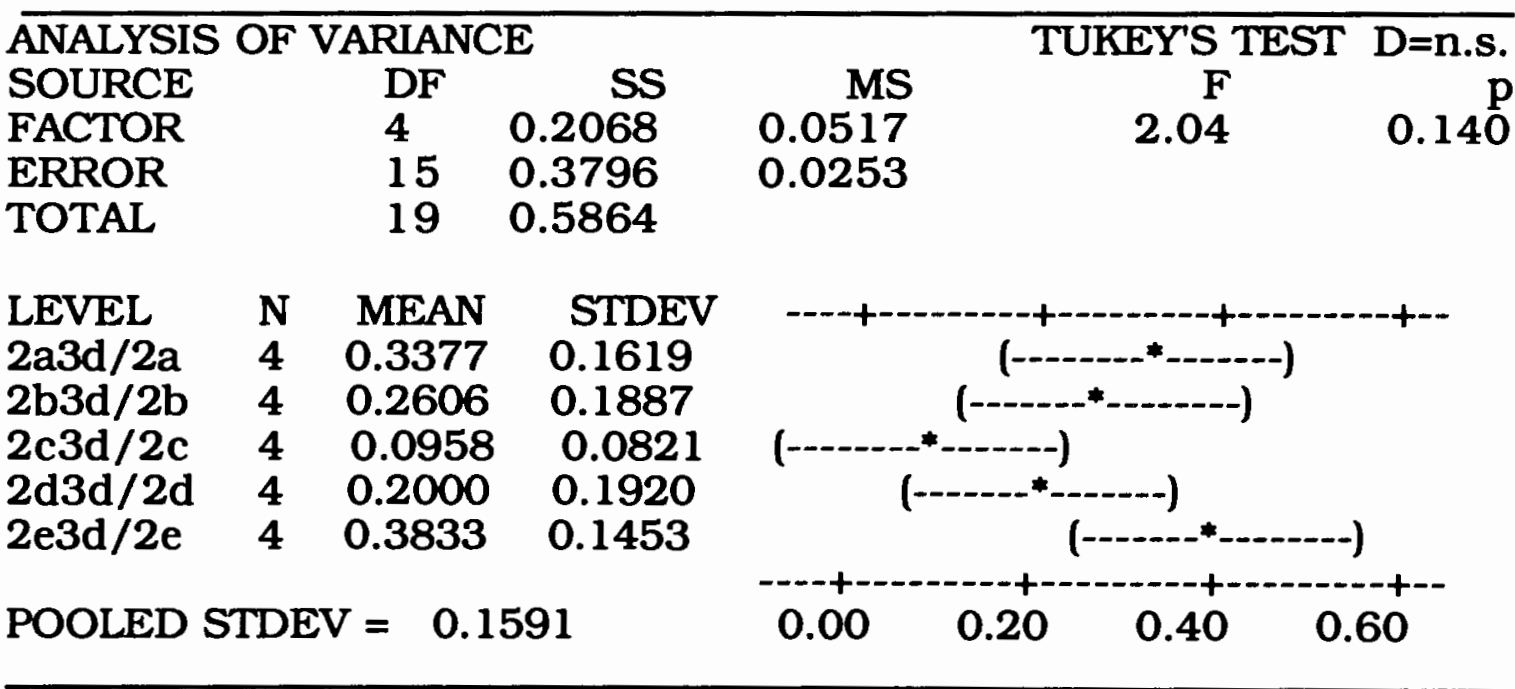

Certainly, the frequency of use of signal types has been shown to be significantly different within native speaker dyad types (Tables 
XXIX, XXXI and XXXII). Again, these findings seem to contradict the preceding argument regarding the effect frequency of signal type use has on comprehensible output responses observed. It is also of interest that none of the individual dyad data results support the findings of Table XXXV. It may be that there existed too little data with large mean standard deviations within the individual dyad counts to support significant statistical analysis.

The findings suggest that frequency of signal type use may influence the amount of comprehensible output given in response to that signal. However, the findings related to the indirect indicator signal appear to be evidence that comprehensible output responses may also occur as a result of the signal type. Indirect indicators may parallel clarification checks in the way they are perceived by the speaker. An optimum response to either of these trigger types requires the speaker to give the hearer new information. It may be responses that give new information to the hearer are more comprehensible utterances than the original trigger utterances were. Signals that force the speaker to give new information may have the effect of increasing the amount of modified output produced by the speaker.

\section{Hypothesis Five}

Hypothesis Five predicted that language learner with peerstranger dyads would contain more comprehensible output responses 
per c-unit than would the other dyad groupings. It was further predicted that the other dyad types would rank from most to least comprehensible output responses observed in the following order; (a) language learner with language learner, (b) language learner with friend and (c) language learner with teacher. The data used to test these predictions were organized by LLHI c-units. Some of the tests measured comprehensible output responses per LLHI c-unit count while others measured the responses per total triggers identified. The discussion of findings related to Hypothesis Five will conclude with analyses of other response categories where significant results were found among the dyad types.

The need to be "pushed" to produce comprehensible output was considered by Swain (1985) to be crucial to second language acquisition. The statistical analysis presented in the discussion of Hypothesis Four suggests that clarification signals may result in the higher amounts of comprehensible output when compared with other signal categories. The Pica et al. (1989) results indicated that native speakers who are not language teachers produce more clarification signals than language teachers. The peer-stranger group was thus considered to be more likely to "push" the language learners towards production of comprehensible output.

It was predicted that the language learner with friend dyads would rank below the peer-stranger dyads because of their increased familiarity with the language learners' speech patterns. This would 
allow the friends to more accurately guess the language learners' intended meaning and thus limit the need for the language learners to "push" for more accurate output. The teachers were ranked last due to the evidence contained in previous research (Pica, 1988, Pica et al. 1989).

The results listed in the Hypothesis Three discussion indicated that language learner dyads use confirmation checks less often than native speaker dyads do. Confirmation checks present the language learners with linguistic models. The language learners can repair the meaning trigger by simply acknowledging the model contained within the confirmation signal. There is no need to supply additional information to the hearer. In other words, confirmation checks do not seem to "push" the language learners to modify their output.

Language learner with language learner dyads, then, were thought to have a high potential for creating a need for the "push" towards comprehensible output. They were nevertheless predicted to rank below the peer-strangers because it was thought that difficulty with language use might impede the types and frequencies of the signals and responses produced.

As reported in the discussion of Hypothesis Four, no significant differences were found among the dyads in clarification requests becoming comprehensible output per total comprehensible output identified $(p=0.691)$. The results of Hypothesis Five support this previous finding. Neither the findings shown in Table XXXVIII (LLHI c- 
units) nor those in Table XXXIX (triggers) show any significant difference between the dyads with respect to comprehensible output production.

\section{TABLE XXXVIII}

COMPREHENSIBLE OUTPUT PER LLHI C-UNITS,

\section{ALL DYADS}

\begin{tabular}{|c|c|c|c|c|c|c|}
\hline \multirow{2}{*}{\multicolumn{7}{|c|}{$\begin{array}{l}\text { ANALYSIS OF VARIANCE } \\
\text { SOURCE }\end{array}$}} \\
\hline & & & & & & \\
\hline \multicolumn{2}{|l|}{ DYAD } & 3 & 0.000761 & 0.000254 & 2.15 & 0.152 \\
\hline \multicolumn{2}{|l|}{ ERROR } & 11 & 0.001297 & 0.000118 & & \\
\hline \multicolumn{2}{|l|}{ TOTAL } & 14 & 0.002057 & & & \\
\hline \multirow{5}{*}{$\begin{array}{l}\text { LEVEL } \\
\text { Teachers } \\
\text { Friends } \\
\text { Strangers } \\
\text { LLs }\end{array}$} & $\mathbf{N}$ & MEAN & STDEV & & & \\
\hline & 4 & 0.04419 & 90.01222 & & $(-\cdots)$ & $\cdots$ \\
\hline & 4 & 0.04286 & $\begin{array}{ll}6 & 0.01168\end{array}$ & & $(-\cdots)$ & ----) \\
\hline & 3 & $0.0255 \varepsilon$ & 0.01423 & $(-\cdots)$ & --:---- & \\
\hline & 4 & 0.03431 & 0.00338 & & $+\ldots$ & \\
\hline \multicolumn{4}{|c|}{ POOLED STDEV $=0.01086$} & 0.012 & 0.036 & 0.048 \\
\hline
\end{tabular}

The mean counts listed in Table XXXVIII suggest that peerstranger dyads may contain significantly fewer comprehensible output responses than do the other native speaker dyad types. The data were reorganized by excluding the language learner dyad data and combining the data of the friends and teacher dyads. While the findings in Table XL show that the results approach a significant level $(p=0.052)$, significant differences are not observed. The peerstranger data were one replicate deficient with respect to the other dyad groupings. It is not known whether the addition of a fourth peerstranger dyad would have changed the results found. In any case, 
Hypothesis Five is not supported by the results.

\section{TABLE XXXIX}

COMPREHENSIBLE OUTPUT PER TOTAL TRIGGERS,

$$
\text { ALL DYADS }
$$

\begin{tabular}{|c|c|c|c|c|c|c|}
\hline \multicolumn{7}{|c|}{ ANALYSIS OF VARIANCE } \\
\hline \multicolumn{7}{|c|}{$\begin{array}{l}\text { ANALYSIS OF VARIANCE } \\
\text { SOURCE }\end{array}$} \\
\hline \multirow{2}{*}{\multicolumn{2}{|c|}{$\begin{array}{l}\text { DYAD } \\
\text { FRROR }\end{array}$}} & 3 & 0.00541 & 0.00180 & 0.48 & 0.70 \\
\hline & & 11 & 0.04134 & 0.00376 & & \\
\hline \multicolumn{2}{|l|}{ TOTAL } & 14 & 0.04675 & & & \\
\hline \multirow{5}{*}{$\begin{array}{l}\text { LEVEL } \\
\text { Teachers } \\
\text { Friends } \\
\text { Strangers } \\
\text { LLs }\end{array}$} & $\mathbf{N}$ & MEAN & STDEV & & --+ & --+- \\
\hline & 4 & 0.24819 & 0.02922 & & $---{ }^{*}---$ & $----)$ \\
\hline & 4 & 0.25140 & 0.06240 & & 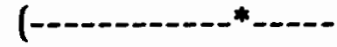 & $----)$ \\
\hline & 3 & 0.22259 & 0.10618 & $(--$ & - & \\
\hline & 4 & 0.20652 & 0.03893 & $(-\cdots)$ & 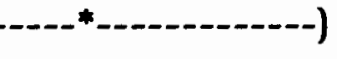 & \\
\hline \multicolumn{4}{|c|}{ POOLED STDEV $=0.06130$} & 0.150 & 0.200 & 0.300 \\
\hline
\end{tabular}

TABLE XL

COMPREHENSIBLE OUTPUT PER LLHI C-UNITS, PEER-STRANGERS

\begin{tabular}{|c|c|c|c|c|c|c|c|}
\hline \multicolumn{8}{|c|}{ ANALYSIS OF VARIANCE } \\
\hline \multirow{3}{*}{$\begin{array}{l}\text { SOURCE } \\
\text { ST/TEFR } \\
\text { ERROR } \\
\text { TOTAL }\end{array}$} & & DF & SS & MS & & \multirow{3}{*}{$\begin{array}{r}F \\
4.99\end{array}$} & \multirow{3}{*}{$\begin{array}{r}p \\
0.052\end{array}$} \\
\hline & & 1 & 0.000702 & \multirow{2}{*}{\multicolumn{2}{|c|}{$\begin{array}{l}0.000702 \\
0.000141\end{array}$}} & & \\
\hline & & 9 & 0.001266 & & & & \\
\hline \multirow{4}{*}{$\begin{array}{l}\text { LEVEL } \\
\text { Strangers } \\
\text { Te \& Fr }\end{array}$} & $\mathbf{N}$ & MFAN & STDFY & \multirow{2}{*}{\multicolumn{3}{|c|}{ 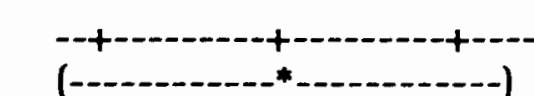 }} & \\
\hline & 3 & 002558 & 0.01423 & & & & \\
\hline & 8 & 0.04352 & 0.01109 & \multicolumn{4}{|c|}{$(-\cdots$} \\
\hline \multirow{2}{*}{\multicolumn{4}{|c|}{ POOLED STDEV $=0.01186$}} & --+- & & -+-- & $-+-\cdots$ \\
\hline & & & & 0.012 & 0.024 & 0.036 & 0.048 \\
\hline
\end{tabular}

Pica et al. (1989) discovered that very few instances of phonological modifications were produced in the data of their 
research. As was mentioned in Chapter III, no instances of phonologically modified responses to signals were identified within the data generated in the dyad experiments of this research. The data in this study found comprehensible output in both semantic and syntactic subcategories. The Pica et al. study also did not find any clear evidence that one of these two subcategories was produced in higher numbers than the other. The results of this study, on the other hand, do show significant results in this area.

The findings in Table XLI indicate that a significant difference between the two types of comprehensible output did occur. Syntactic modifications were identified in much larger numbers than were semantic modifications. According to Swain (1985), it is these morphosyntactic modifications that are most important in the second language acquisition process. Semantic modifications (lexical substitution, examples and paraphrasing) are not judged by Swain to critically influence the second language learner's interlanguage.

In light of the findings in Table XLI, the data were reorganized to test for effects that dyad type might have on the amount of each type of comprehensible output response produced by the language learners. No significant results were found. For a test of semantic modifications per total comprehensible output count by dyad groups the $p$ value was 0.965 . The results of analysis for syntactic modifications were similar at $\mathbf{p}=0.992$. There did not appear to be a statistically verifiable difference between the dyad types with respect 
to the sub-categories of comprehensible output produced by the language learner.

TABLE XII

COMPREHENSIBLE OUTPUT SUBCATEGORIES PER TOTAL COMPREHENSIBLE OUTPUT COUNT, ALL DATA

\begin{tabular}{|c|c|c|c|c|c|c|c|}
\hline & \multirow{5}{*}{$\begin{array}{r}\text { MS } \\
0.6591 \\
0.0299\end{array}$} & \multicolumn{3}{|c|}{ TUKEY'S TEST $\mathrm{D}=0.236$} \\
\hline SOURCE & 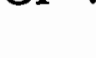 & DF & SS & & \multicolumn{2}{|c|}{ TUKEY'S TEST } & \\
\hline FACTOR & & 1 & 0.6591 & & & 22.07 & 0.000 \\
\hline ERROR & & 28 & 0.8363 & & & & \\
\hline TOTAL & & 29 & 1.4954 & & & & \\
\hline LEVEL & & MEAN & STDEV & $-\cdots+\cdots$ & & -++ & -+--- \\
\hline $\begin{array}{l}3 d \operatorname{sem} / 3 d \\
3 d \operatorname{sun} / 3 d\end{array}$ & 15 & 0.3481 & 0.1745 & $(-----*$ & $---)$ & & \\
\hline yni / Ja & & & & & & & \\
\hline POOLED $S$ & TDE & $V=0.1$ & 728 & 0.30 & 0.45 & 0.60 & 0.75 \\
\hline
\end{tabular}

When the data were reorganized again according to the format shown in Table XLI, statistical differences were found for one of the dyad groups. Peer-stranger dyads did not have a significant difference in the type of comprehensible output produced $(p=0.093)$. The language learner dyads results revealed an even higher $p$ value $(0.249)$. Teacher dyads approached a significant level $(p=0.051)$ with the results following those found in Table XLI (more syntactically comprehensible output). Only data from friend dyads showed a significant difference between the types of comprehensible output produced (Table XLII). 
TABLE XILII

COMPREHENSIBLE OUTPUT SUBCATEGORIES PER TOTAL COMPREHENSIBLE OUTPUT COUNT, FRIENDS ONLY

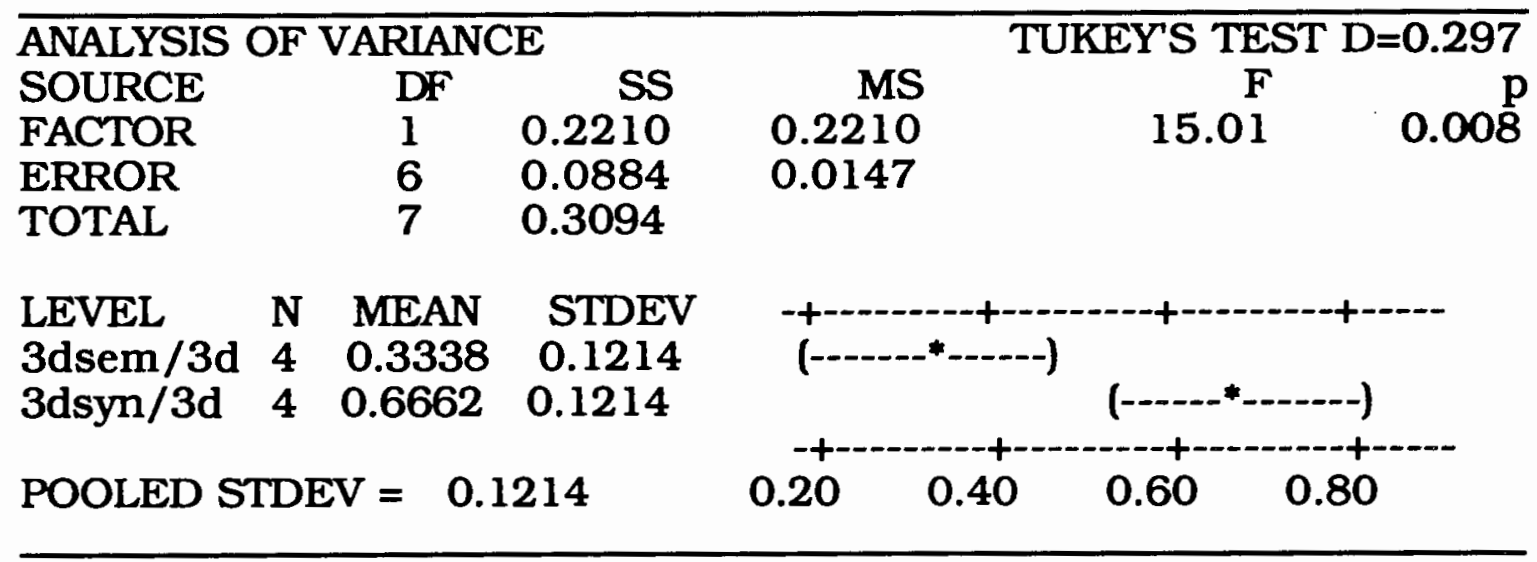

The results listed in Table XII (that language learners produce more syntactically than semantically comprehensible output) may have been skewed by the tendency for language learners in the friend dyads to produce a high amount of syntactically comprehensible output.

The statistical analysis for Hypothesis Four suggested that more comprehensible output responses were the result of clarification requests than of any other signal types (Table XXXV). The friend dyad data did not show a significant difference in this regard (Table XXXVI). The findings in Table XLII suggest, however, that the type of comprehensible output responses most important to language acquisition, syntactic modifications, may not always occur as a result of a high frequency of use of clarification request signals. The relationship of the language learner with a dyad partner may have an effect on the amount of syntactic modifications produced. The results 
of this study suggest that language learners in information exchange task interactions with friends may produce more syntactic modifications of their output than is produced when interacting with peer-strangers, other language learners or teachers.

Comprehensible output responses are one of the nine response categories operationalized in the negotiation of meaning model. Table XLIII lists an analysis of variance on all of the response categories per trigger on the total LLHI data.

\section{TABLE XIIII}

RESPONSE TYPE PER TOTAL TRIGGERS, ALL DATA

\begin{tabular}{|c|c|c|c|c|c|c|c|}
\hline \multicolumn{3}{|c|}{ ANALYSIS OF VARIANCE } & & & \multicolumn{3}{|c|}{ TUKEY'S TEST $\mathrm{D}=0.07$} \\
\hline SOURCE & & DF & SS & MS & & & \\
\hline FACTOR & & 1 & 1.16276 & 0.14535 & & 38.95 & 0.000 \\
\hline ERROR & & 1260 & 0.47013 & 0.00373 & & & \\
\hline TOTAL & & 1341 & 1.63289 & & & & \\
\hline LEVEL & $\mathbf{N}$ & MEAN & STDEV & --+- & & ----+--- & -- \\
\hline $3 a / \operatorname{trg}$ & 15 & 0.00844 & 0.02365 & $5\left(--^{*}-\right)$ & & & \\
\hline $3 \mathrm{~b} / \mathrm{trg}$ & 15 & 0.07796 & 0.05932 & & $--*_{--)}$ & & \\
\hline $3 c / \operatorname{trg}$ & 15 & 0.17166 & 0.08089 & & & $\left(--{ }_{-}^{*-}\right)$ & \\
\hline $3 \mathrm{~d} / \mathrm{trg}$ & 15 & 0.23281 & 0.05778 & & & $(--*--$ & \\
\hline $3 \mathrm{e} / \mathrm{trg}$ & 15 & 0.08579 & 0.07658 & & -.--*--) & & \\
\hline $3 f / \operatorname{trg}$ & 15 & 0.29214 & 0.09459 & & & & $\left(--^{*--}\right)$ \\
\hline $3 g / \operatorname{trg}$ & 15 & 0.07457 & 0.05633 & & -----) & & \\
\hline $3 \mathrm{~h} / \mathrm{trg}$ & 15 & 0.04029 & 0.03217 & $\left(--_{-}^{-}\right)$ & & & \\
\hline $3 i / \operatorname{trg}$ & 15 & 0.02368 & 0.02452 & $\left(--_{---)}\right)$ & & & \\
\hline POOLED & TDE & 0.061 & 108 & 0.00 & 0.10 & 0.20 & 0.30 \\
\hline
\end{tabular}

As the results indicate, there are significant differences among the mean counts response totals. Tukey's test shows that 
comprehensible output (3D), affirmation responses (3F) and repetitions of the signals (3C) were produced by the language learners significantly more often than all of the other response category types. Repetitions of the trigger (3E) and indirect responses (3B) were produced significantly more often than the remaining four response categorles (3G, 3H, 3I, and 3A).

The language learners' response choice remained constant across the dyads in five of the categories (3D, 3A, 3B, 3H and 3I). The other four categories show some significance in their mean count totals. Affirmation responses (3F), as shown in Table XLIII, are used very often by the language learner subjects. An ANOVA test on this response type with the data organized by dyad type does not show significant results $(p=0.63)$. However, when the friend and peerstranger dyad data are combined significant differences in the use of affirmation responses among the dyad groupings are found (Table XLIV). The language learner subjects use the affirmation response less often in the teacher dyads than they do with the other dyad types.

The reason for this response use is not readily apparent. Affirmation responses are given to show that the signal has been recognized. The response is somewhat passive in that the language learners do not offer any new information to help repair the trigger that has occurred. The interaction between the teachers and the language learners apparently did not lend itself to this passive type of behavior to the extent that was identified in the other dyad groupings. 
However, as the results in Table XIIII indicate, affirmation responses were used more often than most other response types. Affirmation responses to teachers followed the same pattern as shown in Table XIIII. Thus, though affirmation responses were given to the teachers significantly less often than to the other dyad partners, they were still used by the language learners in the teacher dyads to a significantly high degree.

TABLE XLIV

AFFIRMATION RESPONSES (3F)

PER TOTAL TRIGGERS, TEACHERS

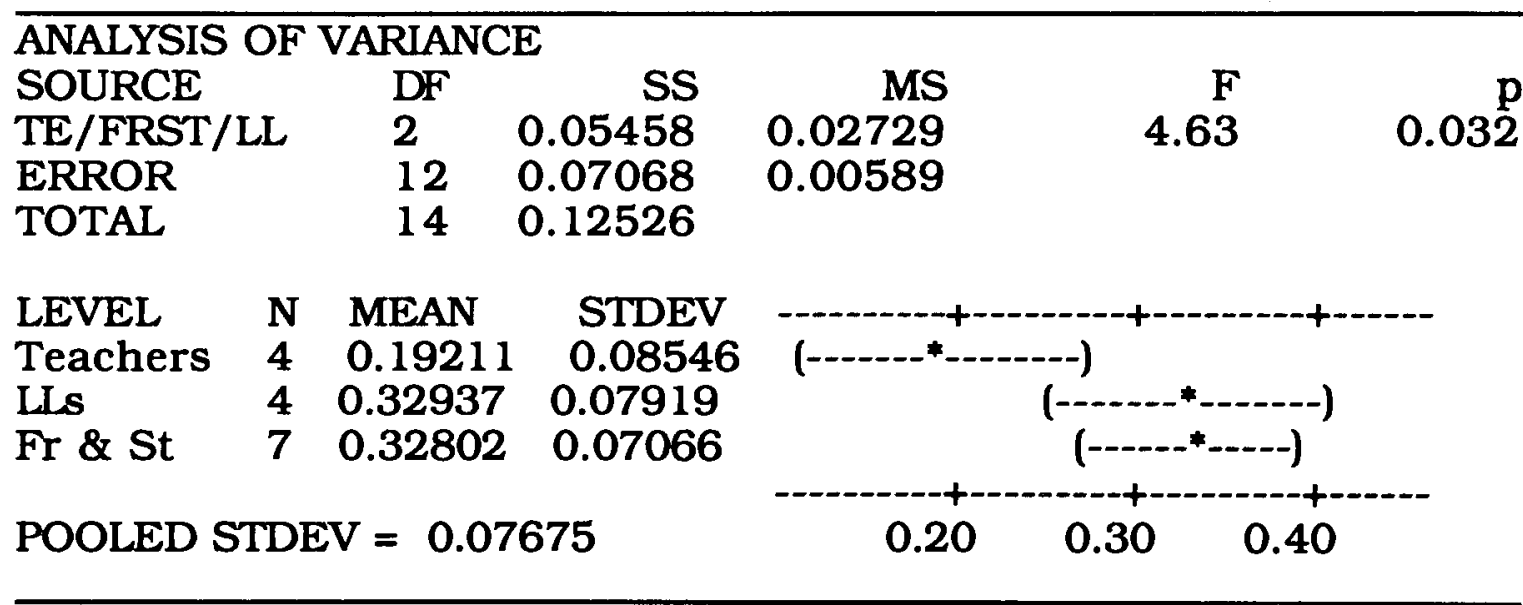

Relative task difficulty may have contributed to the findings of Table XLIV. Language learners may have had to "work" harder to accomplish the "grab bag" task. However, none of the four language learner subjects identified the task with the teacher as being the most difficult to perform. The findings, on the other hand, may relate to the language learners' attention to task performance. Perhaps, in 
interactions with their teachers, the language learner subjects felt compelled to be active and not passive in their response activity. In other words, working with their teacher may have increased their motivation to do well on the task. Active, not passive, responses may have been recognized as more effective in accomplishing the task at hand.

Language learners in teacher and friend dyads repeated the hearers' signals $(3 C)$ significantly more often than they did in the peerstranger and language learner dyads (Table XIV).

\section{TABLE XIV}

REPETITION OF SIGNAL (3C)

PER TOTAL TRIGGERS,

ALL DYADS

ANALYSIS OF VARIANCE

SOURCE

DYAD

ERROR

TOTAL
DF

3

11

14

SS

0.04912

0.04248

0.09160

MS

0.01637

0.00386

F

4.24

0.032

LEVEL

Teachers

N MEAN

Friends

$4 \quad 0.23674$

$4 \quad 0.21210$

Strangers

LLs

$3 \quad 0.11697$

$4 \quad 0.10713$

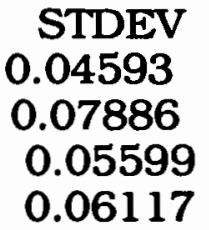

POOLED STDEV $=0.06214$

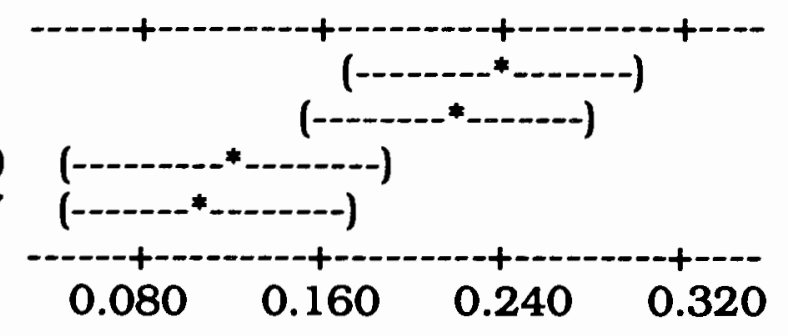

The teachers and friends provided the language learners with more modified and elaborate confirmation checks than did the peerstrangers and language learner dyad partners. The modified 
confirmation signal types would especially seem to encourage a repetition of the signal by the language learner.

The language learners showed an inability to respond to the trigger (3G) more often in the native speaker dyads than in the dyads with another language learner (Table XLVI).

\section{TABLE XIVI}

INABILITY TO RESPOND (3G) PER TOTAL TRIGGERS, LANGUAGE LEARNER AND NATIVE SPEAKER DYADS

\begin{tabular}{|c|c|c|c|c|c|c|}
\hline \\
\hline \multirow{2}{*}{\multicolumn{7}{|c|}{$\begin{array}{lll}\text { SOURCE } & \text { DF } & \text { SS }\end{array}$}} \\
\hline & & 1 & 0.01286 & 0.01286 & 5.30 & \\
\hline \multicolumn{2}{|c|}{$\begin{array}{l}\text { LL/NS } \\
\text { ERROR }\end{array}$} & 13 & 0.03156 & 0.00243 & & \\
\hline \multicolumn{2}{|l|}{ TOTAL } & 14 & 0.04443 & & & \\
\hline \multirow{3}{*}{$\begin{array}{l}\text { LEVEL } \\
\text { LLs } \\
\text { NSs }\end{array}$} & $\mathbf{N}$ & MEAN & STDEV & -----+-- & ---1 & -+- \\
\hline & & 0.026 & 0.0205 & 2 (--------*) & ---) & \\
\hline & & 0.0922 & 30.05505 & & (-----*-----) & \\
\hline \multicolumn{4}{|c|}{ POOLED STDEV $=0.04928$} & 0.000 & 0.100 & 0.150 \\
\hline
\end{tabular}

There was also a significant difference between the peerstranger dyads and the combined data from the teacher and friend dyads (Table XIVII).

It may be that the tasks with the peer-strangers and the language learners were easier to understand and perform than those with the teachers and friends. The signals from these latter two dyad types may have also contained more information that was 
incomprehensible to the language learners, thus making a response difficult to accomplish.

\section{TABLE XIVVII}

INABILITY TO RESPOND (3G) PER TOTAL TRIGGERS,

\section{PEER-STRANGERS}

ANALYSIS OF VARIANCE

SOURCE

ST/TEFR

ERROR

TOTAL
DF

1

9

10
SS

0.01479

0.01552

0.03030

LEVEL N MEAN STDEV $\begin{array}{llll}\text { Strangers } & 3 & 0.03236 & 0.03618\end{array}$ $\begin{array}{llll}\text { Te } \& \text { Fr } & 8 & 0.11468 & 0.04292\end{array}$

POOLED STDEV $=0.04152$
MS
0.01479
F
0.00172
8.58
0.017
0.00172

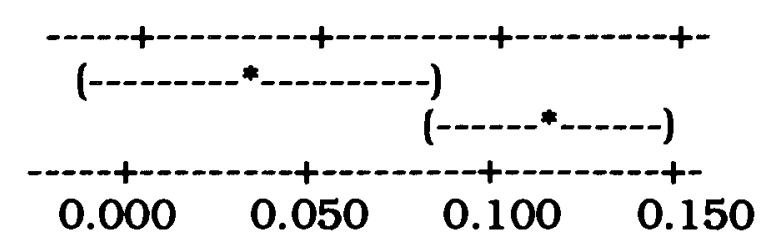

The last response category that had a significant difference in mean counts between the dyads was the repetition of the trigger response type (3E). Language learners in dyads with other language learners were found to use this response type more often than it was used in the native speaker dyad groupings (Table XIVIII).

The reason for this finding may lie in two different areas. First, when native speakers signal that a trigger has occurred the language learners may have assumed that the problem was with the trigger utterance. Repeating the utterance without some modification would not help their native speaker partners' comprehension. With the other language learners, however, the language learners may have assumed that the problem was associated with their partners' 
comprehension of the English language itself. Repeating the trigger may have been an effective strategy that helped promote understanding.

\section{TABLE XIVIII}

REPETITION OF TRIGGER (3E)

PER TOTAL TRIGGERS,

\section{ALL DYADS}

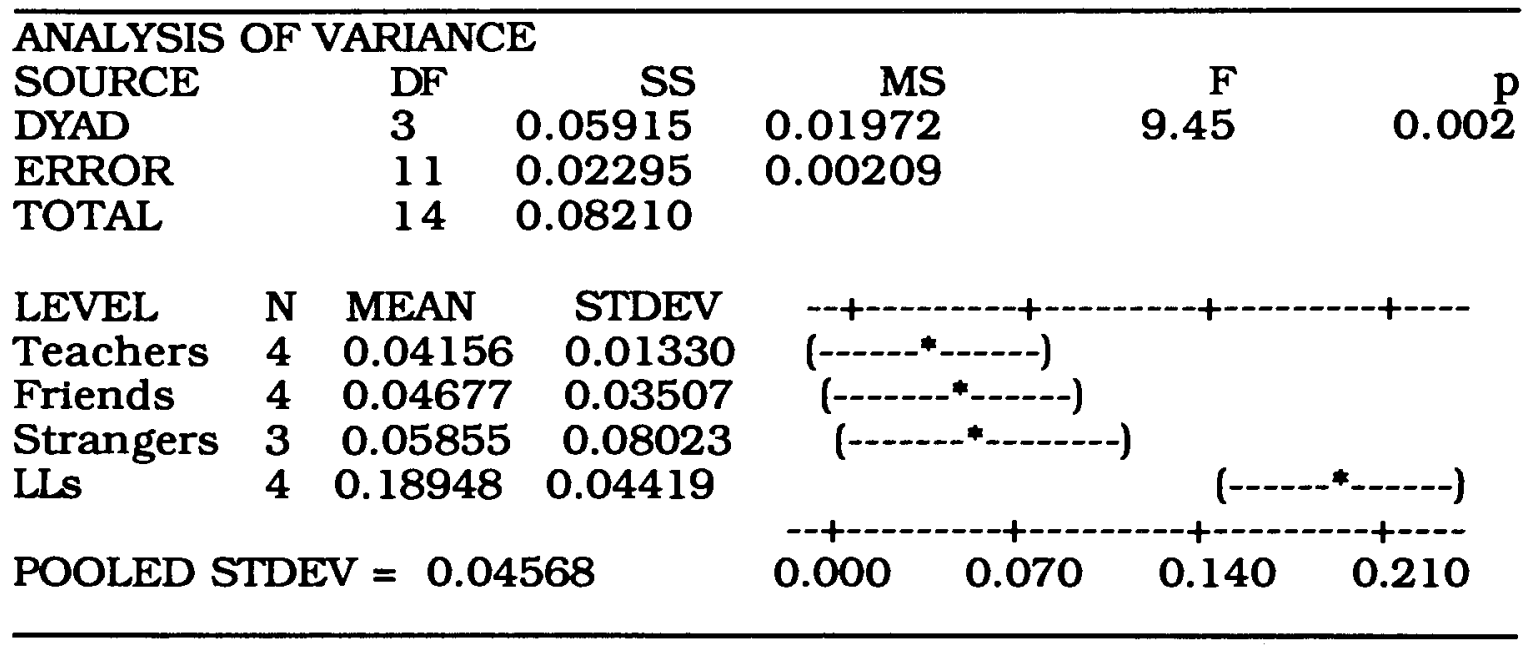

The second reason may be associated with the type of signals that the language learners are given. Language learner dyads contained a high amount of repetition confirmation signals (Table XXV). The repetition of the trigger response may have been a confirmation to the hearer that the repetition confirmation signal was accurate. However, with native speakers, modification confirmation signals were given more often than in the language learner dyads (Table XXVI). Repetition of the trigger after being supplied with a modification of the trigger by the dyad partner would not seem to be an appropriate response. Thus, the language learners' use of this 
response type with native speakers may have been limited by the type of signals supplied to them by the native speakers.

\section{Error Correction Hypotheses}

Hypotheses Six, Seven and Eight make predictions about the types and frequencies of corrections of language learners' linguistic errors made by their dyad partners. The error taxonomy presented in Chapter III was used to code and organize the data for use in the statistical analysis that follows. Each of these three hypotheses, and the findings related to their predictions, will be discussed in turn. Before examining findings related directly to Hypothesis Six, the types and frequencies of the errors that were made by the language learner subjects will be presented.

\section{Error Type And Frequency}

The error taxonomy used to code the data from the dyad experiments contains six different linguistic error categories; (a) discourse errors (DE), (b) factual errors (FE), (c) word choice errors (WC), (d) syntactic errors (SE), (e) omission errors (OE), and (f) phonological errors (PE). A total of 3,676 of these errors were made by the language learner subjects in the dyad experiments. At the same time, the language learners produced 3,982 c-units, approximately one linguistic error for every c-unit produced (0.923).

In Table XLIX, the error types are analyzed for frequency of occurrence per total c-units produced by the language learner 
subjects. As the results show, language learners made significantly more errors of omission and phonology than any of the other four error categories.

\section{TABLE XIIX}

ERROR TYPE PER LANGUAGE LEARNER C-UNITS, ALL DATA

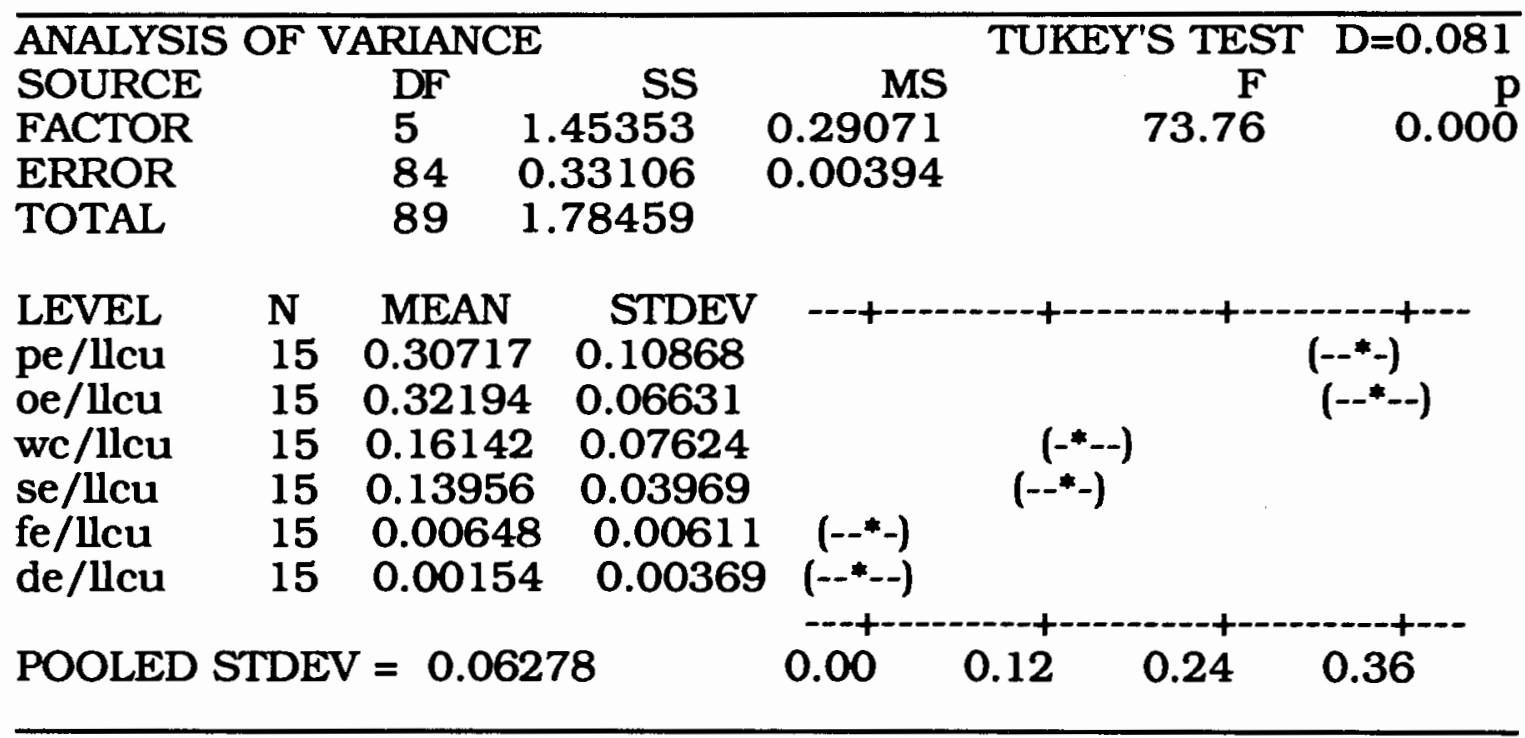

Phonological errors included false starts, as well as errors in lexical pronunciation. Given the large amount of false starts contained in the transcripts, it seems surprising the omission errors were made as frequently as the phonological errors. However, many of the omission errors were caused by the omission of English articles. Since articles are grammatically required in most English sentences, the language learners' apparent lack of competence in the use of articles may have been the factor that caused the omission error count to be so high. Omission errors were not categorized by type and the 
observation concerning article omission is only anecdotal. The same is true concerning the apparent frequency in the transcripts of language learners' false starts.

Word choice errors and syntactic errors occurred significantly more often than did errors of fact and discourse according to a Tukey's test analysis. Factual and discourse errors rarely occurred. The nature of the information exchange tasks may have been a limiting factor on the production of factual and discourse errors. The tasks were highly structured such that discourse errors would be difficult to achieve; turn-taking was highly prescribed, topic-switching was discouraged by the task at hand, and opening and closing moves were repetitive. Inappropriate responses to the input were possibly limited to the language learners' relatively high proficiency level. Factual errors may have also been limited partly due to the nature of the task, and partly because of the language learner subjects' intermediate proficiency level. Learners of lower proficiency may have produced more of both of these error types.

In Table XL, the error types were measured per total error count. The one per one nature of error per c-unit is verified by the almost equivalent results shown here. In analysis of variance tests that follow errors per total error count and errors per total language learner c-units will be considered equal unless otherwise noted.

When the error type per total language learner c-units are tested against data from the native speaker dyads only, the results are the 
same as in Table XIX. Omission and phonological errors are most frequent, followed by word choice and syntactic errors with factual and discourse errors the least frequent of all.

\section{TABLE L}

ERROR TYPE PER TOTAL ERROR COUNT,

\section{ALL DATA}

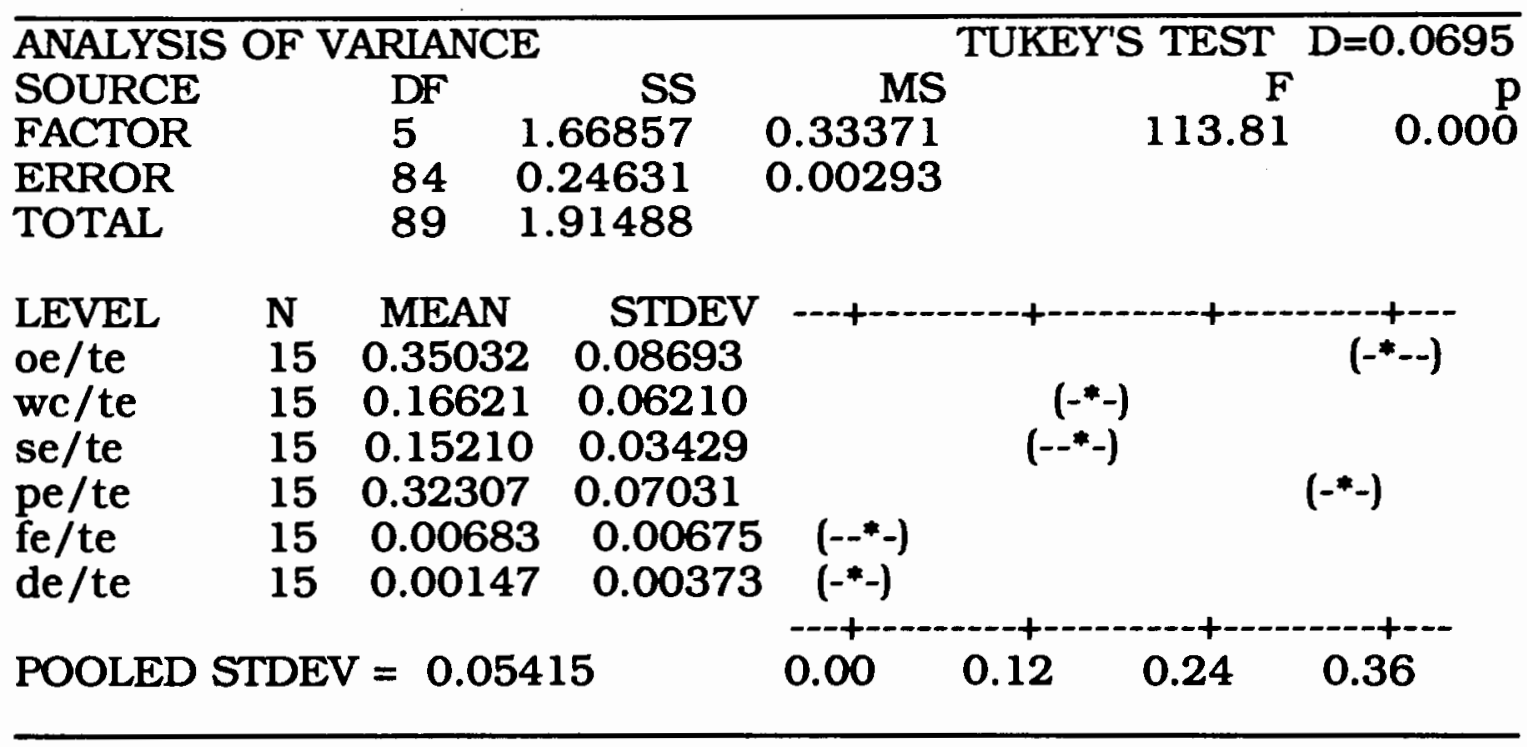

When the analysis is on only the language learner dyads, however, the results are slightly different (Table LI). In the language learner dyads, there is not a significant difference between phonological, word choice and syntactic errors according to Tukey's test. The omission errors still occur significantly more often than all the other error types with the exception of phonological errors. Phonological errors, however, are not produced significantly more often than the word choice and syntactic error categories as shown in Table XLIX and mirrored in the data analysis from the native speaker 
dyads. It would appear from the mean counts that the language learner subjects in language learner dyads $(M=0.2154)$ made fewer phonological errors than they did in dyads with native speakers $(M=0.3405)$.

\section{TABLE LI}

ERROR TYPE PER TOTAL LANGUAGE LEARNER C-UNITS, LANGUAGE LEARNERS ONLY

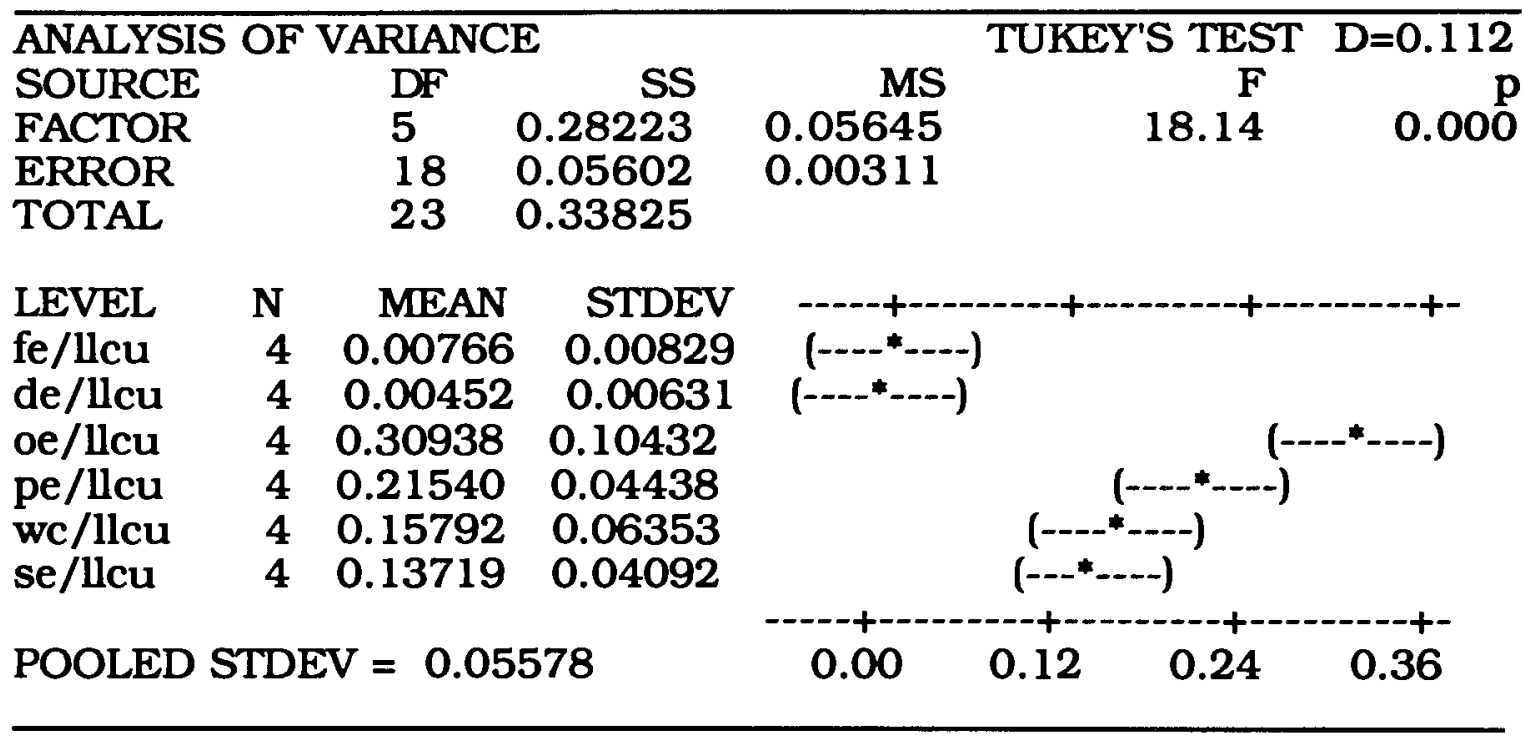

When total errors per language learner c-units are analyzed according to dyad types, there is no significance between the dyads for errors produced by the language learner subjects (Table LII)).

When total errors per language learner c-units are analyzed according to the specific language learner subjects, significant differences are found (Table LIII). Language Learner Subject 113 made significantly fewer errors than did the other language learner subjects. When the data were reorganized by type. Subject 113 was 
found to have made significantly fewer errors in two of the six error types. Syntactic errors $(p=0.001)$ and word choice errors ( $p=0.002$ ) were made more often by the other three language learners than they were made by Language Learner 113. Tukey's test can not be used to check for significance between the subjects due to the unbalanced design. However, the significance of the ANOVA test shown in Table LIII may be due, in part, to the large number of errors made by Language Learner 125.

\section{TABLE LII}

ERRORS PER LANGUAGE LEARNER C-UNITS, ALL DYADS

\begin{tabular}{|c|c|c|c|c|c|c|}
\hline \\
\hline \multicolumn{7}{|c|}{$\begin{array}{l}\text { ANALYSIS OF VARIANCE } \\
\text { SOURCE DF }\end{array}$} \\
\hline \multirow{2}{*}{\multicolumn{2}{|c|}{$\begin{array}{l}\text { DYAD } \\
\text { ERROR }\end{array}$}} & 3 & 0.0522 & 0.0174 & 0.39 & 0.760 \\
\hline & ERROR & 11 & 0.4855 & 0.0441 & & \\
\hline \multicolumn{2}{|l|}{ TOTAL } & 14 & 0.5377 & & & \\
\hline LEVEL & $\mathbf{N}$ & MEAN & STDEV & -- & --+-- & \\
\hline Teachers & 4 & 0.9773 & 0.1724 & $(-$ & $\ldots *$ & \\
\hline Friends & 4 & 0.9756 & 0.2860 & & 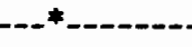 & \\
\hline Strangers & 3 & 0.9772 & 0.1581 & $(--$ & ---_---_-- & \\
\hline LLs & 4 & 0.8432 & 0.1834 & $(----)$ & --------) & \\
\hline \multicolumn{4}{|c|}{ POOLED STDEV $=0.2101$} & 0.8 & 1.00 & \\
\hline
\end{tabular}

In Table II (Chapter III) the TOEFL scores of the language learner subjects revealed a much higher score for Subject 113 (533) than for the others $(M=471)$. Errors in syntax and lexicon were made significantly less frequently by Subject 113 , perhaps reflecting a stronger grasp of English grammar and possession of a larger 
vocabulary than the other language learner subjects. In errors of phonology $(p=0.345)$, omission $(p=0.773)$, fact $(p=0.163)$ and discourse ( $p=0.347$ ), there were no significant differences between Subject 113 and the other language learners. The possibility of Subject 113's higher proficiency level skewing the error correction findings will be discussed when results related to syntax and word choice error correction are examined.

\section{TABLE LIII}

ERRORS PER LANGUAGE LEARNER C-UNITS, LANGUAGE LEARNER SUBJECTS

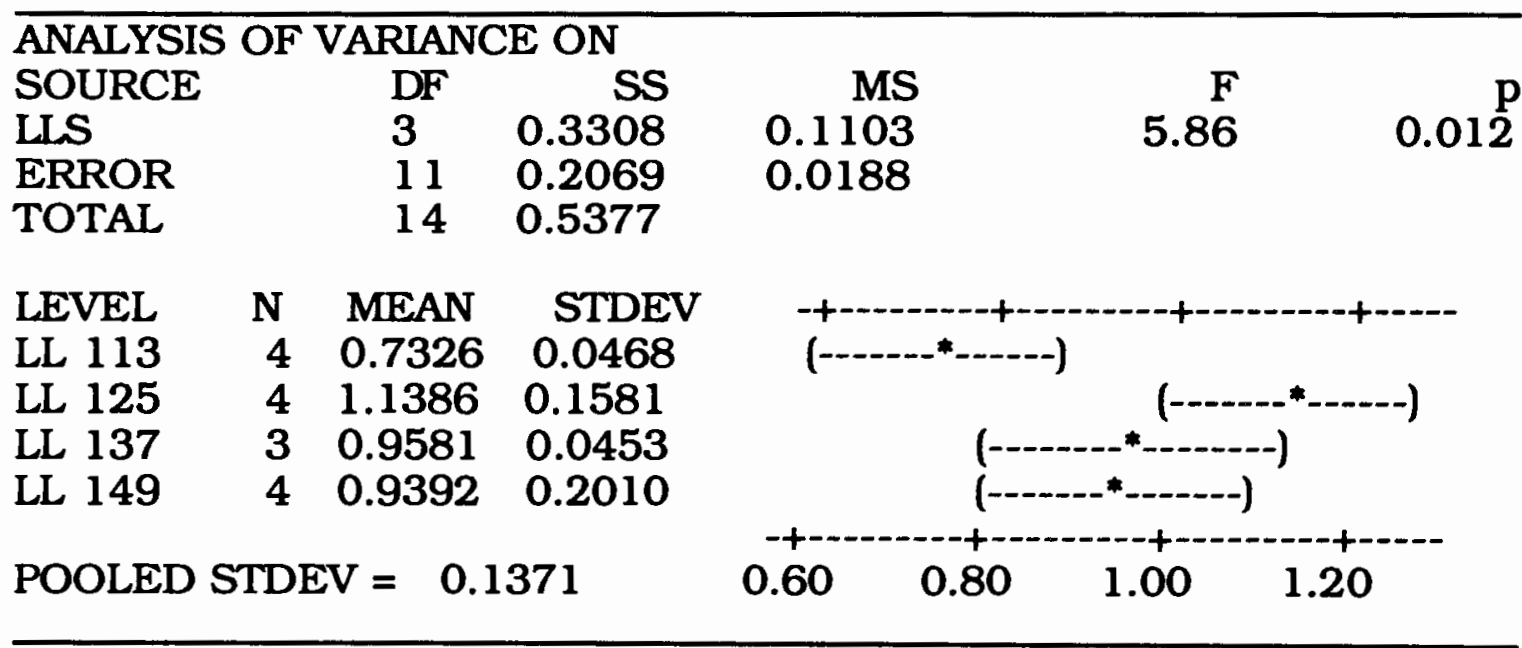

\section{Hypothesis Six}

Hypothesis Six predicted that native speakers' correction of the language learners' linguistic errors would occur most frequently per cunit in the language learner with teacher dyads. The language learner with friend dyads were predicted to contain the second largest count of error corrections while the peer-stranger dyads were predicted to 
contain the fewest. The data used to test this hypothesis include all of the c-units identified in the transcripts from each of the dyad experiments.

Teachers were predicted to provide their language learner partners with the most linguistic error corrections. It was assumed, that teachers were probably in the habit of providing their students with corrected models of the English language. Many studies on error correction in second language classrooms by language teachers document the fact that teachers do correct their students' linguistic errors (Allwright, 1975, Bruton \& Samuda, 1980, Chaudron, 1977. Fanselow, 1977). The student-teacher relationship is generally an unbalanced one, with the teachers taking on the role of conveyor of knowledge and the students assuming the role of recipient and beneficiary of the teachers' expertise. The teachers' correction of their students' English language errors was predicted to carry over from the classroom into the dyad experiment data.

Chun et al. (1982) found that native speaker friends correct the linguistic errors of their nonnative speaker friends. In their conclusion, these researchers speculated that close friendships allow native speakers to feel more comfortable about correcting their friend's language errors. Further, Chun et al. proposed that there are pragmatic and social restraints that limit the linguistic error corrections offered by strangers to non-native speakers. In Hypothesis Six, it was predicted that the friends would correct more errors than 
the peer-strangers because of these social and pragmatic restraints.

Hypothesis Six was not supported by the analysis of the data. In a test on the prediction for Hypothesis Six, that teacher dyads will correct language learners' linguistic errors more frequently than other native speaker dyads, no significant differences were found $(p=0.374)$. When the data are reorganized to include the fourth dyad type, language learner with language learner, significant differences are still not found (Table LIV), though the critical value of $p$ is approaching significance.

TABLE LIV

ERROR CORRECTION PER TOTAL C-UNITS, ALL DYADS

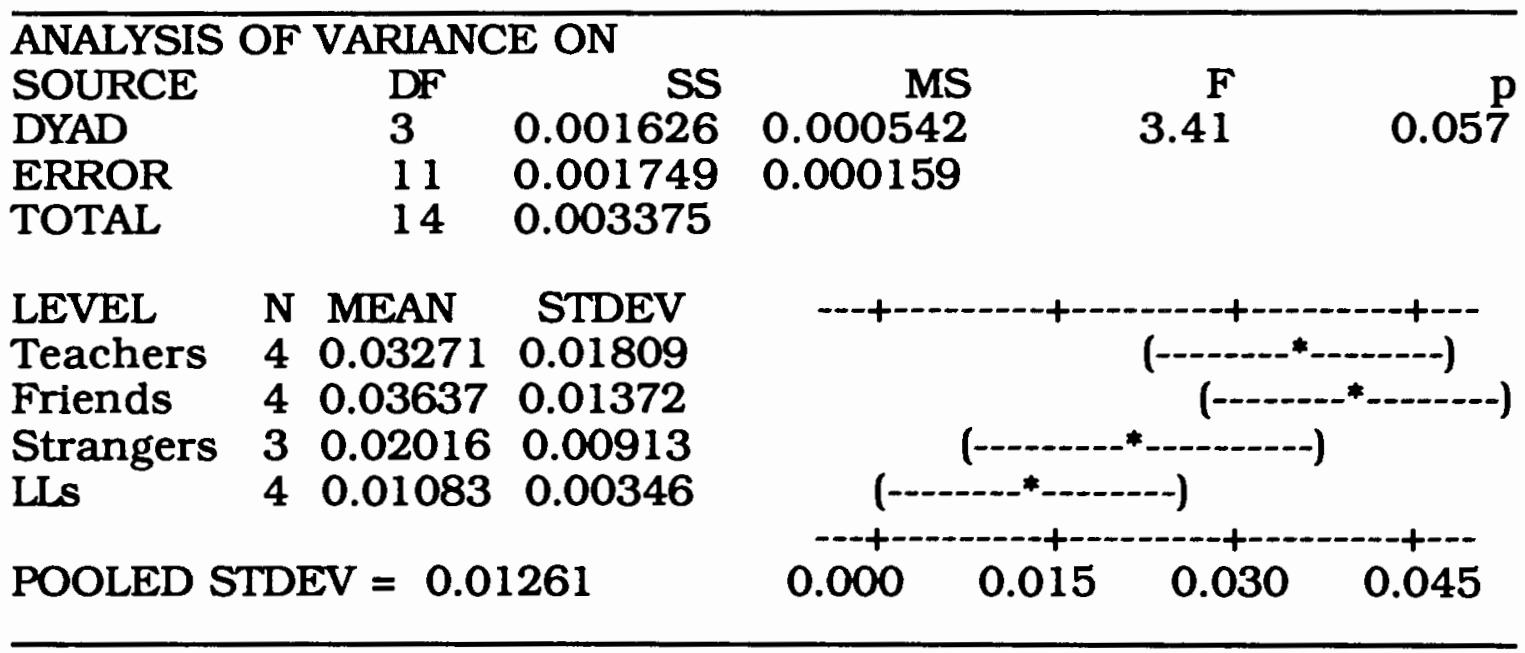

When the data from the combined native speaker dyads are compared to the data from the language learner dyads, a significant difference is supported by the results (Table LV). Native speaker dyads correct more language learner linguistic errors than language 
learner dyads do. These results seem logical and predictable since the native speakers would have more linguistic resources than would the language learner partners.

Whether error correction is helpful to second language acquisition is uncertain (Long, 1977). However, it may be that the correction of errors may affect the amount of comprehensible output that is produced by the language learner subjects. The correlation of error correction to comprehensible output production is taken up in the discussion of Hypothesis Nine.

\section{TABLE LV}

ERROR CORRECTION PER TOTAL C-UNITS, LANGUAGE LEARNER AND NATIVE SPEAKER DYADS

\begin{tabular}{|c|c|c|c|c|c|c|}
\hline \multirow{2}{*}{\multicolumn{7}{|c|}{$\begin{array}{l}\text { ANALYSIS OF VARIANCE } \\
\text { SOURCE }\end{array}$}} \\
\hline & & & & & & \\
\hline \multirow{3}{*}{\multicolumn{2}{|c|}{$\begin{array}{l}\text { LL/NS } \\
\text { ERROR } \\
\text { TOTAL }\end{array}$}} & 1 & 0.001149 & 0.001149 & \multirow{3}{*}{6.71} & \multirow{3}{*}{0.022} \\
\hline & & 13 & 0.002226 & 0.000171 & & \\
\hline & & 14 & 0.003375 & & & \\
\hline \multirow{3}{*}{$\begin{array}{l}\text { LEVEL } \\
\text { LIS } \\
\text { NSs }\end{array}$} & $\mathbf{N}$ & MEAN & STDEV & \multirow{2}{*}{\multicolumn{3}{|c|}{ 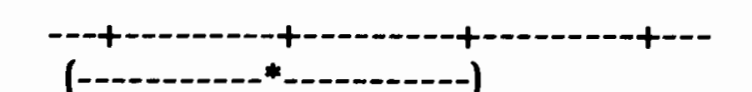 }} \\
\hline & 4 & 0.01083 & 0.00346 & & & \\
\hline & & 0.03062 & 0.01480 & & $(--$ & ----) \\
\hline \multicolumn{4}{|c|}{ POOLED STDEV $=0.01309$} & 0.000 & 0.024 & 0.036 \\
\hline
\end{tabular}

\section{Hypothesis Seven}

In this hypothesis, it was predicted that native speakers would correct more language learners' linguistic errors of a factual or discourse nature per total language learner error count than any of the other error types. The discussion presented here will also focus on 
the types and frequencies of the errors that the language learner subjects self-corrected. The data used to test Hypothesis Seven includes all the c-units identified in the study. Most of the error correction data were measured by the total c-unit count. Some data were also measured by total error type count.

The prediction for Hypothesis Seven was based solely on the results from the Chun et al. study (1982). The findings in their study of error correction by native speaker friends suggested that errors of a factual or discourse nature were corrected by the friends far more often than errors related to grammar (omission, syntax and word choice).

Hypothesis Seven is not supported by the results because native speakers' corrections of language learners' linguistic errors of a factual or discourse nature were never identified within the body of the data. In the preceding discussion regarding the types and frequencies of language learners' linguistic errors, factual and discourse errors per language learner c-units were found to occur significantly less often than all other error types (Table XIIX). In fact, only 5 discourse errors and 23 factual errors were identified within the 3,676 error total. This may partially explain why native speakers did not correct these types of errors. It may also be that the nature of the information exchange tasks made identification of these types of errors by the native speaker subjects difficult. Open-ended discussions, like those conducted in the Chun et al. study, may be more conducive to 
discourse and factual error identification by the native speakers.

There may be another reason why the native speaker subjects in this study did not correct language learners' factual linguistic errors. In Table LVI, the results suggest that language learners self-corrected significantly more factual errors than they did any of the other error types with the exception of phonological errors.

\section{TABLE LVI}

SELF-CORRECTION OF ERROR TYPE PER TOTAL ERROR TYPE COUNT, ALL DATA

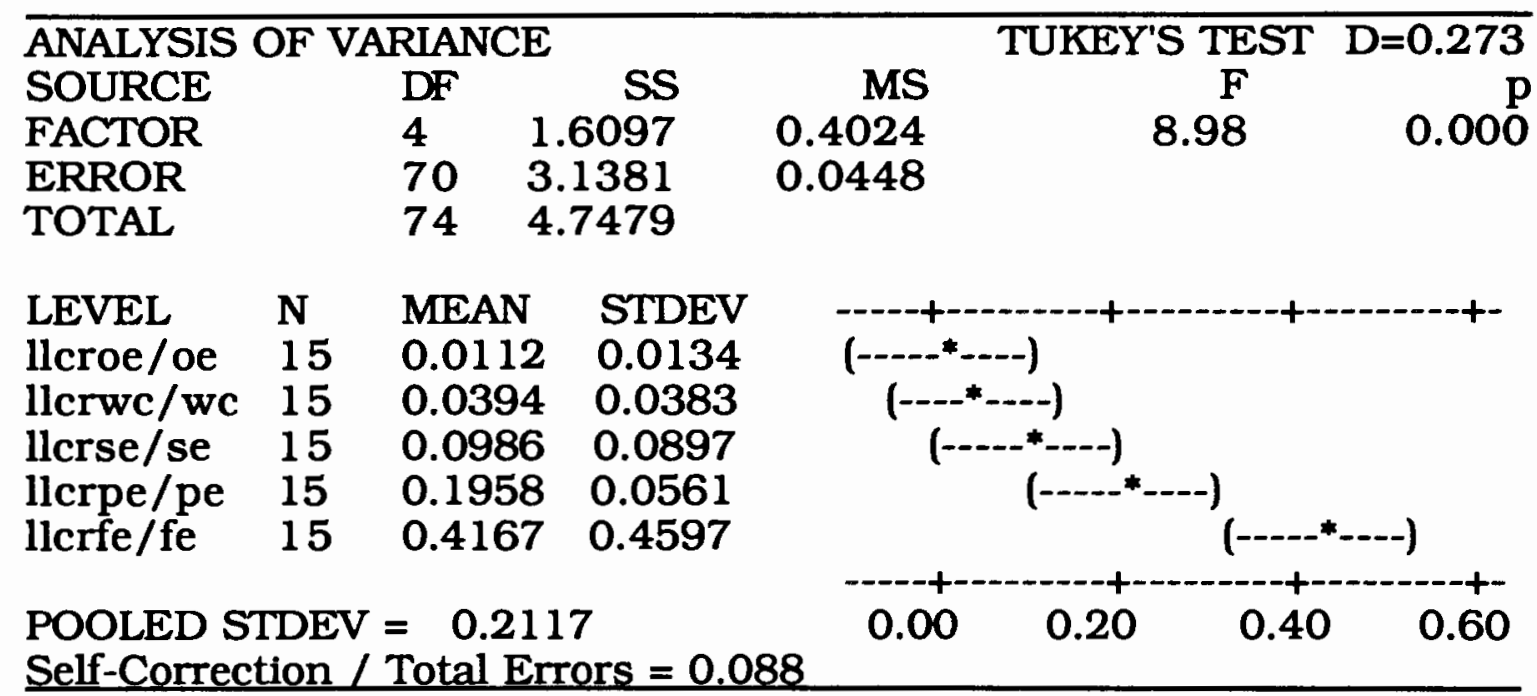

Tukey's test does not support a significant difference between the factual and phonological error self-correction counts. There is also no significant difference in the self-correction means between phonological self-correction and the remaining error types. The results indicate that the language learner subjects may have selfcorrected many of the factual errors $(M=.42)$ before the native 
speakers were able to supply a factual error correction to their dyad partner.

The language learners self-corrected more phonological errors per language learner c-units than any of the other errors including those of a factual nature (Table LVII). Tukey's test shows no significant differences exist between the mean totals of factual error selfcorrection and those of the remaining three error types.

\section{TABLE LVII}

SELF-CORRECTION OF ERROR TYPE PER TOTAL LANGUAGE LEARNER C-UNITS,

$$
\text { ALL DATA }
$$

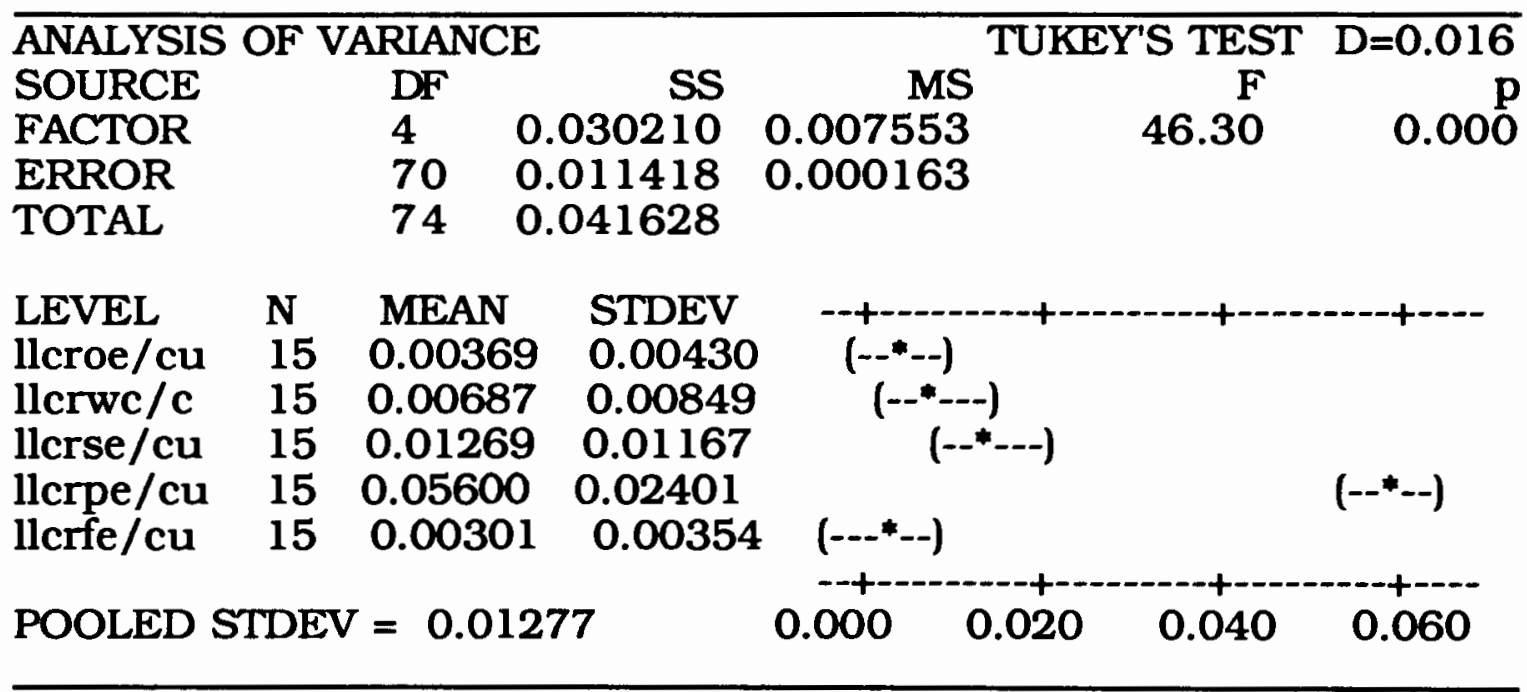

Phonological and omission errors were identified in the largest numbers (Table XLIX) but only phonological errors were self-corrected in large numbers when compared to the language learner subjects' total c-unit production. It may be that many of the false starts were self-corrected while a large amount of the article omission errors were 
never modified. The types of phonological and omission errors that were self-corrected were not identified.

The language learners self-corrected without regard to the dyad type $(p=0.506)$. There were also no significant differences among the individual language learner subjects with regard to self-correction $(p=0.070)$. However, there were differences found between the levels of self-correction of error type and dyad groupings. When the language learner with language learner dyads' data are examined, it is found that there is a significantly higher amount of syntactic error selfcorrections per language learner c-units than self-corrections of word choice, omission and factual error (Table LVIII). Phonological error self-corrections still occur in higher numbers than do any of the other error types.

In Table LIX, the findings support the results found in Table LVIII. Language learners in language learner dyads self-correct more syntactic errors than they do when participating in dyads with native speakers. Language learners appear to pay more attention to their syntactic structure when working in information exchange tasks with other language learners than they do in tasks with native speakers. 


\section{TABLE LVIII}

SELF-CORRECTION OF ERROR TYPE PER TOTAL LANGUAGE LEARNER C-UNITS, LANGUAGE LEARNERS ONLY

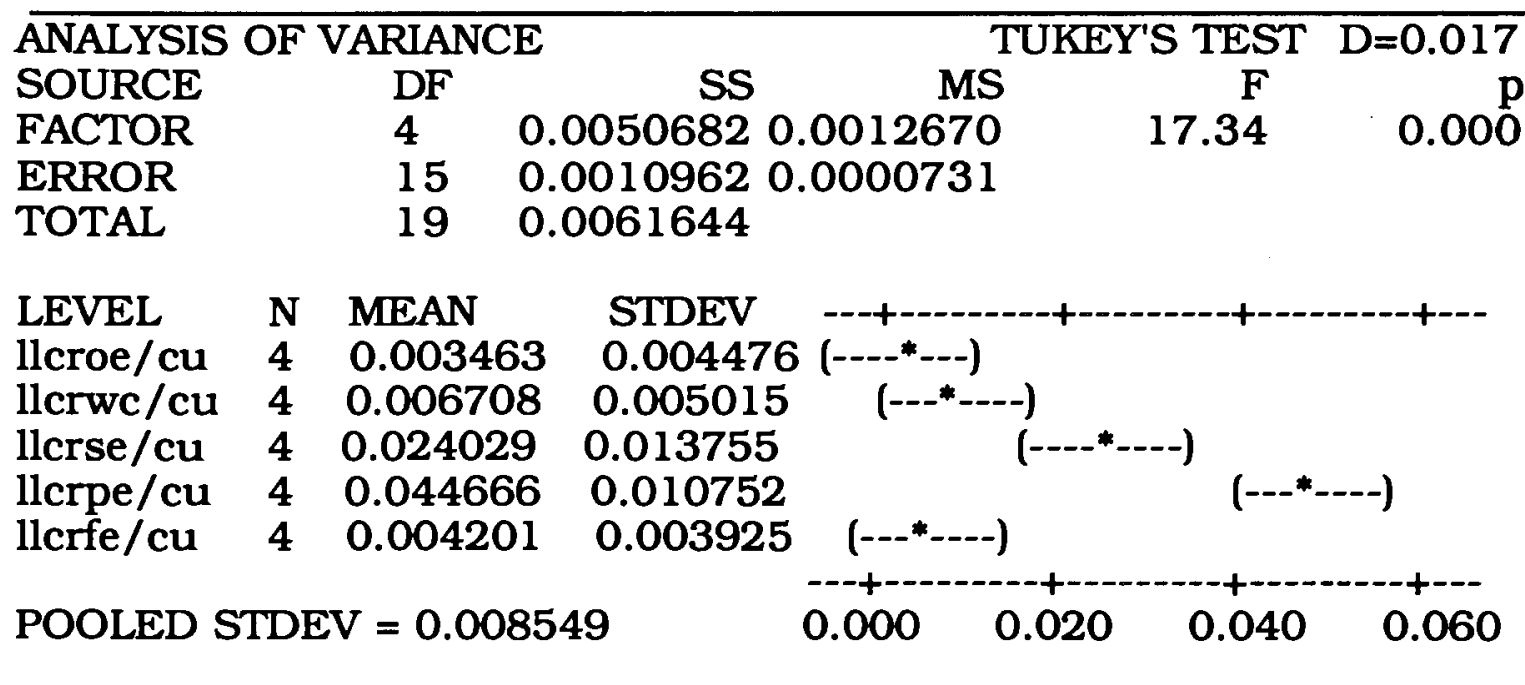

TABLE LIX

SELF-CORRECTION OF SYNTACTIC ERRORS

PER TOTAL LANGUAGE LEARNER C-UNITS, LANGUAGE LEARNER AND

NATIVE SPEAKER DYADS

\begin{tabular}{|c|c|c|c|c|c|c|c|}
\hline \\
\hline \multirow{2}{*}{\multicolumn{4}{|c|}{$\begin{array}{lll}\text { SOURCE } & \text { DF } \\
\text { LL/NS } & 1\end{array}$}} & SS & MS & & \\
\hline & & 1 & \multicolumn{3}{|c|}{0.00070070 .0007007} & 7.56 & 0.017 \\
\hline \multicolumn{2}{|l|}{ ERROR } & 13 & \multicolumn{3}{|c|}{0.00120460 .0000927} & & \\
\hline TOTAL & & 14 & \multicolumn{3}{|c|}{0.0019054} & & \\
\hline \multirow{3}{*}{$\begin{array}{l}\text { LEVEL } \\
\text { LLS } \\
\text { NSs }\end{array}$} & \multirow{3}{*}{$\begin{array}{l}N \\
4 \\
11\end{array}$} & MEAI & \multirow{3}{*}{\multicolumn{2}{|c|}{$\begin{array}{cc} & \text { STDEV } \\
29 & 0.013755 \\
72 & 0.007981\end{array}$}} & \multirow{3}{*}{ (------------ } & & \\
\hline & & 0.024 & & & & -- & 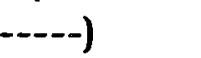 \\
\hline & & 0.008 & & & & & \\
\hline \multicolumn{5}{|c|}{ POOLED STDEV $=0.009626$} & 0.010 & 0.020 & 0.030 \\
\hline
\end{tabular}


Language Learner Subject 113 was found to produce significantly fewer syntactic errors than did the other language learner subjects $(p=0.001)$, yet no significant differences were found among the individual subjects' self-correction of syntactic errors per c-unit production $(p=0.267)$. Subject 113 appeared to self-correct syntactic errors to the same degree per c-unit as the other subjects. His lower syntactic error count suggests that he actually corrected more of his syntactic errors per total syntactic error count. However, an analysis of variance test on the self-correction of syntactic errors among the individual language learner subjects does not support any significant differences $(p=0.072)$.

There was only one more category of language learner selfcorrection that showed a significant difference among the dyad types. When the teacher and friend dyads data are grouped and compared with the data of the peer-stranger dyads and language learner dyads, the results indicate that language learners self-correct significantly more omission errors with peer-strangers than they do with the other native speakers (Table LX).

A separate test excluding the data of the language learner dyads supports this observation $(p=0.007)$. There is no significant difference between the language learner subjects' self-correction of omission errors $(p=0.267)$. The language learner subjects appeared to pay more attention to their omission errors when interacting with peer-strangers than they did with the other native speakers. 


\section{TABLE LX}

SELF-CORRECTION OF OMISSION ERRORS PER

TOTAL LANGUAGE LEARNER C-UNITS,

PEER-STRANGERS

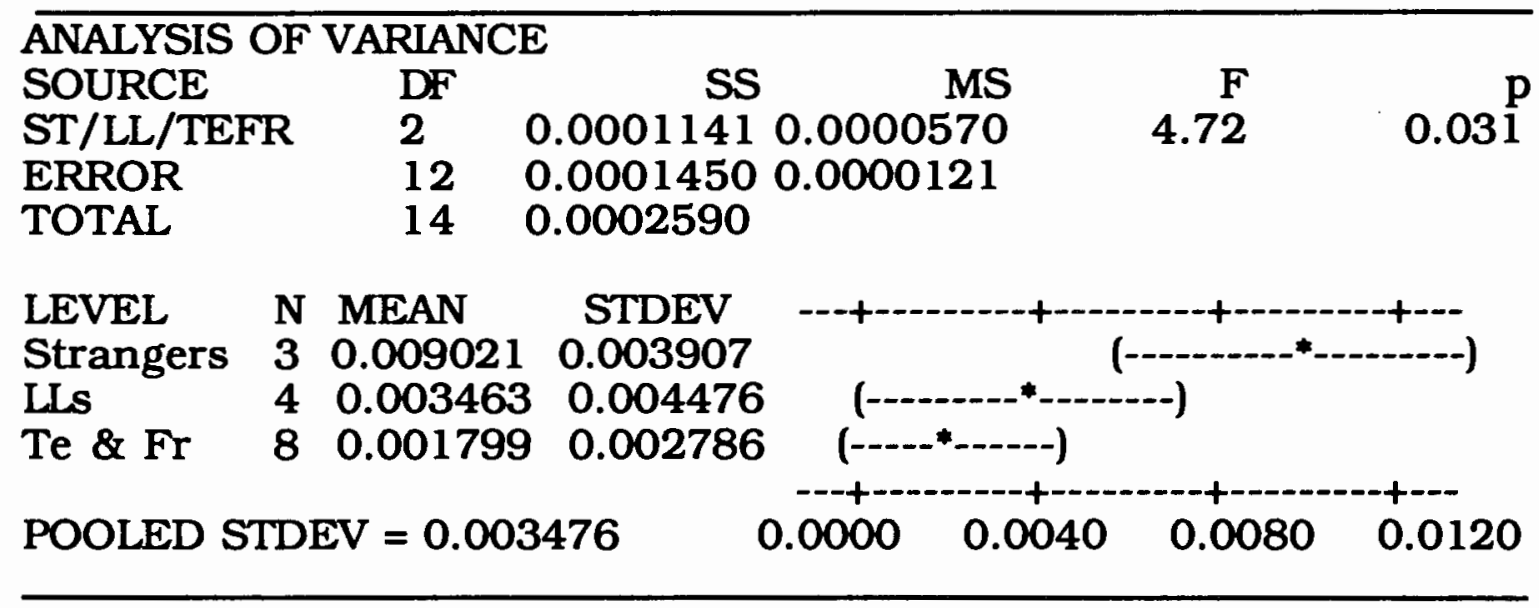

The reason for the significant differences in the language learners' self-correction of syntactic errors with other language learners and omission errors with peer-strangers is not readily apparent. The language learners did not produce significantly more of these error types per c-unit in these two dyad types; (a) omission errors, $p=0.436$, and (b) syntactic errors, $p=0.439$. It may be that relative task difficulty (or ease) allowed the language learners to "monitor" their output more carefully in these two dyad types. However, they appeared to pay more attention to a different type of linguistic error in each of the two dyads.

Hypothesis Seven predicted that errors of a factual or discourse nature would be corrected more often by native speakers than any of the error categories. The prediction was not supported due to the 
lack of any corrections of factual or discourse errors being identified. Nevertheless, native speakers and language learner partners did correct their partners' errors. In Table LXI, findings show that phonological errors were other-corrected significantly more often than any of the other three remaining error types. Tukey's test does not show any significant differences among the frequency counts of other-corrections of omission, word choice and syntactic errors.

\section{TABLE LXI}

OTHER-CORRECTION OF ALL ERROR TYPES

PER TOTAL C-UNITS,

ALL DATA

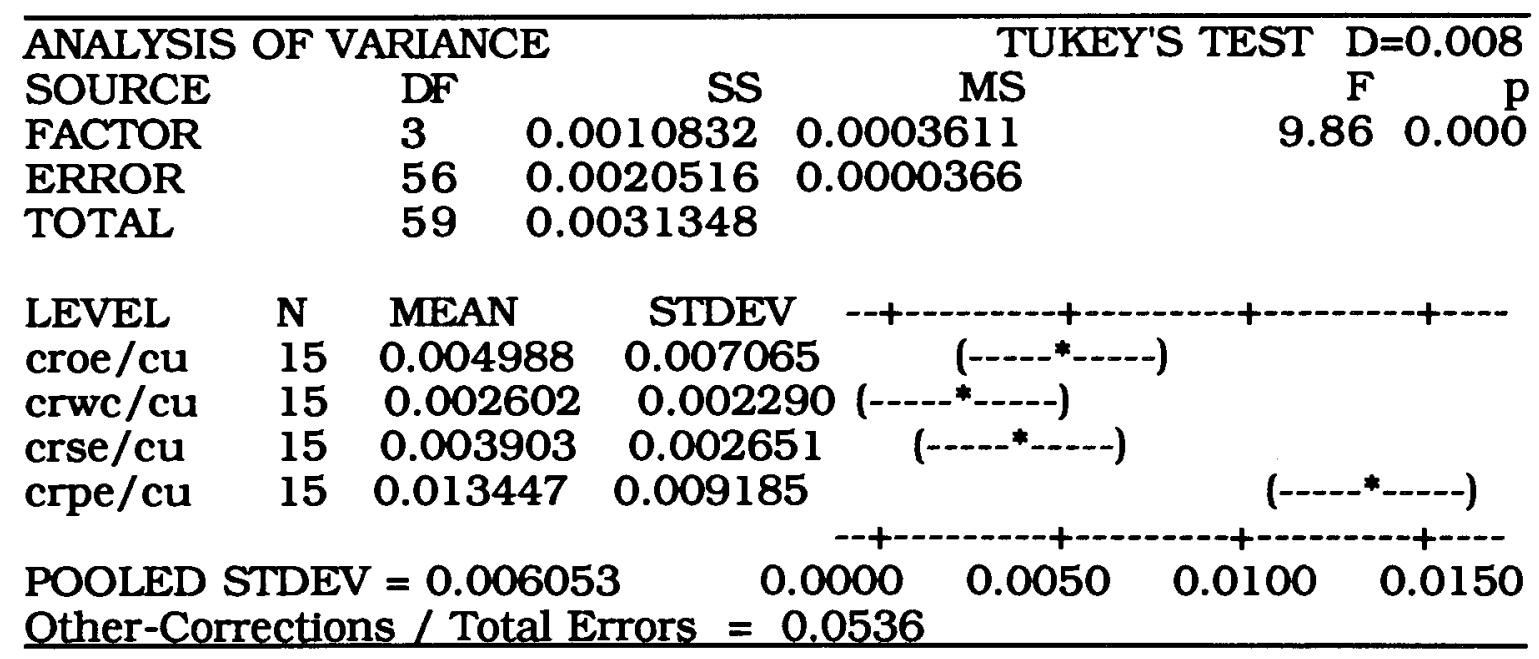

Phonological errors and omission errors were produced in higher numbers than all other errors (Table XLIX). Further, there was no significant difference between the frequency of phonological errors and omission errors per language learner c-units. Yet, omission errors were not other-corrected significantly more often than errors of 
syntax and word choice. It may be that the phonological errors impeded understanding of the language learners' intended meaning to a larger degree than omission errors did.

As has been noted, the omission errors appeared to be largely due to the omission of English articles. These omissions probably did not prevent the language learners' intended meaning from being understood by the dyad partner. Phonological errors, on the other hand, may have confused the language learners' dyad partners.

Phonological errors, thus, may have been other-corrected more often to help the dyad partner in the negotiation of meaning process.

Native speakers, moreover, correct significantly more phonological errors than do language learner partners (Table LXII).

\section{TABLE LXII}

OTHER-CORRECTION OF PHONOLOGICAL ERRORS PER TOTAL C-UNITS, LANGUAGE LEARNER AND NATIVE SPEAKER DYADS

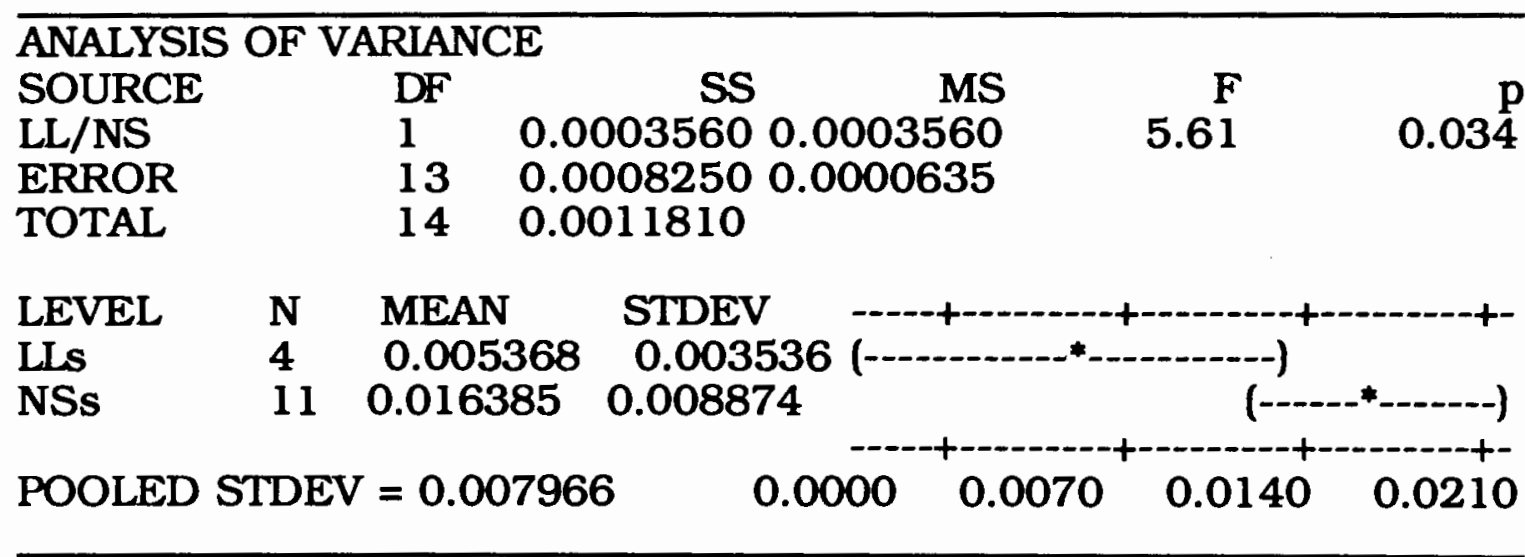


In the discussion of Hypothesis Seven, it was found that native speakers correct significantly more errors than do language learner partners (Table LV). However, it is only within the phonological error type that native speakers were found to correct significantly more errors. Omission errors $(p=0.259)$, syntactic errors $(p=0.087)$ and word choice errors $(p=0.714)$ are all corrected by the two dyad groupings at levels which can not be significantly differentiated from each other. It seems logical that the native speakers would correct more phonological errors than language learner dyad partners do. What is surprising is that native speakers do not correct significantly more language learners' linguistic errors in the area of grammar (omission, word choice and syntactic errors).

Self-correction by the language learner does not seem to offer much explanation of these findings since language learners selfcorrected significantly more phonological errors than any other error type (Table LII). Thus, the frequency of self-correction and othercorrection of phonological errors were both significantly higher than the other error types. The dyad subjects' attention to the task at hand may have limited error correction to only those errors that impeded the conveyance of information.

\section{Hypothesis Eight}

Hypothesis Eight predicted that the dyads containing native speaker friends would correct more factual or discourse errors per 
total language learner linguistic error count than would the other dyad types. It was further predicted that teachers would correct the second highest total of these linguistic error types followed in order by the peer-strangers and language learner partners. The data used to test this prediction included all of the c-units identified in the study. Some of the tests measured other-correction of error type per total cunits while others measured the error type correction per total error type.

The construction of Hypothesis Eight was originally designed with the assumption that the Chun et al. (1982) results would be verified by Hypothesis Seven. The dyad ranking of other-corrections of factual and discourse errors was designed for many of the same reasons listed in the discussion of Hypothesis Six. The social distance between the peer-stranger and the language learner, and the lack of language competence on the part of the language learner partner were thought to be limiting factors on the amount of factual and discourse error corrections produced by these dyad participants.

The order of the friends and teachers is reversed from the prediction listed in Hypothesis Six. Based on the Chun et al. findings, it was predicted that errors that impeded meaning would be more closely attended to by native speaker friends than by language teachers. Language teachers were expected to correct more of the language learners' errors in grammar and fewer of the errors of fact and discourse than the native speaker friends. 
As discussed above, Hypothesis Seven was not verified by the data analysis. Instead, other-corrections of factual and discourse errors were not identified within this study's data. Thus, Hypothesis Eight can not be supported by the data. However, some differences, with regards to dyad type, in other-corrections of language learners' linguistic errors were found.

In Table LXI, the findings indicated that other-corrections of language learners' linguistic errors per c-unit occurred significantly more often for phonological errors than for any of the other error types that were other-corrected. These findings hold true for the teacher and peer-stranger dyads. Teachers and peer-strangers correct more of their partners' phonological errors than any of the other error types. For friends, however, the results do not show any significant differences among the other-correction error types (Table LXIII).

The friends appear to correct their partners' linguistic errors equally across error type. It may be that they are more familiar with their friends' phonological style than are the other native speakers. This familiarity may aid the friends' understanding of their language learner partners' intended meaning. Thus, unlike the othercorrection pattern revealed in Table LXI, friends do not correct significantly more of the phonological error type. 


\section{TABLE LXIII}

FRIEND CORRECTION OF ERRORS

PER TOTAL C-UNITS

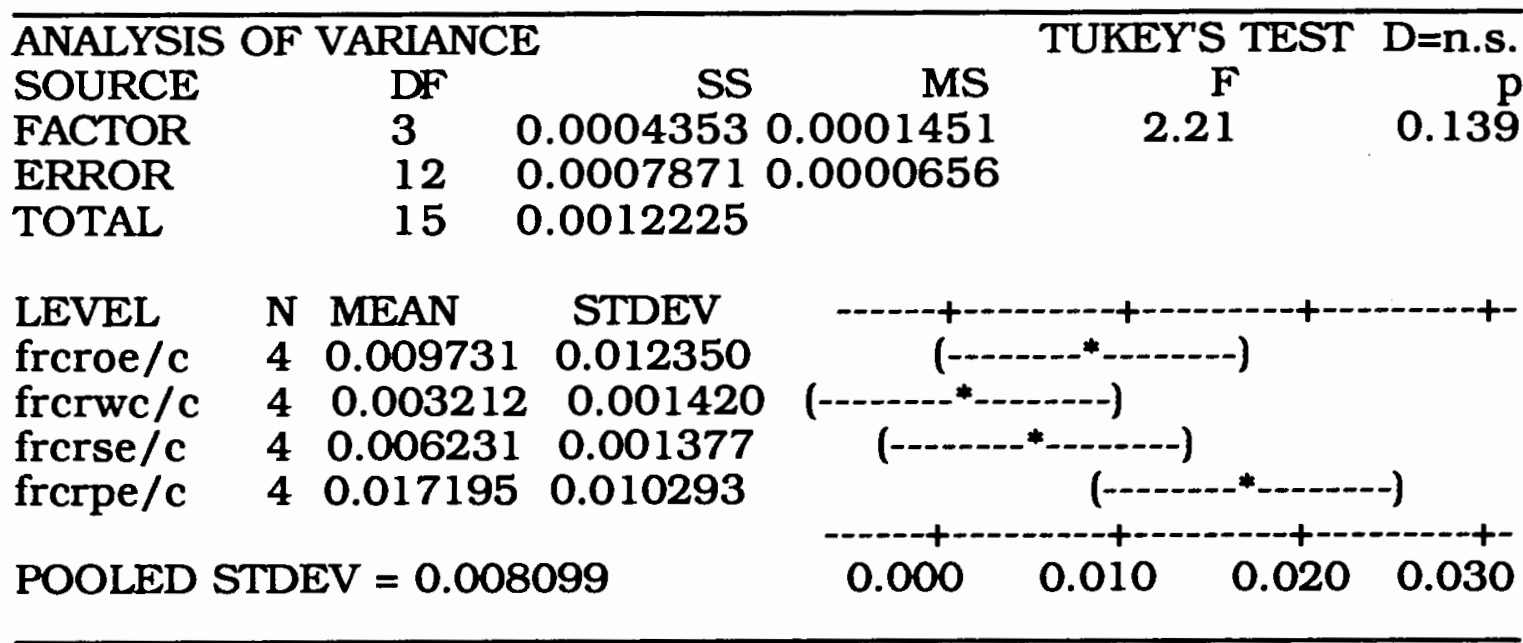

While the friends' familiarity may help explain the difference in error correction behavior when comparing the friends to the peerstrangers, it may not help explain the difference found between the friends and the language teachers. The teachers, after all, see the language learner subjects every day and are most likely very familiar with the subjects' phonological styles. The explanation for the teachers' significantly high use of phonological error correction may be related to the type of signal teachers use in negotiation of meaning interactions. Teachers were found to use modification confirmation checks more often than other types of confirmation checks (Table $\mathrm{XXV}$ ). It may be that their use of this type of confirmation check resulted in more phonological error corrections than corrections of other error types. 
Teachers may find correcting phonological errors to be important for the language learners' understanding of what is a correct pronunciation and what is not. The peer-strangers, on the other hand, may correct phonological errors more than other error types only because the phonological errors hinder their understanding of their partners' intended meaning.

The other-correction of syntactic errors is the only other error category where significant results across the dyads are found (Table LXIV). Peer-strangers and language learner partners correct fewer syntactic errors than do the language teachers and native speaker friends.

TABLE LXIV

OTHER-CORRECTION OF SYNTACTIC ERRORS PER TOTAL C-UNITS,

\section{ALL DYADS}

\begin{tabular}{|c|c|c|c|c|c|}
\hline \multicolumn{6}{|c|}{ ANALYSIS OF VARIANCE } \\
\hline \multicolumn{6}{|c|}{ SOURCE DF } \\
\hline \multirow{2}{*}{\multicolumn{2}{|c|}{$\begin{array}{l}\text { DYAD } \\
\text { ERROR }\end{array}$}} & 3 & 0.0000654 & 0.0000218 & 0.006 \\
\hline & & 11 & 0.0000330 & 0.0000030 & \\
\hline \multicolumn{2}{|l|}{ TOTAL } & 14 & 0.0000984 & & \\
\hline LEVEL & $\mathbf{N}$ & MEAN & STDEV & & 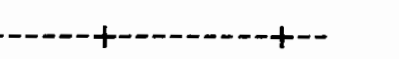 \\
\hline Teachers & 4 & 0.00542 & 40.001903 & & $\left(-\ldots{ }^{*} \ldots \ldots\right)$ \\
\hline Friends & 4 & 0.00623 & 10.001377 & & $\left(-\cdots--*^{*}-----\right)$ \\
\hline Strangers & 3 & 0.00136 & 10.002357 & $(---\cdots--------)$ & \\
\hline LLs & 4 & 0.00196 & 10.001332 & $(-\cdots-----)$ & \\
\hline \multicolumn{4}{|c|}{ POOLED STDEV $=0.001731$} & $0.0000 \quad 0.0025$ & $0.0050 \quad 0.0075$ \\
\hline
\end{tabular}


In the language learner dyads, the language learner subjects were found to self-correct more syntactic errors than they did in dyads with native speakers (Table LVIX). This may, in part, help explain why language learners corrected fewer of the language learner subjects' syntactic errors than did the teachers and friends. It probably is also explained by the fact that the native speaker teachers and friends had more linguistic expertise with which to repair their partners' syntactic errors than did the language learner dyad partners.

The reason for the peer-strangers' apparent low frequency of correction of their partners' syntactic errors may be connected to the probable existence of pragmatic and social restraints that limit the amount of corrections offered by strangers to non-native speakers (Chun et al., 1982). The peer-strangers may have felt less inclined than teachers and friends to intervene by correcting their language learner partners' syntactic errors.' Teachers and friends may have felt more comfortable correcting syntactic errors because of their special relationships with the language learner subjects. It may also be that the peer-strangers were less aware that syntactic errors had occurred than were the teachers and friends.

\section{Hypothesis Nine}

Hypothesis Nine predicted that there would be a negative correlation between the other-correction of the language learners' linguistic errors and amount of comprehensible output produced by 
the language learners. The data used to test this prediction included all the c-units identified in the study.

Hypothesis Nine was formulated in an attempt to find what effect error correction has on comprehensible output. Research into the role of negative feedback (error correction) on second language acquisition has found very little evidence that error correction leads to a more accurate performance on the part of the language learner (Long, 1977; 1983c). Comprehensible output, on the other hand, seems to be fostered by speaker signals that do not provide the language learner with a linguistic model to follow (Pica, 1988, Pica et al., 1989). It was therefore predicted that the more the dyad partners supplied the language learner subjects with error corrections, the less likely the language learner would be to produce comprehensible output.

Native speaker dyads were found to correct significantly more errors than language learner dyads were (Table LV). In the test for correlation, the language learner dyads and the native speaker dyads were treated separately. The correction of errors by language learner dyad partners is not found to have a significant correlation to the amount of comprehensible output produced by the language learner subjects in language learner dyads (Table LXV). 
TABLE LXV

CORRELATION OF COMPREHENSIBLE OUTPUT

PER C-UNIT AND OTHER-CORRECTIONS OF

LANGUAGE LEARNERS' ERRORS PER C-UNIT,

LANGUAGE LEARNER DYADS ONLY

The regression equation is: $3 \mathrm{~d} / \mathrm{cu}=0.0167+0.072 \mathrm{Cr} / \mathrm{cu}$.

$\begin{array}{lrrlr}\text { Predictor } & \text { Coef } & \text { Stdev } & \text { t-ratio } & \text { p } \\ \text { Constant } & 0.016742 & 0.004396 & 3.81 & 0.063 \\ \text { Cr/cu } & 0.0717 & 0.3911 & 0.18 & 0.871\end{array}$

s $=0.002343 \quad$ R-sq $=1 / 7 \% \quad$ R-sq (adj) $=0.0 \%$

ANALYSIS OF VARIANCE

SOURCE

Regression

Error

Total
DF

1

2

3
SS

0.000000184

0.000010978

0.000011162
MS

0.000000184

0.000005489
$\begin{array}{rr}F & P \\ 0.03 & 0.871\end{array}$ 
TABLE LXVI

CORRELATION OF COMPREHENSIBLE OUTPUT

PER C-UNIT AND OTHER-CORRECTIONS OF

LANGUAGE LEARNERS' ERRORS PER C-UNIT,

NATIVE SPEAKER DYADS ONLY

The regression equation is: $3 \mathrm{~d} / \mathrm{cu}=0.00860+0.454 \mathrm{Cr} / \mathrm{cu}$

Predictor

Constant

Coef

0.008602

Stdev
0.004746

t-ratio

$\mathrm{Cr} / \mathrm{cu}$

0.4539

0.1408

1.81

0.103

$s=0.006588 \quad R-s q=53.6 \% \quad$ R-sq(adj) $=48.4 \%$

$s=0.006588 \quad R-s q=53.6 \% \quad$ R-sq(adj) $=48.4 \%$

3.22

0.010

ANALYSIS OF VARIANCE

SOURCE

Regression

Error

Total

DF

1

9

SS

MS

0.00045126

0.00004340

$\begin{array}{rr}\mathrm{F} & \mathrm{p} \\ 10.40^{2} & 0.010^{-}\end{array}$

0.00039062

10

0.00084187

TABLE LXVII

CORRELATION OF NATIVE SPEAKER DYADS

Tedyad

$\mathrm{Cr} / \mathrm{cu}$

Tedyad

Frdyad

Stdyad

Frdyad

Stdyad

0.296

$-0.364$

0.443

$-0.302$

0.727

0.335

$-0.302$

0.354

$-0.452$

While there does exist this positive direction when comparing error correction to comprehensible output production, the actual value of the positive relationship is quite small (comprehensible output $=0.00860+0.454$ native speaker error correction). Yet, the positive direction does exist. Native speakers' correction of language learners' linguistic errors while engaged in information exchange task dyads 
had a positive effect on the language learners' production of comprehensible output. Since phonological errors were corrected significantly more often by the native speakers than any of the other error types, it would appear that other-correction of language learners' pronunciation does not inhibit the language learners' propensity to produce modified language forms. Furthermore, language learner dyad partners corrected significantly fewer errors than did native speakers and no significant correlation was found between this lower mean count of other-corrections by the language learner dyad partners and the language learner subjects' production of comprehensible output. While research has indicated that error correction does not lead to more accurate performances by language learners of the corrected form (Long, 1977), error correction by others may positively affect the language learners' use of modified, more comprehensible language forms. It was not possible to compare other-corrections made during information exchange tasks with other-corrections that occur during different types of conversational interactions. It may be that the nature of the information exchange task encouraged both the production of comprehensible output and the amount of error correction supplied by native speakers. If this is the case, then the significant positive correlation found in Table LXV may be the result of task and not due to other-corrections of error frequency.

The results presented in this Chapter will be summarized and reviewed in Chapter $\mathrm{V}$. 


\section{CHAPTER V}

\section{SUMMARY, DISCUSSION AND CONCLUSION}

\section{SUMMARY}

\section{Research Problem}

The purpose of this research was to investigate what effect, if any, the social roles between second language learners and their conversational partners have on the types and frequencies of the following discourse categories; (a) input interactional modifications, (b) negotiation of meaning interactions, (c) other corrections of language learners' linguistic errors and (d) comprehensible output production. The study was also designed to corroborate previous research findings with regards to negotiation of meaning interactions (Pica et al. 1989) and other-corrections of language learners' errors (Chun et al., 1982). Neither of these previous research efforts had been designed to directly test the effects of participant roles on language learners' conversational interactions. In addition to directly testing for these participant role variables, the design for this study also attempted to control variables related to task type and language learner proficiency. These aspects of research design were two of the problems associated with the previous research findings. Finally, it was hoped that the findings of this study would reveal whether any 
correlation existed between the amount of error correction of language learners' linguistic errors supplied by their conversational partners and the language learners' comprehensible output production.

\section{Methods}

Audio-taped discourse samples were obtained from fifteen conversational dyads tracking four language learner subjects engaged in information exchange tasks. The dyads varied according to the social roles of the language learner subjects and their dyad partners. The four dyad types were (a) language learner and language learner classmate, (b) language learner and English language teacher, (c) language learner and native speaker friend, and (d) language learner and native speaker peer-stranger. The settings of the experiments varied, though most of them took place in college classrooms.

Information exchange tasks were used in the dyad experiments. Information exchange tasks require dyad participants to exchange information in order to successfully complete the task. Previous research had suggested that information exchange tasks have a positive influence on the generation of interactional modifications (Doughty \& Pica, 1986; Pica \& Doughty, 1985a, 1985b). Further, information exchange tasks are communication tasks that require a two-way interaction between the conversational participants. Two-way 
tasks require both participants to engage in negotiation of meaning interactions in order to make input comprehensible (Long, 1983b).

The information tasks used in the dyad experiments of this research were designed to ensure that each dyad participant possessed information needed by the other dyad member in order to complete the task. Four different information exchange tasks were used, one for each type of relationship dyad. The tasks were designed to be of equal difficulty and duration (thirty minutes). In addition, an introductory lesson was designed for presentation in the language learners' regular Listening and Speaking class. The purpose of the introductory lesson was to introduce the language learners to the information exchange concept in order to reduce, or eliminate, the need of the language learner subjects to clarify the procedures of the information exchange tasks when performing the various dyad experiments.

Twenty minutes of each dyad experiment were transcribed for data collection purposes. Each transcript began with the language learner subjects' first turn to share the information that they held. Communication units (c-units) were used to organize the data within the transcriptions (Loban, 1963).

The data were coded using taxonomies originally devised for use in previous research studies. The negotiation of meaning model first devised by Varonis and Gass (1985), and later modified by Pica et al. (1989), was used to code data for negotiation of meaning analysis. The 
taxonomy used for categorizing language learners' linguistic errors, self-corrections and other-corrections was operationalized by Chun et al. (1982). Some additional categories were added to each of the two taxonomies for use in analyzing the data contained in this study.

Negotiation of meaning interactions have four components according to the model and taxonomy developed by Pica et al. (1989). The first is referred to as a trigger and occurs when the language learner conveys information that is not understood, either in part or in total, by the hearer. The hearer performs the second part of the model by "signalling" to the speaker that partial or total lack of understanding has occurred. The speakers' response to the signal is the third component of the model. Sometimes the speakers' response would elicit a new signal from the hearer, effectively embedding the negotiation of meaning interaction within the original trigger. The negotiation of meaning interaction is not concluded until the fourth component, a completion move, is added. In the Pica et al. model, completion moves were only performed by the hearer. However, the data from the dyad experiments of this research revealed that speakers also made negotiation completion moves. Two such moves by the speaker were added to the taxonomy used to code the negotiation of meaning interactions identified in the transcription data.

The Chun et al. (1982) error identification taxonomy contains five error categories: (1) omission errors, (2) word choice errors, (3) 
syntactic errors, (4) factual errors and (5) discourse errors. A sixth error category, phonological errors, was added to the taxonomy for use in coding the data used in this research. Chun et al. had excluded phonological errors from their taxonomy. Their stated reason for doing so was the difficulty they encountered distinguishing phonological errors from systematic pronunciation patterns that characterize some language learners' speech. Many pronunciation errors of this systematic nature occurred in the data from the dyad experiments and were included within the phonological error count identified within this report. False starts were also counted as phonological errors.

Nine hypotheses were included in the original research design. Eight of these hypotheses were statistically tested using a one-way analysis of variance test. When the analysis of variance test showed that significance differences existed between the means of the independent variables, and when the number of replicates among the samples were equal, Tukey's test was used to determine which of the independent variable means were significantly different from each other. The ninth hypothesis was tested for correlation using a simple regression statistical test.

\section{Results}

Only one of the nine hypotheses included in the original research design was supported by the data. There were, however, 
results related to each of the hypotheses that were found to be statistically verifiable. Each of the hypotheses and the findings related to it will be discussed in turn. Possible reasons for some of the results will be included in this summary section. Interpretation of results that relate directly to participants' roles will be presented in the Discussion section of this Chapter.

\section{Hypothesis One}

Hypothesis One predicted that signals of total or partial lack of understanding would occur most often in the language learner with language learner dyads. The dyads with the native speaker friends and peer-strangers were predicted to produce more signals of total or partial lack of understanding than would the dyads with teachers.

Finding \#1. The findings did not support Hypothesis One. No significant differences were found between the language learner dyads and those of the teachers and native speaker friends. Instead, it was discovered that the dyads with the language learner and peerstrangers had fewer negotiation of meaning interactions than did the other dyad groupings, including the language learner with teacher dyads.

Finding \#2. When the language learner with language learner dyad data was compared to the teacher and native speaker friend dyads, no significant differences were found among the mean signal count totals. 


\section{Hypothesis Two}

Hypothesis Two predicted that language learner with teacher dyads would display more completed negotiation of meaning interactions than would the other dyad types.

Finding \#3. Hypothesis Two was not supported by the results. Negotiation of meaning interactions, as described by Pica et al., could not be completed until the hearer had either provided an explicit signal of comprehension or signaled comprehension by making a topic continuation move. When the hearer-initiated completion moves mean counts were statistically tested, no significant differences were found to exist among the four dyad types.

The data collected for this study, however, revealed that hearerinitiated completion move categories were insufficient to account for all completed negotiation of meaning interactions. Some interactions were completed by the language learners. The language learners, before the hearers' next turn could occur, would continue the conversation. The resulting successful completions of negotiation of meaning interactions were termed speaker continuation-resolve moves. When the speaker continuation-resolve moves were added to the successful hearer-initiated completion moves, significant differences were found to occur in the frequency of occurrence among dyad types.

Finding \#4. Peer-stranger dyads, not teachers dyads, had more successfully completed negotiation of meaning interactions than any 
other dyad type. The peer-stranger dyads were also found to contain more instances of speaker continuation-resolve moves than the other two native speaker dyad types. There were no significant differences found among the remaining three dyad groupings.

Not all speaker-initiated completion moves resulted in success. Instead, some of these speaker continuation moves resulted in a new negotiation of meaning interaction. These interactions differed from embedded negotiations. In embedded negotiations, the language learners' response is insufficient to repair the original trigger trouble. In speaker continuation moves, it is the new information offered by the speaker, not the response to the signal, that triggers a new negotiation of meaning interaction. Unsuccessful negotiations of meaning, then, could occur either as a result of embedded triggers or speaker continuation moves that became new triggers.

Finding \#5. When unsuccessful negotiation of meaning interactions were compared among the native speaker dyads, the peerstranger dyads were found to have significantly fewer unsuccessful negotiation of meaning interactions than did the teachers and native speaker friends.

\section{Hypothesis Three}

Hypothesis Three predicted that the dyads containing language teachers would use more repetition confirmation signals than would the dyads with the other native speakers. 
Finding \#6. Hypothesis Three was not supported by the results. This hypothesis attempted to corroborate the findings of the Pica (1988) research. In that study, teachers were found to use repetition confirmation signals more often than any other signal type. However, there were no significant differences found among the native speaker dyads. Significant differences were also not found among all four dyad types when the language learner with language learner dyads' data were included in the statistical analysis.

Finding \#7. It was found, contrary to the Pica results, that teachers used modification confirmation signals significantly more often than they used repetition signals.

Finding \#8. The language learners' classmates used repetition signals significantly more often than the teachers did.

Finding \#9. In findings related to Hypothesis Three, it was found that clarification signals occurred significantly more often than the other four signal categories.

Finding \#10. Among the native speaker dyads, friends were found to use significantly fewer clarification request signals than the teachers and peer-strangers.

Finding \#11. In findings related to the three types of confirmation signals (repetition of trigger, modification of trigger, and elaboration-continuation of trigger), it was found that native speakers modified the language learners' trigger significantly more often than the language learners' classmates did. 
Finding \#12. The results also revealed that native speaker friends elaborated or continued their language learner friends' trigger utterances significantly more often than did the teachers and peerstrangers.

Finding \#13. Indirect indicators were not found to occur with significant difference across the four dyad types. However, results did indicate that all the dyad types used this type of signal significantly less often than clarification requests and repetition confirmation signals.

\section{Hypothesis Four}

Hypothesis Four predicted that language learners would be more likely to produce comprehensible output in response to clarification requests than in response to confirmation checks. Hypothesis Four was included in the research design in an attempt to verify the Pica et al (1989) research findings.

Finding \#14. Hypothesis Four was partially supported by the results although some of the related findings appear to question the reliability of the suggested correlation between clarification requests and comprehensible output production. These contradictions will be taken up in the discussion section of this Chapter.

Finding \#15. When the five signal categories were tested for comprehensible output responses, comprehensible output responses to clarification requests were found to occur significantly more often 
than all other signal categories. The remaining four signal types had no significant differences among them.

Finding \#16. When the three types of confirmation checks were grouped, there was no significant difference found between confirmation checks and clarification checks with regards to the frequency of comprehensible output responses. However, both clarification requests and combined confirmation checks elicited comprehensible output responses significantly more often than indirect indicators did.

\section{Hypothesis Five}

In Hypothesis Five, it was predicted that language learner with peer-stranger dyads would contain the most comprehensible output responses followed in order by language learner with language learner dyads, language learner with native speaker friend dyads and language learner with teacher dyads.

Finding \#17. Hypothesis Five was not supported by the results. There were no significant differences found among the four dyad types in language learners' production of comprehensible output.

Finding \# 18. There also did not appear to be any significant differences among the dyad types in the frequency of clarification requests becoming comprehensible output.

Findings related to Hypothesis Five did contain some significant results. In contrast to the Pica et al. (1989) study, significant 
differences were found between two comprehensible output subcategories.

Finding \#19. Syntactic modifications of trigger utterances were identified in significantly higher numbers than were semantic modifications. According to Swain (1985), it is these morphosyntactic modifications that are most important to the second language acquisition process.

Finding \# 20. There were no significant differences found among the dyad types when comparing the use of syntactic and semantic modifications to trigger utterances. Furthermore, only the native speaker friend dyads showed a significant difference between the two comprehensible output categories. These findings suggest that the data from the friend dyads may have skewed the results listed in Finding \#19. Instead, the findings indicate that the language learner subjects only produced significantly higher levels of syntactic modifications in the friend dyads.

Other findings related to Hypothesis Five concern the frequency of use of some of the other response categories.

Finding \#21. The language learner subjects were found to produce significantly more affirmation responses, repetitions of a trigger modification signal, and comprehensible output responses than the other remaining six response categories. There was no significant difference found among these three response categories. 
Affirmation responses are a communication strategy employed by language learners to show awareness of the hearers' signal of total or partial lack of understanding. In most cases, this response is used by the language learners to confirm the hearers' modification of the trigger through the use of one of the three types of confirmation checks. Signal repetition parallel most affirmation responses in that they respond to the hearers' modification of the language learners' trigger. Of these three most often employed response categories, only comprehensible output responses indicate that the language learners are still providing new information to the conversational interactions.

Finding \#22. Repetitions of the trigger responses and indirect responses were produced significantly more often than the other four remaining response categories. Neither of these response types represent particularly effective strategies in a negotiation of meaning interaction. Indirect responses occur when the language learner supplies new information to the hearer but the information is not directly related to the trigger utterance. In other words, the trigger is not directly repaired. The repetition of the trigger response may indicate that the language learner has no other linguistic resource to use to repair the trouble in the conversation.

Finding \#23. The repetition of the trigger response was found to occur significantly more often in language learner dyads than in native speaker dyads. It may be that trigger repetition between language learners refocuses the hearers' attention on the trigger 
utterance and helps the hearers' comprehension of the second language form. In other words, repeating the trigger to a language learner hearer may have been perceived by the second language learner subjects as an effective strategy that helped promote understanding.

Differences in response types that occurred among the dyad groupings will be taken up in the Discussion section of this Chapter.

\section{Hypothesis Six}

Hypothesis Six predicted that native speakers' correction of the language learners' linguistic errors would occur most frequently in the language learner with teacher dyads. The language learner with native speaker friend dyads were predicted to contain the second largest count of other-error corrections while the peer-stranger dyads were predicted to contain the fewest.

Finding \#24. Hypothesis Six was not supported by the data results. There were no significant differences found among the native speaker dyads with respect to error correction.

Finding \#25. In a related finding, it was discovered that native speakers corrected more errors than the language learner subjects' classmates did. These results seem logical and predictable since the native speaker would have more linguistic resources than would the language learner dyad partners. 
Finding \#26. The frequency of errors committed by the language learners was found to be quite high. The language learner subjects made a total of 3,676 linguistic errors while producing 3,982 c-units, approximately one linguistic error for every c-unit (0.923). Their dyad partners corrected a total of 197 of these linguistic errors (.0536). This figure is lower than was found in the Chun et al. study (1982). In that study, native speaker friends corrected $8.9 \%$ of the errors made by their language learner discussion partners. It may be that the use of information exchange tasks in the dyad experiments limited the amount of error correction supplied by the dyad partners.

Finding \#27. The language learner subjects were found to produce significantly more errors of omission and phonology than the other four error types. Word choice errors and syntactic errors were also found to occur significantly more often than factual and discourse errors. Factual and discourse errors rarely occurred (<.008).

The highly structured nature of the information exchange tasks may have discouraged the production of discourse errors. Factual errors may have also been limited partly due to the nature of the task, and partly because of the language learner subjects' intermediate proficiency level. Learners of lower proficiency may have produced more of both of these error types.

Finding \#28. There were no significant differences found among the four dyad types with respect to the types and frequencies of language learners linguistic error production. 


\section{Hypothesis Seven}

Hypothesis Seven predicted that native speakers would correct more language learners' linguistic errors of a factual or discourse nature than any of the other error types.

Finding \#29. Hypothesis Seven was not supported by the results. Native speakers' corrections of errors of a factual or discourse nature were never identified within the body of the data.

The findings of the Chun et al. (1982) study indicated that native speaker friends corrected significantly more errors of a factual or discourse nature than errors related to grammar (omission, syntax and word choice). It may be that open-ended discussions, like those conducted in the Chun et al. study are more conducive to factual and discourse error correction by native speakers. On the other hand, the structure of the information exchange tasks used in the dyad experiments for this research may have made identification of factual and discourse errors difficult for the dyad partners.

Finding \#30. In findings related to Hypothesis Seven, it was found that the language learner subjects self-corrected significantly more of the factual errors they produced than they did for any of the other error types with the exception of phonological errors. These results indicate that the language learner subjects may have selfcorrected many of the factual errors before their dyad partners were able to supply a factual error correction. 
Finding \#31. In other findings related to language learners' selfcorrection of errors, phonological errors were self-corrected per cunit significantly more often than any of the other error types.

Phonological and omission errors had both been identified as occurring in large numbers, yet omission errors were not selfcorrected significantly more often than any of the other error types. It may be that false starts and systematic pronunciation errors were more closely monitored by the language learner subjects than were errors of omission.

Finding \#32. In language learner dyads, the language learner subjects were found to self-correct more syntactic errors than they did in dyads with native speakers.

Although Hypothesis Seven was not supported by the analysis of the data results, some significant findings related to native speakers' correction of error types were found.

Finding \#33. Native speakers corrected significantly more phonological errors than did the language learner partners.

As with the other-correction of errors results, the results would seem to align with intuitive predictions; native speakers would be more capable and confident in correcting errors of phonology than other language learners would be.

Finding \#34. Native speakers were not found to correct significantly more errors in the area of grammar lomission, word choice and syntax) than the language learner partners. 
The language learners' classmates corrected grammatical errors in frequencies that were not significantly discernible from the native speaker dyad participants. It may be that error correction was limited to only those errors that impeded the conveyance of the language learner subjects' information. Errors of grammar may not have been perceived as being as critical to the understanding of intended meaning as errors of phonology were by the native speakers.

\section{Hypothesis Eight}

Hypothesis Eight predicted that the dyads containing native speaker friends would correct more factual or discourse errors than would the other dyad types. It was further predicted that teachers would correct the second highest total of these linguistic error types followed in order by the peer-strangers and language learner partners.

Finding \#35. Hypothesis Eight was not supported by the results. Other-corrections of factual and discourse errors were not identified within this study's data. However, some differences in othercorrections of language learners' linguistic errors were found.

Finding \#36. Findings for Hypothesis Seven had indicated that phonological errors were corrected by native speakers significantly more often than by the language learners' classmates. Among the native speaker dyads, however, native speaker friends were not found to correct phonological errors in significantly higher numbers. 
Finding \# 37. In other findings related to Hypothesis Eight, it was discovered that language learners' classmate and peer-stranger partners corrected significantly fewer error of syntax than did the teacher and native speaker friend dyad partners.

In language learner dyads, the language learner subjects were found to self-correct more syntactic errors than they did in dyads with native speakers. This may, in part, help explain why language leaner classmates corrected fewer syntactic errors than teachers and native speaker friends did.

\section{Hypothesis Nine}

Hypothesis Nine predicted that there would be a negative correlation between the other-correction of the language learners' linguistic errors and the amount of comprehensible output produced by the language learners.

Finding \#38. Hypothesis Nine was not supported by the findings. A positive, not negative, correlation was found to exist between native speakers' correction of their language learner partners' linguistic errors and the amount of comprehensible output produced.

Finding \#39. The language learner with language learner dyads' data were analyzed separately and no significant correlation was found to exist between the classmates" correction of the language learner subjects linguistic errors and the amount of comprehensible output produced. 


\section{DISCUSSION}

Though eight of the nine hypotheses were not supported by the research results, significant differences were found among the dyad types with regards to several aspects of conversational behavior. In this discussion section, each dyad type will be examined. The findings will be synthesized in an attempt to present a profile for each dyad grouping. The discussion of findings will conclude with an examination of the results related to frequency of use of signal types and subsequent comprehensible output production.

\section{Teacher Dyads}

Previous research (Pica, 1988) suggested that teachers would use repetition confirmation signals more often than clarification requests, however, the data from the dyad experiments indicated otherwise. Not only was the teachers' use of repetition signals found to be less than their use of clarification requests, teachers were found to use clarification requests significantly more often than any other signal type. Moreover, the language learners' classmate partners used repetition more often than the teachers did.

Teachers' use of the repetition confirmation signal was not as prevalent as their use of modification confirmation signals. Modifying the trigger would be the signal type most like a "correction" of the language learners' linguistic errors. The unbalanced nature of the student-teacher relationship may have carried over into the teachers' 
behavior with regard to a preference for the modification of the trigger confirmation check.

The teachers' use of the modification signal may have been partially responsible for their significantly higher use of phonological error correction. It may be that the teachers' use of this type of confirmation check resulted in more phonological error corrections than corrections of other error types including grammatical errors. Though modifications of syntax, word choice and omission errors were possible, it appears that the teachers most often chose to modify the language learners' pronunciation errors.

It may be that teachers chose to correct significantly more phonological errors because they considered pronunciation errors to be important for the language learners' overall proficiency level. In other words, the teachers did not relinquish their role as conveyor of linguistic knowledge even when engaged in the information exchange task format.

The language learner with teacher dyads did not prove to be as adept at negotiation of meaning interactions as had been expected. Teacher and language learner dyads did not have as many successfully completed negotiations as did the peer-stranger dyads. They also had more triggers indicating partial or total lack of understanding occur than were identified within the peer-stranger dyads.

The teachers' use of the modifying confirmation signal may partially explain these results. Signals that modified the trigger may 
not have resulted in responses from the language learner that would be most effective in preventing the occurrence of additional triggers. The peer-strangers appeared to allow the language learners to complete the negotiation of meaning interaction more often than the teachers did. With the teachers, however, the data results indicated that the language learners used more repetition of the signal responses. The modified confirmation signal type would especially seem to encourage a repetition of the signal from the language learner. No new information would be added to the conversational interaction with the repetition of the signal response and, consequently. successful completion of the negotiation of meaning interaction might be forestalled.

The language learners were found to use the affirmation response less often in the teacher dyads than they did with the other dyad types. Affirmation responses, like the repetition of the signal, are passive in that the language learner does not offer any new information to help repair the trigger that has occurred. It may have been that in interactions with their teachers, the language learner subjects felt compelled to be active, not passive, in their response activity. Their use of repetition of the signal modification response with the teacher may have been less of a passive response with regards to the trigger utterance and more of an acknowledgement of the teachers' position as conveyor of linguistic knowledge. 


\section{Friend Dyads}

The data from the native speaker friend dyads indicated that they were more similar to the teacher dyads than they were to either the peer-stranger or the language learner with language learner dyads. Like the teachers, the friends used repetition confirmation signals less often than the language learners' classmates did. The language learner subjects also used the repetition of the signal response more often with the native speaker friends than with the peer-strangers or language learner classmates.

Unlike the teachers, however, the use of the repetition of the signal response by the language learner was not due to a high use of the modification of the trigger utterance on the part of the native speaker friends. Instead, the friends used elaboration-continuation confirmation checks more often than the other two confirmation check categories. However, like the modification confirmation check, an elaboration or continuation of the trigger utterance most likely encouraged either a repetition of the signal or affirmation response from the language learner. The results indicate that the language learners used both of these response types more often with native speaker friends than any other type, with the exception of comprehensible output responses.

The friends appeared to correct their partners' linguistic errors equally across error type. Teachers and peer-strangers, on the other hand, corrected significantly more phonological errors than errors of 
any other type. It may be that the native speaker friends' familiarity with their language learner friends' phonological style aided the native speaker friends in their understanding of the language learners' intended meaning. Thus, the friends perhaps did not need to correct phonological errors to any greater degree than errors of grammar.

In the Chun et al. study (1982), native speaker friends were found to correct $8.9 \%$ of the linguistic errors made by their language learner friends. The dyads in the Chun et al. study were performing conversations in social settings on topics of the dyad members' choosing. In this experiment, the native speaker friends corrected $7.4 \%$ of the linguistic errors made by the language learner subjects while performing information exchange tasks. While the native speaker friend subjects in both studies appear to have corrected errors in the same relative frequencies, it should be kept in mind that in the Chun et al. study phonological error corrections were not included in the data. When the native speaker friends' corrections of phonological errors are excluded from the data of this study, the correction frequency drops to $3.9 \%$. It appears, then, that native speaker friends may correct fewer of their language learner friends' linguistic errors when engaged in information exchange tasks than they do in conversations that take place in a social setting.

The findings in this study revealed that the native speaker friend dyads were significantly different from the teacher and peer-stranger dyads with respect to three other areas of the negotiation of meaning 
model; (a) the use of clarification signals, (b) the signal type that became a comprehensible output response most often, and (c) the subcategory of comprehensible output that was produced in the highest frequency by the language learner partner. The native speaker friends used significantly fewer clarification requests than did the teachers and peer-strangers. While the teachers and peer-stranger data both revealed a significantly higher frequency of comprehensible output in response to clarification requests, there were no significant differences found in the native speaker friends' data in the signal type use and comprehensible output production. Finally, unlike in the teacher and peer-stranger dyads, the language learner subjects in the native speaker friend dyads produced significantly more syntactically modified comprehensible output responses than they did semantically modified comprehensible output responses.

According to Swain (1985), it is the syntactic modifications that are most important in the second language acquisition process. Swain theorized that syntactic modifications were realized as changes in language learners' interlanguage structure. Pica (1988) and Pica et al. (1989) had speculated that clarification request signals would encourage more syntactically modified response than would any other signal types. The data from the study, however, suggest that syntactic modifications may not always occur as a result of a high frequency of use of clarification signals. Instead, it may be that the type of relationship language learners have with their dyad partners has an 
effect on the amount of syntactical modifications produced. The results from this study suggest that language learners in information exchange task interactions with native speaker friends produce more syntactically modified comprehensible output than they do in other relationship types.

\section{Peer-Stranger Dyads}

Peer-stranger dyads had significantly fewer negotiation of meaning interactions than did the other dyad groupings. It was suggested in the findings that the information exchange task used in the peer-stranger dyad experiment may have been easier to perform. The relative performance difficulty of the task may have had an effect on the number of negotiation of meaning interactions identified within a dyad grouping; the easier the task, the less the need to negotiate meaning.

However, the peer-stranger dyads also appeared to have more successfully completed negotiation of meaning interáctions than did the other native speaker dyads. Furthermore, while there were no significant differences among the native speaker dyads with respect to hearer-initiated completion moves, successful language learnerinitiated continuation moves were found to occur significantly more often in the peer-stranger dyads than in the other two native speaker dyad groupings. The peer-strangers appeared to allow the language learners to take more control of the negotiation of meaning process 
than did the teachers or native speaker friends. Thus, the reason for the fewer negotiation of meaning interactions between the peerstrangers and language learners may have had more to do with a high tolerance level for the language learners' incomprehensible output on the part of the peer-strangers than it had to do with task equivalency. One reason for this tolerance may have been a desire on the part of the peer-strangers to promote a friendly, non-threatening atmosphere.

Peer-strangers also corrected significantly fewer of their partners' syntactic errors than did the teachers and native speaker friends. As with the trigger utterances, the peer-strangers seemed to have exhibited a higher level of tolerance for the language learners' linguistic errors than did the other native speakers. Chun et al. (1982) speculated that there are pragmatic and social restraints that limit the amount of corrections of linguistic errors offered by strangers to nonnative speakers. The probable existence of these restraints may account for the peer-strangers' seemingly higher tolerance level towards their partners' syntactic errors and their trigger utterances. The special relationships of the teachers and native speaker friends with their language learner partners may have allowed the teachers and native speaker friends to feel more comfortable intervening in their conversational interactions through the correction of syntactic errors and signalling of trigger utterances than the peer-strangers did. The peer-strangers behaved analogously to the teachers with respect to the correction of their language learner partners' 
phonological errors. Both the peer-strangers and the teachers corrected significantly more phonological errors than they did errors of any other type. The reasons for the significantly high amount of phonological error correction by teachers and peer-strangers are possibly not related. The peer-strangers, unlike the teachers, were not familiar with the phonological style of the language learner dyad partners. Further, a peer-stranger's relationship with a language learner is not necessarily an unbalanced one. The peer-strangers' low correction count of syntactic errors indicates that they were tolerant of their language learner partners' linguistic errors. However, the information exchange task format of the dyad experiment required that the peer-strangers understand the information given to them by their language learner partners. Therefore, the peer-strangers may have corrected phonological errors more than other error types because the phonological errors hindered their understanding of their partners' intended meaning more than grammatical errors did.

The use of confirmation check signals also revealed that the peer-strangers were less likely than the teachers and native speaker friends to intervene in the conversational interaction with the language learner subjects. The teachers and native speaker friends were both found to use confirmation checks that "corrected" the trigger utterance more often than they used simple repetition of the trigger confirmation checks. The teachers used more modification of trigger confirmation checks while the native speaker friends used 
more elaboration or continuation of the trigger confirmation checks. Peer-strangers used all three types of confirmation checks equally. In fact, unlike the native speaker friends and teachers, the peerstrangers did not use the repetition signal significantly less often than the language learners' classmates did in the language learner with language learner dyads. The repetition of the trigger confirmation check is less intrusive than the other two types of confirmation checks because no repair of the trigger utterance is attempted. As also indicated by their low frequencies of syntactic error corrections and negotiation of meaning interactions, the peer-strangers' choice of signal type appeared to show more tolerance of their language learner partners' linguistic difficulties.

\section{Language Learner Dyads}

In negotiation of meaning interactions, there were no significant differences found between the language learner dyads and those of the native speakers in the amount of comprehensible output responses produced. In other words, having a native speaker dyad partner did not seem to be particularly advantageous for the language learners with regards to comprehensible output productions.

It may be that the difference in signal types used by teachers and native speaker friends compared to those employed by the language learner classmates partially explains the results with regards to comprehensible output production. The higher use of modification 
confirmation checks by teachers and elaboration-continuation confirmation checks by native speaker friends would, according to Pica (1988), result in less comprehensible output responses by the language learner subjects. These types of confirmation checks present the language learners with linguistic models. Language learners can repair the trigger by simply acknowledging the model contained within the confirmation signal. There is no need to supply additional information to the hearer. In other words, the language learners are not "pushed" to modify their output. The probability of comprehensible output responses to the teachers and native speaker friends, then, may have been weakened because of their use of these types of confirmation check signals.

The reason for equal levels of comprehensible output responses between the peer-stranger dyads and language learner dyads may be partially due to the probable pragmatic and social restraints that exist between strangers and non-native speakers. The peer-strangers' high tolerance level of their language learner partners' linguistic difficulties apparently resulted in fewer negotiation of meaning interactions than the teachers and native speaker friends had. The need to "push" towards comprehensible output, as described by Swain, may have been weakened in the peer-stranger dyads by this high tolerance level.

From these arguments, it is not clear why the language learner dyads did not show a higher frequency of comprehensible output responses than was evident in the native speaker dyads. The answer 
may be found in the language learners' significantly higher use of a repetition of the trigger response to their classmates than they used with their native speaker partners. Repeating the trigger utterance without modification would not appear to be an effective strategy with native speakers. The language learners most likely assumed that their trigger utterances were flawed when native speakers signaled that a trigger had occurred. With other language learners, however, the language learner subjects may have assumed that the problem was associated with their classmates' comprehension of the English language itself. Repeating the trigger may have been an effective strategy that helped promote understanding. This strategy, if effective, would tend to lessen the need for the language learners to modify the trigger. It may be that the higher use of the trigger repetition response explains, in part, why the language learner dyads did not produce a higher amount of comprehensible output responses than was produced in the native speaker dyads.

The language learner classmates corrected significantly fewer of their dyad partners' linguistic errors than did the native speakers. However, phonological errors were the only error type corrected significantly more often by all of the native speakers. In errors of omission and word choice, the language learner subjects' classmates corrected errors in the same frequencies as did the native speakers.

Teachers and native speaker friends corrected more syntactic errors than the language learner classmates did. However, the 
language learner subjects were also found to have self-corrected significantly more syntactic errors in the dyads with their classmates than they did when interacting with teachers or native speaker friends. The language learners appeared to have paid more attention to their syntactic structure when interacting with their classmates. Though self-corrections are not considered comprehensible output modifications within the negotiation of meaning model, it might be argued that self-corrections do represent modified forms.

Swain (1985) has argued that syntactic modifications of trigger utterances may be realized as changes in the language learners' interlanguage. Syntactic self-corrections may function in the same manner. If this is true, then the findings of no significant differences between language learner dyads and those of native speakers with regards to comprehensible output production may be misleading. Language learners' significantly high frequency of syntactic selfcorrections in the language learner dyads may contribute to their interlanguage development in much the same way that comprehensible output responses are presumed to do.

\section{Signal Frequency}

The findings related to Hypothesis Four are contradictory regarding the correlation of the clarification requests and resulting comprehensible output responses. Some of the findings suggest that the frequency a signal type occurs may be more important to 
comprehensible output production than the intrinsic qualities of the signal itself.

Clarification requests were found to have occurred significantly more often than any of the other four signal categories. The same is true for the number of instances of clarification requests becoming comprehensible output responses. On the other hand, indirect indicators were used as signals significantly less often than clarification requests and the combined confirmation check category. The frequency of comprehensible output responses to indirect indicator signals also was significantly lower than the comprehensible output responses that occurred after clarification requests and the combined confirmation check category. These findings suggest that comprehensible output may occur independently of signal type. The more frequently a signal type occurs, the more chance it has of eliciting a comprehensible output response.

Other findings support the idea that the frequency of use of a particular signal type positively correlates with the frequency of comprehensible output responses to that signal type. Clarification requests were found to occur significantly more often than elaborationcontinuation confirmation checks. The frequency of comprehensible output responses to those two types of signals was also found to be significantly higher for clarification requests when the response totals were measured by the total count of the signal type that was being tested. In other words, comprehensible output responses occurred 
significantly more often per total clarification request signal count than they did per total elaboration-continuation signal count.

Finally, all the dyad types were found to use clarification requests significantly more often than any other signal category with the exception of the native speaker friend dyads. The finding of comprehensible output responses per total clarification request signal count mirrored the frequency of use of clarification requests. In all dyads, with the exception of friends, the percentage of clarification requests that became comprehensible output responses was significantly higher than the percentage of any of the other four signal types.

These findings suggest that the frequency with which a signal type is used positively corresponds to the amount of comprehensible output responses that the language learner produces. However, other findings support Pica's speculation that it is the intrinsic nature of a clarification request that encourages a comprehensible output response (1988).

Clarification requests were found to occur significantly more often than repetition confirmation checks, yet no significant difference was found between the frequency of comprehensible output that was produced when measured against the total signal type count. The same results were found when comparing the amount of comprehensible output produced per total indirect indicator signals and those of clarification requests and repetition confirmation signals. 
Both of these latter two signal types occurred more frequently than did the indirect indicators but neither produced significantly more comprehensible output per total signal type count.

These findings suggest that it is not the frequency of occurrence of clarification requests and other signals that corresponds to the frequency of comprehensible output produced but rather something to do with the intrinsic qualities of the signals that are produced. Indirect indicators, repetition confirmation checks, and clarification requests may be similar in the way they are perceived by the speaker. An optimum response to these signal types would seem to require language learners to give their conversational partners modified information. It may be that responses that give modified information to the hearers are more comprehensible than the original trigger utterances were. Thus, signals such as clarification requests, indirect indicators, and, though possibly to a lesser extent, repetition confirmation checks may oblige language learners to provide more information. In turn, the process of providing more information may "push" language learners to modify their output towards more targetlike forms.

\section{CONCLUSION}

\section{Methodological Limitations}

Task Equivalency. As has been noted throughout this report, there exist some questions about the equivalent difficulty of the 
information exchange tasks used in the different dyad groups. In particular, it may be that the tasks used in the peer-stranger and language learner dyads were easier to perform than those used in the teacher and native speaker friend dyads. The tasks performed in the language learner dyads and peer-stranger dyads were more repetitive in nature. Successful strategies employed by the language learner subjects in the first few exchanges of information may have been effectively repeated. For example, the shapes and colors in the exchange of information in the peer-stranger task varied in size and location but not much in geometric shape (squares, rectangles, triangles and circles). Thus, the language learner could use the geometric shape information repeatedly as a strategy for conveying information about size, location and color (see Appendix C). The repetitive nature of the information exchange may have had the effect of limiting the amount of trigger utterances produced by the language learner subjects. This may help explain the low frequency of trigger signalling by the peer-strangers and the unexpected lack of significantly higher frequencies of comprehensible output responses in the language learner dyads.

In the teacher dyad task, and, to a lesser degree, in the native speaker friend dyad task, each new piece of information that was to be shared was relatively unique. The participants may have found it more difficult to develop effective information sharing strategies in this task. More triggers may have been produced in the language learners' 
attempts to find a common ground of shared knowledge from which to begin their explanations. In many ways, the native speaker friend dyad task was similar to the teacher dyad task. However, the native speaker friends and language learners were provided with a poster to work from, and some of the information to be shared was of the same general type for each of them (i.e., letters from the alphabet).

Some of the data related to the types of signals and responses used by the different dyad types suggest that task equivalency might have had an effect on the data that was gathered. Affirmation responses were given to teachers significantly less often than to the other dyad partners. The affirmation response is somewhat passive in that the language learners do not offer new information to help repair the trigger. It may be that the relative difficulty of the teacher dyad task encouraged the language learners to "work" harder in order to accomplish the task.

Language learners in dyads with their classmates and with the peer-strangers showed an inability to respond to the signal significantly less often than in the dyads with the teachers and native speaker friends. It may be that the tasks were easier to perform with their classmates and peer-strangers, thereby limiting the response difficulty experienced by the language learner subjects.

The language learner subjects also self-corrected more of their syntactic errors in the language learner dyads and more of their omission errors in the peer-stranger dyads than they did in the 
other dyad groupings. It may be that less difficult tasks allowed the language learners to "monitor" their output more carefully in these dyad types. However, they appeared to pay attention to a different type of linguistic error in each of the two dyad types (language learner and peer-stranger). Relative task ease may have had less of an effect than did the dyad participants' social role on the self-corrections in question.

Arguments also exist to defend the relatively equivalent nature of the four different dyad tasks. Only one of the dyad experiments finished the task before the thirty minute time limit had expired. The fact that it was neither a language learner dyad nor a peer-stranger dyad casts some doubt on the arguments against task difficulty equivalency. The subjects also did not rate the tasks as disparate in equivalency on questionnaires administered upon the tasks' completion. Further, the pilot study subjects also found the four tasks to be equal in difficulty.

Use of Gestures. Another factor that may limit the credibility of the data, is the likelihood that the language learner subjects used nonlinguistic communication strategies. Though the participants were asked to avoid their use, non-linguistic communication was not controlled for in the research design. Some negotiation of interactions may have been avoided through the use of gestures.

Relative Proficiency of Language Learners. The relative proficiency of the language learner subjects is another area of concern. 
Although the subjects had all been placed in the same level of the American Language Academy program, their proficiency in English was apparently not equal. One of the language learner subjects was found to make significantly fewer errors of syntax and word choice than the other language learner subjects. However, there were no significant differences among the subjects with regards to selfcorrections and other-corrections of their linguistic errors. There were also no significant differences found among the language learner subjects in the data related to negotiation of meaning interactions.

Unbalanced Design. The design was unbalanced. One of the language learner subjects did not attend class the day the peerstranger dyad experiments were performed. The unequal replicates in the data limited the statistical analysis that could be used. For example, Tukey's test could not be used to test significant differences between the dyad types. However, reorganization of the data for repeated uses of the ANOVA test effectively circumvented the difficulty presented by the unbalanced design.

Other Areas of Limitations. The selection of the subjects was not truly random and the findings found within this report cannot be generalized to the population at large.

The subjects were aware that their dyad interactions were being audio-recorded. Though the subjects appeared to be relaxed and uninhibited, the effect that the tape recording had on their behavior is not known. 


\section{$\underline{\text { Implications }}$}

Second Language Acquisition. Swain (1985) theorized that one important function of language learners' output in negotiation of meaning interactions is that learners are "pushed" to produce a message that is conveyed in a modified, more target-like form. Learners are provided with an opportunity for getting their message across by "stretching"" their existing linguistic resources. Being "pushed" to produce this modified output, the comprehensible output response, has been likened by Swain to Krashen's i+1 theory of comprehensible input. Language learners are able to use comprehensible output to test out hypotheses about the target language both semantically and syntactically. Syntactic modifications, according to Swain, can assist inductive realization of grammatical form within the language learners' interlanguage structure.

The results of the dyad experiments suggest that language learners produce significantly high amounts of comprehensible output while performing information exchange tasks with other dyad participants. These results would seem to provide further support for Swain's arguments that the second language acquisition process is fostered by interactive and dynamic exchanges of information between conversational participants. However, while the social role of the language learners' dyad partner may have accounted for some of the differences that occurred within the dyad experiment data, participant roles apparently have no effect on the amount of 
comprehensible output produced by the language learners engaged in the information sharing communicative activities.

Comprehensible output and language learners' self-correction of linguistic errors may act on the language learners' interlanguage in the much the same manner. When learners were "pushed" to provide modified information to their dyad partners, their output was modified in negotiation of meaning interactions through the use of the comprehensible output response. The language learners likewise modified their output through effective use of self-corrections of their self-recognized linguistic errors. It may be that both of these types of output modifications help alter the language learners' interlanguage towards a more target-like structure.

Other-corrections of the language learners' linguistic errors may be a natural and positive aspect of communication interactions. There did not appear to be any negative correlation between the frequency of other-corrections and the language learners' production of comprehensible output during negotiation of meaning interactions. On the contrary, the data indicated a significant positive correlation existed between these two variables. It may be that other-corrections of language learners' linguistic errors when engaged in dynamic conversational interactions have the effect of "pushing" the language learners to attend more closely to their own production of language structures. Swain has argued that language learners focus on form, not meaning, when they are "pushed" to get their message across. 
Other-correction of language learners' linguistic errors may help in this regard.

The social roles of the language learners and their dyad partners do make a difference. The data concerning the production of syntactically modified comprehensible output responses indicate that friendship has a positive effect on the second language acquisition process. It may be that communication interactions with friends provide the language learners with a high level of motivation for producing language that is target-like in structure. Communication interactions with friends may have the effect of "pushing" and motivating the language learners to stretch their available linguistic resources in order to best convey the information they have to share. Intuitively, it follows that the language learners' motivation to produce effective communication would be highest with conversation partners whom the language learners perceive as having a personal, nonprofessional, stake in their well-being.

Comprehensible output and self-correction of linguistic errors apparently are necessary, but not sufficient, aspects of the second language acquisition process. However, response and signal types that do not reflect comprehensible output also have an important role in second language acquisition. Linguistic modelling by native speakers, as in confirmation check signals, help provide language learners with comprehensible input. According to Krashen's theory of comprehensible input, language learners need to be provided with 
information about the second language while interacting in meaningful communication (1983). Modifications and elaborations of the language learners' trigger utterances perform this important function. The language learners' affirmation and repetition of the signal responses, both of which occurred as frequently as comprehensible output responses in the dyad experiments, indicate to their native speaker partners that the language learners have understood the linguistic information that has been offered to them. Though these two response types may be passive and accepting, they serve a very active purpose within the language learners' interlanguage development. Had this report been focusing on comprehensible input instead of comprehensible output, these two response types would have enjoyed a more positive focus. Both comprehensible input and comprehensible output would appear to be necessary, though not sufficient, aspects of the second language acquisition process.

In the Language Classroom. The data results suggest that information exchange tasks promote negotiation of meaning interactions between the task participants. Teachers, native speaker friends, peer-strangers and other language learners all worked effectively and enthusiastically with the language learner subjects while performing the information exchange tasks used for the dyad experiments. Comprehensible output and language learner selfcorrections were produced in high numbers. Though information exchange tasks should not be promoted to the detriment of other 
effective language teaching techniques, their use should be encouraged within the language teaching process.

There did not appear to be any negative aspects of the language learner with language learner dyad interactions. The language learner dyads were shown to work effectively together. The language learner subjects in the dyad experiment with their classmates produced as much comprehensible output as they did in the native speaker dyads. Moreover, their self-corrections of syntactic errors occurred more frequently in interactions with their classmates than in the native speaker interactions. Continued use of pair work in the classroom should be encouraged as an effective way of promoting dynamic conversational interaction.

Language usage within the English speaking community is diverse. Accordingly, the exposure of language learners to language usage should be just as diverse. The interactions with friends, peerstrangers and teachers as dyad partners did not show any adverse effects on the language learners' production of comprehensible output. Each type of dyad had positive aspects that seemed to promote the language learner subjects' understanding and use of the English language. Attempts should be made within the classroom curriculum to include native speakers from outside the classroom environment in interactions with the language learners. Exposure to a wide variety of native speakers in communication interactions that require an exchange of information may provide language learners with the best 
opportunity to develop interlanguage structures that closely correspond to the target language.

\section{Future Research}

Additional research should be conducted using dyad groupings containing subjects whose social roles vary in relation to the language learner. The data from the dyad experiments contained in this report suggest that communication interactions between friends may enhance the second language acquisition process. More research is necessary to determine whether these results can be generalized to the population at large.

Previous research, as well as the results contained in this report, can be used as a foundation in the design of new research to examine the effect that task type and participant roles have on comprehensible output production, other-corrections of language learners linguistic errors and language learners' self-corrections. The research of Pica et al. (1989) indicated that task type did not have a significant effect on comprehensible output production. However, their research did not control for participant roles. The Chun et al. (1982) study suggested that native speaker friends correct more discourse and factual errors in social open-ended conversational settings than any other types of errors. However, the results of this study showed that none of these types of language learners' linguistic errors were ever corrected. Neither of these previous studies provided information about language 
learners' self-corrections of their linguistic errors. Future research may be able to test for the effect that task type and participant roles have on these various conversational interaction phenomena in order to provide answers for some of the inconsistencies that were found between the results contained in this report with those of the Pica et al. and Chun et al. studies.

Additional research is also needed to examine the correlation between the frequency of other-corrections of language learners' linguistic errors and comprehensible output production. A positive correlation was found to exist in the data of this research. These findings cannot be generalized to the population at large due to the limited population from which the data were drawn. The results from future independent studies are needed in order to verify whether the positive correlation that was found is universal.

In this study, only the negotiation of meaning interactions that occurred when the language learner subjects held the information to be shared were included in the data. However, negotiation of meaning interactions also occurred during the native speakers' information sharing turn. Analyses of the types and frequencies of signals and hearer-initiated completion moves used by language learners may provide additional information about the way language learners interact with native speakers. The strategies and intervention techniques used by language learners to repair native speaker trigger utterances may prove to be quite different from those used by the 
native speakers. The similarities or differences that may be found might provide valuable insights into the second language acquisition process. 


\section{REFERENCES}

Allwright, R. 1975. Problems in the study of the language teacher's treatment of learner error. In M. Burt \& H. Dulay (Eds.). On TESOL 1975. Washington D.C.: TESOL.

Borg, W. \& Gall, M. (1979). Educational Research. New York: Longman.

Brock, C. (1986). The effects of referential questions on ESL classroom discourse. TESOL Quarterly, 20(1), 47-59.

Bruton A. \& Samuda, V. (1980). Learner and teacher roles in the treatment of oral error in group work. RELC Journal, 11(2), 49-63.

Chaudron, C. (1977). A descriptive model of discourse in the corrective treatment of learners' errors. Language Learning, 27(1), 29-46.

Chun, A., Day, R., Chenoweth, N.A. \& Luppescu, S. (1982). Errors, interaction, and correction: A study of native-nonnative conversations. TESOL Quarterly, 16(4), 537-547.

Corder, S.P. (1967). The significance of learner's errors. In J. Richards (Ed.). (1974). Error Analysis (pp. 19-27). London: Longman.

Doughty, C., \& Pica, T. (1986). Information gap tasks: An aid to second language acquisition. TESOL Quarterly 20, 305-325.

Ehrlich, S., Avery, P. \& Yorio, C. (1989). Discourse structure and the negotiation of comprehensible input. Studies in Second Language Acquisition, 11, 397-414.

Ellis, R. (1985). Teacher-pupil interaction in second language development. In S. Gass \& C. Madden. Input in second language acquisition (pp. 69-85). New York: Newbury House Publishers.

Fanselow, J. (1977). The treatment of error in oral work. Foreign Language Annals, 10, 583-593.

Ferguson, C. (1975). Towards a characterization of English foreigner talk. Anthropological Linguistics, 17, 1-14. 
Gaies, S. (1980). Learner Feedback: A taxonomy of intake control. In J. Fisher, M. Clarke \& J. Schachter (Eds.), On TESOL '80 (pp. 88-100). San Francisco: TESOL.

Gass, S. \& Varonis, E. (1985a). Variation in native speaker speech modification to non-native speakers. Studies in Second Language Acquisition. Z(1), 37-57

Gass, S. \& Varonis, E. (1985b). Task variation and nonnative/nonnative negotiation of meaning. In S. Gass \& C. Madden. Input in second language acquisition (pp. 149-161). New York: Newbury House Publishers.

Hatch, E., Shapira, R. \& Gough, J. (1978). Foreigner-talk discourse. ITL Review of Applied Linguistics, 39-60.

Handford, M. (1989). The great waldo search. Boston: Little, Brown and Company.

Hawkins, B. (1985). Is an "appropriate response" always so appropriate? In S. Gass \& C. Madden. Input in second language acquisition (pp. 162-177). New York: Newbury House.

Hirvonen, T. (1985). Children's foreigner talk: Peer talk in play context. In S. Gass \& C. Madden. Input in second language acquisition (pp. 137-148). New York: Newbury House Publishers.

Krashen, S. (1983). Applications of psycholinguistic research. In M. Long \& J. Richards (Eds.), Methodology in TESOL (pp. 33-44). New York: Newbury House.

Loban, W. (1963). The language of elementary school children (Research Rep. No. 1). Champaign, Il: National Council of Teachers of English.

Long, $M, 1977$. Teacher feedback on learner error: Mapping cognitions. In H. Brown, C. Yorio, \& R. Crymes (Eds.). On TESOL 77. Washington D.C.: TESOL.

Long, M. (1981). Input, interaction and second-language acquisition. In $\mathrm{H}$. Winitz (Ed.). Native Language and Foreign Language Acquisition. 379 (pp. 259-278). New York: Annals of the New York Academy of Sciences. 
Long, M. (1983a). Native speaker/non-native speaker conversation and the negotiation of comprehensible input. Applied Linguistics, $4(2), 126-141$.

Long, M. (1983b). Native speaker/non-native speaker conversation in the second language classroom. In M. Long \& J. Richards (Eds.) Methodology in TESOL (pp. 339-354). New York: Newbury House Publishers.

Long, M. (1983c). Does second language instruction make a difference? A review of the research. TESOL Quarterly, 17. 359-82.

Moskowitz, B. (1978). The acquisition of language. Scientific American, 239(5), 92-109.

Pica, T. (1988). Interlanguage adjustments as an outcome of NS-NNS negotiated interaction. Language Learning, 38(1), 45-73.

Pica, T. \& Doughty, C. (1985a). Input and interaction in the communicative language classroom: A comparison of teacherfronted and group activities. In S. Gass \& C. Madden. Input in second language acquisition (pp. 115-132). New York: Newbury House Publishers.

Pica, T. \& Doughty, C. (1985b). The role of group work in classroom second language acquisition. Studies in Second Language Acquisition. 7, 233-248.

Pica, T, Young, R. \& Doughty, C. (1985). The impact of interaction on comprehension. TESOL Quarterly, 21(4), 737-758.

Pica, T., Holliday, L., Lewis, N. \& Morgenthaler, L. (1989). Comprehensible output as an outcome of linguistic demands on the learner. Studies in Second Language Acquisition, 11, 63-90.

Rulon, K. \& McCreary, J. (1986). Negotiation of content: Teacherfronted and small-group interaction. In R. Day, (Ed.), Talking to learn (pp. 182-199). Rowley, Mass.: Newbury House.

Scarcella, R. \& Higa, C. (1981). Input, negotiation and age differences in second language acquisition. Language Learning, 31(2), 409437.

Schachter, J. (1986). Three approaches to the study of input. Language Learning, 36, 211-225. 
Schumann, J. (1982). The early stages on interlanguage. CATESOL Occasional Papers. 8 ,7-19. (ERIC Document \# ED 225 406)

Seliger, H. (1983). Learner interaction in the classroom and its effect on language acquisition. In $\mathrm{H}$. Seliger \& $\mathrm{M}$. Long (Eds.). Classroom oriented research in second language acquisition (pp. 246-267). Rowley, Mass.: Newbury House Publishers Inc.

Snow, C. (1972). Mother's speech to children learning language. Child Development. 43, 549-565.

Stevick, E. (1980). Teaching languages: A way and ways. Rowley, Mass.: Newbury House.

Swain, M. (1985). Communicative competence: Some roles of comprehensible input and comprehensible output in its development. In S. Gass \& C. Madden (Eds.). Input in second language acquisition (pp. 235-253). New York: Newbury House Publishers.

Tarone, E. (1980). Communication strategies, foreigner talk, and repair in interlanguage. Language Learning, 30, 417-431.

Varonis, E. \& Gass, S. (1985). Non-native/Non-native conversations: A model for negotiation of meaning. Applied Linguistics, 6, 71-90.

Wagner-Gough, J. \& Hatch, E. (1975). The importance of input data in second language acquisition studies. Language Learning, 25, 297307. 


\section{APPENDIX A}

SAMPLE QUESTIONNAIRES 


\section{SAMPLE QUESTIONNAIRE INSTRUCTION SHEET}

About the questions:

The answers to these questions will help the researcher better understand the research results. Each question is for you as an individual. there are NO RIGHT and NO WRONG answers. DO NOT WRITE YOUR NAME. All answers will be confidential. Thank you for taking part in this research project.

Directions: [A] Put an X on the line to show your answer, or write a number to show how long you have done something.

Examples:

$$
\begin{array}{lll}
\text { Male } & \text { Female } & X \\
\text { year(s) } 2 & \text { month(s) } & 8
\end{array}
$$

[B] Write in an answer...

Examples:

Where Mexico

Native Language Spanish

[C] Circle an answer...

Example: $\quad$ very good good O.K. not good

[D] Choose one answer...

Example: $\mathrm{X}$ my classmate

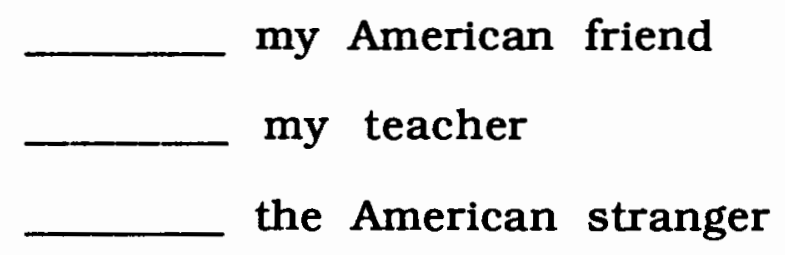




\section{SAMPLE FRIEND GUESTIONNAIRE}

1. Male

Female

Age

2. Do you speak a foreign language? yes if yes, please list the languages that you speak.

no

Foreign Language

3. Have you traveled to other countries? yes if yes, please list the countries that you have traveled to.

4. Have you lived in other countries? yes if yes, how long?

no
(1) year(2)
(2) year(2)
month(s)
(3) year(2)
month(s)
month(s)

Where?

4. Your partner, in the task you just completed, considers you an American friend. How long have you known your partner?

year(s) month(s)

5. How would you describe your friendship with this foreign friend?

very close close casual not very close

6. When my friend and I spend time together we usually: (choose only one)

sit and talk about something

play sports

go out (to the movies, to dinner, dancing, etc.)

teach each other our languages

other: 
7. How did you feel about participating in the task with a friend as your partner?

$$
\text { good O.K. uneasy uncomfortable }
$$

8. How well do you understand your friend's English conversation routines and patterns?

$$
\text { very well O.K. not very much very little }
$$

9. I think that my foreign friend understands my English... all the time most of the time sometimes hardly ever

10. How do you feel about taking part in this research project? very good good bad not good

11. How useful do you think "information-exchange" tasks (like the one you just did) are for language learning? very useful useful possibly useful not useful

12. Does your partner have an accent? yes no

13. How easy was it for you to understand your partner's spoken English?

$$
\text { very easy easy not very easy very difficult }
$$

14. How familiar are you with your partner's native country's culture?

very familiar familiar not very familiar not familiar at all

15. How often do you speak with your partner outside of class? every day most days occasionally rarely never

16. How often do you correct your friend's spoken English? frequently often fairly often occasionally hardly ever 
17. Please rate the information task you just completed on the following scale:

(1)

very easy
(2)

easy
(3)

(4)

difficult very difficult

\section{SAMPLE TEACHER QUESTIONNAIRE}

1. Male

Female

Age

2. Do you speak a foreign language? yes

if yes, please list the languages that you speak.

no

no

3. Have you traveled to other countries? yes

no

if yes, please list the countries that you have traveled to.

Where?

4. Have you lived in other countries? yes no if yes, how long?
(1) year(2)
(2) year(2)
month(s)
(3) year(2)
month(s)
month(s)

\section{Where?}

5. How long have you been teaching English as a second or foreign language?

year(s)

$$
\text { month(s) }
$$

6. How did you feel about participating in the task with your student as your partner?

$$
\text { good O.K uneasy uncomfortable }
$$

7. How well did you understand your student's English conversation routInes and patterns?

very well O.K. not very much very little 
8. I think that my student understood my English... all the time most of the time sometimes hardly ever

9. How do you feel about taking part in this research project? very good good bad not good

10. How useful do you think "information-exchange" tasks (like the one you just did) are for language learning?

very useful useful possibly useful not useful

11. Does your student have an accent? yes no

12. How easy was it for you to understand your student's spoken English?

very easy easy not very easy very difficult

13. How familiar are you with your student's native country's culture?

very familiar familiar not very familiar not familiar at all

14. How often do you speak with your students or other non-native English speakers outside of the classroom structure?

every day most days occasionally rarely never

15. How often did you correct your student's spoken English? frequently often fairly often occasionally hardly ever

16. Please rate the information task you just completed on the following scale:

(1)

very easy
(2)

easy
(3)

(4)

difficult very difficult 


\section{SAMPLE LANGUAGE LEARNER GUESTIONNAIRE}

1. How useful do you think "information-exchange" tasks (like the one you just did) are for language learning?

very useful useful possibly useful not useful

2. Now that you have participated in two sessions, how do you feel about taking part in this research project?

very good good O.K. not good

3. Which information-task was the easiest for you to complete? the first one with my classmate (People Cards) this one with my teacher

4. Your partner, in the task you just completed, is one of your language teachers. In your opinion, the teacher is...

very good good O.K. not good

5. How did you feel about participating in the task with a teacher as your partner?

$$
\text { good O.K. uneasy uncomfortable }
$$

6. I think that my teacher partner understands my English... all the time most of the time sometimes hardly ever 
APPENDIX B

TASK INSTRUCTIONS 


\section{SAMPLE OF LL/LL INSTRUCTION SHEET}

\section{INSTRUCTIONS}

Your partner and you will try to complete the information exchange task in your folders as accurately as possible. An information exchange task requires your partner and you to exchange (share) information in order to be able to successfully and accurately complete the task. Your partner and you will not be able to complete the activity unless you are able to share and understand the different information "facts" that you both possess. When you have shared and understood all of the information that each of you possess, you will have completed this activity. Good Communicating!!

\section{PEOPLE CARD INSTRUCTIONS:}

DO NOT SHOW YOUR PARTNER YOUR POSTER OR YOUR CARDS. Your folder has a propping device that will allow you to look at your poster and cards without your partner being able to see it.

Your partner and you have been provided with different posters. Both posters are divided into sixteen (16) boxes. All of the boxes have pictures of in them. Your partner and you have also been provided with twenty-five (25) cards with pictures on them. Your job is to describe to each other the pictures on your poster so that your partner can arrange his or her cards in the correct order. Of course, you will also listen to your partner's description of the pictures on his or her poster and try to arrange your cards to match your partner's poster. Take turns describing the pictures on your posters. You have more cards than you will need to use. You must be careful to select the correct card. Some of the pictures on the cards are very similar to each other. Often only one detail is different. Make sure that you describe the picture very accurately so that your partner will select the correct card. Likewise, ask questions about your partner's description when you are not sure which of two cards to select.

Use spoken English language only. Do not use gestures or other non-language communication when doing the activity. You may look at each other but use English as your communication tool. Have fun! If you can finish this task, wonderful! However, if you don't finish, it is also O.K. because your communication efforts are more important than your finished drawings. 


\section{SAMPLE OF LL/TE INSTRUCTION SHEET}

\section{INSTRUCTIONS}

Your partner and you will try to complete the information exchange task in your folders as accurately as possible. An information exchange task requires your partner and you to exchange (share) information in order to be able to successfully and accurately complete the task. Your partner and you will not be able to complete the activity unless you are able to share and understand the different information "facts" that you both possess. When you have shared and understood all of the information that each of you possess, you will have completed this activity. Good Communicating!!

GRAB BAG INSTRUCTIONS:

DO NOT SHOW YOUR PARTNER YOUR ITEMS OR DRAWINGS. Your folder has a propping device that will allow you to look at your items and drawings without your partner being able to see it.m

Your partner and you have been provided with paper bags containing different items. You both have also been provided with blank paper to draw on. Your partner and you will try to describe the items that you take from your paper bags so that other person will be able to accurately draw the items on his or her drawing paper. Take turns. First, one of you should select an item by grabbing something in your paper bag. Don't look into the bag, let it be a surprise! Describe the item to your partner so that he or she is able to draw it. Then you listen to your partner and try to draw what she or he is describing. You can ask your partner questions about the item it you like. Your descriptions and your drawings should include as much detail as possible. You may describe the item in any way that you like including telling your partner the name of the item.

Use spoken English language only. Do not use gestures or other non-language communication when doing the activity. Look at each other but use English as the communication tool. Please continue the activity until you have completed three drawings each or until approximately thirty minutes have elapsed since you began the task. Have fun! If you can finish this task, wonderful! However, if you don't finish, it is also O.K. because your communication efforts are more important than your finished drawings. 


\section{SAMPLE OF LL/FR DYAD INSTRUCTION SHEET}

\section{INSTRUCTIONS}

Your friend and you will try to complete the information exchange task in your folders as accurately as possible. An information exchange task requires your friend and you to exchange (share) information in order to be able to successfully and accurately complete the task. Your friend and you will not be able to complete the activity unless you are able to share and understand the different information "facts" that you both possess. When you have shared and understood all of the information that each of you possess, you will have completed this activity. Good Communicating!!

\section{DRAWING PICTURES INSTRUCTIONS:}

\section{DO NOT SHOW YOUR FRIEND YOUR POSTER OR YOUR}

DRAWINGS. Your folder has a propping device that will allow you to look at your poster and drawing page without your friend being able to see it.m

Your friend and you have been provided with different posters. Both posters are divided into sixteen (16) squares. Some of the squares contain pictures and some of the squares are blank. Your job is to describe to your friend the pictures on your poster so that your friend will be able to draw the pictures in the missing spaces on his or her drawing page. Of course, you will also listen to your friend's description of the picture that he or she has and try to draw what you hear on your drawing page. Your descriptions and your drawings should include as much detail as possible. You may describe the item in any way that you like including telling your partner the name of the item. Take turns describing the pictures on your poster, beginning with the native English speaker. Please do not draw on the poster but, instead, draw on the drawing page provided.

Use spoken English language only. Do not use gestures or other non-language communication when doing the activity. You may look at each other but use English as your communication tool. Please continue the activity until you have completed both drawing pages or until approximately thirty minutes have elapsed since you began the task. Have fun! If you can finish this task, wonderful! However, if you don't finish, it is also O.K. because your communication efforts are more important than your finished drawings. 


\section{SAMPLE OF LL/ST INSTRUCTION SHEET}

\section{INSTRUCTIONS}

Your partner and you will try to complete the information exchange task in your folders as accurately as possible. An information exchange task requires your partner and you to exchange (share) information in order to be able to successfully and accurately complete the task. Your partner and you will not be able to complete the activity unless you are able to share and understand the different information "facts" that you both possess. When you have shared and understood all of the information that each of you possess, you will have completed this activity. Good Communicating!!

\section{CODE FLAG AND PENNANTS INSTRUCTIONS:}

\section{DO NOT SHOW YOUR PARTNER YOUR POSTER OR YOUR}

DRAWINGS. Your folder has a propping device that will allow you to look at your poster and information page without your partner being able to see it.

Your partner and you have been provided with different colored posters. Both posters are divided into thirty-five (35) boxes. Some of the boxes have pictures of flags and pennants and while other boxes are blank. Your job is to describe to each other the colors and shapes of the flags and pennants on your poster so that your partner can fill in the missing spaces on his or her information page. Of course, you will also listen to your partner's description of the flags and pennants that he or she has and try to draw what you hear on your information page. Your descriptions and your drawings should include as much detail as possible. You may describe the item in any way that you like. Take turns describing the flags and pennants on your posters beginning with the American SOSC student.

Please do not draw on the colored poster but, instead, draw your flags and pennants on the information page provided. Use the colored markers provided when drawing your flags or pennants.

Use spoken English language only. Do not use gestures or other non-language communication when doing the activity. You may look at each other but use English as your communication tool. Have fun! If you can finish this task, wonderful! However, if you don't finish, it is also O.K. because your communication efforts are more important than your finished drawings. 
APPENDIX C

TASK POSTERS 
SAMPLE OF LL/LL POSTER

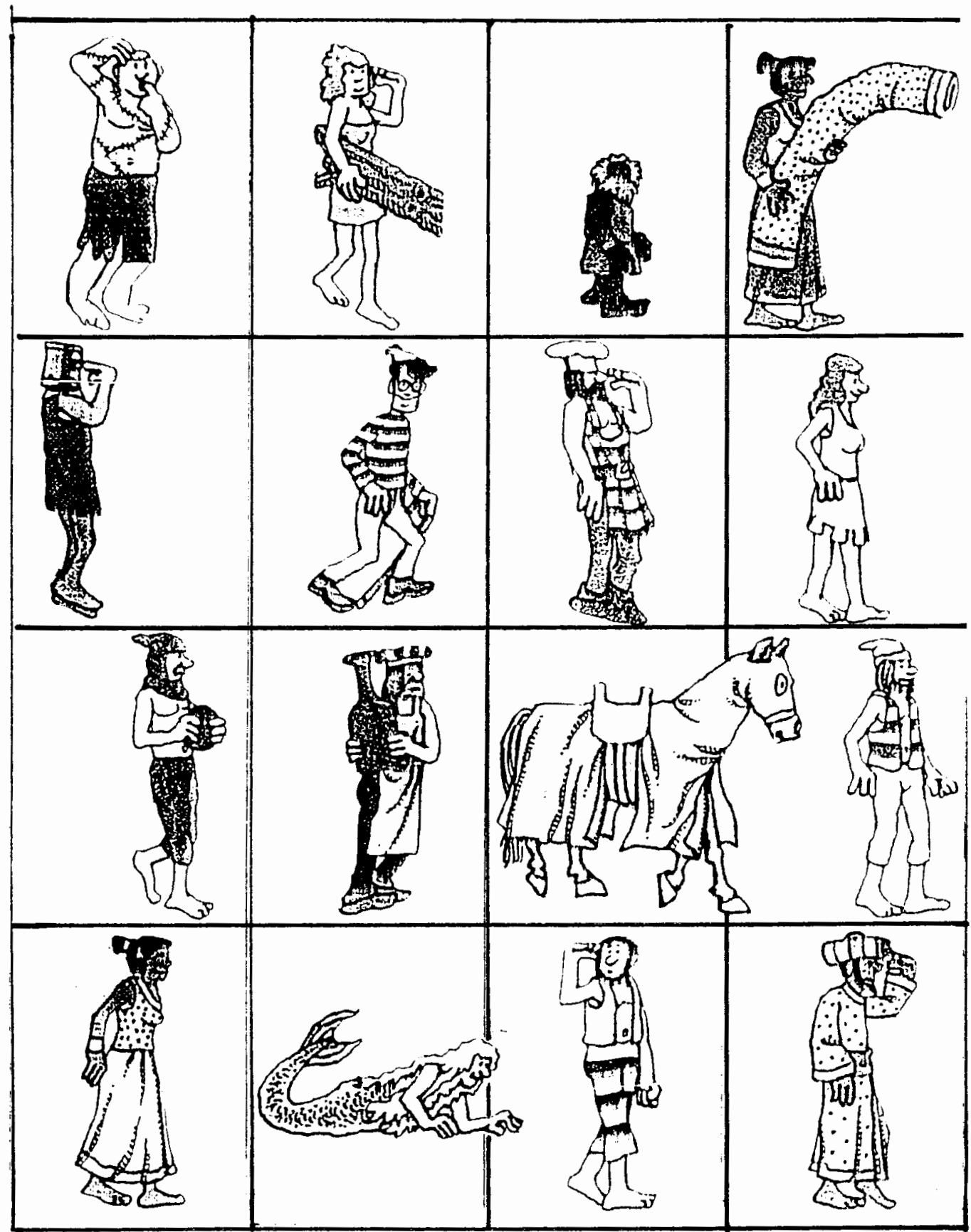


SAMPLE OF LL/FR POSTER

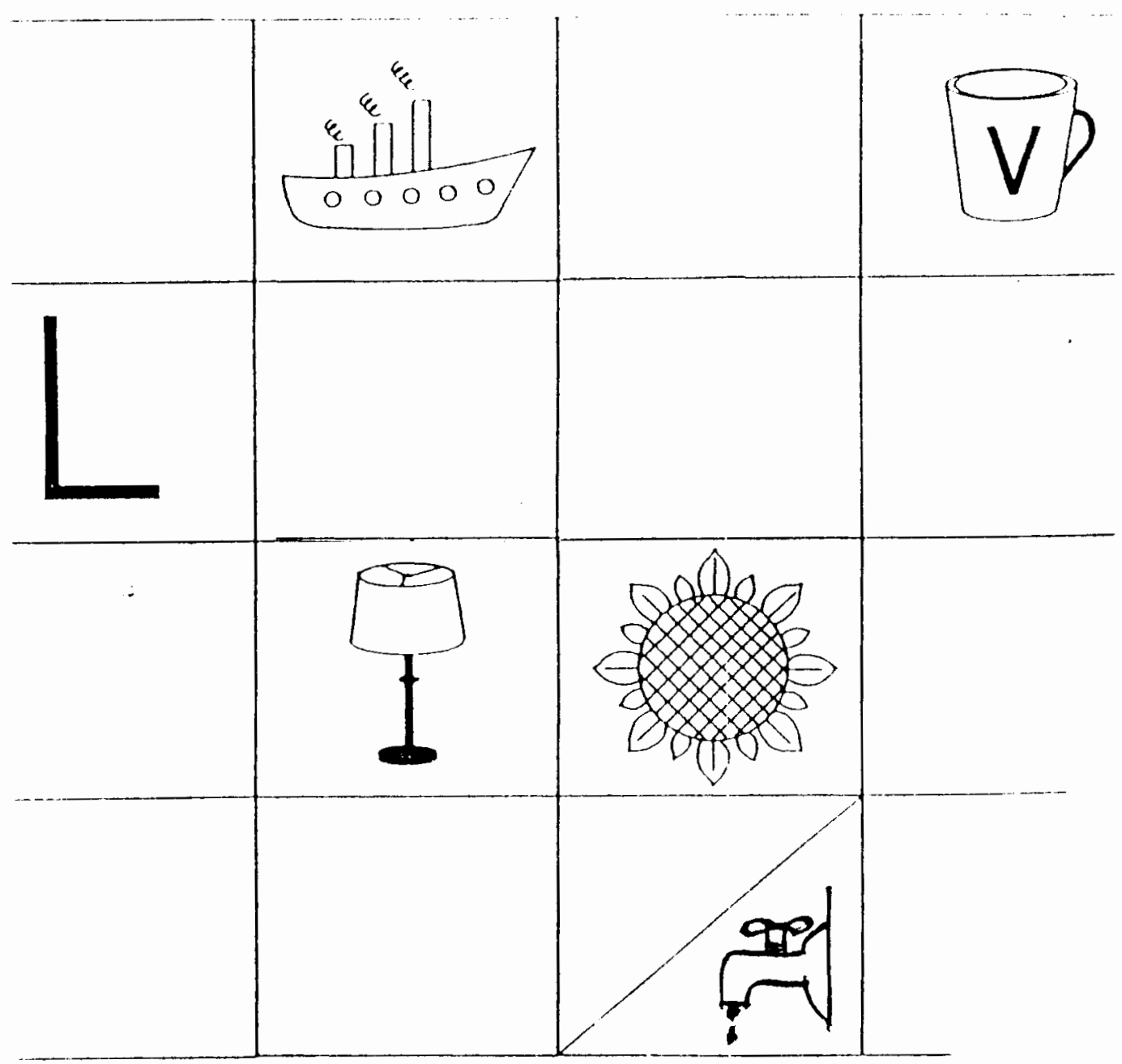

(Reduced 65\%) 
SAMPLE OF LL/ST POSTER

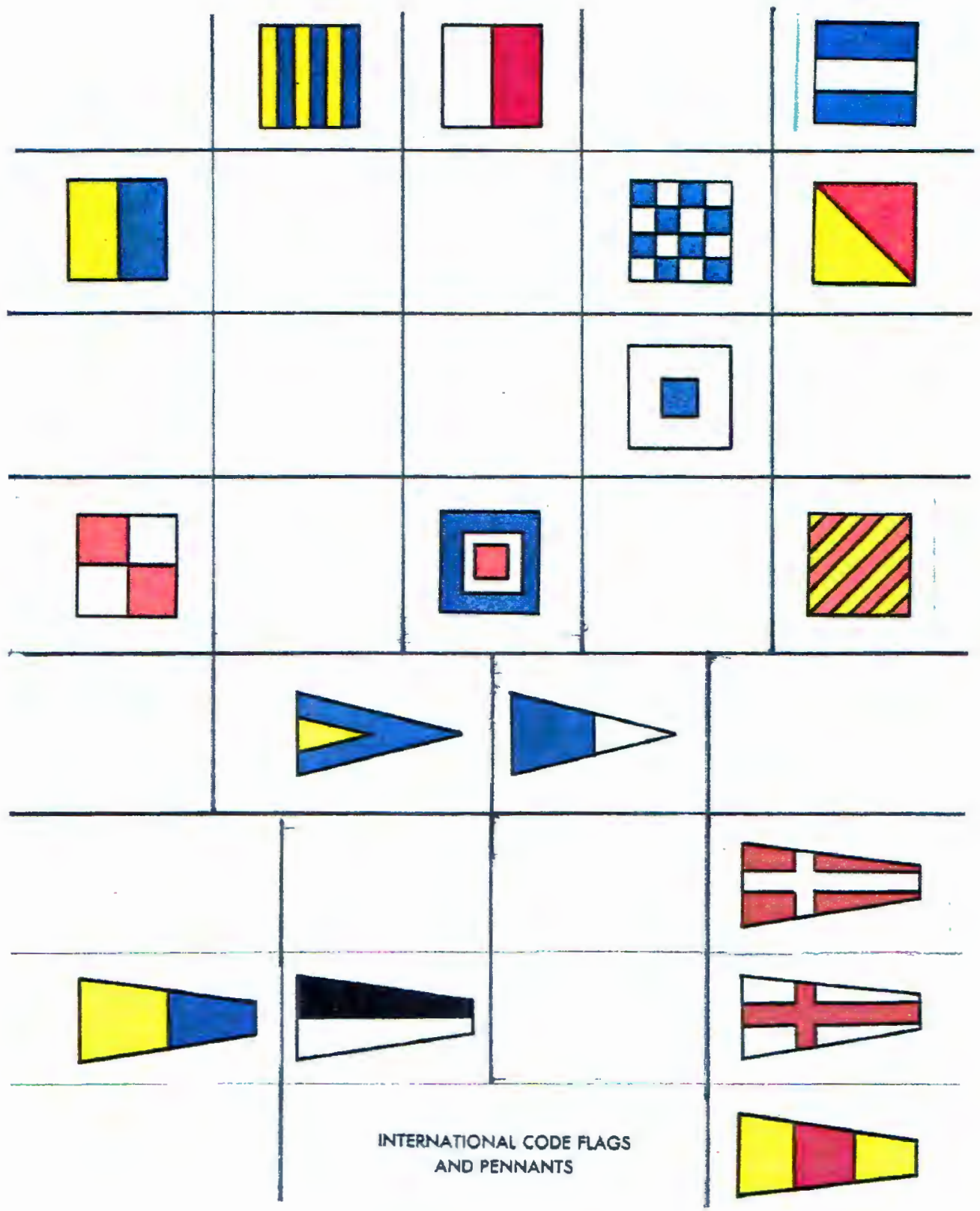


APPENDIX D

TRANSCRIPTION GUIDE 


\section{Transcription Guide}

All of the transcription notation examples that follow refer to the transcription of the discourse interaction indentified as

"LL125/Friend372". A small portion is included below as an example of transcription layout. Please refer to a copy of the entire transcription to find all other relevant examples of transcription notation.

\section{LL125/Friend372}

$1\{0\}$ LL 125 Ah, / I will describe the, (.1) the b6x, (.1) ah, (.) néxt / these one, / that you already describe / me.

$2 \quad$ FR $372 \quad$ O. K.

3 LL 125 On the first line / is the (.) four, / forty.

4 (.1) The last one / in the first line.

$5 \quad$ FR $372 \quad$ O.K.

Transcription layout:

LL125/Friend 372

--- Identifies the task session.

Left Column

--- Numbers text by c-unit.

Second column from left --- Shows elapsed time in minutes.

Third column from left -.- Identifies subjects.

Fourth column from left --- Transcription text.

Noises that can be heard in the background are indicated in the transcription text within parenthesis. Skip one line between the preceding and following c-units to show background or non-text noises that can be heard. An example can be found between c-unit 14 and c-unit 15. 


\section{Text transcription notations:}

Examples listed by c-unit number in transcription "LL125/Friend372"

Symbol

(.)

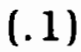

Momentary pause of less than one second in speech cadence. Judged to be the product of cognitive processing.

Also used to indicate a slight pause preceding the first c-unit of a subject's new turn.

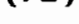

--- Momentary pause of less than of less than two seconds in speech cadence. Judged to be the product of cognitive processing. (.2) is less than three seconds in duration.
$\begin{array}{ll}\text { I..- } & \text { Interrupted c-unit that } \\ \text { is continued again after }\end{array}$
$\begin{array}{ll}\text {... } & \text { Interrupted c-unit that } \\ \text { is continued again after }\end{array}$ interruption. interruption.

-- $\quad$--- Interrupted c-unit that is not continued after interruption.

--- Words spoken at the same time by each subject.
Example Many

Many

Many

$16 a, 16 \mathrm{~b}$, $16 \mathrm{c}$

13

$1,2,3,4$

-- $\quad$ Stressed word.

Many

--- Rising intonation.

6

Shown on last word of rise in pitch. Usually indicates questioning. 
Symbol

$?$

--- Normal interrogative use of c-unit. Rising intonation implicit.

--- Falling intonation.

-.- Mispronounced word.

False starts.

Semantic or grammatical word misusage.
Example

9

231

6 
APPENDIX E

SAMPLE TRANSCRIPT 


\section{LL 125 / Friend 372}

\section{Revised January 21, 1992}

$1 \quad\{0\} \quad$ LL 125

2

3

4

5

6

7

8

9

10

11

12

13

14
FR 372

LL 125

FR 372

LL 125

Fr372

LL 125

FR 372

LL 125

FR 372

LL 125

FR 372
Ah, / I will describe the, (.1) the box, ah. (.) néxt / these one, / that you already describe / me.

O. $\mathrm{K}$.

On the first line / is the (.) four, / forty.

(.1) The lást one / in the first line.

O.K.

And, ahm, / [et's], (.2) ahm, / yóu, / yóu have in your [keet-], / in your kitçhen.

Um-huh.

Uh, you use / to drink [cof-], / in the morning. A cup?

Yes, / a cup.

But, / ah, (.3) ah, (.1) is nót / roúnd, [r-], ah, round.

Not round.

Is more--

() Square?

(sound of cupboard door opening in the background)

\begin{tabular}{|c|c|c|}
\hline 15 & LL 125 & [Sq-], not $(.1)$ more square. \\
\hline 17 & FR 372 & Ah. \\
\hline $16 \mathrm{~b}$ & LL 125 & ... of the (.) cüp,... \\
\hline 18 & FR 372 & $\mathrm{O} . \mathrm{K}$ \\
\hline $16 \mathrm{c}$ & LL 125 & $\ldots$ is [sq-], square. \\
\hline $\begin{array}{l}19 \\
20 \quad\{1\}\end{array}$ & & $\begin{array}{l}\text { Then (.) it come [k-], it goes / up. } \\
\text { Ah, (.1) goes a little. }\end{array}$ \\
\hline $\begin{array}{l}21 \\
22\end{array}$ & & (.) Not narrow. \\
\hline $\begin{array}{l}22 \\
23\end{array}$ & & / The opposite of narrow. \\
\hline $\begin{array}{l}23 \\
24\end{array}$ & FR 372 & (.) Wide? \\
\hline $\begin{array}{l}24 \\
25\end{array}$ & LL 125 & [White]. \\
\hline 26 & FR 372 & Wider? \\
\hline 27 & & At the top? \\
\hline 28 & LL 125 & Wider, / on the top, / yeah. \\
\hline $29 a$ & FR 372 & $\begin{array}{l}\text { And is the, / does / the bottom of the cup / } \\
\text { rést on the bottom of the, / the line of the... }\end{array}$ \\
\hline 30 & LL 125 & The line-- \\
\hline $29 b$ & FR 372 & ...bóx? \\
\hline $\begin{array}{l}31 \\
32\end{array}$ & LL 125 & $\begin{array}{l}\text { No. } \\
\text { (.) [lı, ahm, [de], /, [eet's] / only, (.2) only, / } \\
\text { like / one (.) fińgér-- }\end{array}$ \\
\hline
\end{tabular}


$36 \mathrm{a}$

37

$36 \mathrm{~b}$

38

$39 \mathrm{a}$

40

$39 b$

41

$39 c$

42

43

44

45

46

47

48

49

50

$\{2\}$

51

52

53

54

55

56

57

58

$59 a$

60

$59 b$

61

62

63

64

65

66
FR 372

LL 125

FR 372

LL 125

FR 372

LL 125

FR 372

LL 125

FR 372

LL 125

FR 372

LL 125

FR 372

LL 125

FR 372

LL 125

FR 372

LL 125

FR 372

LL 125

FR 372

LL 125

FR 372

LL 125

FR 372

LL 125

FR 372

LL 125
One finger up from the--

One finger / up / from the [bottlel.

From the bottom?

$\underline{\mathrm{O} . \mathrm{K}}, \ldots$

$\underline{\mathrm{O} . \mathrm{K}}$

...that's where the bottom of the [cúps] (.)

begins?

Begins.

Then...

O.K

...uh, / you / leave one fingér, / uh, to the tóp...

O.K.

... |uh -boat], under [de]--

(.) O.K.

A bow-vel?

No, / not [a-bow-ve].

Eh, / under?

(.) Going, uh, (.) up / from the bottom / of the cup?

Yeah.

O.K.

(.) And down--

Then. (.) there is, ah, a [sma-en], in the /

riǵnt, on the / right síde / of the cup, (.1)

there is a small, (.) um, (.) piéce, (.1) cuŕve, /

like / an [inter-],[inter-o-gation] / sign, (.1) uh,

(.) [ex-], [exp-]--

Oh, a / quéstión mark?

A quéstion mărk.

O.K.

Yes (laughs) a quéstión márk.

/ And, eh, it's like, ah, (.) you can hold / the cíp.

O.K.

/ And is it connected?

$/$ Does it--

$\underline{\text { Is }}$. is connect, / in the cúp...

O.K. O.K.

...together.

(.) All right.

And, and (.) in the middle of the cúp, / there is a / [le-leather] / " $V$ ",

(.) Uh, in, / umm, (.) um, black.

(.) O.K.

(.) Right [eh-], right /just in the middle of the cup?

Just in the middle. 
67

68

69

70

71

72

73

$\{3\}$

74
FR 372

LL 125

FR 372

LL 125

FR 372
(.) Uh, is / kind of (.) big / letter.

O.K.

(.2) And at the top of the cup, / does the cup go / straight / across or is it kind of / curved? Is, is / curved.

Un-buh.

Is like, / like, / uh, (.2) a planet,

(.) [haa]--

O.K

(.1) l'm not very good at / aŕt.

(both laugh)

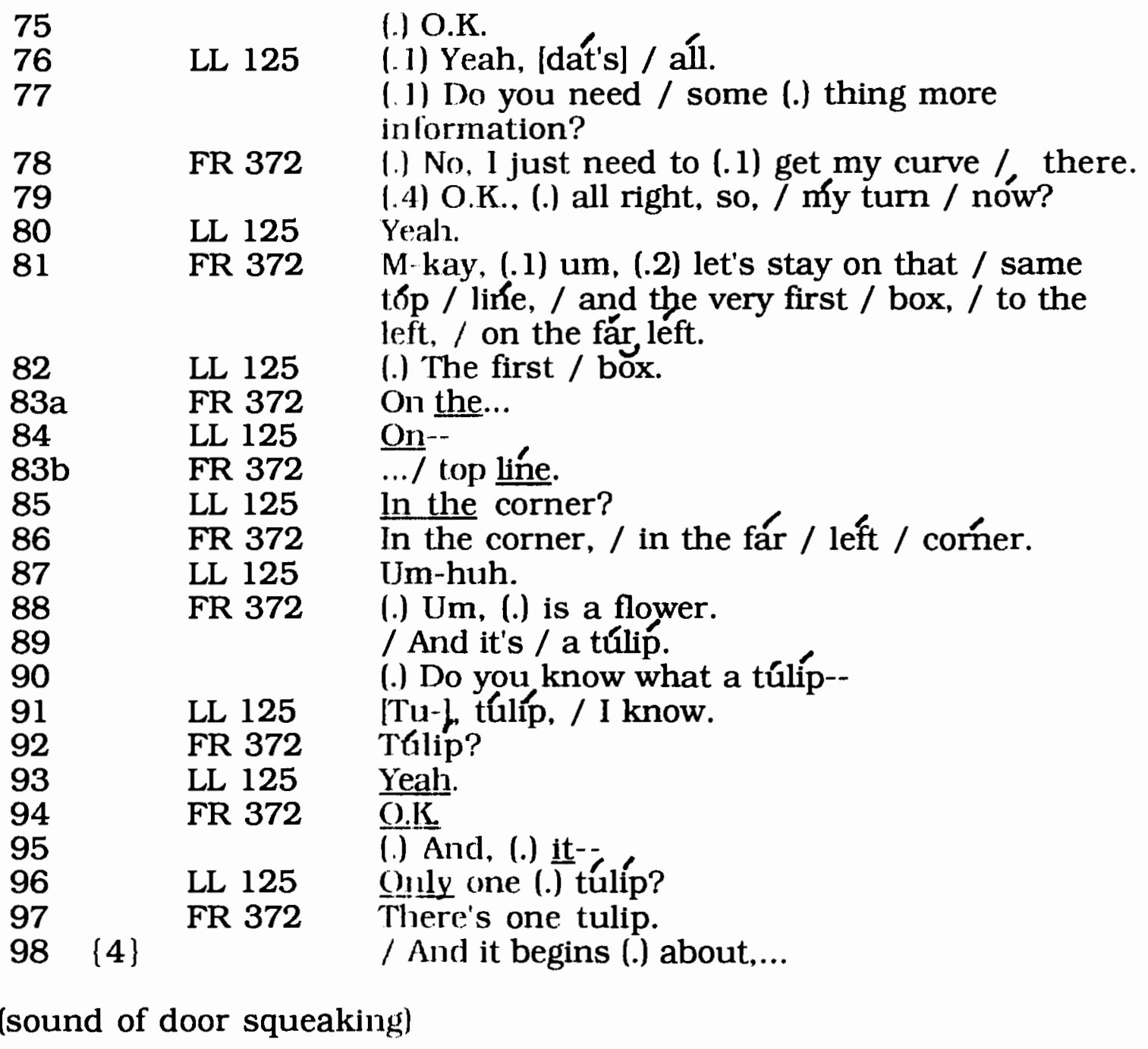

...(.2) uh, (.1) about, / uh, the width of your, er, / about as... 
(sound of door shutting)

...(.) the wider, (.) ah, as your pencil iš, / is about how far up / from the bottom line that...

(sound to metal clanging)

...the tulip / stem / begins.

(sound of metal banging)

$99 a$

$100 \mathrm{a}$

$99 b$

$100 \mathrm{~b}$

$99 \mathrm{c}$
LL 125

FR 372

LL 125

FR 371
(.1) So it's just, / it's just, / it begins / up / from the line (.1) about,...

(.) In the middle...

....about..

... of the box?

.... a quarter of an inch, / is where the stém beǵins.

(sound of metal in the background)

101

102

103

$104 a$

105

$104 \mathrm{~b}$

106

107

(Voice

108

109

110

111

112

113

114

115

116

117
(.) And the stém / is a straight line, / going straight up, / about an inch.

(.) Do you know what an / inch is? (laughs)

LL 125

Ah, yeah. / the inch / is a problem.

(.) I have about / a centimeter,...

[Sixteenl meters.

LL 125

FR 372

LL 125

... about a centimeter.

/ Is a centimeter / about an inch?

$\mathrm{I} ' \mathrm{~m} / \mathrm{not} /$ sure,... 
(voices can be heard in the background)

118

119

$120 \mathrm{a}$

121

$120 \mathrm{~b}$

122

123

124

125

126

127

128

129

130

131

132

133

134

\{6\}

135

136

137

138

139

140

141

142

143

144

145

$146 \mathrm{a}$

$147 \mathrm{a}$

$146 \mathrm{~b}$

$147 \mathrm{~b}$

$146 \mathrm{c}$

$147 \mathrm{c}$

$148 \mathrm{a}$
LL 125

FR 372

LL 125

FR 372

LL 125

FR 372

LL 125

FR 372

LL 125

FR 372

LL 125

FR 372

LL 125

FR 372

LL 125

FR 372

LL 125

FR 372

LL 125

FR 372

LL 125

FR 372
(.1) O.K.

That's the length / of the stém.

(.) I thińk...

That's how, O.K.

...is / almost / one centimeter.

Yeah, O.K.

(.2) Ang, O.K., and then / on the stem / are two leaves.

(.1) And, (.3) ah, (.) [wh-], one leave is about

(.1) a half a [cent-eh].

Each, / there, [wh-], the fir'st leáve / that's

closest to the bóttom of the stem / is about a half a centimeter / long.

(.) And it's all filled in / bláck.

(.) It's all filled in.

(.1) And then the other / stem, or the leaf, (.1) um, $/$ or, and if, $/$ and it comes off $/$ to the right of the stem.

(.2) Right / to this?

on the right / side of the stem.

O.K.

O.K.?

(.) And then (.) where that / leáf (.1) eníds, (.) on the left side of the stem / is where / the next leaf / begins.

And it's just a little bit longer (.) then the first / leaf / was.

lt's blaćk / too?

And it's all blacked ín, / yes.

O.K.

O.K.?

And, and--

And it. they're kind of /thin (.) leaves.

/ They're not very (.1) wide.

(.) Urn, (.) they're just little thin leaves.

About (.2) (sighs), (.3) an eighth / of an inch.

So what would that be / in centimeters?

/ Um--

(.) Ahh, half, uh-um...

About a tenth, ...

...less / than...

...about a...

...half a--

...tenth of a centimeter.

(1) About a millimeter... 
149

$148 \mathrm{~b}$

150

151

152

153

154

155

156

157

158

159

160

161

162

163

164

165

$166 \mathrm{a}$

167

$166 \mathrm{~b}$

168

$169 \mathrm{a}$

$170 \mathrm{a}$

$169 \mathrm{~b}$

$170 \mathrm{~b}$

$171 \mathrm{a}$

$172 \mathrm{a}$

$171 b\{8\}$

$172 \mathrm{~b}$

$171 \mathrm{c}$

$172 \mathrm{c}$

$171 \mathrm{~d}$

$172 \mathrm{~d}$

173

174

175
LL 125

FR 372

LL 125

FR 372

\{7\}

LL 125

FR 372

LL 125

FR 372

LL 125

FR 372

LL 125

FR 372

LL 125

FR 372

LL 125

FR 372

LL 125

FR 372

LL 125

FR 372

LL 125

FR 372

LL 125

FR 372

LL 125

FR 372

LL 125

FR 372
Millimeter.

.../ wide.

(.) O.K.

O.K.?

/ And they're all filled in.

/ Then the, / the, where you get / up to the tóp of the stem is where the flower / begins. / And it's, (.) um, [ye-], you form the flower by making a, ah, (.2) um, (.1) the, the, the bottom of the flower / looks like a half of a circle.

(.) Un-huh.

(.) And then, / um, (.) there are / one, / two, / three, four, / five / points (.) on the top of the, (.) of the tulip.

(.2) Five points.

Un-huh.

The, the, / the, the [f-], (.) um, (.) and they're,

(.) they come down about / a millímeter.

(.1) Each point is about a mílimeter long.

(.1) Does that make sense?

(.) O.K.

O.K., and the [f-], / tulip is all / [blacken'd] in.

(.) Except, / and I don't know / if it's just from / the copy or / what, / but there are / three / little / whíte dóts / that are not / [blacken'd] in.

White (.) dots?

And I don't know if it's just from the cópy, / from the, ah,...

Oh.

...because of the cofy machine--

Yes, just [she] looks

/ I think...

(.) Yeah, but it's all,...

...is O.K.

.../ it's all / [blacken'd] in.

(.) ЏDe-l. Ide-1,...

The [fla- $]$...

...[Dey] / flower...

...the flower...

....is...

....is

...bblăck?

...all, / yeah.

/ With your peńcil, (.) uh, color it all in.

O.K.

(.2) Do you have any questions? 
176 LL 125 Uh, no.

177 FR $372 \quad$ O.K.

$178 \mathrm{a}$ LL 125 (.1) Now, uh, I will describe (.) a picture...

(sound of metal banging in background)

...(.) um, (.1) situated (.1)...

(loud clang in background)

179

$178 \mathrm{~b}$

180

$178 \mathrm{c}$

181

182

183

184

185

186

187

188

189

190

191

$192\{9\} \quad$ FR 372

193

194

$195 \mathrm{a}$

$196 \mathrm{a}$

$195 \mathrm{~b}$

$196 \mathrm{~b}$

197

198

199

200

201

202

203

204
FR 372

LL 125

FR 372

LL 125

FR 372

LL 125

FR 372

LL 125

FR 372

LL 125

FR 372

LL 125

FR 372

LL 125

LL 125

FR 372

LL 125

FR 372

LL 125

FR 372

LL 125

FR 372

LL 125

FR 372

LL 125

FR 372 ...under [dé] flówer,...

O. .

...the tulip on...

O.K

...the / secónd linée.

All right.
(.) Is, / um, (.1) a, / is a letter.

O.K

Ah, my name (.) starts / with / this letter.

/"L".

"L", / O.K.

And, /in the (.1) left side / one (.1) inch, / I, / 1 think.

O.K. O.K.

$\overline{\mathrm{Ah}}$, / you can put your / [pén-cill].

(.) Um-huh.

And, and is [deece], (.1) just, ah, (.1) ah, (.) near [de], [day], / the begin of the [fo-], / the [f-], folder.

O.K., / right on the edge / of the page?

Yes.

Ah, leave / [deece-a] space, ah--

Just a little space...

Just a....

...over?

...[da], [de] space of [de], [de-de], (.) the pencil.

O.K

(.) And about--

Thén / you, / you / dráw / a / line, (.1) um, (.3) [ju-], from the top / just / one pencil / more.

(.) O.K.

(.) And / from the / bottom, / one pencil more too.

O.K.

(.1) [Dees] line / is / not very (.) [theen].

(.1) It's not thin? 


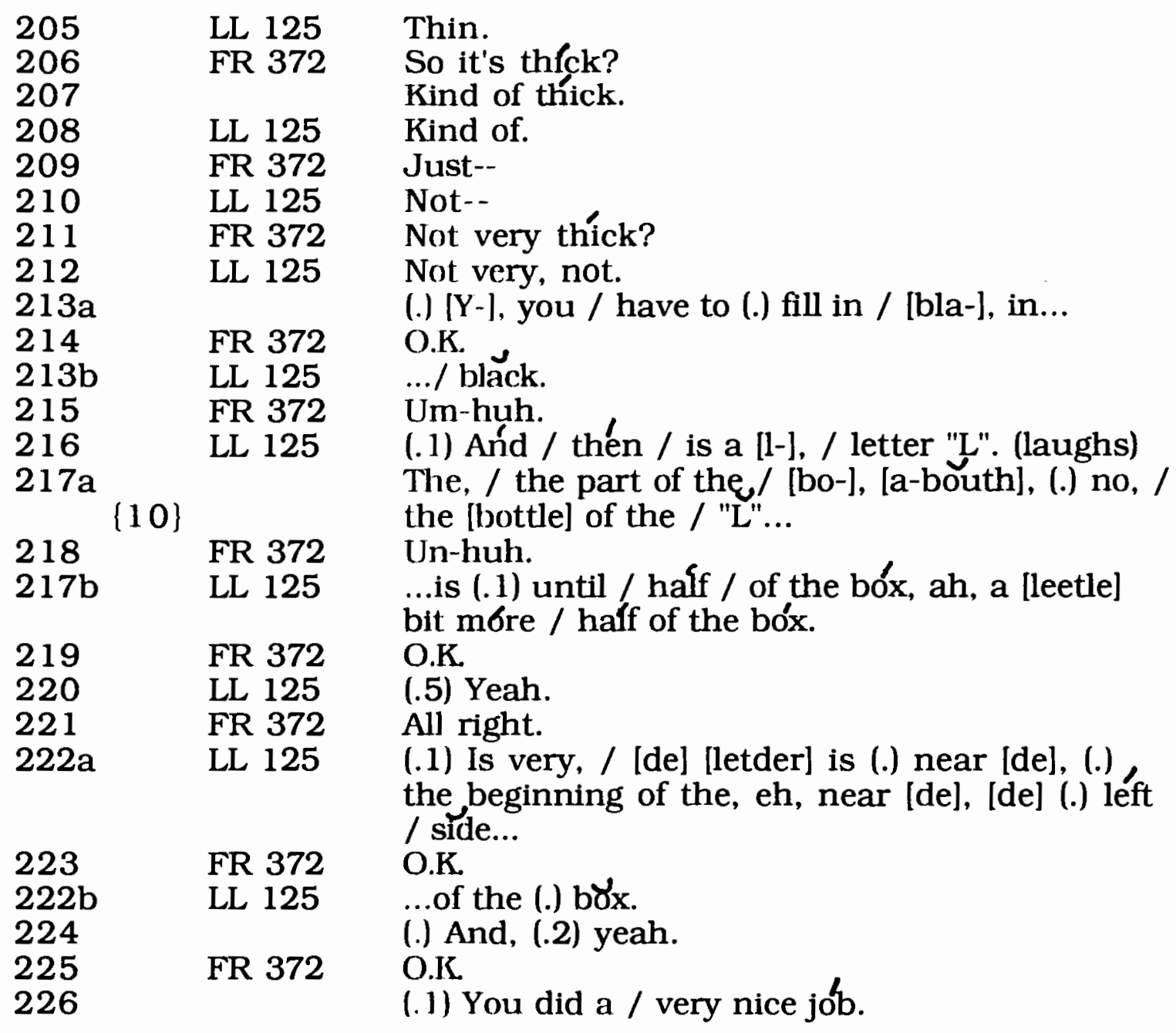

(both laugh)

227

I hope I / did it right.

(both laugh)

228

229

230

231

$232\{11\}$
LL 125

FR 372

(both laugh)
(.) O.K., (.) is that it?

Yeah.

O.K. of boy, (.2) um, (.3) I guéss I'll, (.) hmmm, (.1) I don't want to do this / hard one. I'll save it. 
$235 a$

236

$235 \mathrm{~b}$

237

238

239

240

241

$242 a$

243

$242 \mathrm{~b}$

244

245

246

247

248

249

250

251a

252

251b

253

254

$255 \mathrm{a}$

256a

$255 b$

$256 \mathrm{~b}$

$255 \mathrm{c}$

$256 \mathrm{c}$

$255 d$

256d
LL 125

FR 372

LL 125

FR 372

LL 125

FR 372

LL 125

FR 372

LL 125

\{12\} FR 372

LL 125

FR 372

LL 125

FR 372

the tóp / the third / rơ down. (.1) and / the box / on the fár / right.

(.) So, it would be, (.) um, on the same row that the cup was / only...

Um-huh.

...the third row down.

O.K.

O.K.?

(.) And we're going to be drawing / a letter.

(.) And it's the first / letter of the alphabet, / "A"."

Un-huh.

And it's, um, (.2) uh, / from the way you

described the " $L$ ", / I believe it's the same, /

the height / from the top to the bottom of the "A", / is the same [heigthl...

Un-huh.

...as what your "L" was.

And, (.) um, (.1) the, the "A" begins / about a pencil (.) wiath úp / from the / bottom of the box.

The box.

(.) And (.) it's not, / eh, the, the tóp of the "A" is, is / just off-center.

/ It's, it's a little over to the right / from ceńter.

Um-huh.

It's not / centéred in the box.

(.) Um, (.1) and, the [le-], the ah, (.) the legs on the " $A$ " / are not / real thin.

You'll have to fill 'em in with black / like,...

(.) Um-huh,

.../ like I did on the " $\mathrm{L}$ ".

(.1) And, (.2) uh, / the, / the / cross, / [th-], the line that comgs across, / that connects the two legs / of the "A", / is, / is almost, / ah, / it looks like it's right / in the míddle / of the two legs.

(.1) Does that make sense?

(.) [De], [dey]...

(.) The part...

.... go...

...that goes acróss...

...'cróss...

...is, is ...

....is--

LL 125

FR 372 


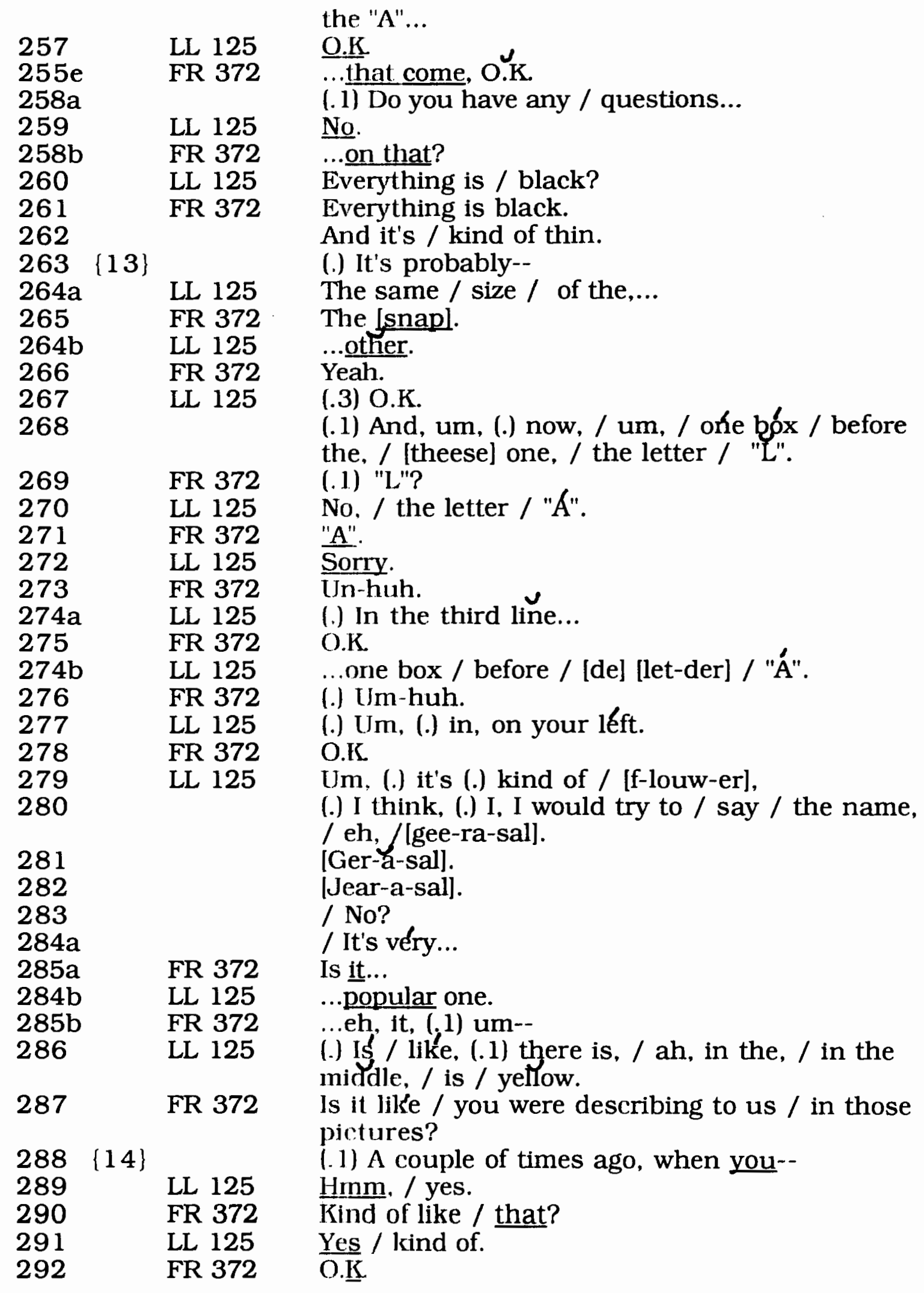


293a LL 125 But, I think [theessel one / is móre, / uh, (.) [day], [dey] / middle,...

294 FR 372 O.K

293b LL 125

...[re-], uh, [de], / the middle is / bigger than the / petals, / petals?

295

FR 372

The petals?

296

O.K

297

LL 125

298

299

FR 372

300

301

$302 \mathrm{a}$

LL 125

FR 372

LL 125

$303 a$

FR 372

$302 \mathrm{~b}$

$303 b$

LL 125

304

FR 372

LL 125

305

FR 372

306

LL 125

307

308

309

310

311

312

313

314

315

316

317

318

FR 372

319

LL 125

320

FR 372

321

322

323

FR 372

LL 125

FR 372

LL 125

FR 372

LL 125

LL 125

FR 372

The petals are, / is small.

(.) Is like / a sun.

(.) O.K.

(.) You can / dráw a [bi-], um--

(.1) A big center?

A big center / in the middle of, / eh, exáctly in the middle of the...

In.....

...in the middle of the box, / O.K.

(.1) And, / and you can draw / like, / uh, /a petals, / uh, one, (.) on the tóp / of [de-], the, (.1) the, (.1) [th-], / cirćle, / you draw, / ah. [pe-], a petal.

(.) O.K.

Size / [m-], / ah, / medium.

/ It goes (.) almost, / uh, / almost (.1) the connect / to [day] / lińe.

/ But, not.

(.) A [leetle] bit / under [de] line.

Of the box?

Of the box.

Oh, O.K.

(.) [De]. [dees] / first / [pét-ál].

The first petal does?

Yeas.

/ Then, / on [day] / right side / of the [pet-], [dees] bíg pétál--

(.) How wide is that petal?

(.) Umm, (.) the size, / the, the size of the, the--

(.) Pencil?

Pencil.

O.K

(.) Let me make it a little wider.

(.) Does it (.) kind of go [s-], (.) is the sáme / wid̂th (.) from, / from the center / clear uo to the / line?

(.1) From the center of the, of the / flower / up to the top of the box, is it, / is it the same, 
/ um, (.3) is it as wide as a pencil / all the way up...

325

$324 b$

326

327

328

329

330

331

332

333

334

335

336

337

338

339

340

341

342

343

344

345

346

347

348

349

350

351

352

353

$354 a$

355

354b $\{17\}$ LL 125

356

$354 \mathrm{c}$

357

LL 125

FR 372

LL 125

FR 372

LL 125

FR 372

LL 125

$\{16\}$

FR 372

LL 125

FR 372

LL 125

FR 372

LL 125

FR 372

LL 125

FR 372

LL 125

FR 372

LL 125

FR 372

LL 125

FR 372

LL 125

FR 372

LL 125

FR 372

FR 372

LL 125

FR 372

(.) No.

.../ to the top / and back?

(.) Ah, (.) no.

Or is it wider at the bottom and then, / and get smáller / at the toop?

Yes.

O.K.

Get smaller / in the top.

In the t6p is very / thin.

Oh, O.K.

The two parts, uh, (.) go (.) [con-], / go connect.

O.K., / I think I got it / now.

(.) And then / in the [médle] / of / these / petal, / you / draw / a, (.1) a reesk].

(.) Risk?

(.) A line.

A line.

A line.

A line.

In, eh, exactly / in the middle of the, / thése

(.) petal.

O.K.

Thése / bíg / pétal.

(.) Because, uh, (.) [ju-eh], (.) [leapl, (.) you / should / leave / just a / [let-dle] space.

/ I don't know / how much in, (.) in / inches.

(.) But, / uh, / one millimeter.

From the top?

(.) No, in the circle.

Oh

To draw / the second petal.

(.) Ohh, (.) so they overláp?

Yes.

So / the [w-], / O.K.

$[\mathrm{E} \cdot], \underline{\mathrm{is}}, \ldots$

O.K

.../ every, [ev-], ah, (.) there is petals / in all of the circle / around...

Q.K

...the circle.

And so, (.) the edge / of the first petal / that I / drew, (.) um, (.1) is that where / the / next petal / begins?

(.) Yes. 
359

$360 \mathrm{a}$
FR 372 Right there?

1.2) And is it the same / siźe / as the first petal...

(ringing phone can be heard in the background)

361

$360 \mathrm{~b}$

362

363

364

365

366

367

368

369

370

371

372

373

374

375

376

377

378

379

380

$381 \mathrm{a}$

$382 \mathrm{a}$

$381 \mathrm{~b}$

$382 \mathrm{~b}$

$381 \mathrm{c}$

$382 \mathrm{c}$

383

384

385

386

387

388

389

$390 \mathrm{a}$

$391 \mathrm{a}$

$390 \mathrm{~b}$

$391 \mathrm{~b}$

$390 \mathrm{c}$
LL 125 No.

FR 372

LL 125 The second is / the / half size.

FR 372 Half of that.

LL 125 Half of that?

FR $372 \quad$ In height?

LL 125 (.) Eh--

FR 372 Tall?

LL 125

FR 372

LL 125

FR 372

LL 125

FR 372

LL 125

FR 372

LL 125

FR 372

LL 125

FR 372

LL 125

FR 372

LL 125

FR 372

LL 125

FR 372

\{18\} LL 125

FR 372

LL 125

FR 372

LL 125

FR 372

LL 125

FR 372

LL 125

FR 372
(.) No, / short.

Ah.

Short in, / in [ta-], in, (.) in tăll,

(.1) half in tăll.

O.K

And, and (.) hálf / in size / too.

Oh, in, in, in / the width, how--

In the [wi-], yes.

Oh, O.K.

It's / like / you dráw / a [leetle] one, uh, inside / the bifg one.

(.) Oh, $/$ is it inside?

No, no.

Oh, it's like,...

ls like,...

...it's...

...it, it's,...

...right next / to it.

...right / next to.

O.K.

Then, (.) uh, the same / one that you draw [fur-st] (.) again.

Oh, O.K., / all right.

Besides / the / [leetle] one.

Beside the little one, / O.K.

With the satne / life / in the middle.

(.1) O.K.

And does, ...

And Ideese]...

...does....

...line--

...the line in the middle, / does it go clear to 
392

$393 a$

$394 a$

$393 \mathrm{~b}$

$394 b$

395

396

397

398

399

400

401

402

403

$404 a$

405

$404 \mathrm{~b}$

406

407

408

409

410

411

412

413

414

415

416

417

418

419

420

421

422

423

$424 a$

425
LL 125

FR 372

LL 125

FR 372

LL 125

FR 372

LL 125

FR 372

LL 125

FR 372

LL 125

FR 372

LL 125

FR 372

LL 125

\{19\}

FR 372

LL 125

FR 372

LL 125

FR 372

LL 125

FR 372

LL 125

FR 372

LL 125

FR 372

LL 125

FR 372

LL 125

FR 372

LL 125

FR 372 the tóp?

/ The [t-] top?

Yeah, the (.) top of,...

(.) Of the...

...to--

...petal?

Yes.

And / [eet's], / uh, (.) vertical.

O.K.

(.) And, uh, (.) and then / a little, [e-], consequently, / um--

(.) Like that all the way around?

A little--

And how many / tall onés / and how many / shoirt onés?

Is like / a wátch.

(.) O.K., / oh, O.K.

Is like, (.) uh, one, (.) uh, two, three, (.) eh, from the beginning, / from the, the [lit-], the / byg one,...

Um-huh.

...the first big one, (.) one, two, three, four,

fife, (.) if you count / five, / the five one / is / big.

(.1) Is like, / like, (.1) is in the number--

Like five o'clock?

Like [trée].

(.2) Oh, like / three o'clock?

Three o'clock.

(.) Oh, O.K., I must be / too high.

Is in the hálf, / is in the half / of [dayyl, (.) the circle.

(.) O.K., so three o'clock / is a big one.?

Yes.

O.K.

Then [leetle] one, / bíg one, / [leetle] one, / bíg one / is / [seéx] / o'clock.

Little one.

And / big one is six o'clock, (.4) O.K.

(.) In, / one more / litfle--

Ard, (.) and then a little one / next to thíe--

Next to the / six / o'clock.

O.K

(.) A blg one, / [leetle] one, / bíg one.

['These] one is nine...

Nine o'clock. 


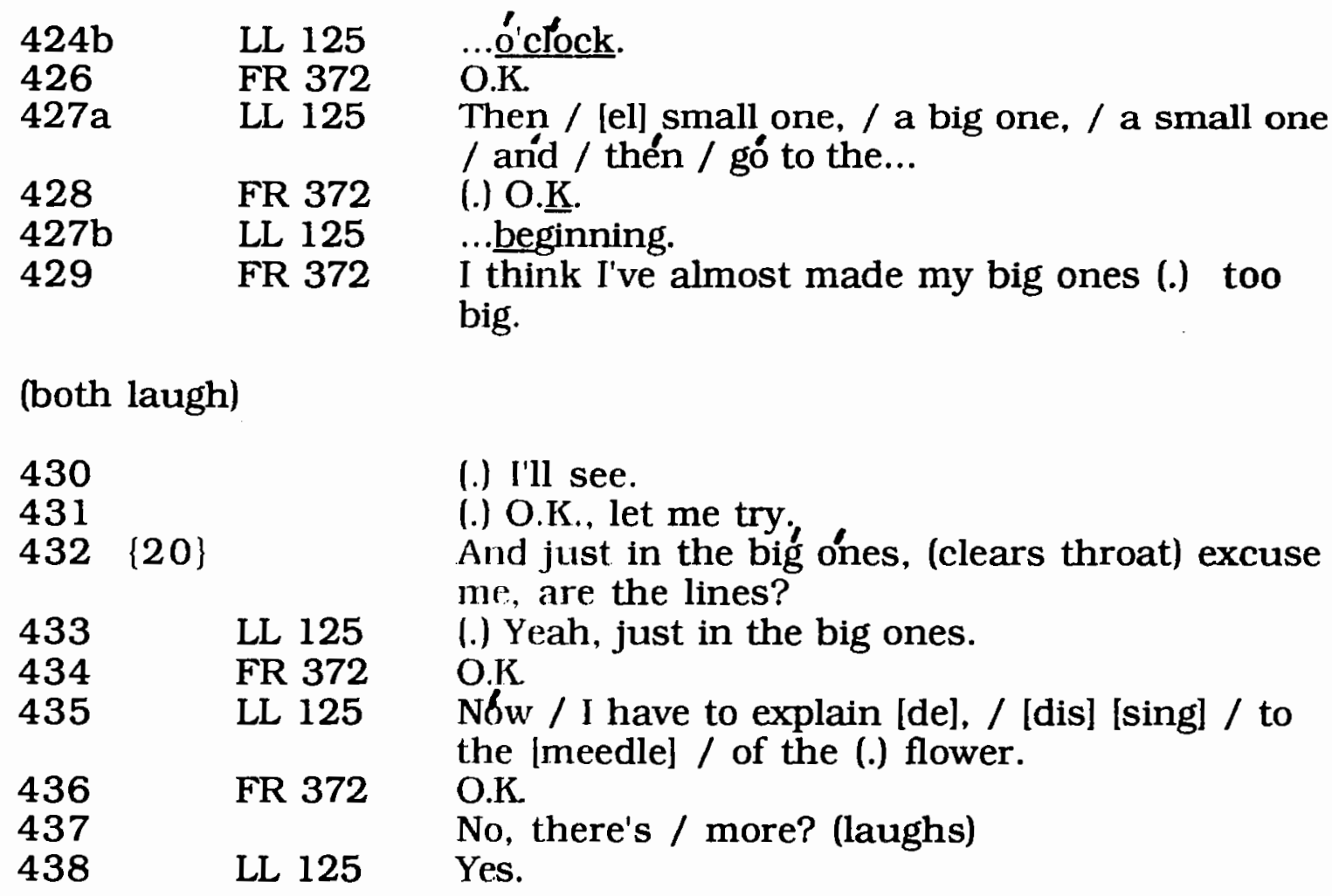

Final Time 20:13 